\title{
CHARACTERIZATION AND COMBUSTION PERFORMANCE OF CORN OIL-BASED BIOFUEL BLENDS
}

\author{
A Thesis \\ by \\ GAUTAM SANDESH SAVANT \\ Submitted to the Office of Graduate Studies of \\ Texas A\&M University \\ in partial fulfillment of the requirements for the degree of \\ MASTER OF SCIENCE
}

May 2012

Major Subject: Mechanical Engineering 
Characterization and Combustion Performance of Corn Oil-Based Biofuel Blends Copyright 2012 Gautam Sandesh Savant 


\title{
CHARACTERIZATION AND COMBUSTION PERFORMANCE OF CORN OIL-BASED BIOFUEL BLENDS
}

\author{
A Thesis \\ by \\ GAUTAM SANDESH SAVANT \\ Submitted to the Office of Graduate Studies of \\ Texas A\&M University \\ in partial fulfillment of the requirements for the degree of \\ MASTER OF SCIENCE
}

\begin{abstract}
Approved by:
Chair of Committee, Jorge Alvarado

Committee Members, Kalyan Annamalai

Sergio Capareda

Head of Department, Jerald Caton
\end{abstract}

May 2012

Major Subject: Mechanical Engineering 


\begin{abstract}
Characterization and Combustion Performance of Corn Oil-Based Biofuel Blends.

(May 2012)

\author{
Gautam Sandesh Savant, B.E., University of Pune \\ Chair of Advisory Committee: Dr. Jorge Alvarado
}

In recent years, the development and use of biofuels have received considerable attention due to the high demand for environmentally acceptable (green) fuels. Most of the recent studies have looked at the processes of converting vegetable oils into biodiesel. It is well known vegetable oil to biodiesel conversion involves many processes including transesterification, which makes biodiesel costly and timeconsuming to produce. In this study, the effects of blending high-viscosity fresh and used corn oils with low-viscosity diesel and jet fuel mixed with butanol and ethanol were studied. Several corn oil-based blends were formulated and characterized to understand the effect of composition on viscosity, fuel stability and energy content. The formulated corn oil blends were combusted in a $30 \mathrm{~kW}$ modified combustion chamber to determine the corresponding $\mathrm{NO}_{\mathrm{x}}$ and $\mathrm{CO}$ emission levels, along with $\mathrm{CO}_{2}$ levels. Used corn oil was made by simply heating fresh corn oil for a fixed period of time (about 44 hours), and was characterized by quantifying its total polar material (TPM), iodine value, free 
fatty acid content, and peroxide value. The combustion experiments were conducted at a constant heat output of $68,620 \mathrm{~kJ} / \mathrm{hr}(19 \mathrm{~kW})$, to observe and study the effects of equivalence ratio, swirl number, and fuel composition on emissions. Used corn oil blends exhibited better combustion performance than fresh corn oil blends, due in part to the higher unsaturation levels in fresh corn oil. $\mathrm{NO}_{\mathrm{x}}$ emissions for used corn oil increased with swirl number. Among all the blends, the one with the higher amount of diesel (lower amount of corn oil) showed higher $\mathrm{NO}_{\mathrm{x}}$ emissions. The blend with fresh corn oil showed decreasing $\mathrm{NO}_{\mathrm{x}}$ with increasing equivalence ratio at swirl number 1.4. All blends showed generally decreasing $\mathrm{CO}$ trends at both swirl numbers at very lean conditions. The diesel fuel component as well as the alcohols in the blends were also important in the production of pollutants. Compared to the diesel-based blends mixed with used corn oil, butanol, and ethanol, the jet fuel-based blends showed higher $\mathrm{NO}_{\mathrm{x}}$ levels and lower CO levels at both swirl numbers. 


\section{DEDICATION}

This thesis is dedicated to my parents, Sandesh and Jayashree Savant, for all their support, guidance, and patience that they have shown throughout this arduous, yet gratifying journey. I would like to thank them for constantly believing in me and always inspiring me to pursue my dreams. Thanks Mom and Dad! 


\section{ACKNOWLEDGEMENTS}

Success is rarely achieved alone. In my opinion, the first taste of real success comes when someone is about to enter into professional life as a rookie, about to embark upon a journey that is entirely his own, and marveling at the plethora of possibilities of how he can make his mark in the world. But, as a rookie, how does he reach this point in his life? The answer, I think, is simple: the learning process. As long as that someone puts his heart and hard work into learning something new and challenging, he knows that he can reach his goals in an ever-changing world. And that learning process is near-toimpossible to undertake alone. That is why I would like to take a pause to recognize and thank all of the individuals who helped and guided me throughout this learning process.

I want to start by first thanking my advisor and committee chair, Dr. Jorge Alvarado, for his guidance, patience, and support. I thank you for giving me the opportunity to undertake this research on alternative fuels, since it not only allowed me to work in a field I really liked, but also since working here only furthered my interest in the area.

I would like to thank Dr. Kalyan Annamalai, for opening the doors to his Coal and Biomass Energy Laboratory, and allowing us to conduct experiments on liquid fuel combustion. Your guidance and advice has been invaluable as well. I also want to extend thanks to his former and current graduate students at Texas A\&M University: Ben Lawrence, who very patiently helped me with the ins-and-outs of the lab, and whenever there were difficulties while running experiments; Siva Sankar Thanapal, Wei Chen, and 
Dustin Eseltine, for their help and advice even for the smallest of things. I thank you all for your cooperation and for being right there whenever I felt like I was lost.

I want to thank Dr. Sergio Capareda, for generously allowing me to use his emissions analyzer, at a time when one was desperately needed. This research would not have been possible without it, and I am ever grateful to you for letting me use it. Your advice on more deeply characterizing my fuels has proven to be very useful and insightful for discerning some of my data, and I thank you for that too. I want to thank some of his graduate students as well: Bjorn Santos, Monet Maguyon, and Amado Maglinao, for taking the time out to help me understand some of the concepts I needed to know for my research, as well as for giving me the chance to use some of Dr. Capareda's lab machines whenever I needed to. You all have been great, and your help in these past few months has not gone unnoticed.

I would like to especially thank Rohit Chintala, Anthony Giacalone, Nathan Ellis, Hsin-Min Tsai, Victor Leon, and Nimish Paripatyadar for physically being there in the lab with me while experiments were being performed, since it was a two-man job. You all have been very patient, especially during the long hours of being in the lab, and every now and again realizing that the experiment would have to be repeated the next day. Trust me, it had tested my patience as well, but I knew ultimately that it was all part-andparcel of doing research. Safe and successful experiments would not have been possible without your help, and I thank you for all the help that you gave me during those lab times. 
A very special thanks goes to Shreyas Bhimani, who actually pioneered this area of research under Dr. Alvarado. Again, without your guidance, patience, and advice based on your own experiences in the very same lab, my own research work would have been very hard to finish properly and on time. I also want to thank Laura Reinisch for taking care of a lot of the logistics, like shipping materials and instruments needed for my research. I would also like to extend thanks to my research team, Hyungseok Nam and Qibo Li, for all their support as well.

I want to also recognize all the professors and professionals that I have interacted with regarding this research work. They helped guide me in the right direction and also gave me a chance to think outside the box and change my approach to certain problems.

Finally, I want to thank my parents, for all the love and support they have given me throughout this whole process. Even when things looked bleak, you never let me back down and pushed me to take every day as a challenge. I was able to do so, only because of the values you instilled in me all these years. You both are my role models in my life, and your constant faith in me helped tremendously in keeping me motivated, and I am now a better, wiser person because of it. 


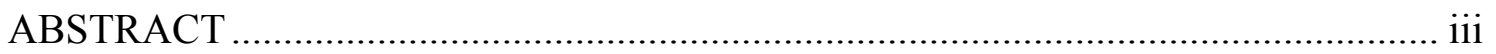

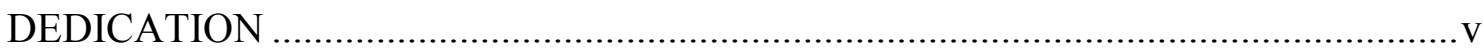

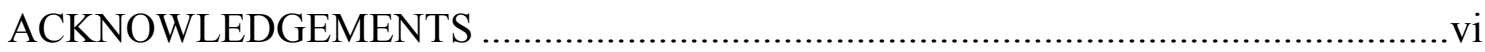

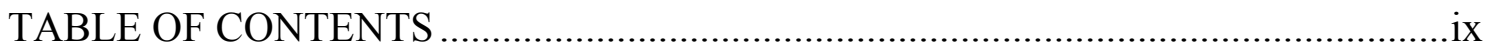

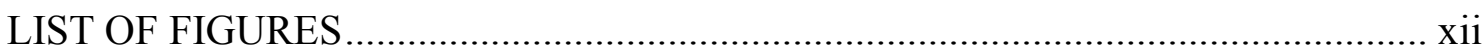

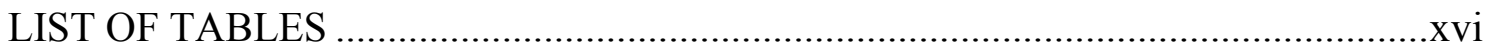

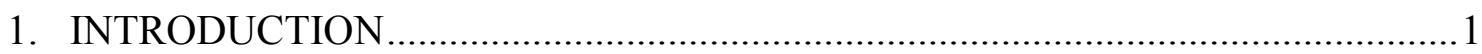

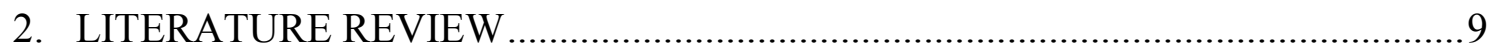

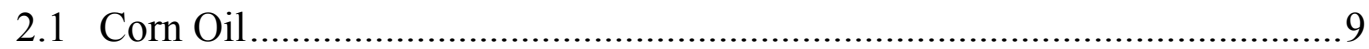

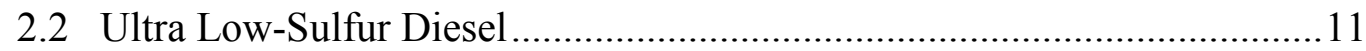

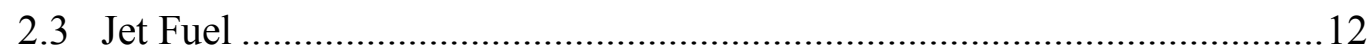

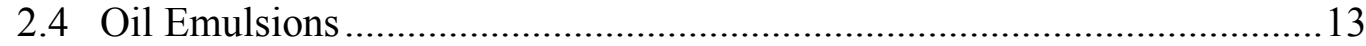

2.5 Emulsion Formation ............................................................................ 14

2.6 Blending Alcohols/Vegetable Oils with Diesel .........................................14

2.7 Past Studies on Blends of Alcohol/Vegetable Oil with Diesel ....................16

2.8 Importance of Vegetable Oil ................................................................... 19

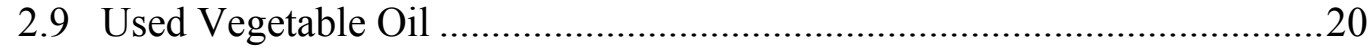

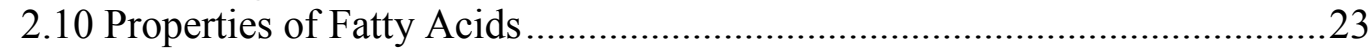

2.10.1 Total Polar Material ...................................................................24

2.11 Characterization of Fatty Acid Properties ....................................................25

2.12 Swirl Effects in Combustion ................................................................26

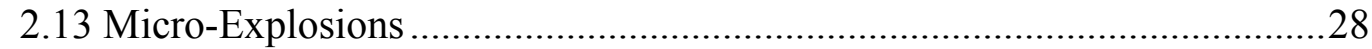

2.14 Fundamentals of Soot Formation .............................................................. 31

2.15 Role of NO in Soot Formation Control ........................................................35

3. RECENT RESEARCH ON MAKING STABLE DIESEL-CORN OIL

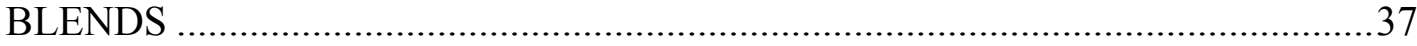

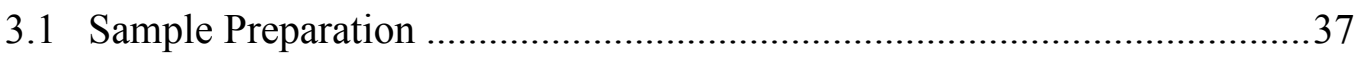




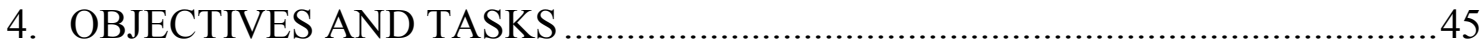

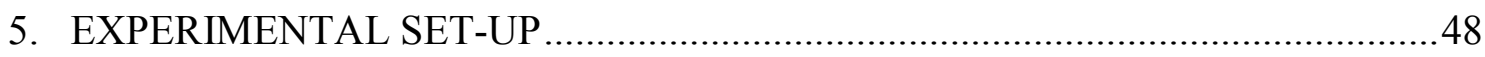

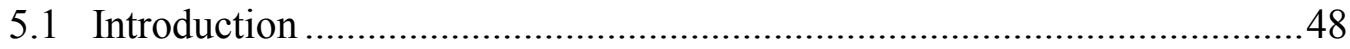

5.2 Combustion Chamber Modifications ......................................................4

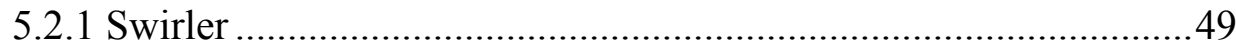

5.2.2 Liquid Fuel Injection System .....................................................50

5.3 Experimental Facility-Modified Combustion Chamber.................................59

5.4 Experimental Procedure ........................................................................65

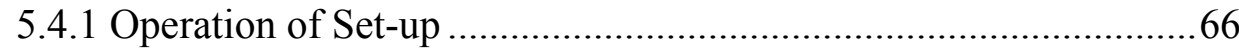

5.4.2 Preheating the Combustion Chamber...............................................67

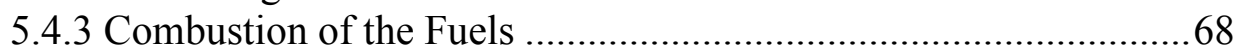

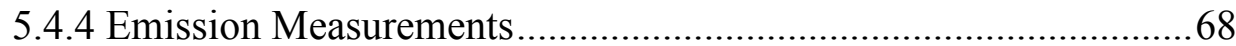

5.5 Preparation of Blends .............................................................................69

5.5.1 Making and Characterizing Used Corn Oil..................................70

5.5.2 Making Stable Corn Oil-Based Blends .............................................74

5.5.3 Viscosity of the Blends ...............................................................76

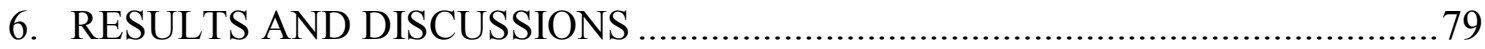

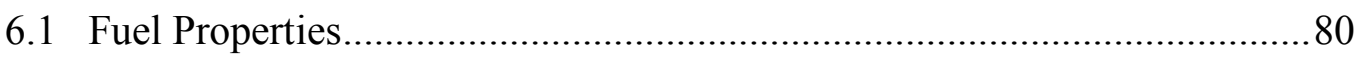

6.1.1 Stability and Viscosity of Blends ..................................................8 80

6.1.2 Ultimate Analysis and Chemical Formula of Parent Fuels .............81

6.1.3 Chemical Formula of the Blends...................................................8

6.1.4 Fuel Chemistry of Blends ................................................................96

6.1.4.1 Total Polar Material Test.................................................98

6.1.4.2 Iodine Value Test ........................................................101

6.1.4.3 Free Fatty Acid Test .........................................................103

6.1.4.4 Peroxide Value Test .......................................................104

6.2 Combustion Experimental Parameters ………………………………......... 105

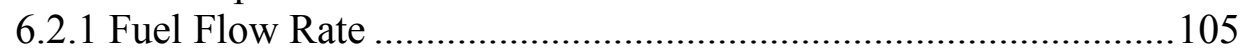

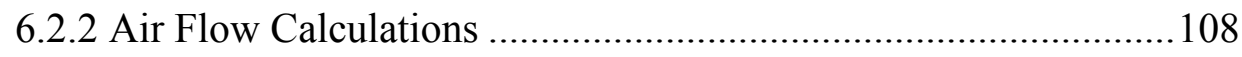

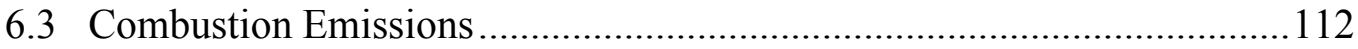

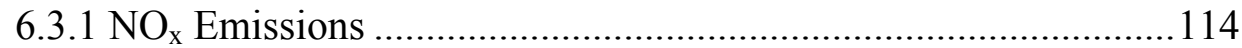

6.3.1.1 Effect of Equivalence Ratio on $\mathrm{NO}_{\mathrm{x}}$ Emissions ..............119

6.3.1.2 Effect of Fuel Type on $\mathrm{NO}_{\mathrm{x}}$ Emissions ...........................123

6.3.1.3 Effect of Swirl Number on $\mathrm{NO}_{\mathrm{x}}$ Emissions ....................126

6.3.2 $\mathrm{NO}_{\mathrm{x}}$ Emissions Corrected for 3\% $\mathrm{O}_{2}$ in the Exhaust......................129

6.3.3 $\mathrm{NO}_{\mathrm{x}}$ Emissions in Terms of Heat Input (g/GJ) ............................133

6.3.4 Carbon Dioxide and Carbon Monoxide Emissions........................137

6.3.4.1 Effect of Equivalence Ratio on $\mathrm{CO}_{2}$ and $\mathrm{CO}$ Emissions 141 
6.3.4.2 Effect of Swirl Number on $\mathrm{CO}_{2}$ and $\mathrm{CO}$ Emissions....... 148

6.3.4.3 Effect of Fuel Type on $\mathrm{CO}_{2}$ and $\mathrm{CO}$ Emissions ............. 148

6.3.5 Burned Fraction (BF) ............................................................151

6.3.5.1 Effect of Equivalence Ratio on BF............................. 156

6.3.5.2 Effect of Swirl Number on BF ..................................157

6.3.5.3 Effect of Fuel Type on BF.......................................157

6.3.6 Temperature Profiles of all Fuels .............................................. 158

6.3.7 Respiratory Quotient (RQ) ...................................................161

6.3.8 Heating Value Based on Stoichiometric Oxygen........................165

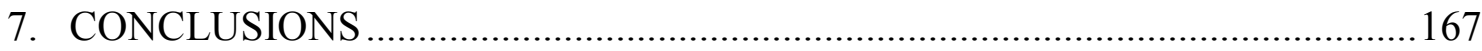

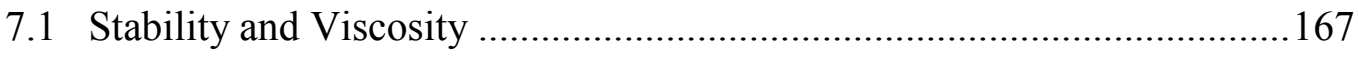

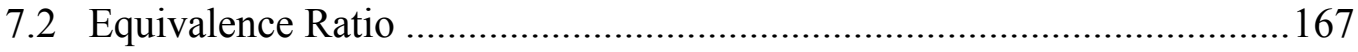

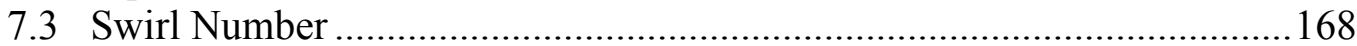

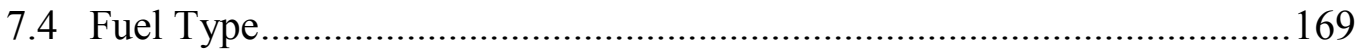

7.5 Burned Fraction......................................................................... 169

7.6 Temperature Profiles ................................................................. 170

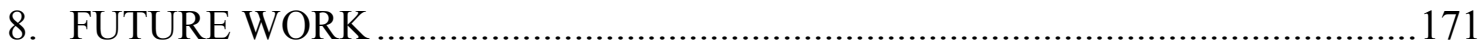

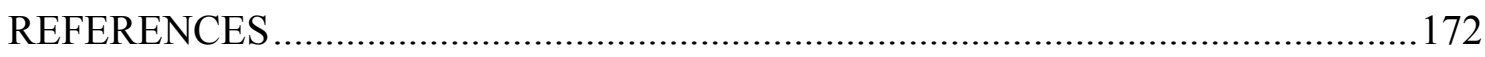

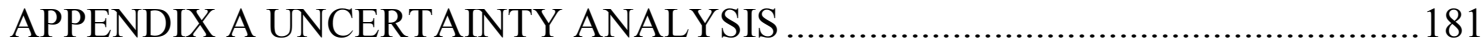

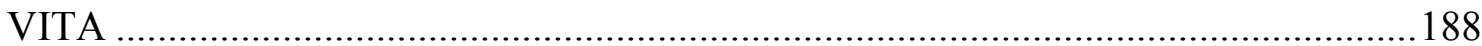




\section{LIST OF FIGURES}

FIGURE $\quad$ Page

1 U.S. liquid fuels consumption growth................................................

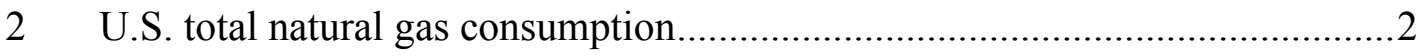

$3 \quad$ U.S. total electricity consumption .....................................................

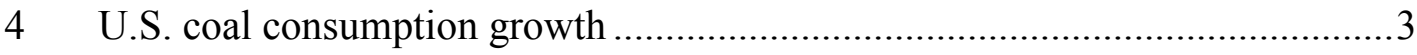

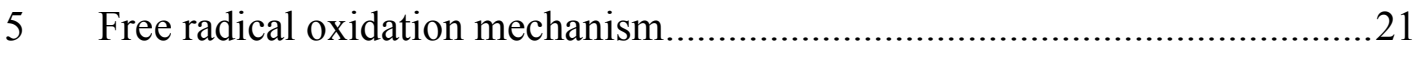

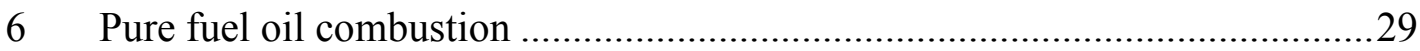

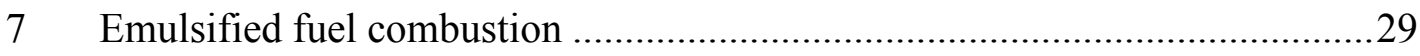

8 Schematic of the mechanism of soot particle formation ...................................

9 Unstable $80 \%$ diesel-20\% corn oil blend with $1 \%$ surfactant .......................41

10 Viscosity measurements at various spindle speeds for

(a) $70 \%$ diesel-30\% corn oil with 1\% surfactant, (b) $70 \%$ diesel-30\% corn oil with $2 \%$ surfactant, (c) $80 \%$ diesel-20\% corn oil with

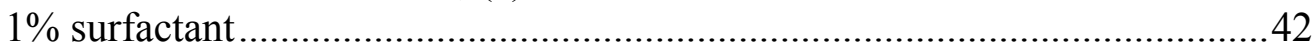

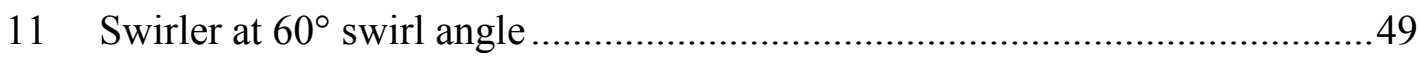

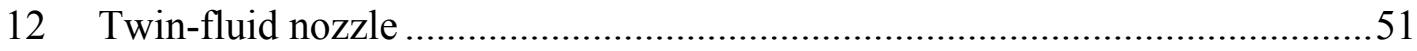

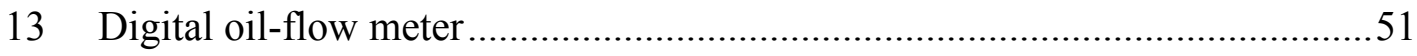

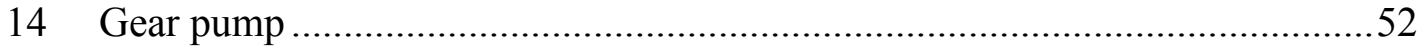

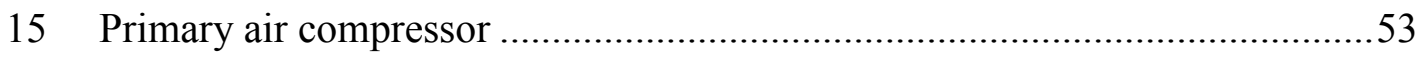

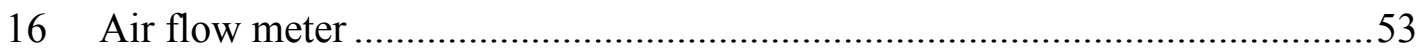

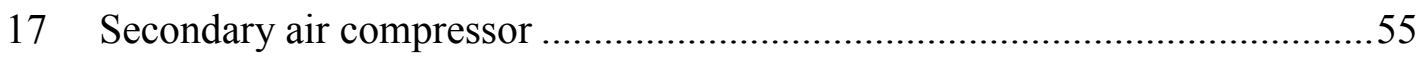

18 Emissions gas analyzer: main unit and probe housing .................................57 
FIGURE Page

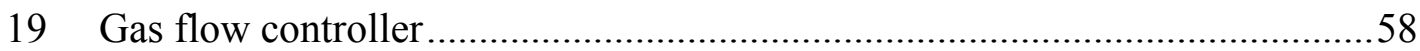

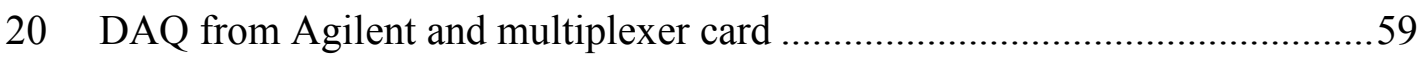

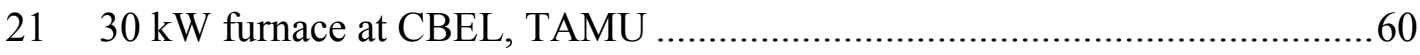

22 Cross-section of the combustion chamber (all dimensions in inches) .............61

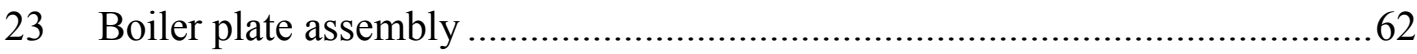

24 Thermocouples in chamber ports ...............................................................63

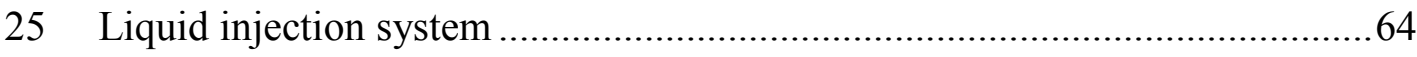

26 Nozzle with aluminum cone placed over swirler ...........................................65

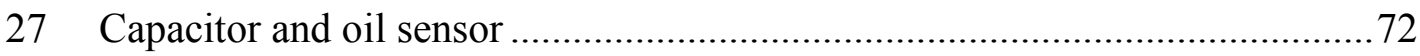

28 Testo 270 cooking oil tester, measuring TPM of corn oil in deep fryer ..........73

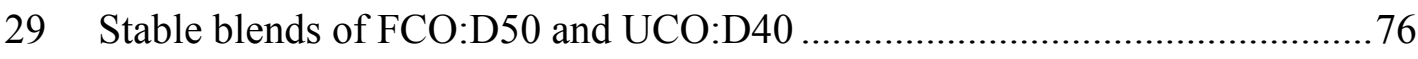

30 Brookfield viscometer with UL adapter, spindle, and cylinder .......................77

31 TPM (\%) of corn oil during heating process ...................................................99

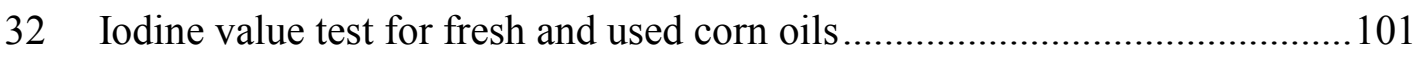

33 Free fatty acid test for fresh and used corn oils.............................................. 103

34 Peroxide value test for fresh and used corn oils............................................104

35 Soot formed on the sintered filter of analyzer probe.......................................113

$36 \mathrm{NO}_{\mathrm{x}}$ emissions for used corn oil, at $\mathrm{SN}$ of 1.4 and 1.0 for a constant heat

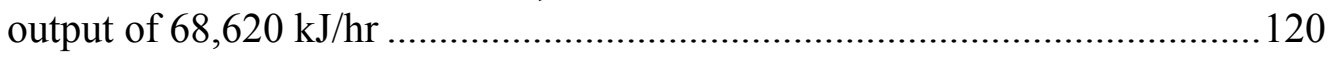

$37 \mathrm{NO}_{\mathrm{x}}$ emissions for UCO:D50 and UCO:D40 at SN of 1.4, at a constant heat output of $68,620 \mathrm{~kJ} / \mathrm{hr}$. 
$38 \mathrm{NO}_{\mathrm{x}}$ emissions for UCO:D40, FCO:D40, and UCO:JF40 at SN of 1.4, at constant heat output of $68,620 \mathrm{~kJ} / \mathrm{hr}$

$39 \mathrm{NO}_{\mathrm{x}}$ emissions for UCO:D40, FCO:D40, and UCO:JF40 at SN of 1.0, at constant heat output of $68,620 \mathrm{~kJ} / \mathrm{hr}$

$40 \mathrm{NO}_{\mathrm{x}}$ emissions for UCO:D40, at $\mathrm{SN}$ of 1.0 and 1.4, at constant heat output of $68,620 \mathrm{~kJ} / \mathrm{hr}$

$41 \mathrm{NO}_{\mathrm{x}}$ emissions for FCO:D40, at SN of 1.0 and 1.4, at constant heat output of $68,620 \mathrm{~kJ} / \mathrm{hr}$

$42 \mathrm{NO}_{\mathrm{x}}$ emissions for UCO:JF40, at $\mathrm{SN}$ of 1.4 and 1.0, at constant heat output of $68,620 \mathrm{~kJ} / \mathrm{hr}$

$43 \mathrm{NO}_{\mathrm{x}}$ emissions, corrected to $3 \% \mathrm{O}_{2}$, for used corn oil at $\mathrm{SN}$ of 1.4 and 1.0 , for a constant heat output of $68,620 \mathrm{~kJ} / \mathrm{hr}$.

$44 \mathrm{NO}_{\mathrm{x}}$ emissions, corrected to $3 \% \mathrm{O}_{2}$, for UCO:D40, FCO:D40, and UCO:JF40 at SN of 1.4, for a constant heat output of $68,620 \mathrm{~kJ} / \mathrm{hr}$

$45 \mathrm{NO}_{\mathrm{x}}$ emissions, corrected to $3 \% \mathrm{O}_{2}$, for UCO:D40, FCO:D40, and UCO:JF40 at SN of 1.0, for a constant heat output of $68,620 \mathrm{~kJ} / \mathrm{hr}$

$46 \mathrm{NO}_{\mathrm{x}}(\mathrm{g} / \mathrm{GJ})$ emissions for all fuels at $\mathrm{SN}$ of 1.4 for a constant heat output of $68,620 \mathrm{~kJ} / \mathrm{hr}$

$47 \mathrm{NO}_{\mathrm{x}}(\mathrm{g} / \mathrm{GJ})$ emissions for all fuels at $\mathrm{SN}$ of 1.0 for a constant heat output of $68,620 \mathrm{~kJ} / \mathrm{hr}$

$48 \mathrm{CO}_{2}$ levels for used corn oil, UCO:D40, FCO:D40, and UCO:JF40 at $\mathrm{SN}$ of 1.4 , at a constant heat output of $68,620 \mathrm{~kJ} / \mathrm{hr}$

$49 \mathrm{CO}_{2}$ levels for used corn oil, UCO:D40, FCO:D40, and UCO:JF40 at $\mathrm{SN}$ of 1.0 , at a constant heat output of $68,620 \mathrm{~kJ} / \mathrm{hr}$

$50 \mathrm{CO}$ emissions for used corn oil at $\mathrm{SN}$ of 1.0 and 1.4, at a constant heat output of $68,620 \mathrm{~kJ} / \mathrm{hr}$ 
FIGURE Page

51 CO emissions for UCO:D40, FCO:D40, and UCO:JF40 at SN of 1.4, at constant heat output of $68,620 \mathrm{~kJ} / \mathrm{hr}$.

52 CO emissions for UCO:D40, FCO:D40, and UCO:JF40 at SN of 1.0, at constant heat output of $68,620 \mathrm{~kJ} / \mathrm{hr}$

53 Burned fraction (BF) of all the fuels at SN of 1.4, at a constant heat output of $68,620 \mathrm{~kJ} / \mathrm{hr}$

54 Burned fraction (BF) of all the fuels at $\mathrm{SN}$ of 1.0, at a constant heat output of $68,620 \mathrm{~kJ} / \mathrm{hr}$

55 Variation of temperature with respect to equivalence ratio for used corn oil, UCO:D40, FCO:D40, and UCO:JF40 at SN of 1.4, at constant heat output of $68,620 \mathrm{~kJ} / \mathrm{hr}$

56 Variation of temperature with respect to equivalence ratio for used corn oil, UCO:D40, FCO:D40, and UCO:JF40 at SN of 1.0, at constant heat output of $68,620 \mathrm{~kJ} / \mathrm{hr}$ 


\section{LIST OF TABLES}

TABLE Page

$1 \quad$ Fatty acid composition of corn oil...................................................... 10

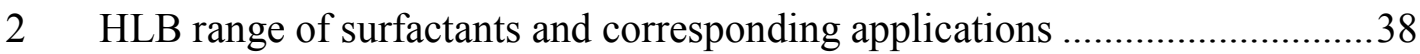

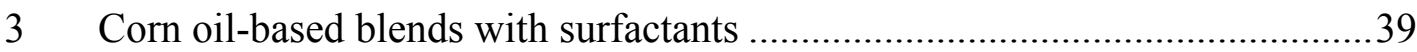

4 Corn oil-based blends (by mass percentage) ............................................... 70

$5 \quad$ Classification of TPM values for fat ageing ......................................... 71

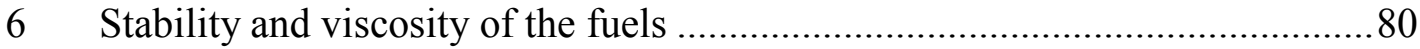

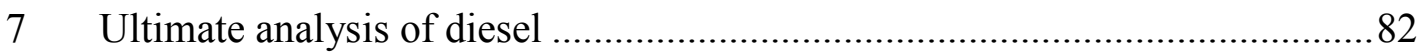

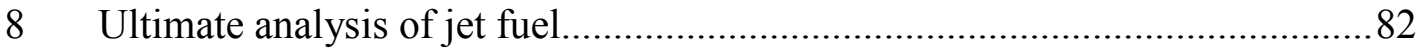

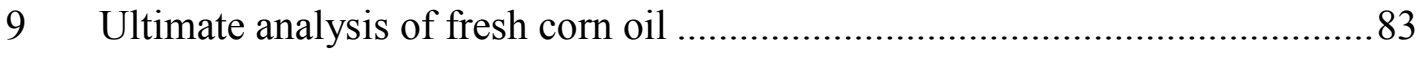

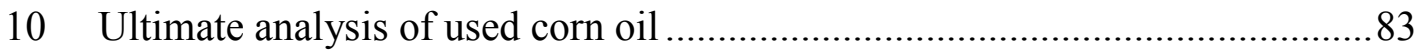

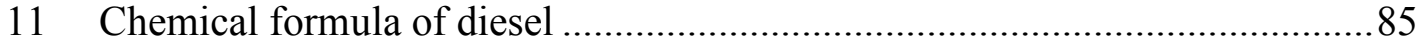

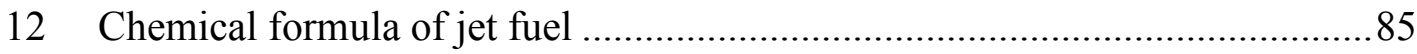

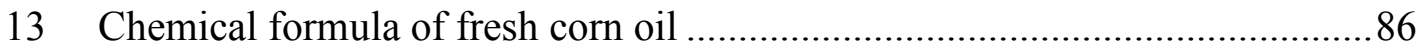

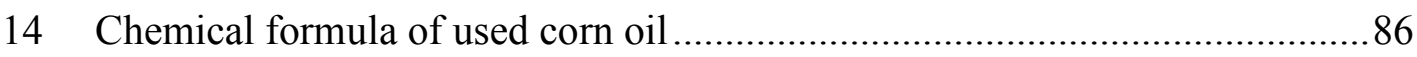

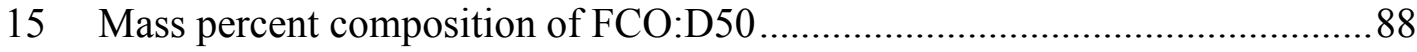

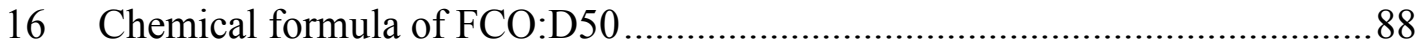

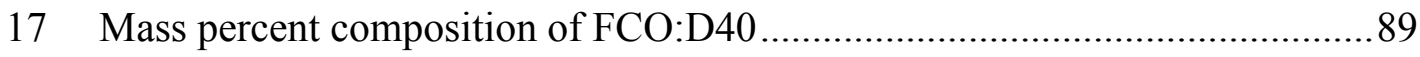

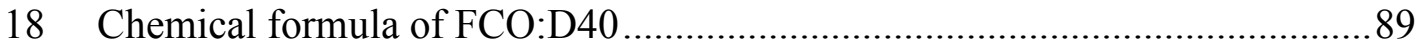

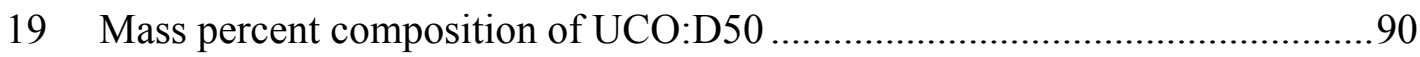


TABLE Page

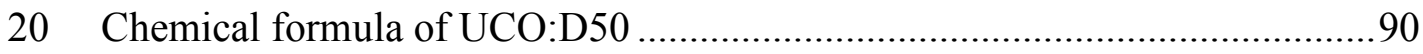

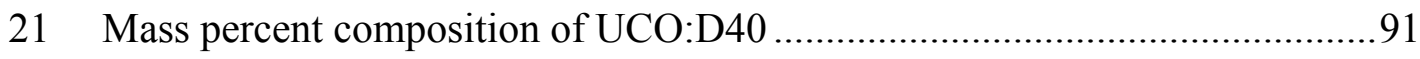

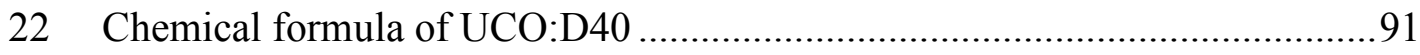

23 Mass percent composition of FCO:JF50 ............................................ 92

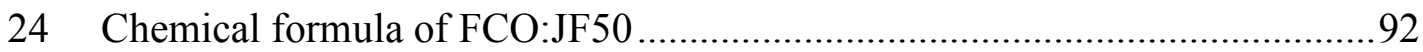

25 Mass percent composition of FCO:JF40 ............................................ 93

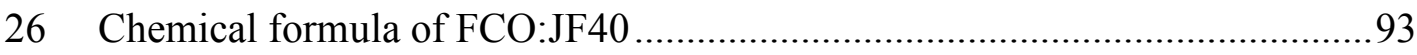

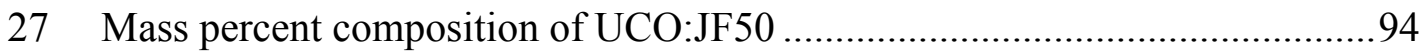

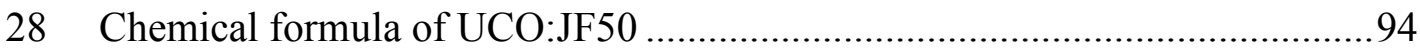

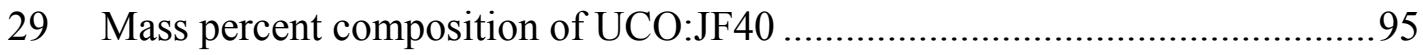

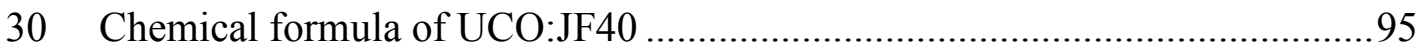

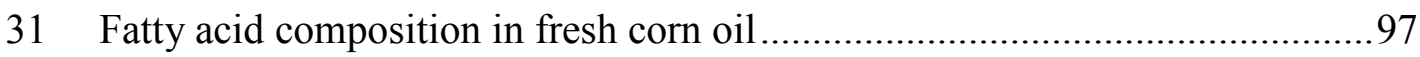

32 Higher heating values of each component in the fuels.............................. 106

33 Empirical formula, HHV, and density of the fuels ..................................107

34 Stoichiometric coefficients for complete combustion of fresh corn oil.........109

35 Air and fuel flow rates for all the combustion experiments ........................111

$36 \mathrm{NO}_{\mathrm{x}}$ emissions for all the fuels at both swirl numbers ............................... 116

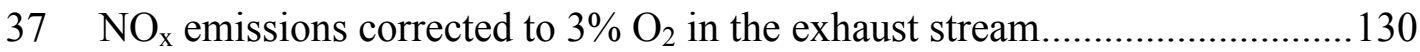

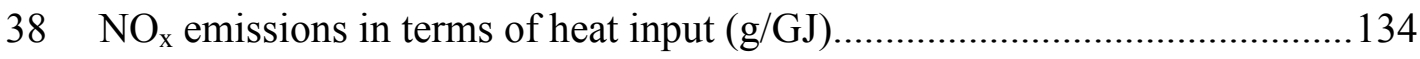

$39 \mathrm{CO}_{2}$ levels for all the fuels at both swirl numbers ................................... 137 
TABLE Page

$40 \mathrm{CO}$ emissions for all fuels at both swirl numbers ...................................139

41 Comparison of $\phi_{\text {flow }}$ and $\phi_{\text {flue }}$ for all tested fuels at $\mathrm{SN}$ of $1.4 \ldots \ldots \ldots \ldots \ldots \ldots . . . . . . . .145$

42 Burned fraction values for all fuels at both swirl numbers ......................... 152

43 Comparison of calculated and measured $\mathrm{CO}_{2}$ using $\mathrm{RQ} \ldots \ldots \ldots \ldots \ldots \ldots \ldots \ldots \ldots . . . . . . . . . . . . . .162$

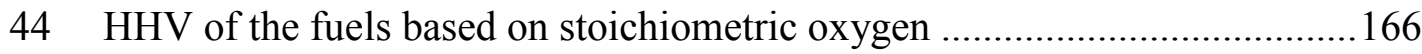

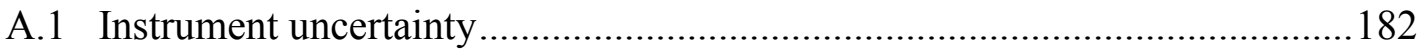

A.2 Complete uncertainty analysis in equivalence ratio for UCO:D40 at

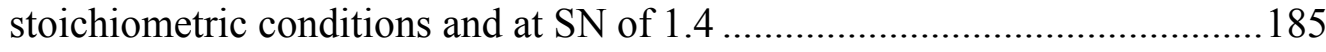

A.3 Percentage equivalence ratio uncertainty for all fuels at both swirl

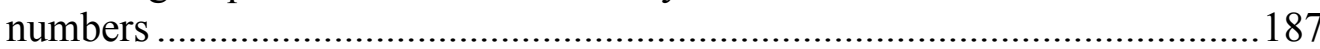




\section{INTRODUCTION}

Over the past several years, there has been growing concern over the ever-increasing use of fossil fuels, which are fast depleting from most of the world's natural reserves. Their highly fluctuating costs and more importantly, the negative impact they have on the environment, has called for the search for more sustainable fuels and for the research and development of new alternative fuel sources. According to the U.S. Energy Information Administration (EIA) [1], crude oil and liquid fuels consumption grew to an astounding 86.7 million barrels per day in 2010. The EIA has also projected that this consumption will continue to grow by about 1.4 million barrels per day through 2011 and by 1.6 million barrels per day in 2012. Similar projections have been made for consumption of natural gas, coal, and electricity.

The projections for liquid fuels and total natural gas consumption in the U.S. are shown in Figure 1 and Figure 2 respectively. Similar projections for electricity and coal consumption are shown in Figure 3 and Figure 4 respectively.

This thesis follows the style of Applied Thermal Engineering. 


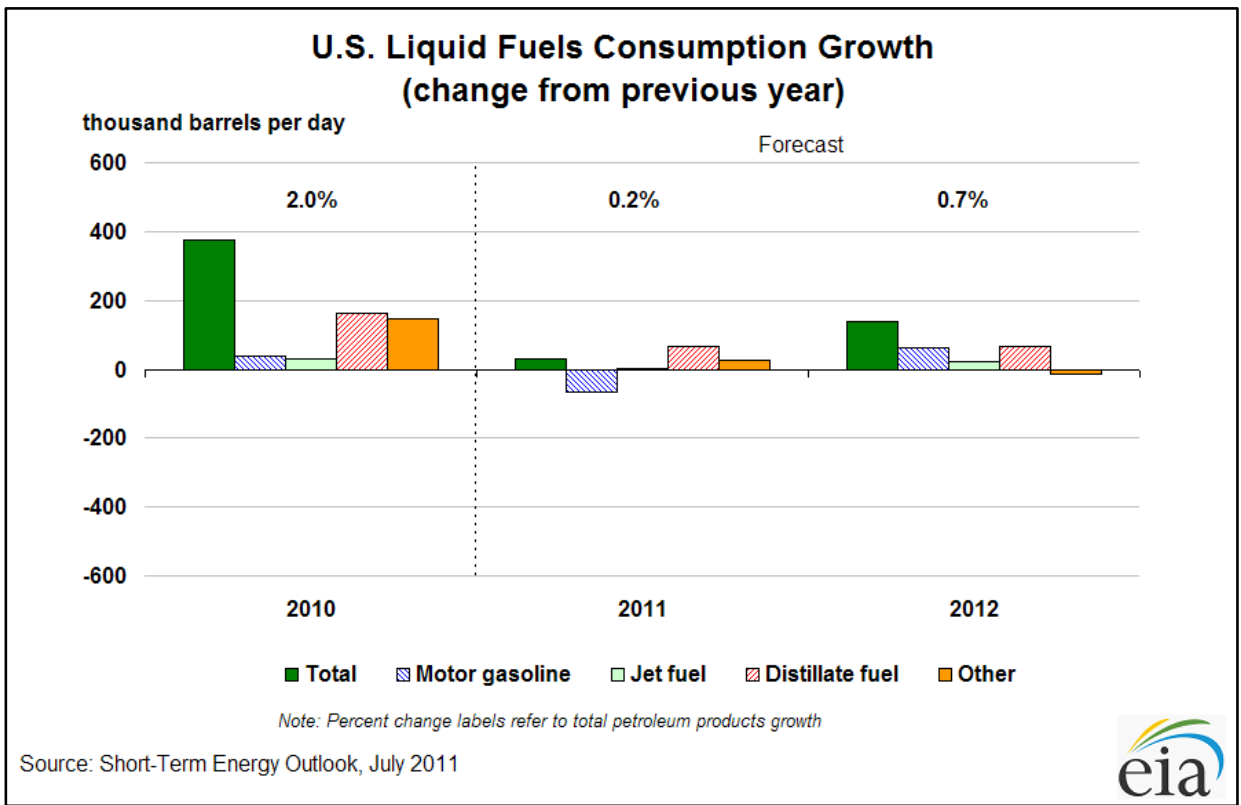

Figure 1: U.S. liquid fuels consumption growth [1]

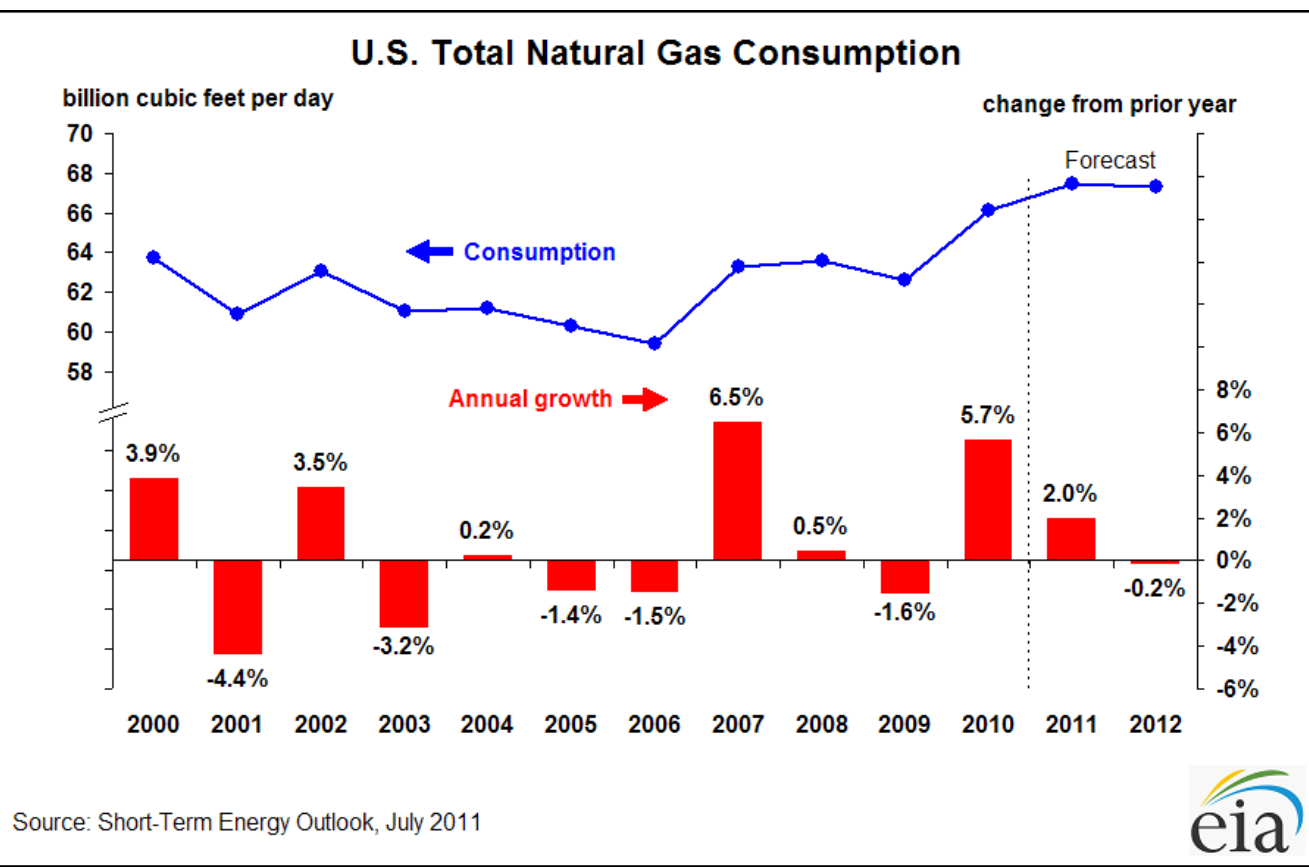

Figure 2: U.S. total natural gas consumption [1] 


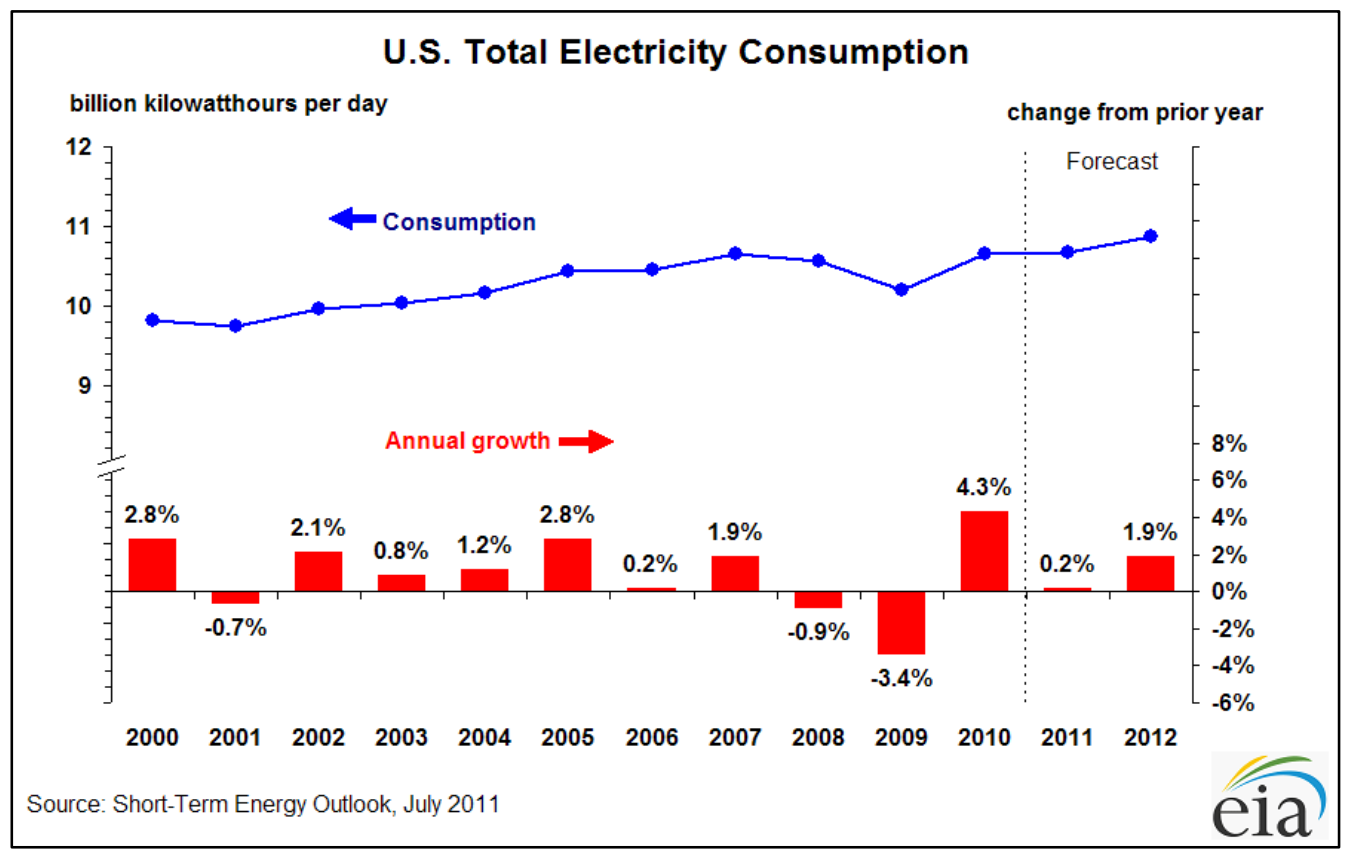

Figure 3: U.S. total electricity consumption [1]

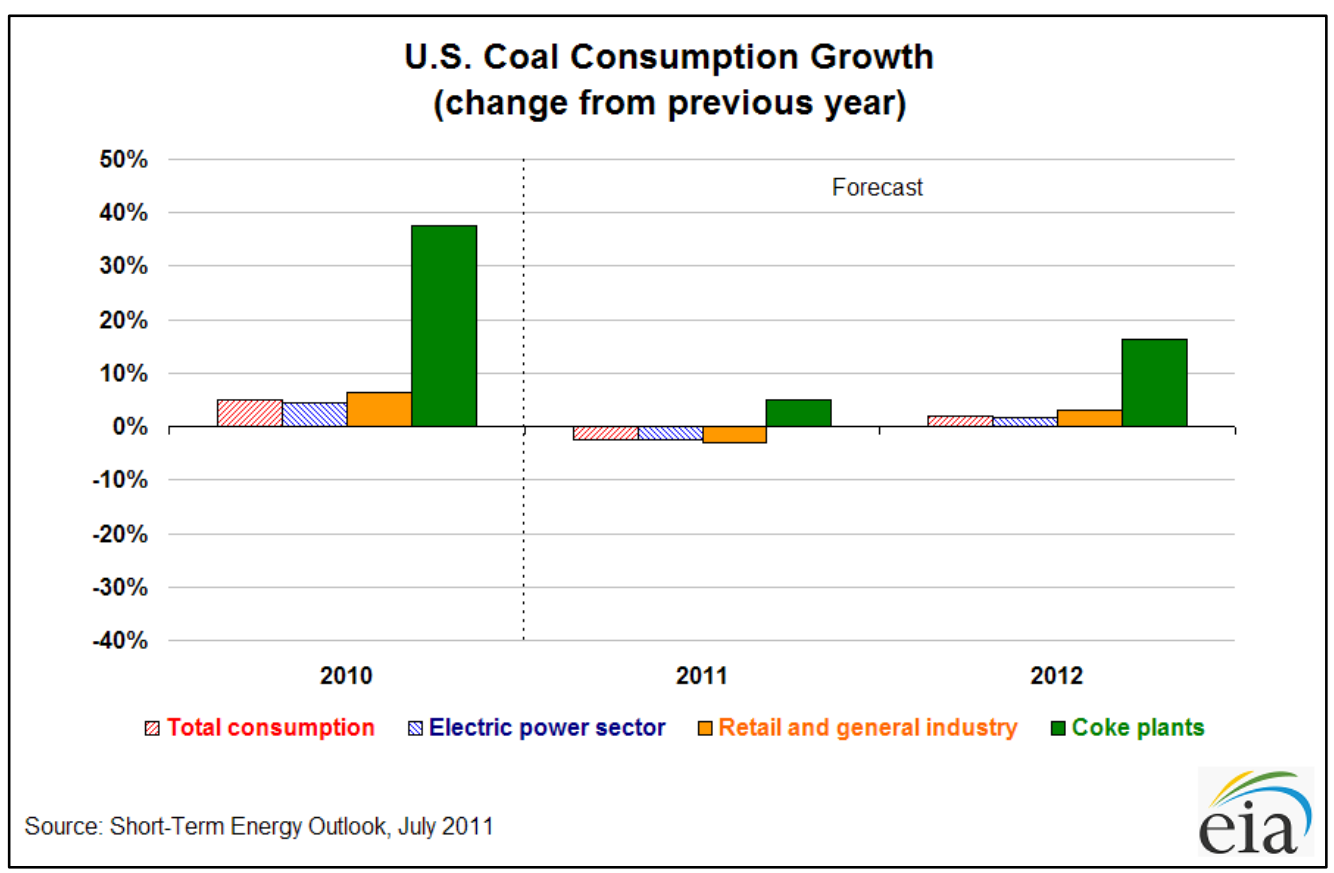

Figure 4: U.S. coal consumption growth [1] 
Coal, natural gas and nuclear energy are the three main sources for electricity generation in the United States, with coal accounting for almost half of the total generation. Most of the stationary furnaces and boilers used nowadays for generating electricity are coal-fired type.

As stated earlier, the emission of harmful gases is one of the most critical issues facing the use of fossil fuels. These gases include nitrogen oxides $\left(\mathrm{NO}_{\mathrm{x}}\right)$, sulfur oxides $\left(\mathrm{SO}_{\mathrm{x}}\right)$, carbon dioxide $\left(\mathrm{CO}_{2}\right)$, carbon monoxide $(\mathrm{CO})$, soot and unburned hydrocarbons. It is the reason why researchers have been giving considerable amount of attention to the use of biofuels including straight vegetable oils as an alternative option to fossil fuels. Straight Vegetable oils (SVO) have negligible amount of sulfur and nitrogen, which is one of the primary reasons why they have great potential to replace conventional fuels. The various methods of using vegetable oil (SVO) as a fuel are:

- Heating the vegetable oil to high temperatures

- Blends of SVO with diesel

- Blends of SVO with diesel, water, and other additives

- Water-in-oil emulsions

- Alcohol-in-oil emulsions

- Producing biodiesel from vegetable oil

The most popular method of utilizing vegetable oils is in the production of biodiesel. In this method, vegetable oil is transesterified with alcohols like ethanol. This transesterification process improves the physical properties of the original vegetable oil, the most important being the decrease in the viscosity which results in better fuel 
atomization and better combustion [2]. However, biodiesel as a fuel has a number of disadvantages. Firstly, the production of biodiesel itself is a costly process. The formation of the by-product glycerol during the transesterification process is another concern, since glycerol is an environmental hazard which should be disposed of properly. Moreover, even small traces of glycerol that may remain in the biodiesel final product can produce the toxic compound acrolein [3]. Researchers have also found that the performance of biodiesel does not show much improvement with respect to $\mathrm{NO}_{\mathrm{X}}$ emissions, when compared to crude oil-based diesel [4]. Other problems associated with biodiesel usage include injector coking [5].

The problem of fuel atomization associated with high viscosity can be alleviated by the direct blending of vegetable oil in diesel or biodiesel, since it is more economically beneficial compared to making biodiesel [2]. Making blends can also offset the time and energy required to produce biodiesel. Tests conducted by Nwafor and Rice [6] have shown that blends of rapeseed oil and diesel were comparable in engine performance to diesel alone. They found improvements in thermal efficiency and hydrocarbon emissions when compared to diesel fuel, significant enough to favorably substitute diesel with diesel-rapeseed oil blends.

Co-solvent blending [7] is another simple and flexible technology that decreases the viscosity of the SVO by mixing it with a lower molecular weight alcohol. A co-solvent (like butanol) is added to solubilize otherwise nearly immiscible oil-alcohol mixtures into an isotropic (single layer) and stable solution. Adding co-solvents has other benefits also, such as enhancing cetane number, heats of combustion, and resistance to oxidation. 
Blends produced by this method typically have viscosity values comparable to fatty acid methyl esters, but slightly higher than diesel. These blends are often referred to as “microemulsion" fuels. Mixtures of soybean oil and $95 \mathrm{wt} \%$ ethanol (E95) stabilized by the co-solvent n-butanol exhibited characteristics consistent with the formation of microemulsions, according to the reports of Schwab et al. [8]. Studies by Goering et al. [9] have shown that co-solvent blends of soybean oil/E95 with n-butanol produce about the same ignition quality and power as No. 2 diesel fuel, when tested in an engine. This shows that co-solvent blends are not only cheaper, but also potentially more viable than diesel in the long run.

These blends, which can also be considered as a type of alcohol-in-vegetable oil emulsions, have the added advantage of experiencing micro-explosions, since it has been shown from previous research that this phenomenon lowers fuel emissions [10]. Microexplosions are characterized by the following sequence of events. At high temperatures, there is a significant increase in surface area of the highly volatile alcohol droplet surrounded by the less volatile vegetable oil. This results in the shattering of the surrounding vegetable oil because of the superheating of the inner alcohol droplet which undergoes liquid to gas phase transformation near the critical point. This in turn causes the oil to explode into numerous minute droplets, which act as centers for auto-ignition, thereby providing the optimal conditions for a more complete combustion, lesser emissions, and better combustion efficiency.

The current research focused on running combustion experiments in a $30 \mathrm{~kW}$ (100,000 BTU/hr) furnace located at the Coal and Biomass Energy Laboratory (CBEL) 
at Texas A\&M University. The furnace was originally designed to fire coal, but was modified with a liquid fuel injection system, a twin-fluid atomizing nozzle, and a swirler. The fuels studied were as follows (by mass):

\section{Fresh Corn Oil}

\section{Used Corn Oil}

3. $27 \%$ fresh corn oil-in- $50 \%$ diesel blend with $19 \%$ butanol and $4 \%$ ethanol-95

4. $35 \%$ fresh corn oil-in- $40 \%$ diesel blend with $21 \%$ butanol and $4 \%$ ethanol-95

5. $27 \%$ used corn oil-in-50\% diesel blend with $19 \%$ butanol and $4 \%$ ethanol-95

6. $35 \%$ used corn oil-in- $40 \%$ diesel blend with $21 \%$ butanol and $4 \%$ ethanol-95

7. $27 \%$ fresh corn oil-in-50\% jet fuel blend with $19 \%$ butanol and $4 \%$ ethanol-95

8. $35 \%$ fresh corn oil-in- $40 \%$ jet fuel blend with $21 \%$ butanol and $4 \%$ ethanol-95

9. $27 \%$ used corn oil-in-50\% jet fuel blend with $19 \%$ butanol and $4 \%$ ethanol-95

10. $35 \%$ used corn oil-in- $40 \%$ jet fuel blend with $21 \%$ butanol and $4 \%$ ethanol-95

The blends all remained stable since phase separation only takes place at very low temperatures for the type of blends made in this project [7]. Corn oil was chosen as the straight vegetable oil for a number of reasons. It is relatively less expensive than other types of vegetable oils. Since the U.S. accounts for over $42 \%$ of the corn produced in the world, corn oil naturally is the one of the most easily available vegetable oils. Finally, researchers have pursued work in the past that mainly deals with soybean oil and rapeseed oil as possible alternative fuels. Thus, in this project, it was decided to explore the combustion and emissions characteristics of an energy source rarely touched upon: 
corn oil. Pure corn oil was used as the baseline fuel to compare the performance of all the blends.

The main goal of this project was to observe and study the effect of different corn oil blends, swirl blade angles, and equivalence ratios on the exhaust emissions and combustion efficiency of the furnace. The fuel composition of the different corn oil blends varied from $50 \%$ diesel and $27 \%$ corn oil, to $40 \%$ diesel and $35 \%$ corn oil. The swirler was used with two sets of blades, with each set positioned at $51^{\circ}$ and $60^{\circ}$ angles, giving swirl numbers of 1.0 and 1.4 , respectively. The equivalence ratios were $0.8,0.9$, $1.0,1.05$, and 1.1, and were controlled by varying the amount of secondary air into the furnace. All the experiments were performed for a constant heat output of $68,620 \mathrm{~kJ} / \mathrm{hr}$. Emission levels for $\mathrm{CO}, \mathrm{NO}_{\mathrm{X}}, \mathrm{CO}_{2}$, and exhaust $\mathrm{O}_{2}$ were recorded. Therefore, an attempt has been made to demonstrate the potential use of these co-solvent blends as alternate fuels, in applications ranging from stationary utility boilers to electricity generation via steam production. Future applications could perhaps see a market in diesel engines and other dynamic systems as well. 


\section{LITERATURE REVIEW}

In this section, a basic overview of corn oil and diesel and their corresponding physical properties are presented. The section also discusses emulsions, uses of lower and higher alcohols as solvents in diesel-vegetable oil blends, used vegetable oil, swirl effects, micro-explosions and research done in the past in the area of diesel and vegetable oil emulsions.

\subsection{Corn Oil}

Corn oil is basically oil that has been extracted from the germ of corn. It can be extracted either mechanically (oil pressing) or chemically (solvent extraction with hexane). This is followed by refining of the oil by degumming or alkali treatment. The latter is used to also neutralize the free fatty acids and remove the colors in the oil [11]. The final step includes winterization and deodorization of the oil.

Like most other vegetable oils, corn oil is comprised of mostly triglycerides, which are formed by the basic reaction of fatty acids with a molecule of glycerol. As a result of this, the structure of the triglyceride consists of three fatty acid "chains" linked to a glycerol "backbone". The fatty acids here are classified broadly into saturated and unsaturated fatty acids, and corn oil contains a mixture of both types, as is illustrated in Table $1[12]$ : 
Table 1: Fatty acid composition of corn oil

\begin{tabular}{|c|c|c|}
\hline $\begin{array}{c}\text { Fatty Acid } \\
\text { Composition }\end{array}$ & $\begin{array}{c}\text { No. of C atoms: } \\
\text { No. of double } \\
\text { bonds }\end{array}$ & $\begin{array}{c}\text { \% in corn } \\
\text { oil }\end{array}$ \\
\hline Palmitic acid & $\mathrm{C} 16: 0$ & 11 \\
\hline Stearic acid & $\mathrm{C} 18: 0$ & 2 \\
\hline Oleic acid & $\mathrm{C} 18: 1$ & 28 \\
\hline Linoleic acid & $\mathrm{C} 18: 2$ & 58 \\
\hline Linolenic acid & $\mathrm{C} 18: 3$ & 1 \\
\hline
\end{tabular}

The fatty acids palmitic and stearic, comprises of the saturated fatty acids whereas the oleic, linoleic and linolenic acids are the unsaturated fatty acids. More specifically, about $80 \%$ of the saturated fatty acids are palmitic acid, $14 \%$ stearic acid and about $3 \%$ arachidic acid. Of the monounsaturated fatty acids, about $99 \%$ are oleic acid. Of the polyunsaturated fatty acids, about $98 \%$ are linoleic acid and the remaining $2 \%$ are linolenic acid.

Cooking oil was first extracted and used for cooking purposes in 1898. It was extracted using machinery developed by Benjamin and Theodore Hudnut, of Hudnut Hominy Company, which was located in Indiana.

As mentioned above, corn oil is high in polyunsaturated fats, and low in saturated fats, the latter being one of the causes for heart problems. So this distribution of fatty acids is only somewhat desirable. The moderate amount of monounsaturated fats is actually beneficial for the heart, with some studies showing that they are instrumental in lowering cholesterol. However the high percentage of polyunsaturated fats makes corn oil highly susceptible to oxidative damage and formation of free radicals. 
While many associate corn oil with cooking, it is finding its uses in other areas to a great extent. It is used in soaps, moisturizers, in bubble baths, and hair and skin conditioners. Corn oil is also the main ingredient in insecticides, nitroglycerines, and paints. But the most recent and probably the most important use is being one of the building blocks in the production of biodiesel. Just like for rapeseed and soybean oil, corn oil is reacted with methanol in the presence of a catalyst to form mono-alkyl esters (biodiesel) and glycerin as a by-product.

\subsection{Ultra Low-Sulfur Diesel}

Diesel fuel is basically any liquid fuel that can be used in a diesel engine. The word "diesel" is actually named after Rudolf Diesel, who invented the diesel engine in 1892. Diesel is widely used in many transportation applications.

On the other hand, ultra-low sulfur diesel is diesel with about $15 \mathrm{ppm}$ or lower sulfur content. It is a clean burning diesel fuel that actually contains $97 \%$ less sulfur than low sulfur diesel. The U.S. Environmental Protection Agency (EPA) requires that by 2010 all diesel-driven vehicles should be using only ULSD [13]. Recently, the vast majority of ULSD has been produced from petroleum. Petroleum-based ULSD is not considered as an alternative fuel under the Energy Policy Act of 1992, but most ULSD fuels produced from non-petroleum and renewable sources are considered as alternative fuels under the same act [14].

In order to produce petroleum-based ULSD, the sulfur is removed during the oil refining process via "hydrotreating". Here, the petroleum feedstock and hydrogen are 
mixed and heated together, before passing through a reactor with catalysts, which enable the separation of sulfur from the hydrocarbon molecules. Sulfur adsorption, sulfur oxidation and biodesulfurization are other ULSD production technologies that are being currently used [14].

ULSD combined with advanced emission control technologies has the capability of reducing emissions greatly, such as nitrogen oxides $\left(\mathrm{NO}\right.$ and $\left.\mathrm{NO}_{2}\right)$ and particulate matter. Since diesel engines are more efficient than comparable gasoline engines (on a brake horse power basis), the use of ULSD should result in lower transportation related emissions in the future compared to normal diesel. This would in turn reduce the use of petroleum fuel and greenhouse gas emissions. Moreover, it can be used with existing engine technologies. Today, most diesel pumps in the U.S. dispense ULSD [14].

\subsection{Jet Fuel}

Jet fuel is a type of kerosene fuel that mainly finds its application in the aviation industry. It mainly consists of hydrocarbon compounds such as paraffins, cycloparaffins, aromatics, and olefins, along with additives that are determined depending on the specific use of the fuel [15].

Jet fuels are primarily derived from crude oil, but can also be derived from an organic material found in shale, called kerogen [16]. Depending on the type of specifications, whether they are military or commercial, jet fuels are generally made by blending and refining different crude oil (petroleum) distillation products like naphtha, gasoline, or kerosene [17]. 


\subsection{Oil Emulsions}

An emulsion is a mixture of two or more liquids wherein one is present as droplets (usually of microscale or even nanoscale size), distributed throughout the other. The liquid in the form of the finely distributed spherical droplets is called the dispersed phase while the liquid in which these droplets are distributed is called the continuous phase. Emulsions are formed when surfactants or emulsifiers are used, or by mechanical means, like agitation, as long as the emulsion's net Gibbs free energy reaches a stable value [18].

Emulsions are broadly classified according to emulsion type and emulsion size, as follows:

1. Emulsion type
a. Water-in-Oil (W/O) emulsion
b. Oil-in-water $(\mathrm{O} / \mathrm{W})$ emulsion
c. Double emulsions - i. Water-in-oil-in-water emulsion $(\mathrm{W} / \mathrm{O} / \mathrm{W})$
ii. Oil-in-water-in-oil emulsion $(\mathrm{O} / \mathrm{W} / \mathrm{O})$

2. Emulsion size [19]
a. Micro-emulsion - 10 to $100 \mathrm{~nm}$
b. Nano-emulsion -100 to $1000 \mathrm{~nm}$
c. Macro-emulsion -0.5 to $100 \mu \mathrm{m}$ 


\subsection{Emulsion Formation}

As mentioned above, there is more than just one way of making an emulsion. There are, in fact, several ways to produce an emulsion from liquid phases which are not mutually or only slightly soluble with each other. The first step is to break the dispersed phase into droplets by mechanical means. Then these droplets are introduced in another liquid, such that the latter forms the continuous phase thereby forming a stable emulsion. Stirring and blending, ultrasonication, high pressure homogenizer, laminar and turbulent pipe flow are some of the more common methods for providing the mechanical energy.

\subsection{Blending Alcohols/Vegetable Oils with Diesel}

Recently, the diminishing supplies of fossil fuels, increases in fuel costs, and concerns over global warming have prompted research worldwide on renewable liquid type bio-fuels. The increased demand of petroleum fuels has caused this increase in fuel costs and has in turn put an economic burden on oil importing nations. Equally importantly, global warming concerns have raised the scrutiny on emissions of greenhouse gases such as carbon dioxide formed by the combustion of fossil fuels [2].

Diesel engines are one of the most common engines used today. However, they produce nitrogen oxides and smoke emissions to a great extent and have given rise to stringent emission standards. This is yet another reason for researchers to look for clean, alternative fuels. Bio-fuels made from agricultural products (oxygenated by nature) can reduce the world's dependence on oil imports, support local agricultural industries and enhance farming incomes. It also offers benefits in terms of lower emissions, lower 
smokiness levels, and less particulate matter from diesel engines. Among those, bioalcohols and vegetable oils or their derived biodiesels (methyl or ethyl esters) are considered as very promising fuels [20].

Since alcohols have less carbon and almost no sulfur content and more oxygen than conventional fossil-based fuels, they result in lower emissions in internal combustion engines. Moreover, their addition to diesel does not require major modifications to be made in the engine fuel system. Alcohol fuels like methanol, ethanol, propanol and butanol can be used with fossil-based fuels in various percentages for diesel engines as a clean alternative fuel source [21].

In blends of diesel fuel and ethanol, phase separation has been the most critical problem. They are basically miscible at room temperature, but small traces of water in the mixture causes a phase separation resulting in the movement of ethanol and water according to their density value. Actually the water tolerance of blends increases with temperature. At $0^{\circ} \mathrm{C}$, a water concentration of only $0.05 \%$ will cause phase separation. Thus, the water tolerance for ethanol-diesel fuel blends is inadequate for practical use [22]. If water tolerance could be increased, the use of 190-proof (or lower) ethanol, which is less costly to produce owing to its water absorption ability, can be incorporated, sometimes with an emulsifying agent. 


\subsection{Past Studies on Blends of Alcohol/Vegetable Oils with Diesel}

Rakopoulos et al. [20] made blends of ethanol and diesel and used a twodimensional, multi-zone combustion model for each zone, taking into account the direction of the fuel injection within the combustion chamber. This model enabled them to simulate the combustion process taking into account equivalence ratio, temperature, and NO and soot formation inside the cylinder of a DI diesel engine. These plots were instrumental in understanding the combustion and pollutants formation mechanisms of diesel-ethanol blends when compared to diesel fuel.

The experiments showed that the high fuel-air equivalence ratio was reduced when ethanol was used since ethanol contains oxygen groups which progressively were released during the combustion process. This helped in the combustion of the fuel, especially in fuel-rich areas. This in turn supported the enhancement of the soot oxidation rate, with a negligible rise in the NO concentration with increasing oxygen.

Over the past several years, ethanol has been researched comprehensively as a possible alternative fuel to be used in diesel engines, and to a much lesser extent, methanol has also been studied. Unlike methanol, ethanol is a biomass-based renewable fuel produced via fermentation of sugar from various biomass materials like corn, barley, sorghum and sugar cane. However there are several issues to consider with regards to the use of ethanol in diesel engines. While anhydrous ethanol is soluble in gasoline, additives need to be added to ensure solubility of the same in diesel. Moreover, it possesses low viscosity and low flash point, and its addition to diesel fuel can reduce lubricity and increase potential wear problems in fuel pumps. Ethanol's low cetane 
number reduces the overall cetane number of the ethanol-diesel blend, which would require cetane number enhancing additives.

Another emerging alcohol competitor for use in diesel engines is butanol. It is actually preferable to ethanol because it is less hydrophilic and it possesses higher heating value, higher cetane number, lower vapor pressure, and higher miscibility than ethanol. In short, butanol has properties much closer to diesel fuel than ethanol. Butanol has a 4-carbon structure and is more complex than ethanol since it can form either a straight chain or a branched structure, resulting in different properties. 1-butanol is generally the most common isomer which is straight-chained with hydroxyl group (-OH) located at the terminal carbon locations [20].

Dogăn et al. [21] conducted tests on a single-cylinder, four-stroke, high-speed diesel engine to study the influence of n-butanol/diesel fuel blends on engine performance and exhaust emissions. The following observations were made:

- N-butanol could be blended easily with diesel fuel, without phase separation occurring.

- The brake specific fuel consumption (BSFC) and the brake thermal efficiency (BTE) were increased a little with increasing n-butanol content in fuel blends with respect to those of the reference diesel fuel.

- Temperature of the exhaust gases reduced with increasing n-butanol content in the fuel blends.

- $\mathrm{CO}$ and $\mathrm{NO}_{\mathrm{x}}$ emissions decreased with increasing n-butanol, but the hydrocarbon emissions increased. 
For the past many years, there has also been an ever-growing interest in renewable biofuels produced domestically from agricultural feedstock, viz. vegetable oils. This has prompted research studies that consider the use of vegetable oils mixed with diesel fuel. Vegetable oil is routinely converted into biodiesel through the process of transesterification which is already quite prevalent in many countries. The direct use of vegetable oils blended with diesel still encounters many issues including high viscosity and fuel stability.

San Jose Alonso et al. [23] performed tests on a $27 \mathrm{~kW}$ house-heating boiler and burner, testing blends of diesel and soya, sunflower and rapeseed vegetable oils. The following observations were made:

- The calorific value of the vegetable oils is close to that of diesel, but the viscosity is up to 10 times higher. As a result, mixtures of less of $40 \%$ of vegetable oil were used to keep viscosity low.

- As the quantity of oil in the mixture increased, the quantity of air needed for combustion decreased. Because of this, the performance of the combustion improved, meaning that less air was needed to reach flame temperature, resulting in lesser amounts of $\mathrm{NO}$ and $\mathrm{CO}$ produced.

Panchasara et al. [2] ran combustion experiments with two types of biodiesel and diesel-VO blends in a gas turbine burner. Their combustion results were compared experimentally using an atmospheric pressure burner with an air-assisted injector and a swirler. Unlike in past research studies, they found that emissions were greatly affected by atomization and fuel-air mixing processes, not just fuel chemistry alone. $\mathrm{CO}$ and $\mathrm{NO}_{\mathrm{x}}$ 
emissions for both diesel-VO blends and the biodiesel fuels were found to decrease dramatically with an increase in the atomizing airflow rate. Even though $\mathrm{NO}_{\mathrm{x}}$ emissions for all fuels in the study depended on the flame temperature or heat release rate, atomization and fuel-air mixing processes also had a major impact on emissions. CO emissions decreased by a factor of 5 and $\mathrm{NO}_{\mathrm{x}}$ emissions decreased by a factor of 10 when the atomizing airflow rate was increased by $67 \%$.

\subsection{Importance of Vegetable Oil}

One of the main advantages of vegetable oil is that it can be considered to be a carbon neutral fuel. Vegetable oil is obtained from crops which absorb carbon dioxide via photosynthesis from the atmosphere. Oil is extracted from these crops which can be directly used as fuel. Additionally, after the appropriate transformations, a fuel can be obtained which, when combusted, generates carbon dioxide that can be absorbed once again by the plants. The environmental advantages of using vegetable oil as a fuel are [23]:

- Total reduction of sulfur emissions

- $50 \%$ reduction in $\mathrm{CO}$ emissions

- $65 \%$ reduction in particulate emissions

- $50 \%$ reduction in hydrocarbon emissions

- Potential for reduction in greenhouse effect when used instead of fossil fuels

Other advantages include its ability to decrease the strain on the incessant dependence on fossil fuels and its contribution to a positive energy balance. Only 
marginal land is needed for the growth of parent crops. Moreover, it maintains employment and income levels, especially in rural areas, and ultimately contributes to the creation of new jobs, particularly in agro-industries. Also, since the oil is obtained from plants, and with the resulting rise in production and profitability, the cost of vegetable oils can be controlled. Vegetable oils pose little risk to the environment when stored [23].

\subsection{Used Vegetable Oil}

For many years, used vegetable oil has been used extensively to make biodiesel. Generally, feedstock costs dictate biodiesel production costs. In fact, the cost of the fat or oil used to produce biodiesel directly affects the cost of the finished product. Thus, less expensive raw materials are preferred. Restaurant waste oils or waste frying oils have been given more attention due to the fact that they are relatively cheaper to acquire. The main drawback is that they would require filtration before using them for alternative fuels production.

Technically, vegetable oil can be considered "used" when it is exposed to light, air, heat or moisture, since it undergoes a process called auto-oxidation or simply oxidation. This process alters in many different ways, the physical and chemical structure of the vegetable oil molecules. Used oil can therefore be broadly defined as oil that has undergone rapid oxidation.

Section 2.1 describes the formation of a vegetable oil molecule from fatty acids and a molecule of glycerol. Oxidation can be characterized by the release of free fatty acids 
from the triglyceride structure of the vegetable oil molecule, much like a reverse reaction of the one described above. However, according to Nawar et al. [24], oxidation in vegetable oils proceeds via the more complex "free radical mechanism," which is illustrated in Figure 5.

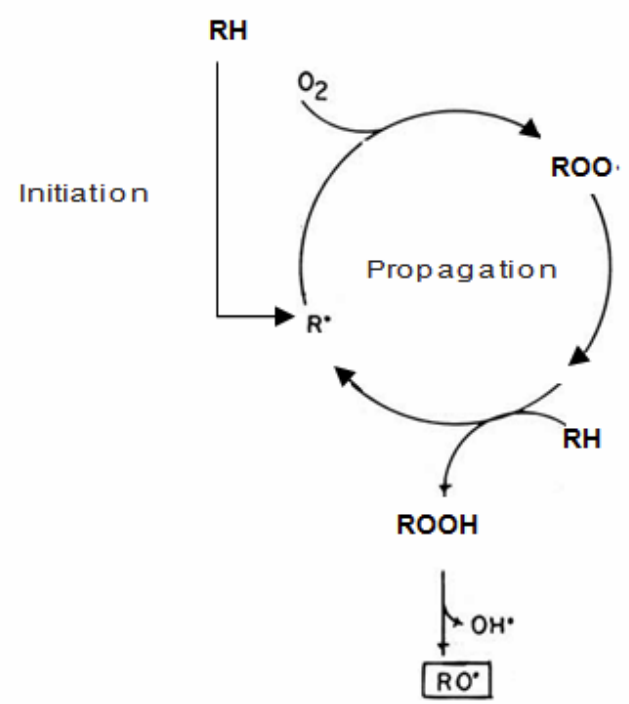

Figure 5: Free radical oxidation mechanism [24]

The free radical mechanism is broadly classified as a type of oxidative reaction in which unsaturated fatty acids react with molecular oxygen. Heating the vegetable oil enables the production of the first few radicals necessary to initiate the reaction. Heat (or light) decomposes the preformed hydroperoxides which become free radicals. Once they are produced in sufficient quantity, the chain reaction is propagated by the removal of hydrogen atoms from the double bonds ( $\mathrm{RH}$ to $\mathrm{R}$ ) present in the fatty acids. This is followed by oxygen molecules quickly reacting with $\mathrm{R}^{•}$ to form ROO' or peroxy radicals. 
These in turn remove the hydrogen from other RH molecules to form hydroperoxides, ROOH. The newly formed $\mathrm{R}$ groups, in a similar fashion, start their own cycle of reacting with oxygen and so on. Finally, the hydroperoxides undergo complex breakdowns, which can involve scission of the O-O bond to give an alkoxy radical, which can further interact with hydrogen, or can further decompose and form oxidation products like aldehydes, semi-aldehydes, and acids [24].

Oxidation can be measured by the primary products that the process generates in vegetable oils including its peroxide value. It is the amount of peroxide oxygen per kilogram of oil present in oil. Secondary products such as carbonyl compounds also contribute to the oxidized oil. Actually, carbonyl compounds are associated with the development of off-flavors due to oxidative rancidity in vegetable oils [25].

Saturated fats are not much affected by oxidation because they are very stable and have high resistance to oxidation. Monounsaturated fats are somewhat susceptible to oxidation, since they have a pair of missing hydrogen atoms. Polyunsaturated oils, which are missing several pairs of hydrogen atoms, are highly vulnerable to oxidation and very unstable (even at room temperature) [26]. Erhan et al. [27] conducted experiments which showed that oxidation stability of vegetable oils increases as the degree of unsaturation decreases. They used pressure differential scanning calorimetry to determine the oxidation stability using onset temperature (OT) of the oil as indicator. OT is defined as the temperature at which a rapid increase in rate of oxidation occurs. High OT indicates high oxidation stability. 
Naz et al. [28] hypothesized that the decrease in unsaturation content during oxidation of vegetable oils may be due to the elimination of $\mathrm{H}$ atom adjacent to double bonds, which results in formation of free radicals. This is indicated by a reduction in what is known as the iodine value. Oxidation also leads to the formation of free fatty acids, double bond isomerization, saturation, products of higher molecular weight, and an increase in viscosity. While oxidation of oil increases with time and temperature, it is also influenced by other factors like fatty acid composition and minor components such as tocopherols. Reaction between tocopherols and free radicals or oxygen causes degradation of tocopherols, as was concluded by Hwang et al. [29].

Tocopherols are actually a type of antioxidant present in vegetable oils like corn oil. Antioxidants help against oxidation in oils, in that they react with most free radicals (in induction stage) before they react to form the aforementioned peroxides and more free radicals. They help in peroxide decomposition, but at the same time form more free radicals in addition to those already present in the oil. The antioxidant concentration may not be enough to react with all these free radicals. This gives rise to carbonyl compounds. Thus, in addition to their beneficial attributes, the antioxidants' effect on the initiation and rate of peroxide decomposition also need to be taken into account [25].

\subsection{Properties of Fatty Acids}

There are various terms that are defined for evaluating various properties of fatty acids, such as the peroxide value and iodine value as mentioned above. The following are the definitions of some important properties [30]: 
- Peroxide value: This gives the measure of the degree of oxidation in fats and oils. The value is actually the concentration of peroxides present in the oil and is indicative of the extent to which spoilage has occurred. The peroxide value is defined as the amount of peroxide oxygen per $\mathrm{kg}$ of fat or oil.

- Iodine value: This is the measure of the degree of unsaturation in fatty acids. It is defined as the mass of iodine in grams that is consumed by 100 grams of the fat or oil.

- Acid value: It gives a measure of the amount of carboxylic acid groups in a fatty acid. It is defined as the mass of potassium hydroxide in milligrams that is required to neutralize the free fatty acids in one gram of fat or oil.

- Saponification value: This is defined as the amount of potassium hydroxide or sodium hydroxide in milligrams that is needed to saponify one gram of oil or fat.

\subsubsection{Total Polar Material}

Total polar material (TPM) gives a measure of the amount of polar compounds or degraded substances formed in fats or oils after it has undergone oxidation. It not only affects the consistency, taste and appearance of the oil, but also its quality. TPM encompasses a broad range of free fatty acids, monoglycerides and diglycerides, as well as oxidation products like aldehydes or ketones [31].

Takeoka et al. [32] performed experiments involving heating different frying oils and fats, including corn oil at two different frying temperatures. The aim was to evaluate the 
thermal stability of these oils and fat under varying heating cycles by measuring TPM, polymerized triglycerides content, color index, and iodine value. It was observed that there was a highly negative correlation $(\mathrm{r} \leq-0.97)$ and very significant correlation $(\mathrm{P}<$ 0.001 ) between TPM and iodine value. Out of all the oils and fats tested, it was seen that corn oil had both fastest rate of production of TPM and the fastest loss of unsaturated content when heated at a constant frying temperature of $190^{\circ} \mathrm{C}$.

The method of determining the total polar material and TPM results are discussed in Sections 5.5.1 and 6.1.4.1, respectively.

\subsection{Characterization of Fatty Acids Properties}

In order to observe and study the extent to which oxidation in fats or oils has occurred, different methods have been adopted to measure the values mentioned above. Many researchers have observed and defined maximum limits or values beyond which the oil can be deemed unusable. The standard procedures for most of these methods are defined and maintained by the American Oil Chemists' Society (AOCS).

Peroxide and iodine values are measured primarily via titration with iodine. Their units are milliequivalents of Oxygen per kilogram of oil and milligrams of iodine per 100 grams of oil, respectively. Acid value measurements involve titration with potassium hydroxide. Its units are in milligrams of $\mathrm{KOH}$ per gram of oil.

AOCS also defines alternate procedures to determine iodine and peroxide values that do not require titration. These involve FTIR analyses, color measurements, and gas chromatography methods. Iodine value of oils for example can be determined using 
Fourier Transform Near-Infrared Spectrometry (FT-NIR). This method is discussed in more detail in Section 5.5.1.

\subsection{Swirl Effects in Combustion}

Swirlers are used for controlling flames and ensuring proper mixing of fuel and oxygen in combustion chambers. When a rotary motion is given to a fluid upstream of an fuel injector orifice, the resulting fluid-air mixture flow has a tangential velocity component in addition to axial and radial components of velocity as well. In effect, a swirler is responsible for imparting vorticity to the air passing through it, which enables better mixing of fuel and air during combustion.

Swirl number can be defined as the ratio of the angular momentum to the axial momentum of the airflow within the combustion chamber [33]. The swirl number of an annular swirler with a constant vane angle $\alpha$ is given by [33]:

$\mathrm{SN}=\frac{2}{3} *\left[\frac{\left\{1-\left(\frac{\mathrm{Rh}}{\mathrm{R}}\right)^{3}\right\}}{\left\{1-\left(\frac{\mathrm{Rh}}{\mathrm{R}}\right)^{2}\right\}}\right] * \operatorname{Tan}(\alpha)$

where,

$\mathrm{SN}=$ Swirl Number

$\mathrm{R}_{\mathrm{h}}=$ Outer radius of the hub

$\mathrm{R}=$ Inner radius of the tube

$\alpha=$ Vane Angle 
The presence of a swirl gives rise to radial and axial pressure gradients in the combustion chamber. For a strong swirl $(\mathrm{S}>0.6)$, a point is reached wherein the adverse pressure gradient along the jet axis cannot be overcome by the fluid particles flowing in the axial direction. Due to this, a recirculating flow in the reverse direction is set up along the combustion chamber axis. This is called the Internal Recirculation Zone (IRZ). The IRZ, which has the form of a torroidal vortex plays a crucial role in flame stabilization. It consists of a well-mixed zone of chemically active combustion products where heat can be stored, thereby enabling easy burning of the newly sprayed reactants [33].

On the other hand, a weak swirl $(\mathrm{S}<0.6)$ leads to axial pressure gradients too large to cause internal recirculation. As a result, poor air-fuel mixtures are formed, leading to an increase in emissions. The following paragraphs describe the use of swirlers in burners, which help in the combustion of different liquid fuels by providing good mixing and optimal heat transfer properties [33].

Mafra et al. [34] conducted experiments with Liquefied Petroleum Gas in a cylindrical chamber to study the effect of swirl number (S) on NO formation. From these experiments, it was concluded that for the same equivalence ratio, when the swirl number was increased from 0.488 to 1.315 , the $\mathrm{NO}$ formation decreased from $70 \mathrm{ppmv}$ to 55 ppmv. The effect of varying equivalence ratio at the same swirl number on NO emissions was also studied. When the equivalence ratio was decreased from 0.84 to 0.61 , at the same swirl number, NO formation decreased from $120 \mathrm{ppmv}$ to $70 \mathrm{ppmv}$. Thus, 
the minimum NO formation occurred at the highest swirl number of 1.315 and the lowest equivalence ratio of 0.61 .

Ishak et al. [35] ran a series of combustion experiments with diesel fuel inside a liquid fuel burner system with a radial swirler. At a constant equivalence ratio of 0.83 , the vane angle was increased from $10^{\circ}(\mathrm{S}=0.046)$ to $70^{\circ}(\mathrm{S}=1.911)$ in increments of $10^{\circ}$, and the emissions were observed in each case. It was found that there was a dramatic decrease in the $\mathrm{NO}_{\mathrm{x}}, \mathrm{CO}$, and $\mathrm{CO}_{2}$ emissions as the vane angle increased. At $60^{\circ}(\mathrm{S}=1.427)$, a $\mathrm{NO}_{\mathrm{x}}$ reduction of $26 \%$ was observed when compared to $10^{\circ}$. $\mathrm{CO}$ emissions were reduced by $48 \%$ and $\mathrm{CO}_{2}$ emissions by $15.5 \%$ for the vane angle $70^{\circ}$.

\subsection{Micro-Explosions}

Micro-explosions occur when a fuel blend comprising of two or more fuels with differing vapor pressures is emulsified and combusted. For instance, in water-in-oil emulsions, water has a high vapor pressure which leads to micro-explosion. As soon as the water phase reaches superheated conditions, the water droplets surrounded by the oil phase explode, causing the oil to disperse into very minute particles. Figures 6 and 7 show the difference between pure homogenous fuel and emulsified fuel combustion. 


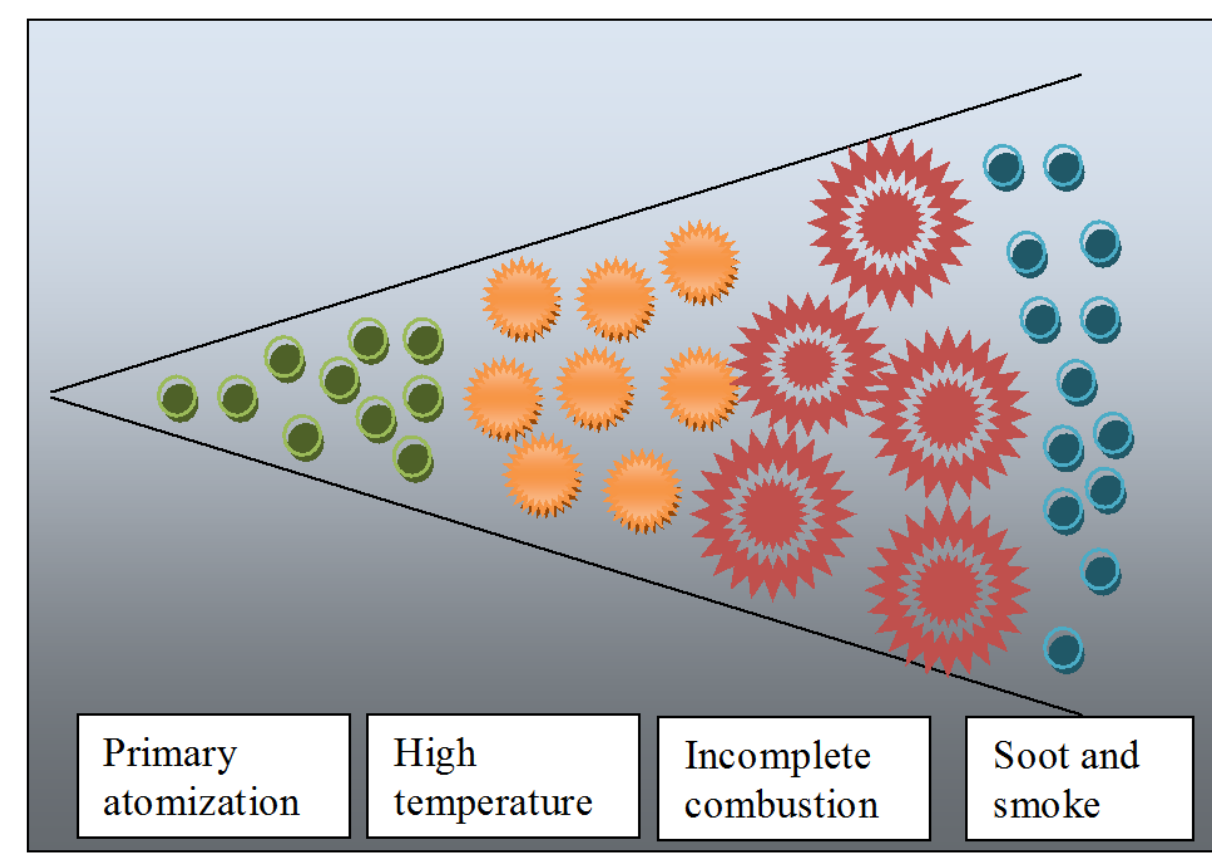

Figure 6: Pure fuel oil combustion [10]

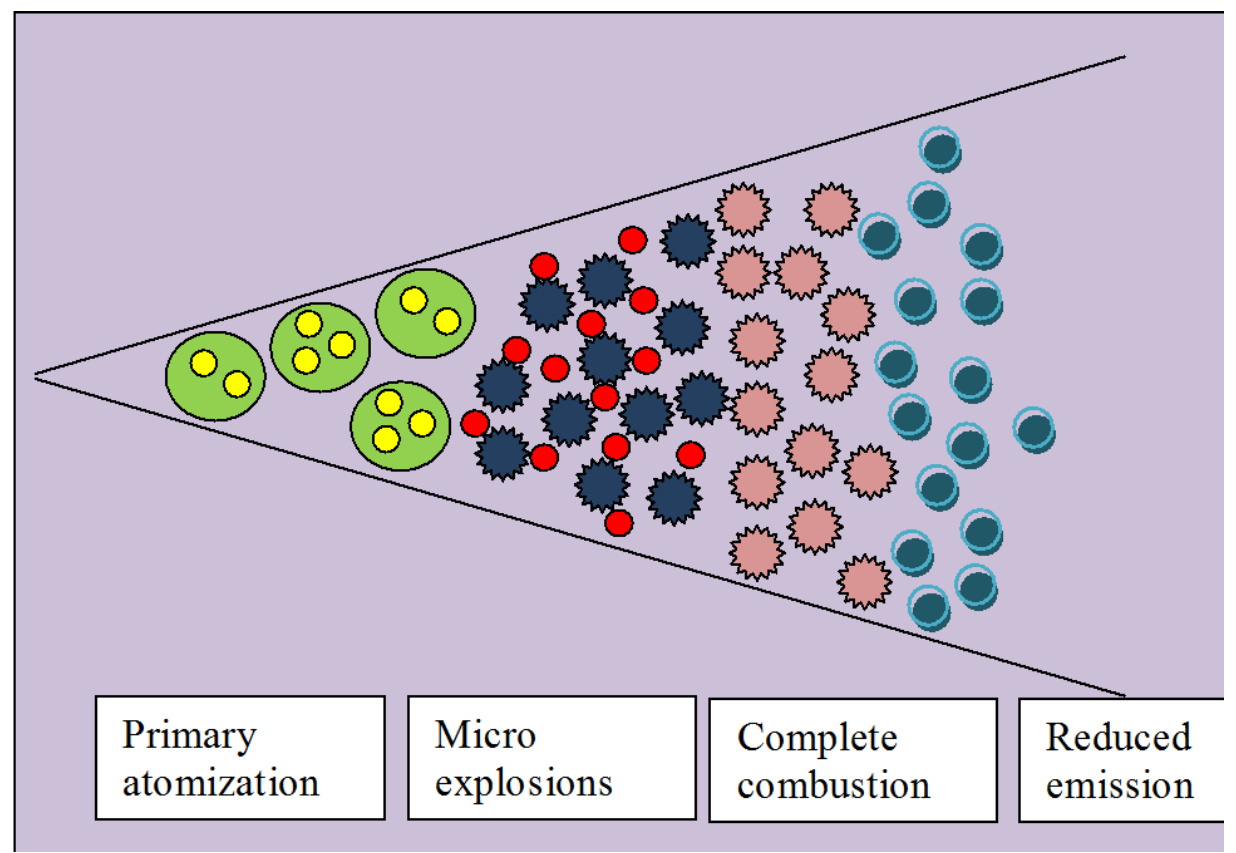

Figure 7: Emulsified fuel combustion [10] 
Kadota et al. [36] studied the fundamental mechanisms responsible for the combustion process in water-fuel emulsions with focus on the micro-explosion phenomenon. According to them, micro-explosions taking place during the combustion of emulsions offer a number of advantages over the combustion of a neat fuel. This physical process involves the secondary atomization of the emulsion caused by the violent evaporation of the interior droplets (water). The resulting smaller droplets evaporate very quickly thereby reducing the time for pyrolytic reactions and inhibiting the formation of carbonaceous residue. Fuel-air mixing in the combustion field is enhanced due to the disintegration of primary emulsion into finer secondary droplets, which in turn results in an improvement in combustion efficiency and a reduction in the formation of soot and unburned hydrocarbons. Moreover, the participation of water in the aforementioned evaporation process tends to lower droplet temperature, which eventually reduces the rate of heat release in the flame. Since high flame temperatures cause thermal $\mathrm{NO}_{\mathrm{x}}$, using water can significantly reduce its formation. These processes are illustrated in Figure 7. Water addition can also raise the ignition delay, allowing more residence time and a cleaner combustion. Also, adding water increases the amount of $\mathrm{OH}$ radicals, which help in the oxidation of the soot precursors. Thus, the authors [36] suggest that the use of emulsified fuels in the combustion process would not only allow for the design of more flexible fuel atomization devices, but also for extending the range of fuel resources, including the less volatile fuels such as vegetable oils.

Houlihan [10] provides a detailed illustration about how emulsified fuels have the potential to deliver the "triple-crown" advantages, both from the environmental and 
economical point of view. These benefits include reduction of $\mathrm{NO}_{\mathrm{x}}$ and particulate matter, the increase in fuel efficiency, and the reduction of greenhouse gases (GHG). The addition of water in the emulsion causes it to superheat in the combustion zone, producing steam bubbles and resulting in the explosion of the surrounding fuel oil. This in turn results in a more complete combustion and hence, less particulate matter is produced. Moreover, water vapor in the combustion zone reduces the temperature in the combustion zone due the water's high heat capacity. This enables a much less energetic oxidation of both fuel and air-borne nitrogen resulting in an overall decrease in $\mathrm{NO}_{\mathrm{x}}$ production. The author suggests that emulsified fuel can give more power output per fuel input due to secondary atomization. Thus, the total amount of hydrocarbon base fuel (fuel forming the continuous phase in an emulsion) required for gaining a specific power output is less for emulsified fuels compared to just its pure form. This is indicative of higher fuel efficiency. Also, the consumption of lesser fuel directly translates to a reduction in GHG. In conclusion, all these benefits are attributed to the micro-explosion phenomenon.

\subsection{Fundamentals of Soot Formation}

The combustion of hydrocarbons should lead to carbon dioxide and water as the reaction products under ideal conditions. These conditions may be specified by the stoichiometric composition of the combustible mixture (i.e. the oxygen taking part in the reaction) should be sufficient to combust the fuel completely with maximum heat release and maximum chemical energy available for work [37]. 
In practical applications, however, these conditions deviate locally from ideality. When oxygen present in a combustion chamber is insufficient to react with the fuel completely, other products of incomplete combustion like carbon monoxide, hydrogen, hydrocarbons and soot form, in addition to carbon dioxide and water [37]. The quantity of soot emitted by a flame is directly dependent upon the competition between the soot particulate formation mechanism and the oxidation of soot precursors. When the oxidation rate of soot precursors exceeds the formation rate of soot, the flame appears more luminous indicating a lower rate of soot production which is characterized by a lesser amount of smoke. When the rate of soot formation exceeds the oxidation rate of soot precursors, soot forms in sufficient amounts to increase the amount of smoke. In short, it is the competition between the soot formation and soot precursor oxidation mechanisms that actually determine the final appearance of the soot, as well as the intensity of the combustion flame [38]. However, very little is known about how flame temperature affects the formation of soot.

The main constituents of soot are sole carbon atoms. It appears as a luster-less black substance which is different from graphite [38]. Its formation, which broadly involves the conversion of hydrocarbon fuel containing a few carbon atoms into a carbonaceous agglomerate containing millions of carbon atoms, is a very complex process. Soot formation is also associated with the formation of different kinds of hydrocarbons, particularly polycyclic aromatic hydrocarbons (PAH) [37]. These are known to be toxic and have hazardous effects on human health. 
The time available for soot formation during combustion is of the order of milliseconds, and usually forms at temperatures ranging between $1000{ }^{\circ} \mathrm{C}$ to $2500{ }^{\circ} \mathrm{C}$. During this time, a solid phase of soot particles forms from the hydrocarbon molecules via fuel oxidation or pyrolysis products [38]. The following paragraph gives a brief description of the formation of soot during the combustion of diesel fuel.

When diesel droplets are sprayed into an engine cylinder at high pressures but do not mix completely with oxygen, it results in incomplete combustion [39]. The subsequent mechanism is a complicated one having many possible paths, which leads to the formation of the aforementioned PAHs, the building blocks of soot. One of these paths involves the pyrolysis of certain molecules into unsaturated molecules where the main component is ethyne. Ethyne polymerizes to polyethyne and eventually forms polycyclic closed rings called platelets, which are tiny graphite-like sheets. These graphite-like sheets stack together to form crystallites, which further stack together to form turbostratic particles. This is followed by coagulation and surface growth initiated by the addition of precursor gas molecules. Soot particles get their typical spherical shape because of the mechanics of the surface growth process. When this growth ceases, the spherical particles stop growing as well giving what are called primary soot particles. They continue to coagulate to give rise to chain-like aggregates, which in turn can stick together to form larger agglomerates [40]. Figure 8 illustrates the mechanism of soot formation. 


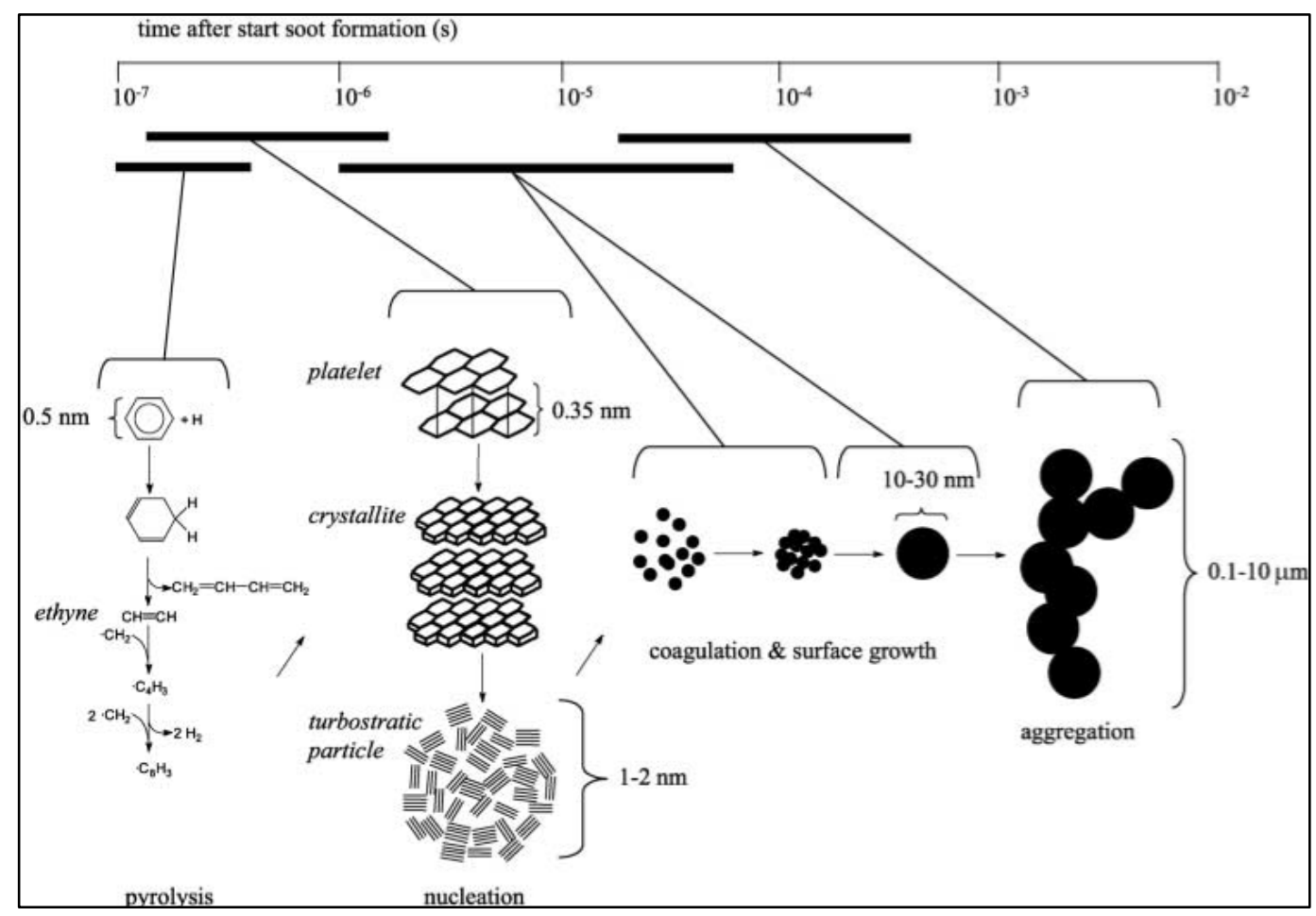

Figure 8: Schematic of the mechanism of soot particle formation [41]

Soot formation is favored when the molar ratio of carbon to oxygen approaches unity, but in premixed flames the critical $\mathrm{C} / \mathrm{O}$ ratio for soot formation is about 0.5 . This is due to the fact that a large amount of carbon is tied up with stable molecules such as $\mathrm{CO}_{2}[42]$

Soot formation heavily depends on fuel type. Thus, in order to reduce the amount of soot formed, fuel modification could be done. For example, diesel fuel could be mixed with other fuels having a low smoking tendency. Diesel blended with methanol and ethanol separately has shown a clear reduction in soot particles as opposed to only diesel [38]. Air parameters also have a crucial role in controlling soot particle formation. Soot has been found to significantly reduce with increasing air velocity due to better mixing 
between air and the fuel. Lower flame temperatures also cause a decrease in soot formation.

Puhan et al. [43] ran diesel engine experiments to compare the performance of biodiesel produced from various sources to the performance of petroleum-based diesel fuel. During the experiments, it was discovered that the unsaturated linseed oil methyl ester produced more soot when compared to the highly saturated coconut oil methyl ester (biodiesel). Combustion of unsaturated linseed oil methyl ester led to higher exhaust gas temperature caused by the higher ignition delay and shorter premixed combustion period (which increased the after-burn time). This led to a greater amount of soot particles formed during the combustion process.

\subsection{Role of NO in Soot Formation Control}

Cooper et al. [44] proposed a mechanism which involved the use of a Pt catalyst to convert $\mathrm{NO}$ to $\mathrm{NO}_{2}$ which reacted favorably with soot particulates. $\mathrm{NO}_{2}$ reacts much better with soot particles than NO resulting in the annihilation of soot particles attached to a wire mesh. It was observed in their findings that $\mathrm{NO}$ (which oxidizes to $\mathrm{NO}_{2}$ ) does play a major role in soot combustion.

Many $\mathrm{NO}_{\mathrm{x}}$-soot control techniques have been studied and implemented such as Exhaust Gas Recirculation (EGR) which helps reduce $\mathrm{NO}_{\mathrm{x}}$ and soot emissions. Cooper et al. [44] however, focused more on the improvement of the Catalytic Trap Oxidizer (CTO) developed by Johnson Matthey [44]. It involved the use of precious metal catalysts in a ceramic-coated stainless steel wire mesh trap. 
In their experiments, when a Pt monolith catalyst was placed in front of a diesel particulate-coated wire mesh plug in a flow reactor, it was found that there was a pressure drop in the exhaust back pressure when exposed to a synthetic exhaust stream. But when an uncatalyzed washcoated plug was placed behind a fresh Pt catalyst, there was no decrease in the exhaust back pressure. This was indicative of the production of an active gas phase species by the Pt monolith catalyst ( $\mathrm{NO}+1 / 2 \mathrm{O}_{2} \rightarrow \mathrm{NO}_{2}$ ), which combusted the soot trapped further downstream. The reaction for $\mathrm{NO}$ oxidation to $\mathrm{NO}_{2}$, and that for soot oxidation by $\mathrm{NO}_{2}$ can be illustrated by the following global reaction [44]:

$\mathrm{NO}+1 / 2 \mathrm{O}_{2} \rightarrow \mathrm{NO}_{2}+\mathrm{C} \rightarrow \mathrm{NO}+\mathrm{CO}$

Another possibly related mechanism through which $\mathrm{NO}_{\mathrm{x}}$ reacts with soot is given by the following reaction [45]:

$\mathrm{NO}+\mathrm{C} \rightarrow \mathrm{CO}+1 / 2 \mathrm{~N}_{2}$

In summary, soot particles react with $\mathrm{NO}_{\mathrm{x}}$ in a way to decompose soot particles at the expense of $\mathrm{NO}_{\mathrm{x}}$. 


\section{RECENT RESEARCH ON MAKING STABLE DIESEL-CORN OIL BLENDS}

The main goal of this project was to observe and study the effects of mixing fresh and used corn oil with diesel and jet fuel. Since little is known about the miscibility and compatibility of corn oil with conventional fuels, attempts were made to make blends using diesel, corn oil and two surfactants. Several blends were made to determine their degree of stability. Only those that were stable were combusted to understand the effect of blend composition on emission levels.

\subsection{Sample Preparation}

In order for achieving good atomization in the combustion chamber, it was crucial that all the corn oil-based blends remain stable and depict Newtonian behavior. SPAN 80 and TWEEN 80 were selected as surfactants to reduce the interfacial tension between

diesel and corn oil and to ensure a homogenous blend. The amount of each surfactant required was determined using the concept of Hydrophile-Lipophile Balance (HLB) [46].

Various surfactants could be quantitatively characterized by this balance using the HLB number scale, which was introduced in 1949 by Griffin [46]. He claimed that HLB reflects the balance between the hydrophilic and hydrophobic (lipophilic) parts of the surfactant molecule. The HLB number scale takes into account the percentage of hydrophilic and hydrophobic groups present in such a molecule. In general, low HLB numbers are ascribed to the lipophilic surfactants, which are used in Water-in-Oil emulsions. Similarly, high HLB numbers are ascribed to hydrophilic surfactants, and are 
used in Oil-in-Water emulsions [46]. Table 2 summarizes the range of HLB numbers that surfactants possess along with the corresponding application for each range [47]:

Table 2: HLB range of surfactants and corresponding applications

\begin{tabular}{|c|c|}
\hline HLB range & Application \\
\hline 3 to 6 & Water-in-Oil emulsifier \\
\hline 7 to 9 & Wetting agent \\
\hline 8 to 18 & Oil-in-Water emulsifier \\
\hline 13 to 15 & Detergent \\
\hline 15 to 18 & Solubilizer \\
\hline
\end{tabular}

Blends of diesel and corn oil were first made without adding any surfactant. Then additional blends having different proportions of diesel and corn oil were made using $1 \%, 2 \%$ and $3 \%$ surfactant. The following table shows the different blends that were made. It also displays the percentages by mass of the required SPAN 80 and TWEEN 80 surfactants along with the HLB numbers for each blend. 
Table 3: Corn oil-based blends with surfactants

\begin{tabular}{|c|c|c|c|c|c|}
\hline Base Fuel & $\begin{array}{c}\text { Secondary } \\
\text { Fuel }\end{array}$ & $\begin{array}{c}\text { Surfactant } \\
\text { amount }\end{array}$ & Additives & HLB & Stable \\
\hline $70 \%$ Diesel & $30 \%$ Corn Oil & No surfactant & - & No \\
\hline $69 \%$ Diesel & $30 \%$ Corn Oil & $1 \%$ surfactant & $72.9 \%$ Span $80 ; 27.1 \%$ Tween 80 & 7.2 & No \\
\hline $68 \%$ Diesel & $30 \%$ Corn Oil & $2 \%$ surfactant & $72.9 \%$ Span $80 ; 27.1 \%$ Tween 80 & 7.2 & No \\
\hline $67 \%$ Diesel & $30 \%$ Corn Oil & $3 \%$ surfactant & $72.9 \%$ Span $80 ; 27.1 \%$ Tween 80 & 7.2 & No \\
\hline $80 \%$ Diesel & $20 \%$ Corn Oil & No surfactant & - & - & No \\
\hline $79 \%$ Diesel & $20 \%$ Corn Oil & $1 \%$ surfactant & $76.63 \%$ Span $80 ; 23.36 \%$ & 6.8 & No \\
& & & Tween 80 & & \\
\hline
\end{tabular}


The procedure followed to make these blends was simple. Each sample was made by pouring 30 grams (for the second blend) of corn oil in a measuring cylinder. Then, the HLB formula suggested by Mollet et al. [48] was used to determine the amount of surfactants (SPAN 80 and TWEEN 80) needed to achieve the required HLB number ' $\mathrm{X}$ ' as shown below.

(\%) SPAN $80=100 *\left(\frac{\mathrm{X}-\text { HLBTwEen80 }}{\text { HLBSPAN80-HLBTwEEN80 }}\right)$

(\%) TWEEN $80=100-(\%)$ SPAN 80

The total surfactant needed in each case ( $1 \%$ by mass in the first case) was used to calculate the HLB number. The HLB values of corn oil and diesel were 10 and 6 , respectively [49]. The HLB value ' $\mathrm{X}$ ' for the second blend was calculated to be 7.2 as follows:

$\left(70 \%\right.$ diesel $\left.* \mathrm{HLB}_{\text {diesel }}\right)+\left(30 \%\right.$ corn oil $\left.* \mathrm{HLB}_{\text {corn oil }}\right)=\mathrm{X}$

Substituting this value of $\mathrm{X}$ in Equation (4), and knowing the HLB values for SPAN 80 and TWEEN 80 as 4.3 and 15, respectively, the amount of each surfactant was determined to be $72.9 \%$ of SPAN $80(0.729 \mathrm{~g})$ and $27.1 \%$ of TWEEN $80(0.271 \mathrm{~g})$ which was added to corn oil.

Then this mixture was poured into a blender and thoroughly mixed for 2-3 minutes to finely distribute the surfactant molecules in corn oil. After that, 69 grams of diesel was poured in a measuring cylinder and then mixed for about 10 minutes. This blend 
was then poured into glass vials in order to assess its stability, as seen in Figure 9. About $25 \mathrm{ml}$ of the blend was used for viscosity measurement.

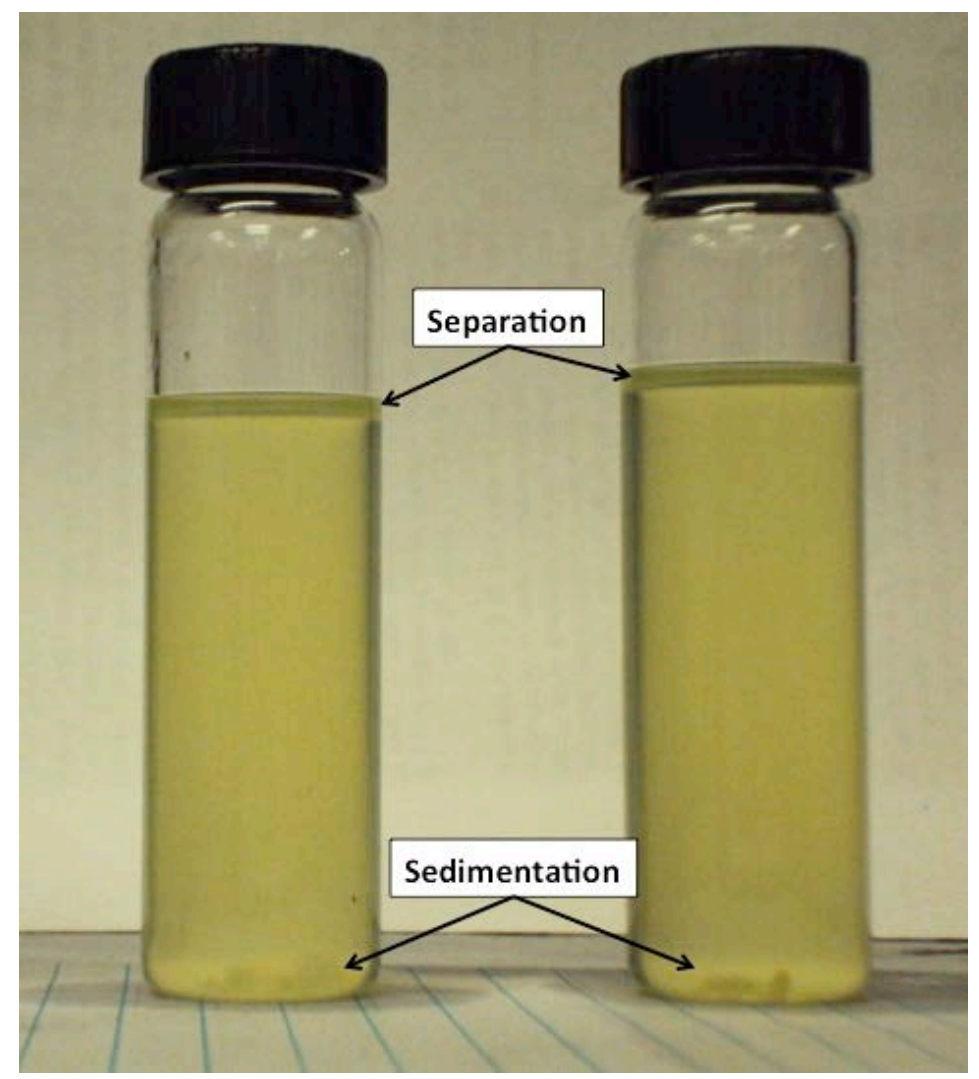

Figure 9: Unstable $80 \%$ diesel-20\% corn oil blend with $1 \%$ surfactant

After pouring all the samples into separate vials, they were left alone for few hours to see if they had remained stable. All the samples shown in Table 3 were found to be unstable. As it can be seen in Figure 9, corn oil and diesel began to separate at the surface just 10 minutes after the blends were made. Moreover, sedimentation was seen at the same time forming at the bottom of the vials. This could have been due to surfactants precipitating out as a result of their inability to finely distribute themselves and attach to 
the parent molecules in the blend. A very similar trend was observed for all the blends containing the surfactants. The blends without any surfactants remained stable for about half an hour longer, after which turbidity and eventual separation was observed.

Concurrently, the viscosity of all the blends was measured by using a Brookfield DV-I Prime viscometer. A detailed explanation about viscosity measurement can be found in the next section. The viscosity of corn oil alone was 54.2 centipoise (cP) at 25 ${ }^{\circ} \mathrm{C}$. The viscosity variation with shear rate for some of blends are depicted in Figure 10. Unstable blends were not used for the remainder of the project since they were found to be unsuitable for proper atomization during the combustion phase of the project.

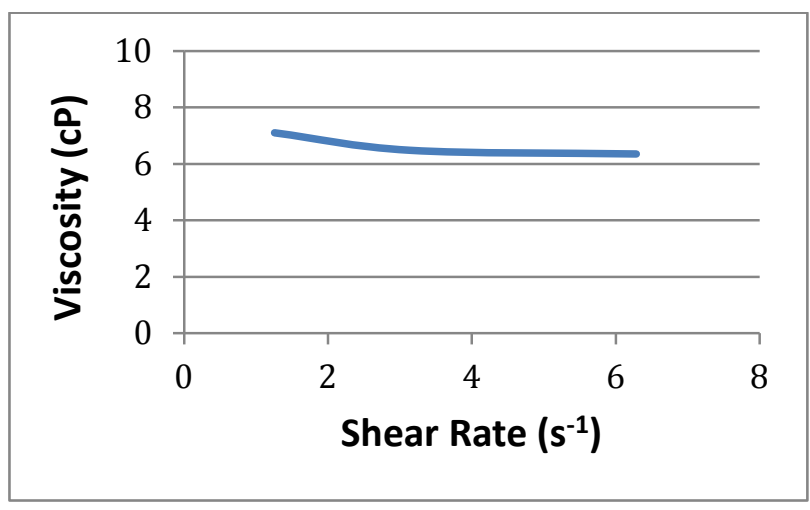

(a)

Figure 10: Viscosity measurements at various shear rates for (a) $70 \%$ diesel-30\% corn oil with $1 \%$ surfactant, (b) $70 \%$ diesel-30\% corn oil with $2 \%$ surfactant, (c) $80 \%$ diesel- $20 \%$ corn oil with $1 \%$ surfactant 


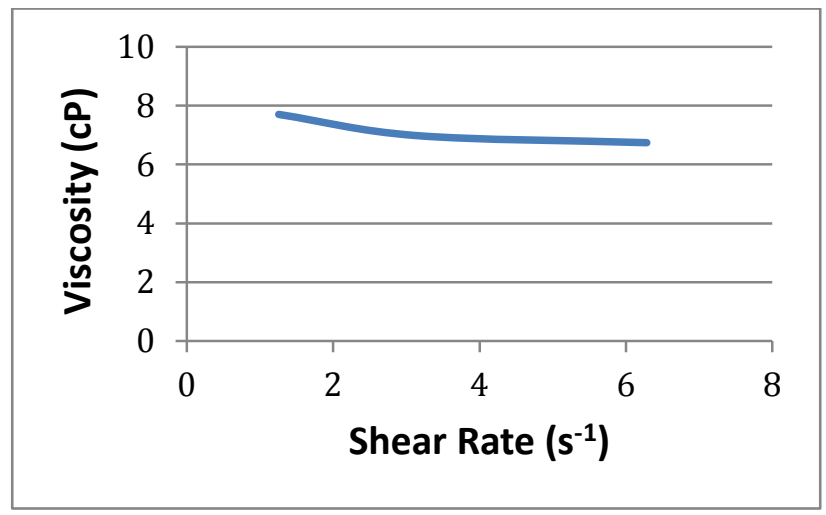

(b)

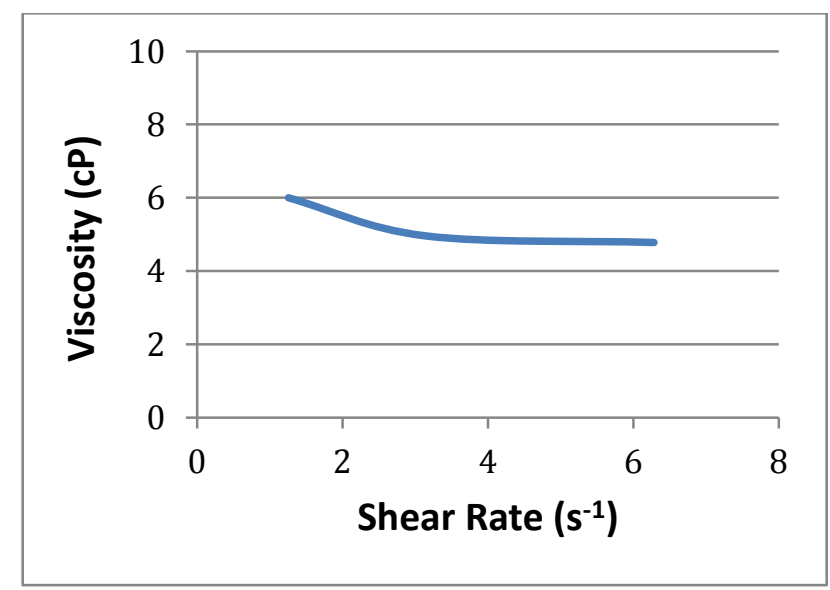

(c)

Figure 10 (Continued)

It was concluded that surfactants actually adversely affected the stability of the corn oil-based blends rather than contributing to it. As a result, the use of greater concentration of surfactants was not attempted since surfactants would have increased viscosity of the blends and increased their cost. For the 70\% diesel-30\% corn oil blend, 
$3 \%$ surfactant was decided as the maximum amount to be added with the aim of being cost-effective and to avoid high viscosity levels.

However, since all the blends that were made with surfactants were unstable, a different approach had to be adopted to ensure proper miscibility of corn oil in diesel and jet fuel. It was decided to use alcohols as solvents instead of surfactants to emulsify corn oil in diesel and jet fuel as suggested by Bagby and Dunn [7]. The following sections explain the efforts undertaken in this direction. 


\section{OBJECTIVES AND TASKS}

This research work was performed with the aim of observing, studying and ultimately understanding the effects of corn oil-based blend composition on viscosity, fuel stability and energy content. Moreover, the effects of blend composition on combustion emissions were evaluated. During the execution of the combustion experiments, equivalence ratio and swirl number were also considered to understand their effects on emissions. The emissions in question were mainly nitrogen oxides, carbon monoxide and carbon dioxide. The parent fuels used in the experiments were fresh corn oil and used corn oil. Ultra-low sulfur diesel, ethanol-95 and n-butanol were mixed with each of these two fuels to make corn oil-in-diesel blends at two different compositions (by mass), such that there were six fuel blends. Jet fuel was used instead of diesel to assess the viability of using corn oil in gas turbines. The following oils and blends were studied in detail:

1. Fresh Corn Oil

2. Used Corn Oil

3. $27 \%$ fresh corn oil-in-50\% diesel blend with 19\% n-butanol and 4\% ethanol-95

4. $35 \%$ fresh corn oil-in- $40 \%$ diesel blend with $21 \%$ n-butanol and $4 \%$ ethanol-95

5. $27 \%$ used corn oil-in-50\% diesel blend with 19\% n-butanol and 4\% ethanol-95

6. 35\% used corn oil-in- $40 \%$ diesel blend with $21 \%$ n-butanol and $4 \%$ ethanol-95

7. $27 \%$ fresh corn oil-in-50\% jet fuel blend with $19 \%$ n-butanol and $4 \%$ ethanol-95

8. $35 \%$ fresh corn oil-in- $40 \%$ jet fuel blend with $21 \%$ n-butanol and $4 \%$ ethanol-95

9. $27 \%$ used corn oil-in-50\% jet fuel blend with $19 \%$ n-butanol and $4 \%$ ethanol-95 
10. $35 \%$ used corn oil-in- $40 \%$ jet fuel blend with $21 \%$ n-butanol and $4 \%$ ethanol-95

The following tasks were performed with the overall objectives in mind:

1. Making of Used Corn Oil: Used corn oil was made by heating fresh corn oil in a deep fryer for a fixed period of time. Its Total Polar Material (TPM), Iodine Value, Free Fatty Acid Value and Peroxide Value were determined to fully understand the effect of time and frying temperature on corn oil's physical and chemical properties.

2. Characterization of Fuel Components: Heating values of all fuel components were obtained through ultimate analyses to find out their chemical compositions.

3. Making of Stable Corn Oil Based Blends: Stable corn oil-in-diesel and corn oil-in-jet fuel blends were made.

4. Chemical Formulae and Heating Values of Blends: The chemical formula and heating value of each blend were determined based on ultimate analysis.

5. Viscosity Measurements: Viscosity of all corn oil based blends was measured using a viscometer.

6. Air and Fuel Flow Rate Calculations: Air-to-fuel ratios at each equivalence ratio for every fuel were determined.

7. Combustion Experiments and Emission Data at Different Swirl Number: Combustion experiments for fresh corn oil, used corn oil and the corresponding blends were undertaken at two swirl angles at constant heat output.

The objectives were undertaken to illustrate the effects of combusting corn oil and the various fuel blends under different operating conditions. These operating conditions 
enforced on the combustion process had significant effects on emissions and are explained in detail in Section 6. 


\section{EXPERIMENTAL SET-UP}

The following sections give a detailed description about the laboratory where experiments were performed. A detailed explanation of the instruments used and experimental procedures followed are also included.

\subsection{Introduction}

All the experiments were run on a small-scale combustion chamber having a capacity of $30 \mathrm{~kW}(100,000 \mathrm{BTU} / \mathrm{hr})$, built and located at the Coal and Biomass Energy Laboratory (CBEL) at Texas A\&M University, College Station, TX. The combustion chamber was initially designed by Dr. Kalyan Annamalai's former research students. It was built to combust only solid fuels such as coal and biomass and has been in operation for more than 10 years. Modifications needed for combusting liquid fuels were done by Shreyas Bhimani [50], one of Dr. Jorge Alvarado's former research students. The following sections give a description of these modifications and instrumentation [50].

\subsection{Combustion Chamber Modifications}

Modifications to the combustion chamber to enable it to burn liquid fuels were done primarily by designing and making the following modifications:

1. Use of a radial type swirler

2. A liquid fuel injection system 


\subsubsection{Swirler}

The swirler used in this project was a radial vane-type. Two concentric steel cylinders were used to make it with steel vanes of $0.5 \mathrm{~mm}$ thickness attached to it as shown in Figure 11. There were 2 sets of 8 vanes: the first set placed at an angle of $60^{\circ}$ $($ swirl number $=1.4)$ and the second set placed at an angle of $51^{\circ}($ swirl number $=1.0)$, both with respect to the vertical axis. Steel nuts and bolts were used to hold the vanes securely in between the inner and outer cylinders. Tungsten wires were also used for additional support of the vanes.

Dimensions of the inner and outer diameters of the inner cylinder were $53.9 \mathrm{~mm}$ (2.124 in) and $59.4 \mathrm{~mm}$ (2.34 in), respectively. The swirler had a height of $25.4 \mathrm{~mm}$ (1 in). Dimensions of the inner and outer diameters of the outer cylinder were $100.4 \mathrm{~mm}$ (4.10 in) and $113.6 \mathrm{~mm}$ (4.475 in), respectively.

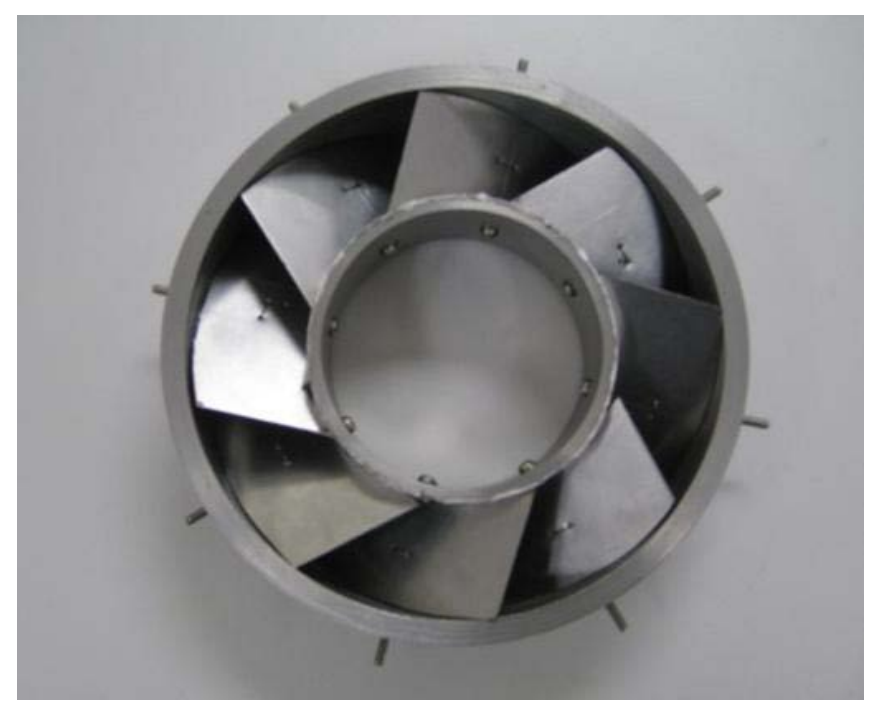

Figure 11: Swirler at $60^{\circ}$ swirl angle 


\subsubsection{Liquid Fuel Injection System}

The injection system used for spraying fuel comprised of the following equipment and materials:

\section{Twin fluid atomizer or nozzle}

This component was designed to finely atomize and spray viscous fluids. As is evident from its name, the atomizer was supplied with two fluids. One was a liquid and the other was a gas at some particular pressure, usually air. There was a mixing plenum inside the nozzle, wherein the gas stream impinges on the liquid stream and forms a liquid-gas mixture which is then sprayed into the combustion chamber in the form of a very fine mist. It was found that dispersion of fine droplets coming out of the nozzle was directly proportional to the air pressure supplied to the nozzle. In other words, the higher the air pressure of the fluid, the higher the level of dispersion achieved.

A twin-fluid nozzle was bought from BETE Spray Nozzles Company, USA. The nozzle was an alloy made from the material Hastelloy C276 (Nickel-MolybdenumChromium alloy with Tungsten). This alloy was selected due to its high melting point of $1100{ }^{\circ} \mathrm{C}$ (rated by the manufacturer). The nozzle had two $6.35 \mathrm{~mm}(1 / 4 \mathrm{in})$ inlet ports for liquid and air as well as a $0.5 \mathrm{~mm}(0.020$ in) diameter orifice at its bottom-center, from which the fuel-air mixture was sprayed in the combustion chamber. The twin-fluid nozzle is shown in Figure 12. 


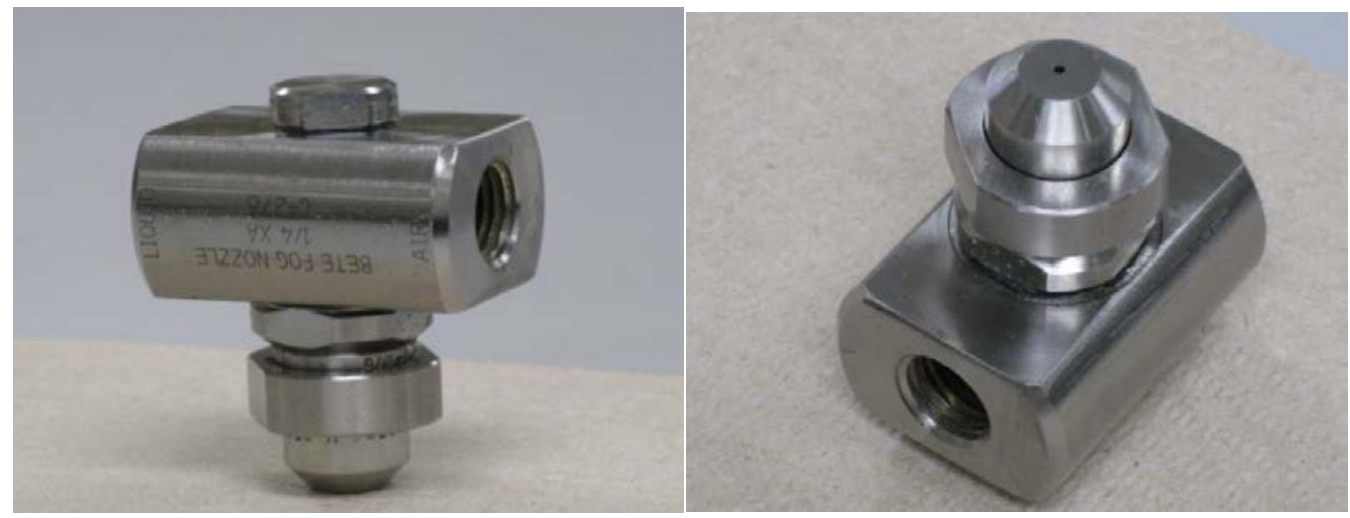

Figure 12: Twin-fluid nozzle

2. Digital oil-flow meter

The digital oil-flow meter used in the project, shown in Figure 13, had an oval gear and was purchased from McMaster-Carr Supply Company, USA. It was used to read the flow rate of fresh corn oil and the corresponding blends. It could read flows ranging from a minimum of $0.51 / \mathrm{hr}$ to a maximum of $50 \mathrm{l} / \mathrm{hr}$ with an accuracy of $\pm 1 \%$. The flow meter was also compatible with liquids having viscosities between $5 \mathrm{cP}$ to $1000 \mathrm{cP}$.
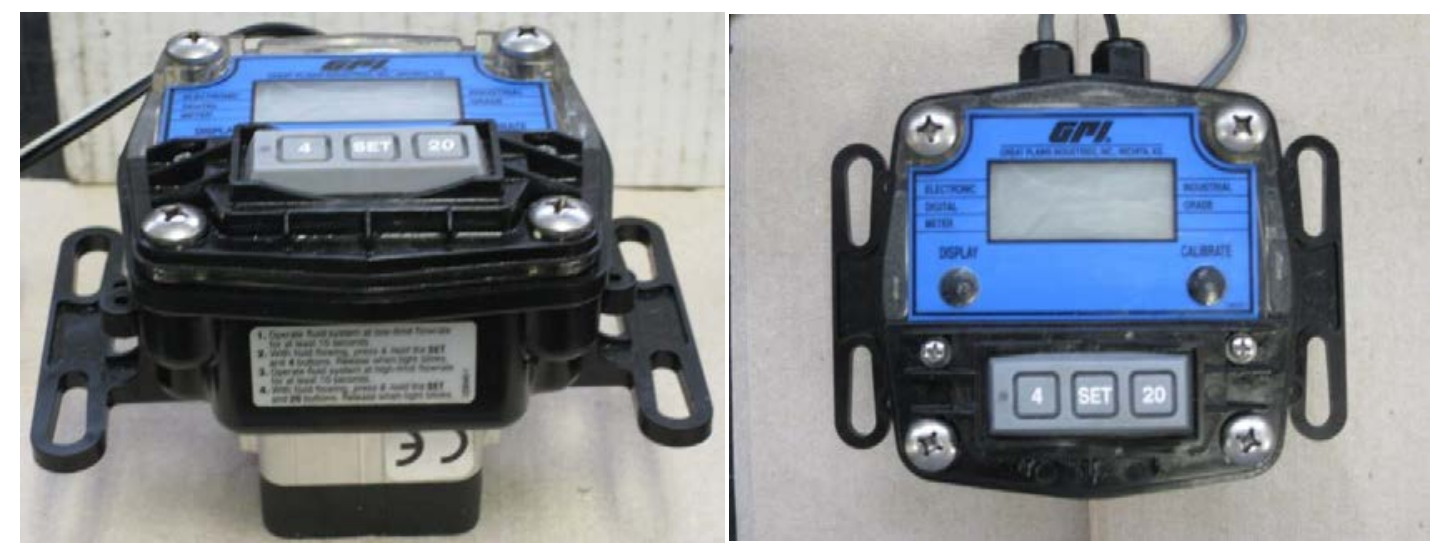

Figure 13: Digital oil-flow meter 


\section{Gear pump}

A low-flow gear-type pump was purchased from Suntec Industries Inc., USA. The pump had a factory setting of $690 \mathrm{kPa}$ or 100 psi fluid pressure at its outlet and pumping capacity was between $3.81 / \mathrm{hr}(1 \mathrm{GPH})$ to $11.4 \mathrm{l} / \mathrm{hr}$ (3 GPH). The pump supplied the corn oil and the blends to the nozzle through the fuel transport lines. It is shown in Figure 14.

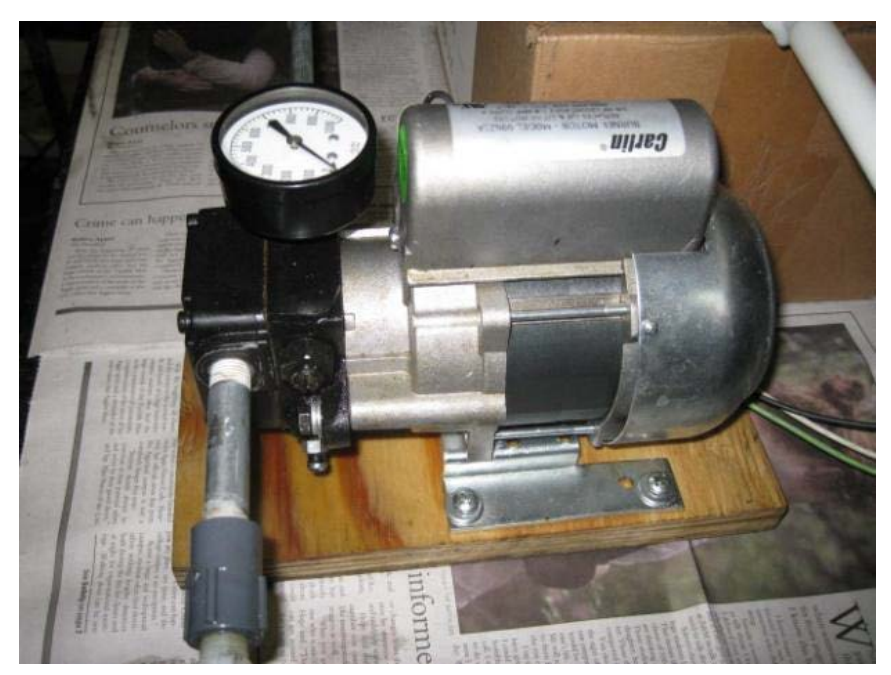

Figure 14: Gear pump

\section{Primary air compressor}

A high capacity air compressor was bought from Cole-Parmer Instrument, USA. It was rated by the manufacturer at a free air capacity of $31.2 \mathrm{1} / \mathrm{min}$ and maximum air pressure of $413.6 \mathrm{kPa}$ (60 psi). This compressor was used to supply the primary air to the nozzle. The air flow was regulated with the help of a regulating valve on the compressor. It is shown in Figure 15. 


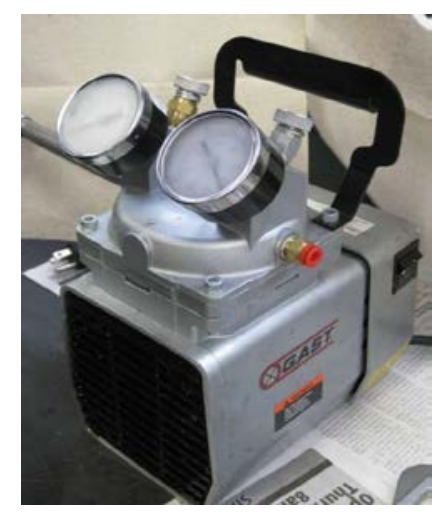

Figure 15: Primary air compressor

\section{Air flow meter}

The air flow meter was purchased from Omega Engineering Inc., USA and was used to measure the primary air flow rate. This component had a display screen and could measure flows between $4 \mathrm{l} / \mathrm{min}$ to $20 \mathrm{l} / \mathrm{min}$. It is shown in Figure 16.

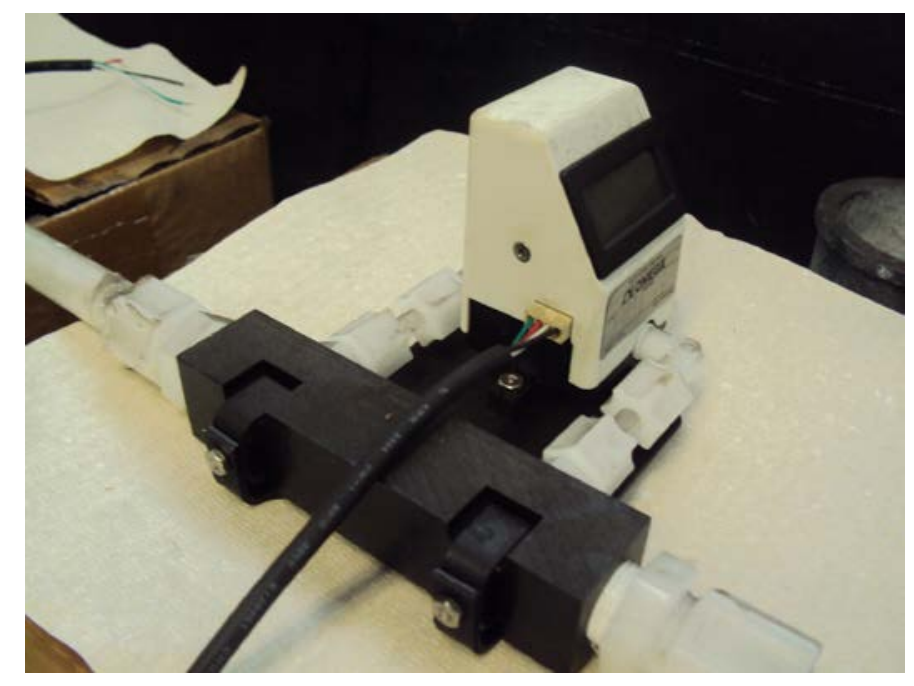

Figure 16: Air flow meter 
6. Ball valve and pressure gauge

In order to regulate the fuel flow to the nozzle, a $3.175 \mathrm{~mm}(1 / 8 \mathrm{in})$ ball valve was attached in between the fuel pump and oil flow meter. A pressure gauge was also used in the fuel line to keep track of the pressure of the fuel. A needle valve was used instead of a ball valve for low-viscosity fuel blends.

The following paragraphs give a detailed description of the other important instruments, which were already available at the Coal and Biomass Energy Laboratory.

1. Secondary air compressor

The secondary air compressor used was a rotary positive displacement air compressor, manufactured by Gardner Denver, Inc. It was powered by a 1730 RPM OPTIM-built electric motor, and was able to provide a maximum air flow rate of 650 1/min at a pressure of $117.2 \mathrm{kPa}$ (17 psia). A digital air flow meter measured the flow rate of the secondary air, which accounted for the majority portion of the total air supplied for the combustion process. The secondary air compressor is shown in Figure 17. 


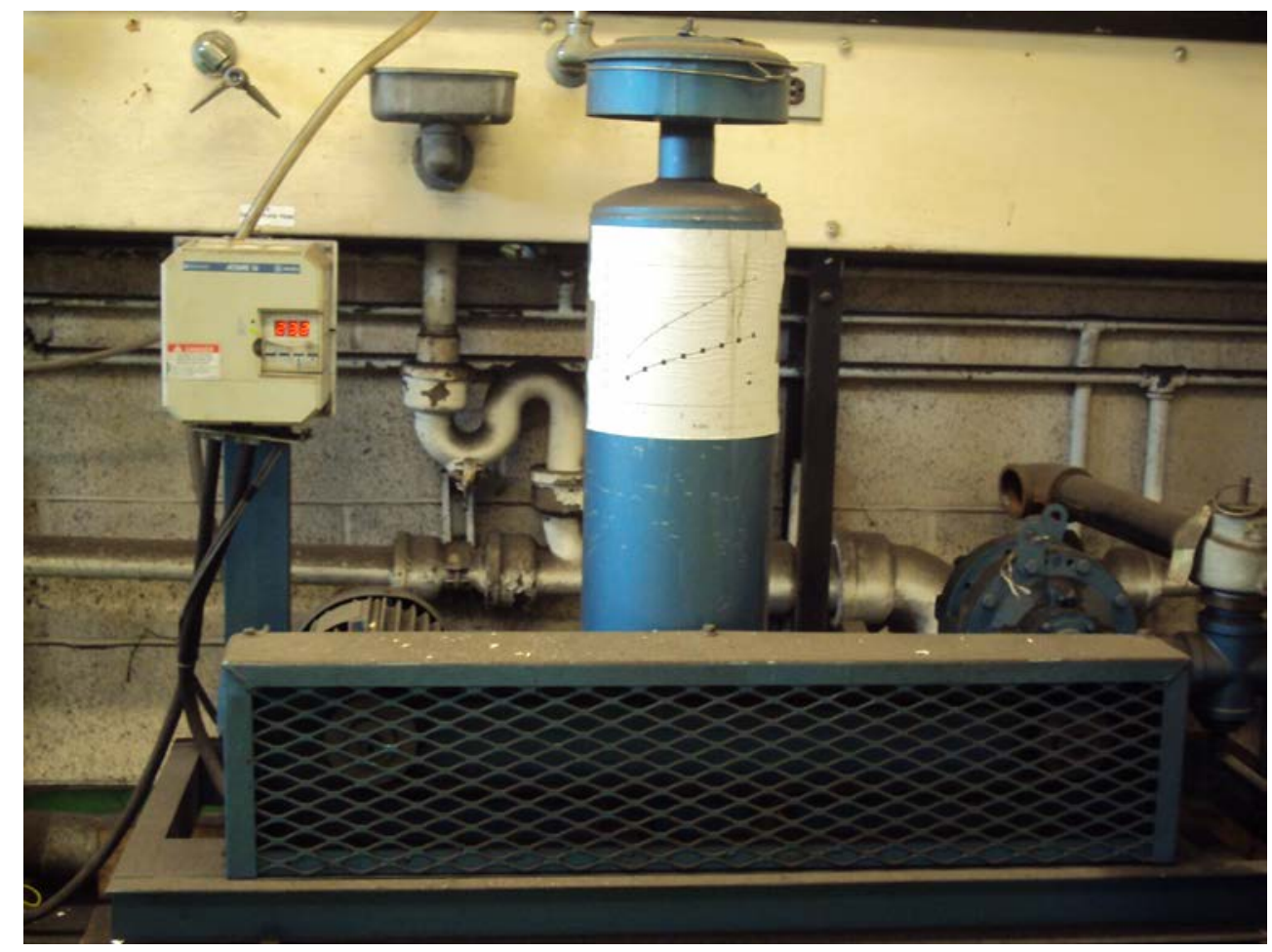

Figure 17: Secondary air compressor

2. Emissions gas analyzer

The emissions were studied and analyzed using a portable gas analyzer ENERAC Model 3000E Integrated Emissions System purchased from ENERAC. 
It has the capability to measure and give a digital and printed summary for levels of $\mathrm{O}_{2}, \mathrm{CO}, \mathrm{CO}_{2}, \mathrm{NO}, \mathrm{NO}_{2}, \mathrm{SO}_{2}$ and $\mathrm{C}_{\mathrm{x}} \mathrm{H}_{\mathrm{y}}$ present in the exhaust gases. The instrument consists of two major parts: the main unit, which is responsible for the emissions' measurements, and the probe, which is designed to extract, clean (to keep soot out) and dry the emission sample before it is sent to the main unit.

The analyzer is equipped with two types of sensors. Temperature sensors are used to measure the stack (combustion chamber) temperature and the ambient temperature. Gas sensors are located inside the main unit (sensor housing). The concentrations of $\mathrm{CO}$ (low range), $\mathrm{NO}, \mathrm{NO}_{2}, \mathrm{SO}_{2}$ and exhaust $\mathrm{O}_{2}$ are measured with electrochemical cells while the concentrations of $\mathrm{CO}$ (high range), hydrocarbons, and $\mathrm{CO}_{2}$ are measured with NDIR (non-dispersive infrared) sensors.

The ranges for $\mathrm{CO}$ and $\mathrm{NO}$ sensors could be selected with the help of toggle switches, depending on the gas concentrations expected. The emissions gas analyzer with the two major parts is shown in Figure 18. 


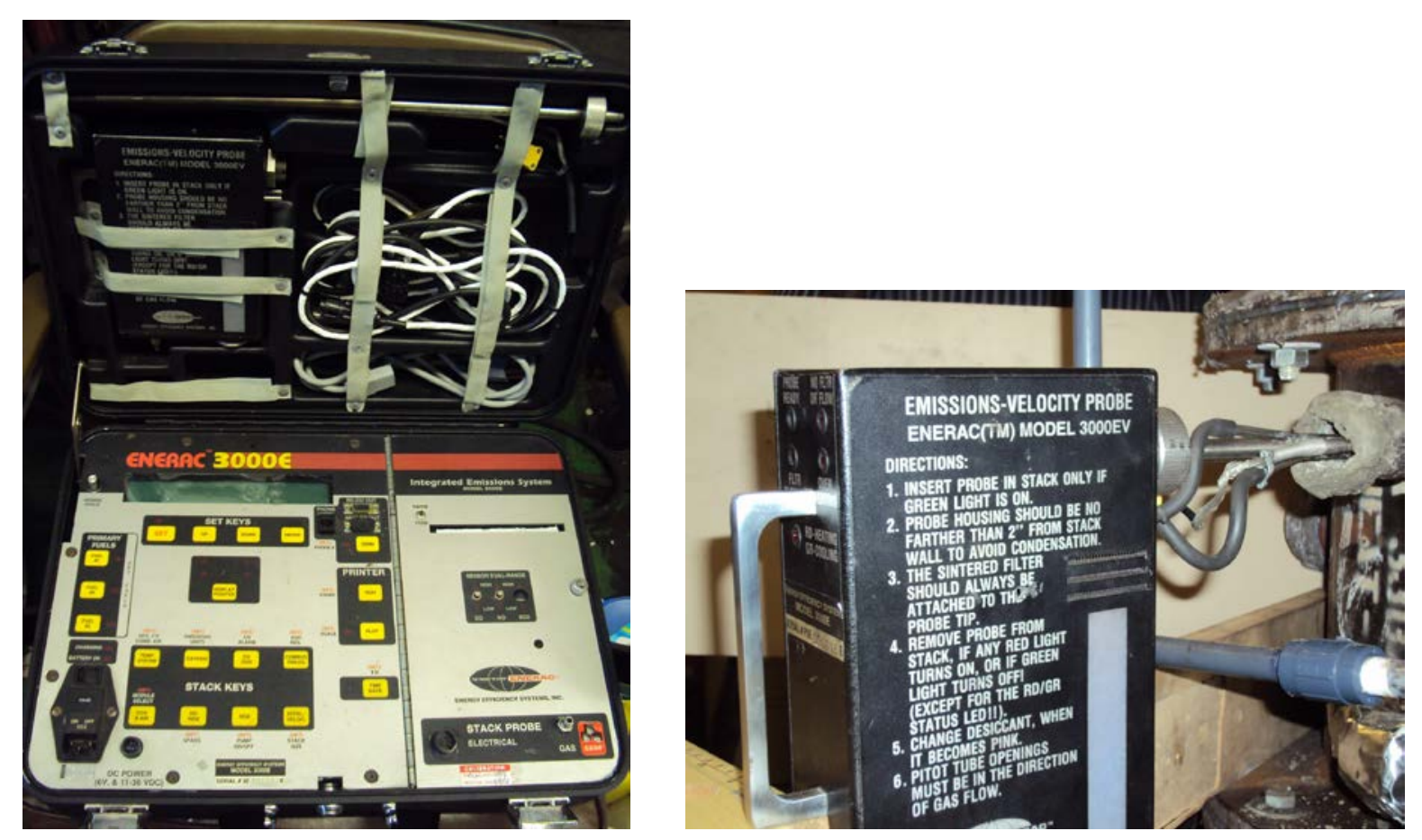

Figure 18: Emissions gas analyzer: Main unit (L) and probe housing (R) 
3. Gas flow controller

The volumetric flow rate of natural gas used for preheating the combustion chamber was controlled with the help of a digital gas flow controller, bought from Cole-Parmer Instruments, USA. It is shown in Figure 19.

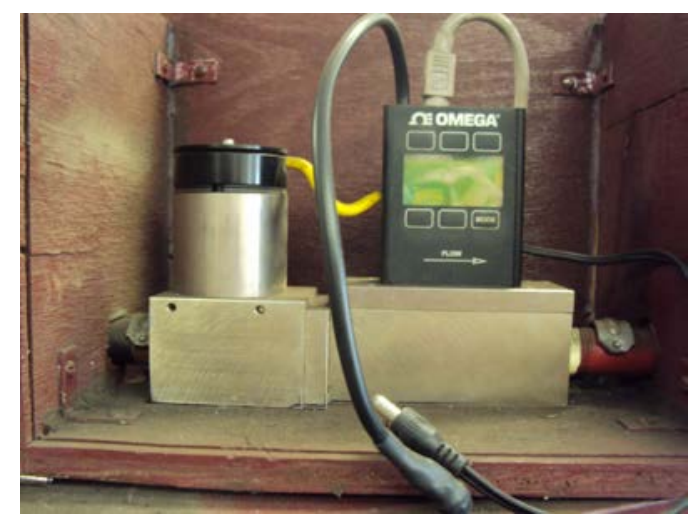

Figure 19: Gas flow controller

\section{Data acquisition system}

The data acquisition system (DAQ) was purchased from Agilent Technologies, USA. It consisted of a multiplexer card to which all the thermocouples from the combustion chamber were attached. The DAQ was then connected to a computer where the temperature data during combustion experiments was logged at intervals of 5 seconds. The DAQ and multiplexer card are shown in Figure 20. 


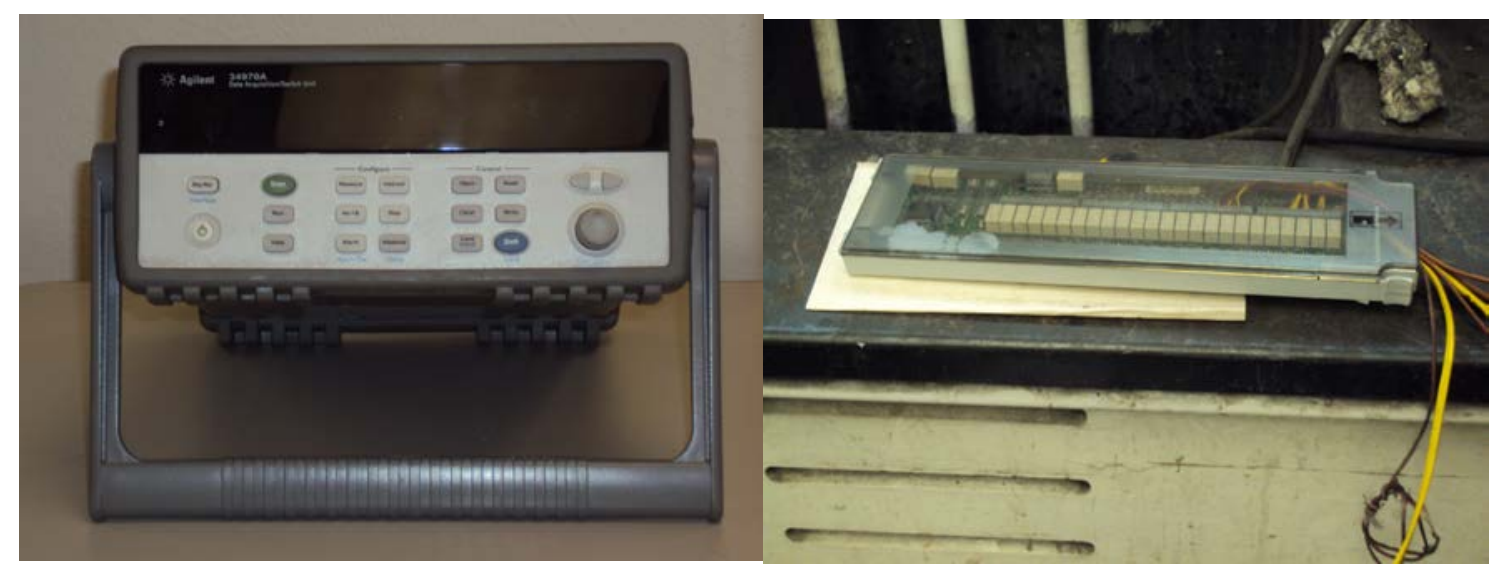

Figure 20: DAQ from Agilent and multiplexer card

\subsection{Experimental Facility - Modified Combustion Chamber}

The $30 \mathrm{~kW}$ furnace at CBEL was modified to be able to combust liquid fuels by incorporating the following components: Twin-fluid atomizer or nozzle, radial vane-type swirler, fuel pump, fuel flow meter, primary air compressor, air flow meter and PVC piping. Figure 21 shows the combustion chamber after all the modifications were completed. 


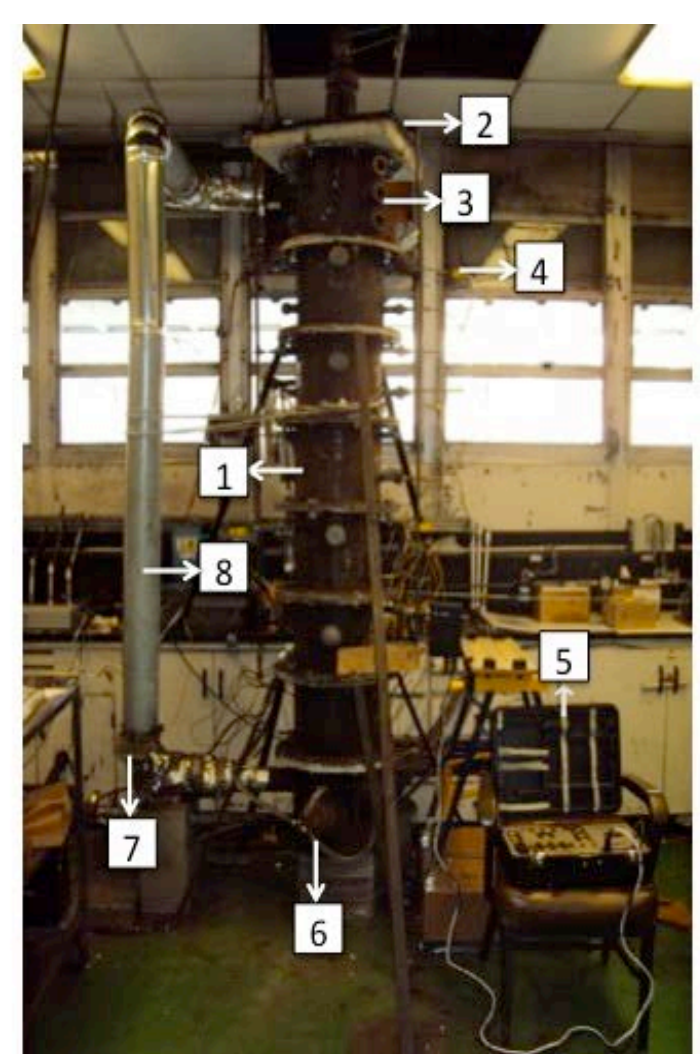

1. Combustion Chamber; 2. Boiler Plate; 3. Eye-hole; 4. Thermocouples; 5. Analyzer; 6. Water-cooling spray; 7. Exhaust vent port; 8. Exhaust duct

Figure 21: $30 \mathrm{~kW}$ furnace at CBEL, TAMU

The modified combustion chamber had a total height of 2.4 meters. Refractory lining made up for the inner wall of the chamber, made specifically from Greencast 94 Ceramic. The net hollow diameter of the chamber was $152.4 \mathrm{~mm}$ (6 in) along the entire height of the chamber. Figure 22 shows a cross-section of one cylindrical element of the combustion chamber. It was built with 8 such elements, stacked one on top of the other. 


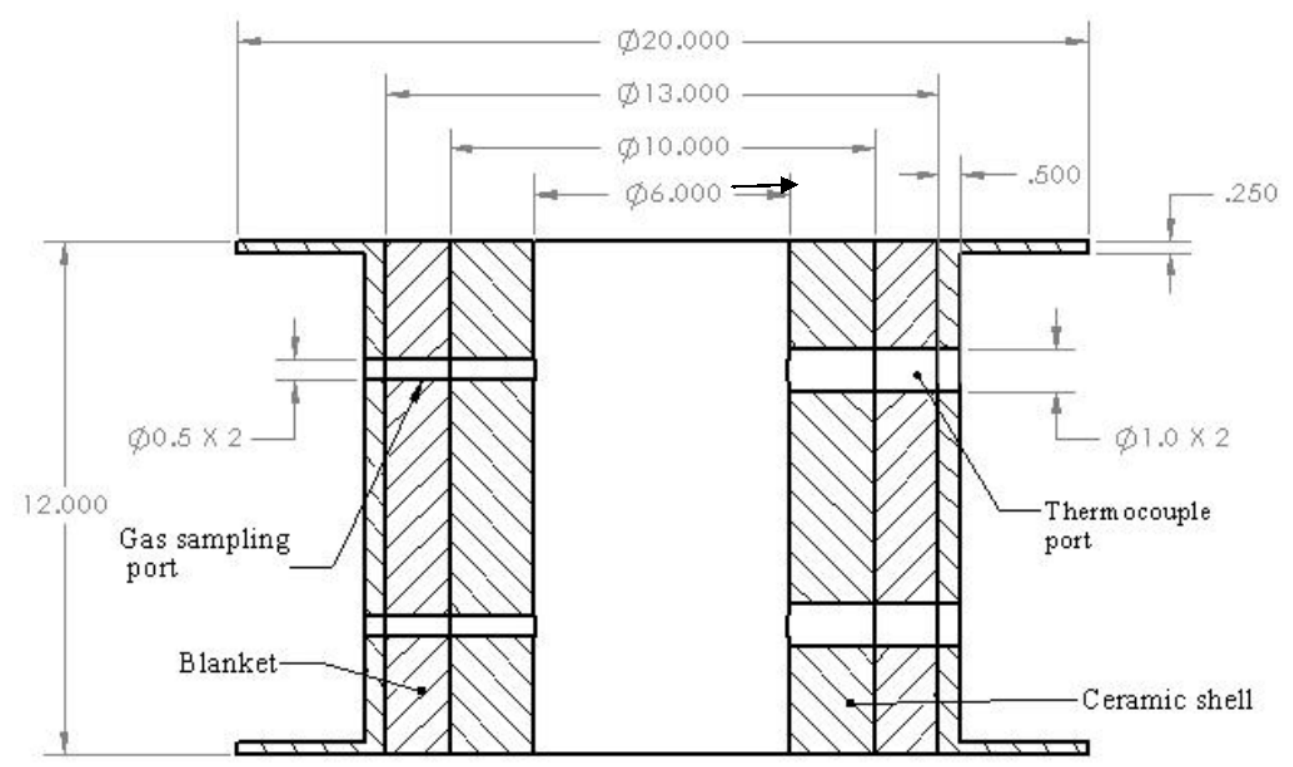

Figure 22: Cross-section of the combustion chamber (all dimensions in inches)

The top of the chamber was enclosed with furnace cement insulation block having dimensions $0.55 \mathrm{~m} \times 0.55 \mathrm{~m} \times 0.05 \mathrm{~m}$ (22 in $\times 22$ in $\times 2.125$ in). The insulation was capable of withstanding temperatures as high as $2700{ }^{\circ} \mathrm{C}$. The cement insulation block had a $152.4 \mathrm{~mm}$ (6 in) diameter hole at its center. A $0.6 \mathrm{~m} \times 0.6 \mathrm{~m} \times 0.006 \mathrm{~m}(24 \mathrm{in} \times 24$ in $x 0.25$ in) iron plate was placed on top of the block, with a similar hole of diameter $104.1 \mathrm{~mm}(4.1 \mathrm{in})$ at its center. The vane-type swirler was installed on top of this plate via screws and nuts, thus covering the hole at the center.

For natural gas to enter the chamber for preheating, a small $12.7 \mathrm{~mm}(1 / 2 \mathrm{in})$ hole was drilled in the iron plate, such that the natural gas pipeline was just able to fit completely inside the chamber. Finally, a $101.6 \mathrm{~mm}$ (4 in) steel pipe connected to a reduced coupling (101.6 $\mathrm{mm}$ or 4 in to $50.8 \mathrm{~mm}$ or $2 \mathrm{in}$ ) indicated the exit of the 
secondary air line at the top of the chamber as shown in Figure 23. The steel pipe was sealed to the swirler wall with silicone to make sure no leakages occurred and also to enable uniform turbulent conditions required for proper combustion.

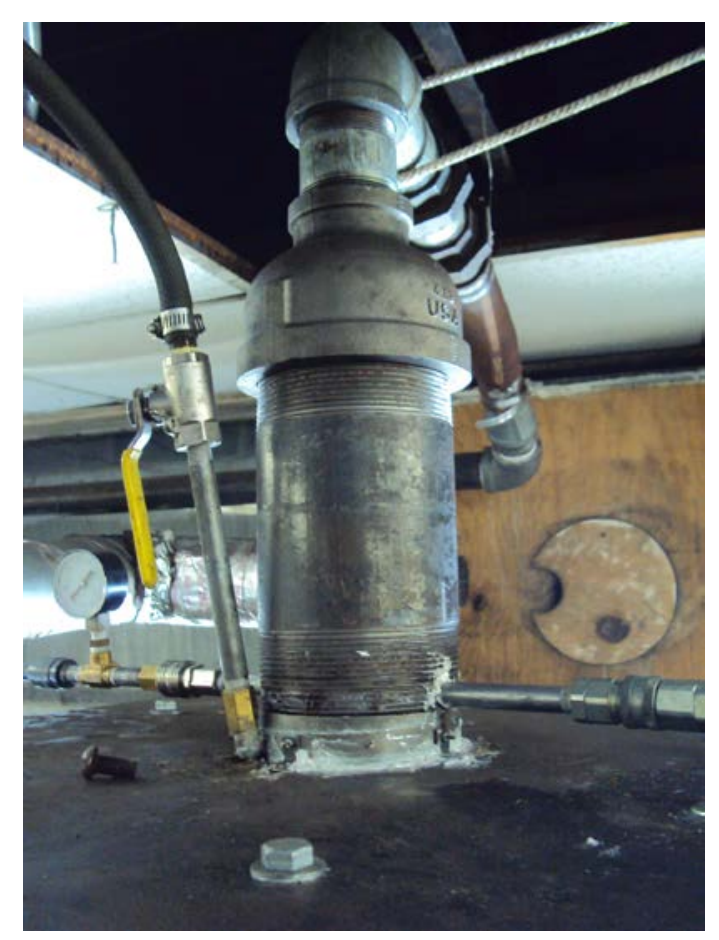

Figure 23: Boiler plate assembly

With the help of natural gas, the combustion chamber was initially preheated to about $800{ }^{\circ} \mathrm{C}$ for corn oil, and $550{ }^{\circ} \mathrm{C}$ for the fuel blends. This was done by inserting a propane torch into the second eyehole located towards the top of the chamber to ignite the natural gas coming out through the hole on top of the iron plate.

The thermocouples were used to obtain the temperature profile of the entire combustion zone, which is why they were fixed in the ports on the chamber, located 
throughout its height. The first thermocouple was at a distance of $444.5 \mathrm{~mm}$ (17.5 in) below the tip of the nozzle. The chamber had three eye-holes to view the combustion flame safely, each separated by a distance of $90 \mathrm{~mm}$ (3.54 in). The first eye-hole was located $140 \mathrm{~mm}$ (5.5 in) below the tip of the nozzle.

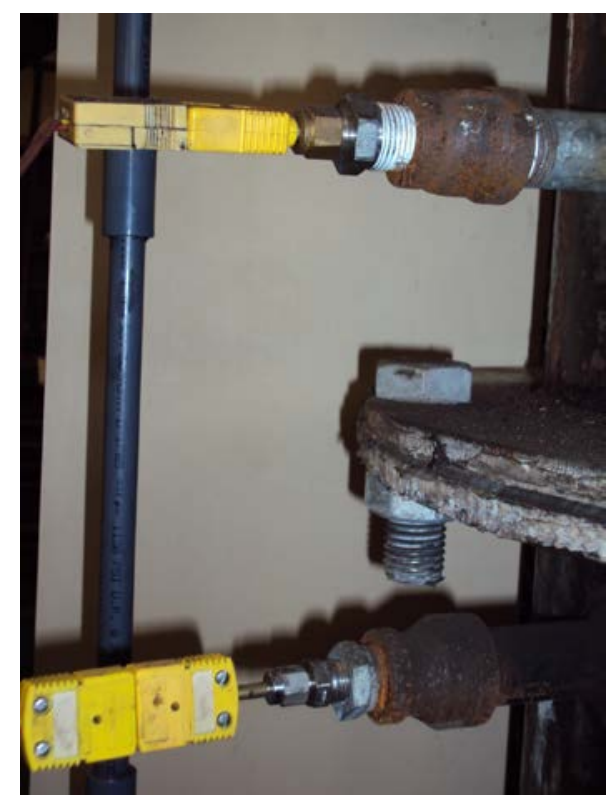

Figure 24: Thermocouples in chamber ports

Pipelines used for carrying the fuel and the primary air to the nozzle from the fuel beaker and primary air compressor respectively were made from $6.35 \mathrm{~mm}(1 / 4 \mathrm{in})$ and $3.175 \mathrm{~mm}(1 / 8$ in) $\mathrm{PVC}$ and steel pipes. Pipe fittings such as couplings, quick disconnects and adapters were also used for easier assembly and disassembly of the liquid injection system. Figure 25 shows the entire assembly of the components in the air and fuel transport lines. 


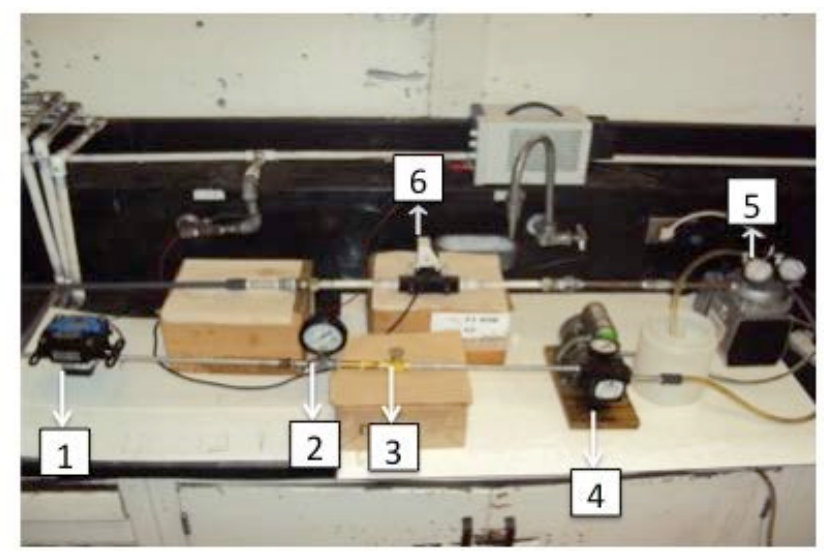

1. Digital Oil Flow Meter; 2. Pressure Gauge; 3. Needle Valve; 4. Gear Pump; 5. Primary Air Compressor; 6. Air Flow Meter

Figure 25: Liquid injection system

The twin-fluid nozzle was placed inside an aluminum cone with holes drilled on its sides for the primary air line and fuel line. This cone was placed over the hub of the swirler as shown in Figure 26. This part of the assembly was done in order to make sure that all the secondary air passed through the swirler vanes, thus enabling the formation of a vortex downstream. The nozzle was positioned such that its tip was approximately 5 $\mathrm{mm}$ above the swirler's edge. Figure 26 also shows the placement of the nozzle and the cone inside the swirler. 


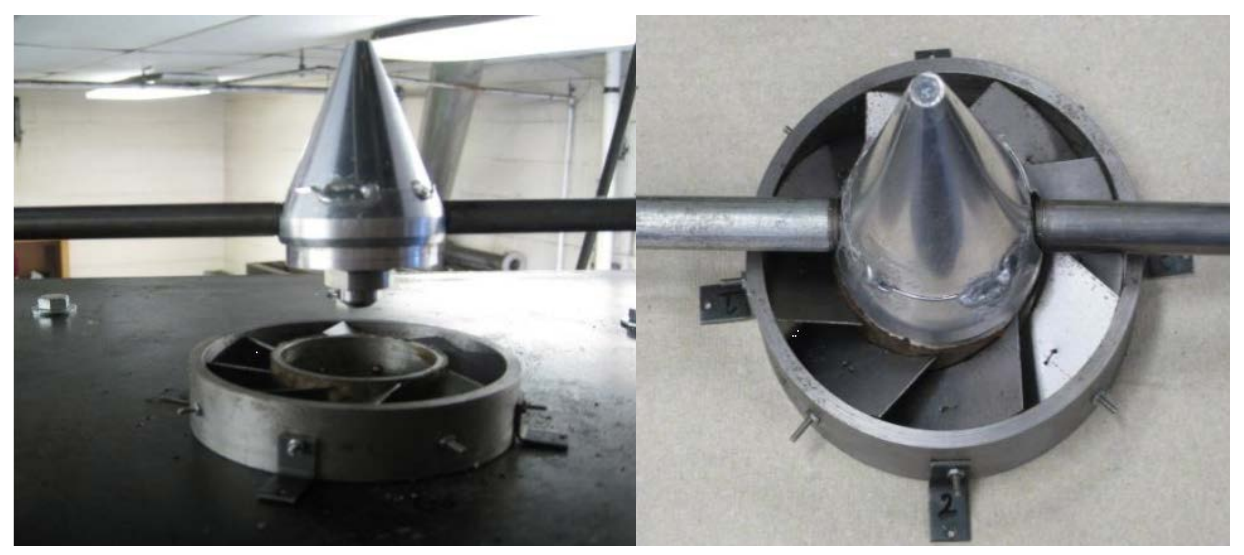

Figure 26: Nozzle with aluminum cone placed over the swirler

The gas analyzer was then connected to one of the ports located towards the bottom of the combustion chamber, which was approximately $1.6 \mathrm{~m}(63 \mathrm{in})$ from the nozzle at the top. Before the exhaust gases entered the analyzer's main unit, they first passed through the probe housing containing a disposable filter and desiccant to remove excess soot and water vapor, respectively. A water-cooling spray located at the very bottom of the combustion chamber was utilized during the experiments for lowering the temperatures of the exhaust gases before releasing them to the atmosphere via the aluminum exhaust duct. This was done mainly for safety purposes.

\subsection{Experimental Procedure}

Following the modification of the combustion chamber and its inspection for possible air leakages, combustion experiments for the 10 fuels and fuel blends were conducted. Although the flash point for corn oil is around $254{ }^{\circ} \mathrm{C}$ [51], it was necessary to preheat the chamber to about $800{ }^{\circ} \mathrm{C}$ (according to the chamber's uppermost 
thermocouple), in order to produce a self-sustaining flame of the corn oil-based fuels. Each experiment took about 2 to 3 hours including about 1 hour for preheating. The diesel-corn oil and jet fuel-corn oil blends on the other hand, required preheating to 550 ${ }^{\circ} \mathrm{C}$, owing to their much lower flash points. Care was taken not to preheat the chamber to temperatures much higher than $550{ }^{\circ} \mathrm{C}$, as there would be a danger of an explosion due to the large percentage of the highly flammable diesel and jet fuel in the blends. The procedure followed is discussed in detail below.

\subsubsection{Operation of Set-up}

The following operational steps were followed before running combustion experiments-

- The cooling water spray was turned on and controlled with the cooling water valve. This was used to cool the exhaust gases before they were discharged through the exhaust duct.

- The exhaust fan was turned on to induce negative pressure in the combustion chamber. The exhaust port of the combustion chamber was opened to remove any residual combustible gases from previous experiments.

- The secondary air flow rate was adjusted to about $3001 / \mathrm{min}$ using the compressor's software.

- The power of the secondary air compressor had to be adjusted so enough supply air was received in the combustion chamber. This was achieved by using the compressor's main air controller.

- The primary air compressor was turned on. This was done to keep the interior of the 
nozzle cool during the preheating stage of the combustion chamber with natural gas.

\subsubsection{Preheating the Combustion Chamber}

- Before purging the boiler with natural gas, the natural gas pipeline was inserted into the hole located on the top plate next to the swirler, and the valve on this pipeline was kept open.

- The natural gas flow rate was then adjusted to about $30 \mathrm{l} / \mathrm{min}$. Initially natural gas was allowed to flow in the chamber to purge it of residual combustion gases for 1-2 minutes.

- The natural gas flow was then discontinued. The second eyehole on the side of the chamber was opened.

- The propane torch was inserted into the eyehole pointing away from the nozzle and swirler in the center of the chamber

- Only after ensuring that the torch was on and fully inserted was the flow of natural gas resumed. When the flame could be seen through the eyeholes, it indicated the start of the natural gas combustion process.

- Once the flame was continuous, and after the first (uppermost) thermocouple showed a temperature of about $650{ }^{\circ} \mathrm{C}$ the propane torch was removed, and the valve on propane tank was closed and the torch was purged. The eyehole was then closed.

- If the flame started flickering, the primary air was reduced.

- The preheating of the furnace from $650{ }^{\circ} \mathrm{C}$ to $800{ }^{\circ} \mathrm{C}$ was done exclusively by burning natural gas $\left(400{ }^{\circ} \mathrm{C}\right.$ to $550{ }^{\circ} \mathrm{C}$ in case of the fuel blends). 


\subsubsection{Combustion of the Fuels}

- The pump was then turned on so that fuel was continuously being sprayed from the nozzle and combusting (along with natural gas from the preheating phase). The fuelside pressure was adjusted to $89.6 \mathrm{kPa}(13 \mathrm{psi})$ for the fresh and used corn oils using a ball valve. A needle valve was used to adjust the fuel pressure to $68.9 \mathrm{kPa}(10 \mathrm{psi})$ in case of the lower-viscosity blends.

- The primary air pressure for all the fuels was set at $82.7 \mathrm{kPa}$ (12 psi). These conditions ensured proper atomization of all the fuels during the combustion experiments.

- The next step was to reduce the natural gas flow to zero so that the flame could sustain itself by burning just liquid fuel. To do this, the natural gas flow was reduced from $40 \mathrm{l} / \mathrm{min}$ to $10 \mathrm{l} / \mathrm{min}$ in decrements of $10 \mathrm{l} / \mathrm{min}$. As a result, the natural gas and liquid fuel were burning simultaneously for about 5 minutes. Then the natural gas flow was discontinued.

- The entire chamber was visually inspected once again to make sure that it was completely sealed and that the fuel was self-igniting and a flame was still present.

\subsubsection{Emission Measurements}

- The emissions analyzer was connected to the lower port of the chamber (1.6 m from the nozzle) via the probe housing and tubing. The probe was sealed with Resbond 970 ceramic adhesive.

- The fuel flow rate was set as per the known heating value of each fuel in order to 
achieve a constant $19 \mathrm{~kW}$ of heat of combustion. The primary air flow rate was adjusted to $10 \mathrm{l} / \mathrm{min}$. The secondary air flow was adjusted in order to achieve lean combustion of the fuel (equivalence ratio $=0.8$ ).

- The fuel was burned for about 30 to 45 minutes in order for the temperature inside the combustion chamber to stabilize. After that, the first reading at the first equivalence ratio was recorded by the analyzer. Then after 5 minutes, a second reading was taken.

- The secondary air flow was adjusted for the other equivalence ratios, and data were collected accordingly. The fuel and primary air flows and pressures were maintained constant throughout the data collecting process.

- At every equivalence ratio, it was necessary to wait for about 20-30 minutes for the temperatures and the oxygen output levels to stabilize.

- After all readings were taken, the fuel flow to the chamber was discontinued by turning the fuel pump off. The exhaust vents were opened completely and secondary air was adjusted to $400 \mathrm{l} / \mathrm{min}$.

- The water-cooling spray and primary air were switched off after the temperature readings from the thermocouples read less than $200{ }^{\circ} \mathrm{C}$. The chamber was allowed to finally cool to ambient temperature.

\subsection{Preparation of Blends}

The blends used in the research project were made from $100 \%$ pure corn oil of Mazola brand, ultra-low sulfur diesel from the local Shell Oil Company, n-butanol (99.9\% pure) and ethanol-95 (E95), purchased from Sigma-Aldrich, USA. Similarly, jet 
fuel bought from the local airport was used instead of diesel to make another set of fuel blends. As mentioned before, there were eight blends that were made, in addition to fresh and used corn oil. These are listed in Table 4.

Table 4: Corn oil-based blends (by mass percentage)

\begin{tabular}{|c|c|c|c|c|}
\hline $\begin{array}{c}\text { Blend } \\
\text { Designation }\end{array}$ & Vegetable Oil & $\begin{array}{c}\text { Secondary } \\
\text { Fuel }\end{array}$ & Butanol & Ethanol \\
\hline FCO:D50 & $27 \%$ Fresh Corn Oil & $50 \%$ Diesel & $19 \%$ n-butanol & $4 \%$ ethanol-95 \\
\hline FCO:D40 & $35 \%$ Fresh Corn Oil & $40 \%$ Diesel & $21 \%$ n-butanol & $4 \%$ ethanol-95 \\
\hline UCO:D50 & $27 \%$ Used Corn Oil & $50 \%$ Diesel & $19 \%$ n-butanol & $4 \%$ ethanol-95 \\
\hline UCO:D40 & $35 \%$ Used Corn Oil & $40 \%$ Diesel & $21 \%$ n-butanol & $4 \%$ ethanol-95 \\
\hline FCO:JF50 & $27 \%$ Fresh Corn Oil & $50 \%$ Jet Fuel & $19 \%$ n-butanol & $4 \%$ ethanol-95 \\
\hline FCO:JF40 & $35 \%$ Fresh Corn Oil & $40 \%$ Jet Fuel & $21 \%$ n-butanol & $4 \%$ ethanol-95 \\
\hline UCO:JF50 & $27 \%$ Used Corn Oil & $50 \%$ Jet Fuel & $19 \%$ n-butanol & $4 \%$ ethanol-95 \\
\hline UCO:JF40 & $35 \%$ Used Corn Oil & $40 \%$ Jet Fuel & $21 \%$ n-butanol & $4 \%$ ethanol-95 \\
\hline
\end{tabular}

\subsubsection{Making and Characterizing Used Corn Oil}

Used corn oil was made from fresh corn oil by heating approximately 3.8 liters (1 gallon) of it in a deep fryer for about 44 hours, at a constant temperature of $190{ }^{\circ} \mathrm{C}$ (typical frying temperature). The oil was basically heated or oxidized until the total polar content in the oil reached 20\% TPM (Total Polar Material). TPM is a generic term used for the free fatty acids, monoglycerides, diglycerides and other oxidation products that are formed during the heating of oil [31]. This measurement was done using the Testo 270 cooking oil tester. This instrument had the capability to track the breakdown of oil 
as it was heated up. It was defined that $20 \%$ TPM would be the limit to designate the oil as "used". This value actually varies in different countries, depending on their respective national regulations. Table 5 shows some typical TPM value ranges [31].

Table 5: Classification of TPM values for fat ageing

\begin{tabular}{|c|c|}
\hline $\begin{array}{c}\text { Percentage of Polar } \\
\text { Materials }\end{array}$ & Classification of Fat Ageing \\
\hline $1-14 \%$ TPM & Fresh Cooking Oil \\
\hline $14-18 \%$ TPM & Slightly used \\
\hline $18-22 \%$ TPM & Moderately Used \\
\hline $22-24 \%$ TPM & Heavily used \\
\hline More than $24 \%$ & Spent Cooking Oil \\
\hline
\end{tabular}

Measurement of TPM of the corn oil is based on the concept of capacitance. As seen in Figure 27 below, the Testo 270 cooking oil tester consists of two capacitor plates, with gold strip conductors attached to the capacitor plates (Figure 28). Measurement using the cooking oil tester involves measurement of the dielectric constant of oil [31]. The increasing amount of polar material in corn oil (while it gets oxidized) changes the dielectric constant as the polar material align themselves in the presence of an alternating electrical field in between the two capacitor plates. This change in the dielectric constant is measured by a change in capacity of the plates. This is then converted to the required TPM (\%) display variable on the Testo 270 cooking oil tester. 


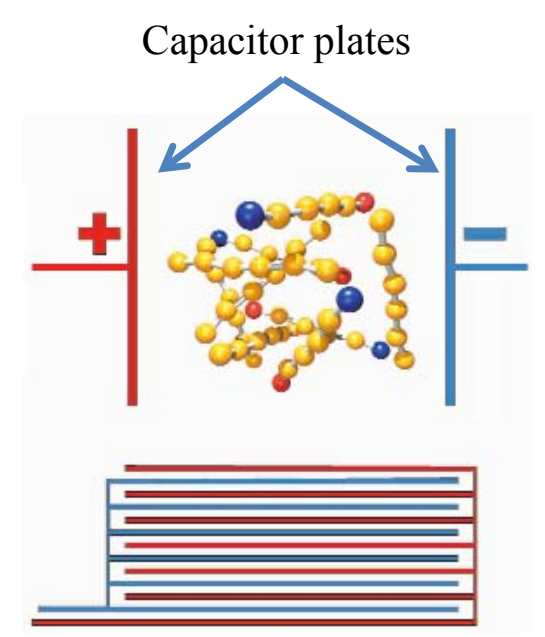

Figure 27: Capacitor (above) and oil sensor (below) [31]

The deep fryer had a heating element with a thermostat for setting the temperature at certain pre-fixed values. 3.8 liters ( 1 gallon) of the pure corn oil was poured in the deep fryer and the temperature of the heating element set to $190{ }^{\circ} \mathrm{C}$. After calibrating the cooking oil tester with a 4.4\% TPM reference liquid, it was immersed into the oil and the temperature and TPM readings were recorded. An initial reading of $8.5 \%$ TPM was noted after it stabilized. Similarly, readings were taken every half an hour to one hour until the display showed 20\% TPM. This occurred after about 44 hours of heating the corn oil. This was defined as the used corn oil. Figure 28 shows the measurement of TPM of corn oil using the cooking oil tester. 

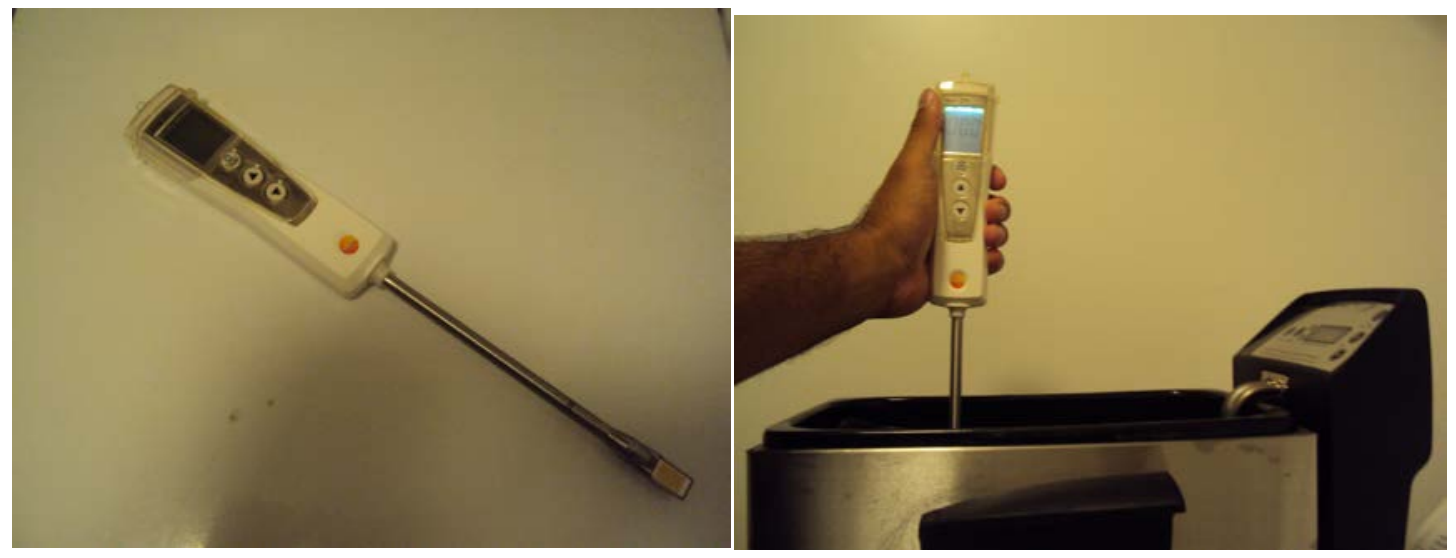

Figure 28: Testo 270 cooking oil tester, measuring TPM of corn oil in deep fryer

An illustration of the variation of TPM with respect to heating time is shown in Section 6.1.4.1. It also describes how the oxidation process commences as corn oil is heated.

Additional characterization experiments were conducted to quantify the effect of temperature and time on corn oil while it was converted to "used" oil. In order to quantitatively differentiate between the fresh corn oil and used corn oil, about $10 \mathrm{ml}$ of each sample was sent to Bruker Corporation, USA for estimation of iodine values, free fatty acid values, and peroxide values. All three were determined using the Fourier Transform Near Infrared spectrometry (FT-NIR spectrometry). This method is AOCS Standard Procedure Cd 1e-01 [52]. The methodology used to carry out the iodine value test is explained in the following paragraph. The results of these tests are described in Sections 6.1.4.2 and 6.1.4.3.

The iodine value (IV) for fresh and used corn oil was determined by using precalibrated FT-NIR spectrometers. Calibration procedures followed standard protocols 
such as ensuring repeatability and reproducibility as stipulated by the American Society for Testing and Materials (ASTM). Samples of the oil were stirred and placed in disposable glass vials. They were kept in a heated water bath having a temperature of about $75 \pm 1{ }^{\circ} \mathrm{C}$, to ensure that the samples always remained in liquid form. The spectrometer was then set up and its resolution adjusted to $16 \mathrm{~cm}^{-1}$. The number of scans was set up so as to correspond to two minutes worth of analysis time. An air background spectrum was obtained without the vial to get a reference scan every 30 to 120 minutes. The vial was then places into the sampling accessory. The temperature was once again checked to see if thermal equilibrium of the sample was achieved at $75 \pm 1{ }^{\circ} \mathrm{C}$. After collecting the sample spectrum by transmitting the IR beam across the diameter of the vial, the ratio of this spectrum against the air background spectrum was taken and converted to absorbance in the $\mathrm{C}-\mathrm{H} 2^{\text {nd }}$ overtone region. Then a series of analytical calculations involving preprocessing (subtracting average spectrum from each individual spectrum) and multivariate approaches were performed in accordance with AOCS Standard Procedure Cd 1e-01 [52].

\subsubsection{Making Stable Corn Oil-Based Blends}

Several corn oil-based blends were made following the approach presented by Bagby and Dunn [7]. They used the concept of co-solvent blending, which involves reducing the viscosity of vegetable oil by blending it with a low molecular weight alcohol. Their study found that a blend of soybean oil and 95\% weight ethanol (E95) could be solubilized by n-butanol. This blend was further mixed with No. 2 diesel fuel, and the 
extent to which the entire blend remained stable at low temperatures was studied. Their study also revealed that such blends showed significantly reduced engine deposits compared to neat vegetable oil. These kinds of blends also showed several advantages over using biodiesel, which requires the more expensive process of transesterification. Fuels formulated with vegetable oils were also shown to reduce $\mathrm{NO}_{\mathrm{x}}$, hydrocarbons, particulate matter, carbon monoxide and polyaromatic hydrocarbons $(\mathrm{PAH})$ in exhaust emissions.

As was followed by the authors mentioned above [7], corn oil was used as a base component fuel. It was first blended on a mass percentage basis with n-butanol and ethanol-95 (E95). This was then blended with ultra-low sulfur diesel. The blends were made following this method and the detailed procedure for making 50\% diesel-27\% fresh corn oil-19\% n-butanol-4\% ethanol-95 (FCO:D50) is given below:

1. 270 grams $(293.16 \mathrm{ml})$ of fresh corn oil was measured in a glass test tube and poured into a beaker.

2. 190 grams $(234.6 \mathrm{ml})$ of n-butanol was measured in another test tube and poured into the same beaker.

3. Similarly, 40 grams $(50.69 \mathrm{ml})$ of ethanol-95 was poured into the beaker.

4. Using a blender, these 3 components were mixed together for about 2 minutes.

5. Finally, 500 grams $(600.9 \mathrm{ml})$ of ultra-low sulfur diesel was mixed for about 5 minutes with this mixture of corn oil, n-butanol, and ethanol-95.

Likewise, blends for the second composition proposed for this study ( $40 \%$ diesel$35 \%$ corn oil-21\% n-butanol-4\% ethanol-95) were made. Fresh corn oil was replaced 
with used corn oil to make two more blends. Furthermore, diesel was replaced with jet fuel in order to make a new set of four more blends, thus giving a total of eight blends. The blends were stored in sealed containers. Figure 29 shows the stable blends of FCO:D50 and UCO:D40.

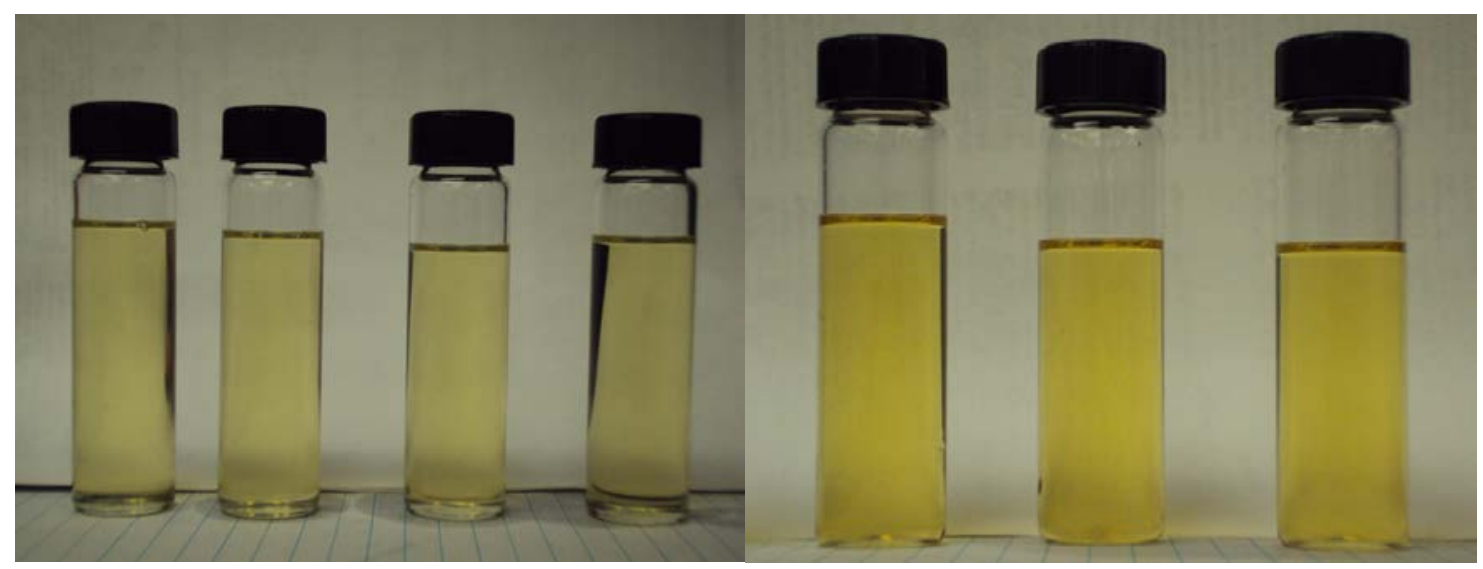

Figure 29: Stable blends of FCO:D50 [L] and UCO:D40 [R]

\subsubsection{Viscosity of the Blends}

The viscosity measurement of the blends was a critical step in this project. The viscosity of the blends was measured with the help of a rotating type viscometer purchased from Brookfield Engineering Laboratories, Inc., USA. It is shown in Figure 30. The viscometer had the capability to determine the amount of torque required to rotate a spindle immersed in the liquid. The maximum torque rating of the viscometer used was 0.06737 milli-Newton- $m$ and a specified accuracy of $\pm 1 \%$. The display screen showed the torque values in terms of centipoise (dynamic viscosity). A UL adapter was provided with the viscometer, and was used to take the measurements. 


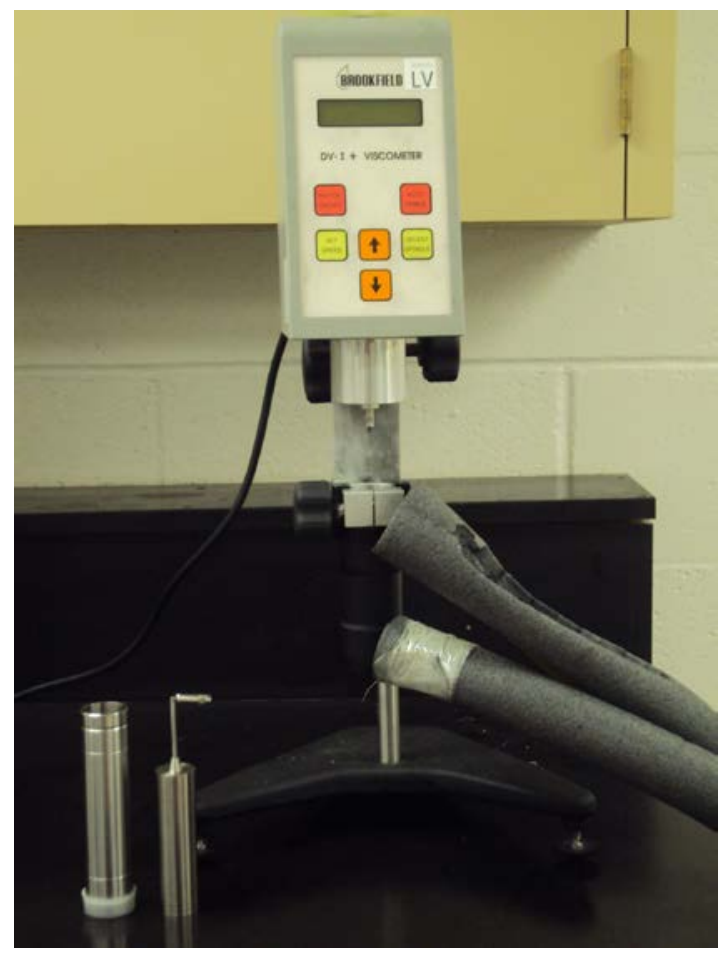

Figure 30: Brookfield Viscometer with UL adapter, spindle and cylinder

The viscosities of fresh corn oil, used corn oil, 50-27-19-4 (fresh and used) and 4035-21-4 (fresh and used) blends were measured at a temperature of $25^{\circ} \mathrm{C}$. A chiller purchased from Thermo Scientific Inc., USA, regulated the temperature of the sample liquid during the viscosity measurements. The chiller used a mixture of methanol and deionized water as the temperature-regulating fluid. This mixture flowed in a closed loop between the UL adapter and the chiller. This maintained the liquid sample at a constant temperature. The chiller was switched on about 30 minutes before viscosity 
measurements in order to bring the temperature of the liquid sample to $25{ }^{\circ} \mathrm{C}$. The procedure for measuring the viscosity of a liquid sample is as follows:

1. The viscometer was turned on and allowed to auto zero for 1 minute.

2. After auto zeroing was complete, the spindle was screwed on to the viscometer.

3. About $20 \mathrm{ml}$ of the liquid sample was filled in a cylindrical container and the container was attached to the UL adapter.

4. After fixing the container in the UL adapter, it took about 10 minutes for the liquid sample to reach a temperature of $25^{\circ} \mathrm{C}$, which was controlled by the chiller. This was verified by a thermocouple.

5. The speed of the spindle was set to a value such that, the percentage torque measured by the viscometer was as close to $100 \%$ as possible. This ensured maximum accuracy from the instrument.

6. It took about 2 minutes for the percentage torque value to stabilize.

7. The viscosity reading in centipoise $(\mathrm{cP})$ was taken once a stable state was reached.

The stability and viscosity results for the all the fuels are presented in the next section. 


\section{RESULTS AND DISCUSSIONS}

This section deals with the properties of fresh corn oil, used corn oil, and all the blends of fresh and used corn oil with diesel, jet fuel, n-butanol and ethanol-95. The fuel properties discussed include stability, viscosity, chemical formulae and higher heating values of the fuels. Data for the characterization of used corn oil (Total Polar Material, Iodine Value, Free Fatty Acid Value and Peroxide Value) are also presented. The results of the combustion experiments of all ten fuels are discussed in detail as well. Combustion emissions data including $\mathrm{NO}_{\mathrm{x}}, \mathrm{CO}, \mathrm{CO}_{2}$ and excess $\mathrm{O}_{2}$ were collected and studied. Also, using burned fraction calculations, an approximation of the combustion efficiency at different combustion conditions was determined.

All the experiments at the CBEL were conducted for a constant heat output of 68,620 $\mathrm{kJ} / \mathrm{hr}(65,082 \mathrm{BTU} / \mathrm{hr})$. All the fuels were tested at equivalence ratios of $0.8,0.9,1.0$, 1.05 and 1.1 and at swirl angles of $60^{\circ}$ and $51^{\circ}$ (swirl numbers 1.4 and 1.0 respectively). By varying only the secondary air supply while keeping the primary air constant at 10 $1 /$ min, the equivalence ratios were varied. The equivalence ratio was calculated by using the following equation [45]:

$$
\phi=\frac{\left(\frac{f u e l}{\text { air }}\right) \text { actual }}{\left(\frac{f u e l}{\text { air }}\right)_{\text {stoichiometric }}}
$$




\subsection{Fuel Properties}

The following sections outline the details of the stability and viscosity test results, chemical formulae and higher heating values (HHV) of the parent fuels and the blends.

\subsubsection{Stability and Viscosity of Blends}

The Brookfield viscometer was used to measure the viscosity of the fuels at $25{ }^{\circ} \mathrm{C}$. The blends were also checked for stability by keeping track of any kind of phase separation, if it occurred. The stability criterion and viscosity values for fresh and used corn oil as well as their respective blends are shown in Table 6. Parent oils are fresh corn oil and used corn oil.

Table 6: Stability and viscosity of the fuels

\begin{tabular}{|c|c|c|c|}
\hline Fuel Type & $\begin{array}{c}\text { Viscosity } \\
(\mathbf{c P}) \text { at } 2 \mathbf{5}^{\circ} \mathbf{C}\end{array}$ & $\begin{array}{c}\text { Stable } \\
\text { (Y/N) }\end{array}$ & $\begin{array}{c}\text { \% Reduction in } \\
\text { Viscosity (w.r.t } \\
\text { parent oil) }\end{array}$ \\
\hline Fresh Corn Oil & 54.2 & $\mathrm{Y}$ & - \\
\hline Used Corn Oil & 76.7 & $\mathrm{Y}$ & 91.2 \\
\hline FCO:D50 & 4.7 & $\mathrm{Y}$ & 89.1 \\
\hline FCO:D40 & 5.8 & $\mathrm{Y}$ & 92.7 \\
\hline UCO:D50 & 5.6 & $\mathrm{Y}$ & 90.8 \\
\hline UCO:D40 & 7.1 & $\mathrm{Y}$ & 93.4 \\
\hline FCO:JF50 & 3.5 & $\mathrm{Y}$ & 91.5 \\
\hline FCO:JF40 & 4.6 & $\mathrm{Y}$ & 95.2 \\
\hline UCO:JF50 & 3.7 & $\mathrm{Y}$ & 93.8 \\
\hline UCO:JF40 & 4.7 & $\mathrm{Y}$ & - \\
\hline
\end{tabular}


It is seen from Table 6 that the viscosities drastically reduce for the blends. This is because the viscosities and molecular weights of diesel, butanol and ethanol are significantly less than that of corn oil. Moreover, the fresh and used corn oils account for only $27 \%$ and $35 \%$ (by mass) of each type of blend.

\subsubsection{Ultimate Analysis and Chemical Formula of Parent Fuels}

Mazola brand fresh corn oil (100\% natural) was purchased from a grocery store in College Station, TX. Used corn oil was obtained by continuously heating fresh corn oil for about 44 hours in a deep fryer. Ultra-low sulfur diesel was purchased from SHELL Oil Company. It was made sure that these fuels were bought from the same sources throughout the course of the experiments. Tables 7, 8, 9, and 10 show the results of the ultimate analysis and heating value tests for diesel, jet fuel, fresh corn oil, and used corn oil respectively, as done by Hazen Research Inc., USA. 
Table 7: Ultimate analysis of diesel

\begin{tabular}{|c|c|}
\hline Element & \% weight \\
\hline Carbon & 89.89 \\
\hline Hydrogen & 11.9 \\
\hline Oxygen & 0.01 \\
\hline Nitrogen & 0.13 \\
\hline Sulfur & 0.002 \\
\hline Water & 0.009 \\
\hline Ash & 0.001 \\
\hline & \\
\hline Higher Heating Value (kJ/kg) & 45,775 \\
\hline
\end{tabular}

Table 8: Ultimate analysis of jet fuel

\begin{tabular}{|c|c|}
\hline Element & \% weight \\
\hline Carbon & 85.81 \\
\hline Hydrogen & 14.5 \\
\hline Oxygen & 0.01 \\
\hline Nitrogen & 0.04 \\
\hline Sulfur & 0.008 \\
\hline Water & 0.03 \\
\hline Ash & 0.001 \\
\hline & \\
\hline Higher Heating Value $\mathbf{( k J / k g )}$ & 45,989 \\
\hline
\end{tabular}


Table 9: Ultimate analysis of fresh corn oil

\begin{tabular}{|c|c|}
\hline Element & \% weight \\
\hline Carbon & 78.75 \\
\hline Hydrogen & 9.97 \\
\hline Oxygen & 11.12 \\
\hline Nitrogen & 0.12 \\
\hline Sulfur & 0.005 \\
\hline Water & 0.026 \\
\hline Ash & 0.009 \\
\hline & \\
\hline Higher Heating Value (kJ/kg) & 39,364 \\
\hline
\end{tabular}

Table 10: Ultimate analysis of used corn oil

\begin{tabular}{|c|c|}
\hline Element & \% weight \\
\hline Carbon & 81.45 \\
\hline Hydrogen & 10.5 \\
\hline Oxygen & 7.9 \\
\hline Nitrogen & 0.12 \\
\hline Sulfur & 0.001 \\
\hline Water & 0.028 \\
\hline Ash & 0.004 \\
\hline & \\
\hline Higher Heating Value (kJ/kg) & 39,250 \\
\hline & \\
\hline
\end{tabular}


From the ultimate analysis tests of the parent fuels, it is seen that diesel had more amount of carbon ( $\%$ weight) than fresh or used corn oils. The amount of nitrogen $(\%$ weight) was very small for all the parent fuels, with jet fuel having the least amount. Oxygen (\% weight) for diesel and jet fuel was negligibly small. The same is seen to decrease from fresh corn oil (11.12\%) to used corn oil $(7.9 \%)$. This could have been due to elemental oxygen being taken up by free radicals in corn oil as it was oxidized (see Section 2.9). Fresh corn oil also had a significant amount of ash and sulfur when compared to the other parent fuels.

Higher heating value (HHV) is defined as the amount of heat released when a unit mass of a substance is combusted. It is determined by bringing all the combustion products back to pre-combustion temperatures and assumes that water products are in liquid form. From the heating value tests, diesel and jet fuel have significantly higher heating values than fresh and used corn oils. The slightly higher amount of water in used corn oil might have contributed to a lower value of HHV compared to fresh corn oil, although this difference is not too significant.

From the elemental compositions of the parent fuels above, the chemical formula of each was determined and is shown in Tables 11-14. 
Table 11: Chemical formula of diesel

\begin{tabular}{|c|c|c|c|}
\hline Element & $\begin{array}{c}\text { Weight (g) per 100g } \\
\text { of diesel }\end{array}$ & $\begin{array}{c}\text { Number of } \\
\text { moles per 100 g } \\
\text { of diesel }\end{array}$ & Chemical Formula of diesel \\
\hline $\mathrm{C}$ & 89.89 & 7.4908 & $\mathrm{C}_{7.4908} \mathrm{H}_{11.9} \mathrm{O}_{0.00063} \mathrm{~N}_{0.0093} \mathrm{~S}_{0.000063}$ \\
\hline $\mathrm{H}$ & 11.9 & 11.9 & \\
\hline $\mathrm{O}$ & 0.01 & 0.000625 & Empirical Formula of \\
\hline $\mathrm{N}$ & 0.13 & 0.00929 & diesel \\
\hline $\mathrm{S}$ & 0.002 & 0.0000625 & $\mathrm{CH}_{1.5886} \mathrm{O}_{0.000083} \mathrm{~N}_{0.00124} \mathrm{~S}_{0.000008}$ \\
\hline
\end{tabular}

Table 12: Chemical formula of jet fuel

\begin{tabular}{|c|c|c|c|}
\hline Element & $\begin{array}{c}\text { Weight (g) per 100g } \\
\text { of jet fuel }\end{array}$ & $\begin{array}{c}\text { Number of } \\
\text { moles per 100 g } \\
\text { of jet fuel }\end{array}$ & Chemical Formula of jet fuel \\
\hline $\mathrm{C}$ & 85.81 & 7.1508 & $\mathrm{C}_{7.151} \mathrm{H}_{14.5} \mathrm{O}_{0.00063} \mathrm{~N}_{0.00286} \mathrm{~S}_{0.00003}$ \\
\hline $\mathrm{H}$ & 14.5 & 14.5 & \\
\hline $\mathrm{O}$ & 0.01 & 0.000625 & \multirow{2}{*}{ Empirical Formula of } \\
\cline { 1 - 2 } $\mathrm{N}$ & 0.04 & 0.00286 & Jet fuel \\
\hline $\mathrm{S}$ & 0.001 & 0.00003125 & $\mathrm{CH}_{2.028} \mathrm{O}_{0.000088} \mathrm{~N}_{0.0004} \mathrm{~S}_{0.0000042}$ \\
\hline
\end{tabular}


Table 13: Chemical formula of fresh corn oil

\begin{tabular}{|c|c|c|c|}
\hline Element & $\begin{array}{c}\text { Weight (g) per 100g } \\
\text { of corn oil }\end{array}$ & $\begin{array}{c}\text { Number of } \\
\text { moles per 100 g } \\
\text { of corn oil }\end{array}$ & Chemical Formula of corn oil \\
\hline $\mathrm{C}$ & 78.75 & 6.5625 & $\mathrm{C}_{6.563} \mathrm{H}_{9.97} \mathrm{O}_{0.695} \mathrm{~N}_{0.0086} \mathrm{~S}_{0.0002}$ \\
\hline $\mathrm{H}$ & 9.97 & 9.97 & \\
\hline $\mathrm{O}$ & 11.12 & 0.695 & Empirical Formula of \\
\hline $\mathrm{N}$ & 0.12 & 0.00857 & corn oil \\
\hline $\mathrm{S}$ & 0.005 & 0.0001563 & $\mathrm{CH}_{1.52} \mathrm{O}_{0.106} \mathrm{~N}_{0.0013} \mathrm{~S}_{0.000024}$ \\
\hline
\end{tabular}

Table 14: Chemical formula of used corn oil

\begin{tabular}{|c|c|c|c|}
\hline Element & $\begin{array}{c}\text { Weight (g) per 100g } \\
\text { of used corn oil }\end{array}$ & $\begin{array}{c}\text { Number of } \\
\text { moles per 100 g } \\
\text { of used corn oil }\end{array}$ & $\begin{array}{c}\text { Chemical Formula of used corn } \\
\text { oil }\end{array}$ \\
\hline $\mathrm{C}$ & 81.45 & 6.7875 & $\mathrm{C}_{6.788} \mathrm{H}_{10.5} \mathrm{O}_{0.494} \mathrm{~N}_{0.0086} \mathrm{~S}_{0.00003}$ \\
\hline $\mathrm{H}$ & 10.5 & 10.5 & \\
\hline $\mathrm{O}$ & 7.9 & 0.49375 & Empirical Formula of \\
\cline { 1 - 2 } $\mathrm{N}$ & 0.12 & 0.00857 & used corn oil \\
\hline $\mathrm{S}$ & 0.001 & 0.00003125 & $\mathrm{CH}_{1.55} \mathrm{O}_{0.073} \mathrm{~N}_{0.0013} \mathrm{~S}_{0.000005}$ \\
\hline
\end{tabular}


The empirical formula of each parent fuel was determined by normalizing to 1 mole of carbon.

\subsubsection{Chemical Formula of the Blends}

The chemical formulae for FCO:D50, FCO:D40, UCO:D50, and UCO:D40 were calculated by taking into account the percentage mass of each component in $100 \mathrm{~g}$ of the blend. Tables 15 and 16 show the mass percent distribution of the components in the FCO:D50 blend and its chemical formula respectively.

The empirical formula for the blend was determined by normalizing to 1 mole of carbon. Tables 17-22 show the same calculations for the remaining diesel-corn oil blends.

Likewise, the chemical formulae for the jet fuel-corn oil blends were determined. Similar to the diesel-corn oil blends, these blends were designated as FCO:JF50, FCO:JF40, UCO:JF50, and UCO:JF40. They are presented in Tables 23-30. 
Table 15: Mass percent composition of FCO:D50

\begin{tabular}{|c|c|c|}
\hline Component & Chemical Formula & \% mass \\
\hline Diesel & $\mathrm{C}_{7.4908} \mathrm{H}_{11.9} \mathrm{O}_{0.00063} \mathrm{~N}_{0.0093} \mathrm{~S}_{0.000063}$ & 50 \\
\hline Corn Oil & $\mathrm{C}_{6.563} \mathrm{H}_{9.97} \mathrm{O}_{0.695} \mathrm{~N}_{0.0086} \mathrm{~S}_{0.0002}$ & 27 \\
\hline Butanol & $\mathrm{C}_{4} \mathrm{H}_{9} \mathrm{OH}$ & 19 \\
\hline Ethanol & $\mathrm{C}_{2} \mathrm{H}_{5} \mathrm{OH}$ & 4 \\
\hline
\end{tabular}

Table 16: Chemical formula of FCO:D50

\begin{tabular}{|c|c|c|c|c|c|c|}
\hline & Moles of C & Moles of $\mathbf{H}$ & Moles of $\mathbf{O}$ & Moles of $\mathbf{N}$ & Moles of S & Chemical Formula of FCO:D50 \\
\hline Diesel & 3.7454 & 5.95 & 0.00032 & 0.00465 & 0.000032 & $\mathrm{C}_{6.357} \mathrm{H}_{10.782} \mathrm{O}_{0.418} \mathrm{~N}_{0.00695} \mathrm{~S}_{0.000086}$ \\
\hline Corn Oil & 1.772 & 2.692 & 0.188 & 0.0023 & 0.000054 & \\
\hline Butanol & 0.76 & 1.9 & 0.19 & & & \\
\hline Ethanol & 0.08 & 0.24 & 0.04 & & & Empirical Formula of FCO:D50 \\
\hline Total moles & 6.3574 & 10.782 & 0.41832 & 0.00695 & 0.000086 & $\mathrm{CH}_{1.696} \mathrm{O}_{0.066} \mathrm{~N}_{0.0011} \mathrm{~S}_{0.000035}$ \\
\hline
\end{tabular}


Table 17: Mass percent composition of FCO:D40

\begin{tabular}{|c|c|c|}
\hline Component & Chemical Formula & \% mass \\
\hline Diesel & $\mathrm{C}_{7.4908} \mathrm{H}_{11.9} \mathrm{O}_{0.00063} \mathrm{~N}_{0.0093} \mathrm{~S}_{0.000063}$ & 40 \\
\hline Fresh Corn Oil & $\mathrm{C}_{6.563} \mathrm{H}_{9.97} \mathrm{O}_{0.695} \mathrm{~N}_{0.0086} \mathrm{~S}_{0.0002}$ & 35 \\
\hline Butanol & $\mathrm{C}_{4} \mathrm{H}_{9} \mathrm{OH}$ & 21 \\
\hline Ethanol & $\mathrm{C}_{2} \mathrm{H}_{5} \mathrm{OH}$ & 4 \\
\hline
\end{tabular}

Table 18: Chemical formula of FCO:D40

\begin{tabular}{|c|c|c|c|c|c|c|}
\hline & Moles of C & Moles of H & Moles of O & Moles of N & Moles of S & Chemical Formula of FCO:D40 \\
\hline Diesel & 2.996 & 4.76 & 0.00025 & 0.0037 & 0.000025 & $\mathrm{C}_{6.213} \mathrm{H}_{10.59} \mathrm{O}_{0.4936} \mathrm{~N}_{0.0067} \mathrm{~S}_{0.0001}$ \\
\hline Corn Oil & 2.297 & 3.49 & 0.2433 & 0.003 & 0.00007 & \multirow{2}{*}{} \\
\cline { 1 - 5 } Butanol & 0.84 & 2.1 & 0.21 & & & \multirow{2}{*}{ Empirical Formula of FCO:D40 } \\
\hline Ethanol & 0.08 & 0.24 & 0.04 & & & \\
\hline Total moles & 6.213 & 10.59 & 0.49355 & 0.0067 & 0.000095 & $\mathrm{CH}_{1.704} \mathrm{O}_{0.079} \mathrm{~N}_{0.00108} \mathrm{~S}_{0.00002}$ \\
\hline
\end{tabular}


Table 19: Mass percent composition of UCO:D50

\begin{tabular}{|c|c|c|}
\hline Component & Chemical Formula & \% mass \\
\hline Diesel & $\mathrm{C}_{7.4908} \mathrm{H}_{11.9} \mathrm{O}_{0.00063} \mathrm{~N}_{0.0093} \mathrm{~S}_{0.000063}$ & 50 \\
\hline Used Corn Oil & $\mathrm{C}_{6.788} \mathrm{H}_{10.5} \mathrm{O}_{0.494} \mathrm{~N}_{0.0086} \mathrm{~S}_{0.00003}$ & 27 \\
\hline Butanol & $\mathrm{C}_{4} \mathrm{H}_{9} \mathrm{OH}$ & 19 \\
\hline Ethanol & $\mathrm{C}_{2} \mathrm{H}_{5} \mathrm{OH}$ & 4 \\
\hline
\end{tabular}

Table 20: Chemical formula of UCO:D50

\begin{tabular}{|c|c|c|c|c|c|c|}
\hline & Moles of C & Moles of $\mathbf{H}$ & Moles of $\mathbf{O}$ & Moles of $\mathbf{N}$ & Moles of S & Chemical Formula of UCO:D50 \\
\hline Diesel & 3.7454 & 5.95 & 0.00032 & 0.00465 & 0.000032 & $\mathrm{C}_{6.4184} \mathrm{H}_{10.925} \mathrm{O}_{0.3637} \mathrm{~N}_{0.007} \mathrm{~S}_{0.00004}$ \\
\hline Corn Oil & 1.833 & 2.835 & 0.1334 & 0.00232 & 0.000008 & \\
\hline Butanol & 0.76 & 1.9 & 0.19 & & & \\
\hline Ethanol & 0.08 & 0.24 & 0.04 & & & Empirical Formula of UCO:D50 \\
\hline Total moles & 6.4184 & 10.925 & 0.36372 & 0.00697 & 0.00004 & $\mathrm{CH}_{1.702} \mathrm{O}_{0.0567} \mathrm{~N}_{0.00109} \mathrm{~S}_{0.000006}$ \\
\hline
\end{tabular}


Table 21: Mass percent composition of UCO:D40

\begin{tabular}{|c|c|c|}
\hline Component & Chemical Formula & \% mass \\
\hline Diesel & $\mathrm{C}_{7.4908} \mathrm{H}_{11.9} \mathrm{O}_{0.00063} \mathrm{~N}_{0.0093} \mathrm{~S}_{0.000063}$ & 40 \\
\hline Used Corn Oil & $\mathrm{C}_{6.788} \mathrm{H}_{10.5} \mathrm{O}_{0.494} \mathrm{~N}_{0.0086} \mathrm{~S}_{0.00003}$ & 35 \\
\hline Butanol & $\mathrm{C}_{4} \mathrm{H}_{9} \mathrm{OH}$ & 21 \\
\hline Ethanol & $\mathrm{C}_{2} \mathrm{H}_{5} \mathrm{OH}$ & 4 \\
\hline
\end{tabular}

Table 22: Chemical formula of UCO:D40

\begin{tabular}{|c|c|c|c|c|c|c|}
\hline & Moles of C & Moles of $\mathbf{H}$ & Moles of $\mathbf{O}$ & Moles of $\mathbf{N}$ & Moles of S & Chemical Formula of UCO:D40 \\
\hline Diesel & 2.996 & 4.76 & 0.00025 & 0.0037 & 0.000025 & $\mathrm{C}_{6.292} \mathrm{H}_{10.775} \mathrm{O}_{0.423} \mathrm{~N}_{0.0067} \mathrm{~S}_{0.000035}$ \\
\hline Corn Oil & 2.3758 & 3.675 & 0.1729 & 0.003 & 0.00001 & \\
\hline Butanol & 0.84 & 2.1 & 0.21 & & & \\
\hline Ethanol & 0.08 & 0.24 & 0.04 & & & Empirical Formula of UCO:D40 \\
\hline Total moles & 6.2918 & 10.775 & 0.42315 & 0.0067 & 0.000035 & $\mathrm{CH}_{1.713} \mathrm{O}_{0.067} \mathrm{~N}_{0.00106} \mathrm{~S}_{0.0000056}$ \\
\hline
\end{tabular}


Table 23: Mass percent composition of FCO:JF50

\begin{tabular}{|c|c|c|}
\hline Component & Chemical Formula & \% mass \\
\hline Jet Fuel & $\mathrm{C}_{7.151} \mathrm{H}_{14.5} \mathrm{O}_{0.00063} \mathrm{~N}_{0.00286} \mathrm{~S}_{0.00003}$ & 50 \\
\hline Fresh Corn Oil & $\mathrm{C}_{6.563} \mathrm{H}_{9.97} \mathrm{O}_{0.695} \mathrm{~N}_{0.0086} \mathrm{~S}_{0.0002}$ & 27 \\
\hline Butanol & $\mathrm{C}_{4} \mathrm{H}_{9} \mathrm{OH}$ & 19 \\
\hline Ethanol & $\mathrm{C}_{2} \mathrm{H}_{5} \mathrm{OH}$ & 4 \\
\hline
\end{tabular}

Table 24: Chemical formula for FCO:JF50

\begin{tabular}{|c|c|c|c|c|c|l|}
\hline & Moles of C & Moles of H & Moles of O & Moles of N & Moles of S & $\begin{array}{l}\text { Chemical Formula of } \\
\text { FCO:JF50 }\end{array}$ \\
\cline { 1 - 5 } Jet Fuel & 3.5755 & 7.25 & 0.00032 & 0.00143 & 0.000015 & $\mathrm{C}_{6.188} \mathrm{H}_{12.08} \mathrm{O}_{0.4183} \mathrm{~N}_{0.00373} \mathrm{~S}_{0.000069}$ \\
\hline Corn Oil & 1.772 & 2.692 & 0.188 & 0.0023 & 0.000054 & \multirow{2}{*}{} \\
\cline { 1 - 5 } Butanol & 0.76 & 1.9 & 0.19 & & & \multirow{2}{*}{ Empirical Formula of FCO:JF50 } \\
\hline Ethanol & 0.08 & 0.24 & 0.04 & & & \multirow{2}{*}{$\mathrm{CH}_{1.95} \mathrm{O}_{0.0676} \mathrm{~N}_{0.000603} \mathrm{~S}_{0.0000112}$} \\
\hline
\end{tabular}


Table 25: Mass percent composition for FCO:JF40

\begin{tabular}{|c|c|c|}
\hline Component & Chemical Formula & \% mass \\
\hline Jet Fuel & $\mathrm{C}_{7.151} \mathrm{H}_{14.5} \mathrm{O}_{0.00063} \mathrm{~N}_{0.00286} \mathrm{~S}_{0.00003}$ & 40 \\
\hline Fresh Corn Oil & $\mathrm{C}_{6.563} \mathrm{H}_{9.97} \mathrm{O}_{0.695} \mathrm{~N}_{0.0086} \mathrm{~S}_{0.0002}$ & 35 \\
\hline Butanol & $\mathrm{C}_{4} \mathrm{H}_{9} \mathrm{OH}$ & 21 \\
\hline Ethanol & $\mathrm{C}_{2} \mathrm{H}_{5} \mathrm{OH}$ & 4 \\
\hline
\end{tabular}

Table 26: Chemical formula of FCO:JF40

\begin{tabular}{|c|c|c|c|c|c|c|}
\hline & Moles of C & Moles of $\mathbf{H}$ & Moles of $\mathbf{O}$ & Moles of $\mathbf{N}$ & Moles of S & $\begin{array}{l}\text { Chemical Formula of } \\
\text { FCO:JF40 }\end{array}$ \\
\hline Jet Fuel & 2.8604 & 5.8 & 0.00025 & 0.00114 & 0.000012 & $\mathrm{C}_{6.0774} \mathrm{H}_{11.63} \mathrm{O}_{0.4935} \mathrm{~N}_{0.00414} \mathrm{~S}_{0.000082}$ \\
\hline Corn Oil & 2.297 & 3.49 & 0.2433 & 0.003 & 0.00007 & \\
\hline Butanol & 0.84 & 2.1 & 0.21 & & & \\
\hline Ethanol & 0.08 & 0.24 & 0.04 & & & Empirical Formula of FCO:JF40 \\
\hline Total moles & 6.0774 & 11.63 & 0.49355 & 0.00414 & 0.000082 & $\mathrm{CH}_{1.914} \mathrm{O}_{0.0812} \mathrm{~N}_{0.00068} \mathrm{~S}_{0.0000135}$ \\
\hline
\end{tabular}


Table 27: Mass percent composition for UCO:JF50

\begin{tabular}{|c|c|c|}
\hline Component & Chemical Formula & \% mass \\
\hline Jet Fuel & $\mathrm{C}_{7.151} \mathrm{H}_{14.5} \mathrm{O}_{0.00063} \mathrm{~N}_{0.00286} \mathrm{~S}_{0.00003}$ & 50 \\
\hline Used Corn Oil & $\mathrm{C}_{6.788} \mathrm{H}_{10.5} \mathrm{O}_{0.494} \mathrm{~N}_{0.0086} \mathrm{~S}_{0.00003}$ & 27 \\
\hline Butanol & $\mathrm{C}_{4} \mathrm{H}_{9} \mathrm{OH}$ & 19 \\
\hline Ethanol & $\mathrm{C}_{2} \mathrm{H}_{5} \mathrm{OH}$ & 4 \\
\hline
\end{tabular}

Table 28: Chemical formula of UCO:JF50

\begin{tabular}{|c|c|c|c|c|c|l|}
\hline & Moles of C & Moles of H & Moles of O & Moles of N & Moles of S & $\begin{array}{l}\text { Chemical Formula of } \\
\text { UCO:JF50 }\end{array}$ \\
\cline { 1 - 5 } Jet Fuel & 3.5755 & 7.25 & 0.00032 & 0.00143 & 0.000015 & $\mathrm{C}_{6.249} \mathrm{H}_{12.23} \mathrm{O}_{0.3637} \mathrm{~N}_{0.0038} \mathrm{~S}_{0.000023}$ \\
\hline Corn Oil & 1.833 & 2.835 & 0.1334 & 0.00232 & 0.000008 & \\
\cline { 1 - 5 } Butanol & 0.76 & 1.9 & 0.19 & & & \\
\cline { 1 - 5 } Ethanol & 0.08 & 0.24 & 0.04 & & & \multirow{2}{*}{ Empirical Formula of UCO:JF50 } \\
\hline Total moles & 6.2485 & 12.225 & 0.36372 & 0.00375 & 0.000023 & $\mathrm{CH}_{1.96} \mathrm{O}_{0.0582} \mathrm{~N}_{0.000608} \mathrm{~S}_{0.00000368}$ \\
\hline
\end{tabular}


Table 29: Mass percent composition for UCO:JF40

\begin{tabular}{|c|c|c|}
\hline Component & Chemical Formula & \% mass \\
\hline Jet Fuel & $\mathrm{C}_{7.151} \mathrm{H}_{14.5} \mathrm{O}_{0.00063} \mathrm{~N}_{0.00286} \mathrm{~S}_{0.00003}$ & 40 \\
\hline Used Corn Oil & $\mathrm{C}_{6.788} \mathrm{H}_{10.5} \mathrm{O}_{0.494} \mathrm{~N}_{0.0086} \mathrm{~S}_{0.00003}$ & 35 \\
\hline Butanol & $\mathrm{C}_{4} \mathrm{H}_{9} \mathrm{OH}$ & 21 \\
\hline Ethanol & $\mathrm{C}_{2} \mathrm{H}_{5} \mathrm{OH}$ & 4 \\
\hline
\end{tabular}

Table 30: Chemical formula of UCO:JF40

\begin{tabular}{|c|c|c|c|c|c|c|}
\hline & Moles of C & Moles of $\mathbf{H}$ & Moles of $\mathbf{O}$ & Moles of $\mathbf{N}$ & Moles of S & $\begin{array}{l}\text { Chemical Formula of } \\
\text { UCO:JF40 }\end{array}$ \\
\hline Jet Fuel & 2.8604 & 5.8 & 0.00025 & 0.00114 & 0.000012 & $\mathrm{C}_{6.156} \mathrm{H}_{11.815} \mathrm{O}_{0.42} \mathrm{~N}_{0.00414} \mathrm{~S}_{0.000022}$ \\
\hline Corn Oil & 2.3758 & 3.675 & 0.1729 & 0.003 & 0.00001 & \\
\hline Butanol & 0.84 & 2.1 & 0.21 & & & \\
\hline Ethanol & 0.08 & 0.24 & 0.04 & & & Empirical Formula of UCO:JF40 \\
\hline Total moles & 6.1562 & 11.815 & 0.42315 & 0.00414 & 0.000022 & $\mathrm{CH}_{1.92} \mathrm{O}_{0.069} \mathrm{~N}_{0.000673} \mathrm{~S}_{0.0000036}$ \\
\hline
\end{tabular}


From the chemical formula tables above, the empirical formula for each fuel was determined. The $\mathrm{O} / \mathrm{C}$ ratios for fresh and used corn oils were found to differ significantly. There was no significant difference in $\mathrm{H} / \mathrm{C}$ and $\mathrm{N} / \mathrm{C}$ ratios for the same two fuels. Among the fuel blends, when the composition is kept constant, the $\mathrm{H} / \mathrm{C}$ ratio was found to increase when fresh corn oil was replaced with used corn oil (ex: H/C ratio of UCO:D40 is greater than $\mathrm{H} / \mathrm{C}$ ratio of FCO:D40). However, under the same condition, $\mathrm{O} / \mathrm{C}$ ratio decreased, owing to the lower amount of elemental oxygen in used corn oil (Table 10). The $\mathrm{H} / \mathrm{C}$ ratios for jet fuel blends were significantly higher than those for diesel blends. Very low amounts of elemental nitrogen in jet fuel contributed to the low $\mathrm{N} / \mathrm{C}$ ratios in jet fuel blends.

\subsubsection{Fuel Chemistry of Blends}

Corn oil, just like most vegetable oils, is made up of triglycerides. Triglycerides are basically esters of a molecule of glycerol and three molecules of fatty acid. Table 31 gives the distribution of saturated and unsaturated fatty acids present in fresh corn oil [53]: 
Table 31: Fatty acid composition in fresh corn oil [53]

\begin{tabular}{|c|c|c|}
\hline Fatty Acid & $\begin{array}{c}\text { C chain length }: \text { No. } \\
\text { of double bonds }\end{array}$ & \% of total fatty acids \\
\hline Palmitic acid & C16:0 & $11.0 \pm 0.55$ \\
\hline Stearic acid & $\mathrm{C} 18: 0$ & $1.7 \pm 0.25$ \\
\hline Oleic acid & $\mathrm{C} 18: 1$ & $25.8 \pm 0.90$ \\
\hline Linoleic acid & $\mathrm{C} 18: 2$ & $59.8 \pm 1.20$ \\
\hline Linolenic acid & $\mathrm{C} 18: 3$ & $1.1 \pm 0.39$ \\
\hline
\end{tabular}

It can be seen from Table 31 that the most common fatty acids constituting corn oil are the polyunsaturated fatty acids with 18 carbon atoms (linoleic acid).

It has been found that certain properties of these fatty acids in a molecule of triglyceride directly affect the viscosity of corn oil. Most bonds in fatty acid chains are single bonds, having a zigzag shape. Due to London Dispersion force (a kind of Van der Waal's force), the long hydrocarbon chains of fatty acids are held close to each other, eventually inhibiting fluid flow [51]. This in part explains the high viscosity. The double bonds present (mostly due to linoleic acid) produce "kinks" in the geometry of the corn oil molecule. This prevents the chains from coming very close together to form intermolecular contacts, which in theory limits the viscosity from being too high. Moreover, as the surface area and molecular weight of the molecule increases, the dispersion forces of attraction increase also. The corn oil molecule has a large surface area due to the 18 carbon atoms in a hydrocarbon chain, which leads to many dispersion forces between the different hydrocarbon chains. This also contributes to the high viscosity of corn oil. The shape of the molecule, characterized by the straight single- 
bonded chains and the kinks due to double bonds, also affects the magnitude of dispersion forces.

When corn oil is heated, the oxidation process is effectively accelerated. As explained in Section 2.9, oxidation is characterized by a decrease in the total unsaturated content in the corn oil. This is due to the removal of a hydrogen atom adjacent to a double bond, leading to the formation of free radicals. Double bond isomerization (cis to trans), formation of free fatty acids and overall tendency for saturation and formation of higher molecular weight products all account for the increase in viscosity of used corn oil [28].

\subsubsection{Total Polar Material Test}

Total polar material (TPM) is basically a measure of the amount of free fatty acids, monoglycerides, diglycerides and oxidation products like aldehydes and ketones [31]. As described in Section 5.5.1, measuring TPM involves using the Testo 270 cooking oil tester, and is based on capacitive measurement.

Figure 31 illustrates the amount of heating time needed for corn oil to reach $20 \%$ TPM. When a linear regression is applied to the graph, it is observed that TPM is a more or less linear function of heating time in hours. Other factors such as moisture in the atmosphere are likely to have contributed to the increase in TPM also. 


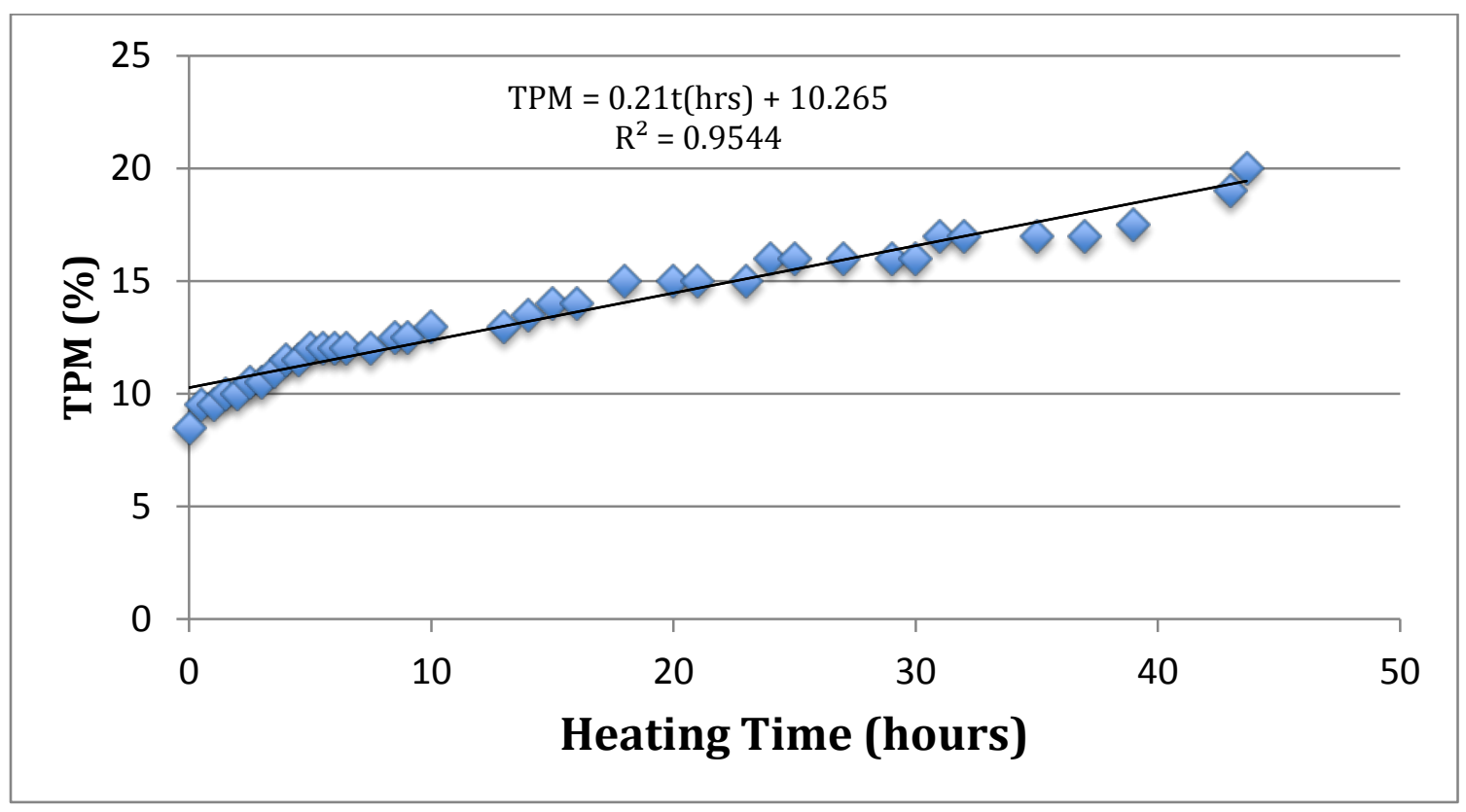

Figure 31: TPM (\%) of corn oil during heating process

Vegetable oils like corn oil have antioxidants in them that help against immediate oxidation when they are exposed to air and light. These antioxidants react with most free radicals already present in the oil and decompose peroxides via monomolecular and bimolecular reactions. This in turn creates more free radicals as well as carbonyl compounds, which are associated with development of off-flavors. Thus antioxidants only help to a certain extent, until the point that they have been overwhelmed by the number free radicals. This is how oxidation or auto-oxidation commences [25]. It basically involves a series of complex chemical reactions and is characterized by a decrease in the level of unsaturated compounds in the oil. Besides temperature, oxidation is influenced by other factors such as fatty acid composition and minor components such 
as tocopherols. Oxidation of corn oil basically increases with both time and temperature [29].

Figure 31 illustrates the variation of total polar material in corn oil with respect to heating time in hours. Generally, the oil can be classified based on the extent of oxidation, by defining the range of TPM percentages it falls under, as shown in Table 5 in Section 5.5.1. In this study, 20\% TPM was defined as the point at which the corn oil was characterized as "used". It took about 44 hours of total heating time for the total polar material to reach this value.

The following are some of the physical changes that corn oil undergoes upon heating [24]:

- Increase in viscosity

- Increase in specific heat

- Development of dark color

- Change in refractive index

- Decrease in surface tension

- $\quad$ Tendency of oil to foam

Some of the chemical changes that occur are:

- Decrease in iodine value

- Production of volatile compounds

- Formation of free fatty acids

- Increase in polar content

- Increase in peroxide value 
In order to determine quantitative differences between fresh and used corn oils, Iodine Value, Free Fatty Acid, and Peroxide Value tests were performed on both samples using FT-NIR spectrometry.

\subsubsection{Iodine Value Test}

The iodine value test gave a measure of the decrease in the number of double bonds when fresh corn oil was converted to used corn oil. As seen in Figure 32, the average iodine value for fresh corn oil was estimated to be $123.1 \mathrm{~g} \mathrm{I}_{2} / 100 \mathrm{~g}$ oil. Used corn oil was found to have an iodine value of $117.43 \mathrm{~g} \mathrm{I}_{2} / 100 \mathrm{~g}$ oil.

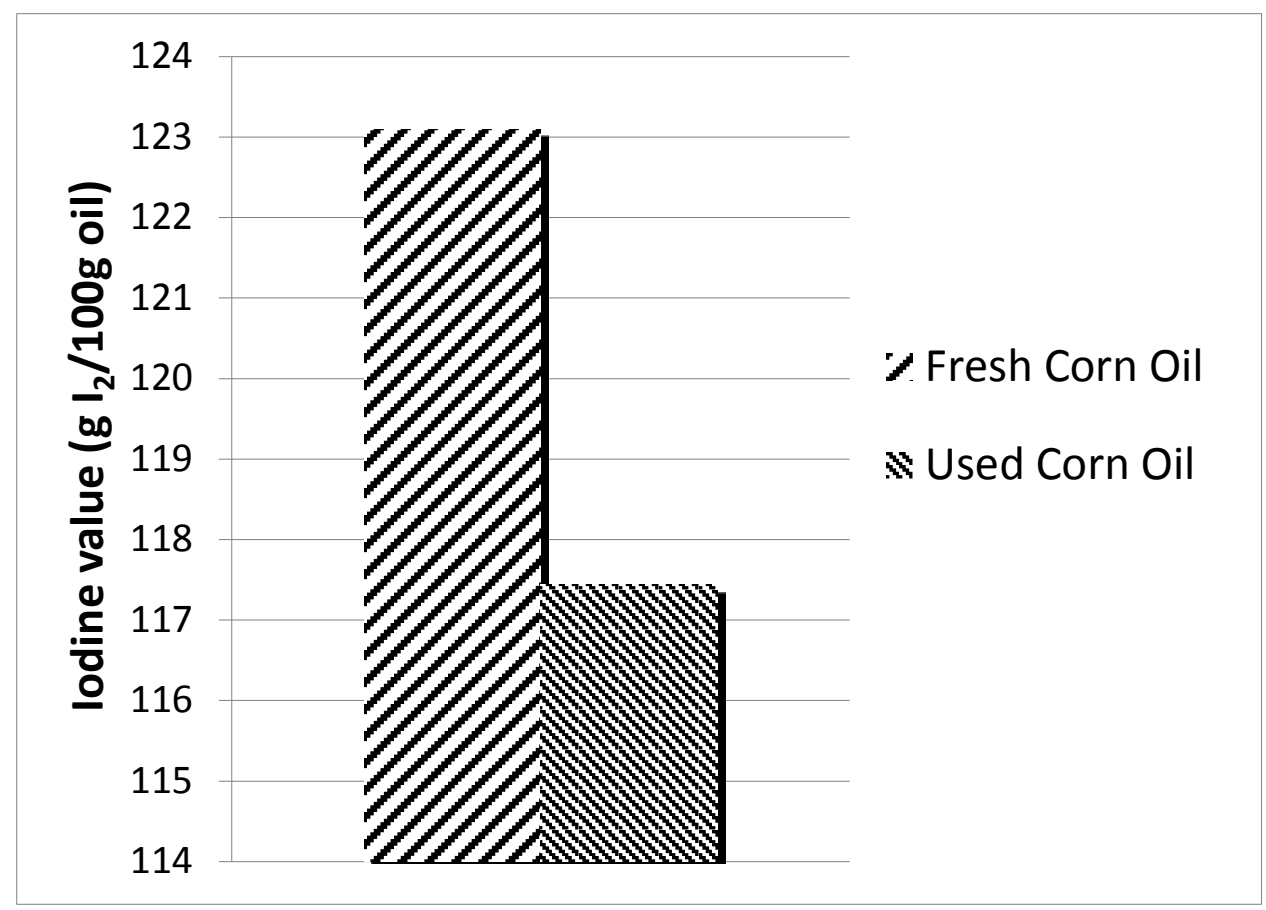

Figure 32: Iodine value test for fresh and used corn oils 
Takeoka et al. [32] established, via their heating oil experiments, iodine value and total polar material are highly and significantly correlated. Since corn oil had the highest degree of unsaturation, it was most susceptible to oxidation and thereby experienced the fastest loss in unsaturated content as explained in Section 2.9. From Figure 31, fresh corn oil had an initial TPM value of $8 \%$, which corresponds to an iodine value of $123.1 \mathrm{~g}$ $\mathrm{I}_{2} / 100 \mathrm{~g}$ oil. After heat-treating it for about 44 hours, the used corn oil had a TPM value of $20 \%$, corresponding to $117.43 \mathrm{~g} \mathrm{I}_{2} / 100 \mathrm{~g}$ oil iodine value. Due to the time gap between measuring the above values and running the combustion experiments, the TPM for used corn oil was measured once again right before the experiments, as $25 \%$. The corresponding iodine value was calculated to be $115.0675 \mathrm{~g} \mathrm{I}_{2} / 100 \mathrm{~g}$ oil using regression analysis. All used corn oil in this study, as a stand-alone fuel and as a component in the blends was at $25 \%$ TPM.

Iodine value is determined by the amount of iodine that 100 grams of corn oil absorbs. This iodine absorption takes place at the double bond positions in the fatty acids, such that an iodine atom is attached to each carbon atom at a given double bond [55]. Thus, more grams of iodine are needed to saturate or break the double bonds in fresh corn oil (Figure 32) which indicate that there are more double bonds in fresh corn oil than used corn oil. Section 2.9 explains how this decrease in iodine value from fresh to used corn oil is directly related to a decrease in total unsaturated content of corn oil when it undergoes oxidation. 


\subsubsection{Free Fatty Acid Test}

The free fatty acid (FFA) test gives an estimation on a percentage basis of the total free fatty acid constituents that form when corn oil is oxidized. It was estimated that fresh corn oil had $0.117 \%$ FFA whereas used corn oil had $0.47 \%$ FFA, as seen in Figure 33.

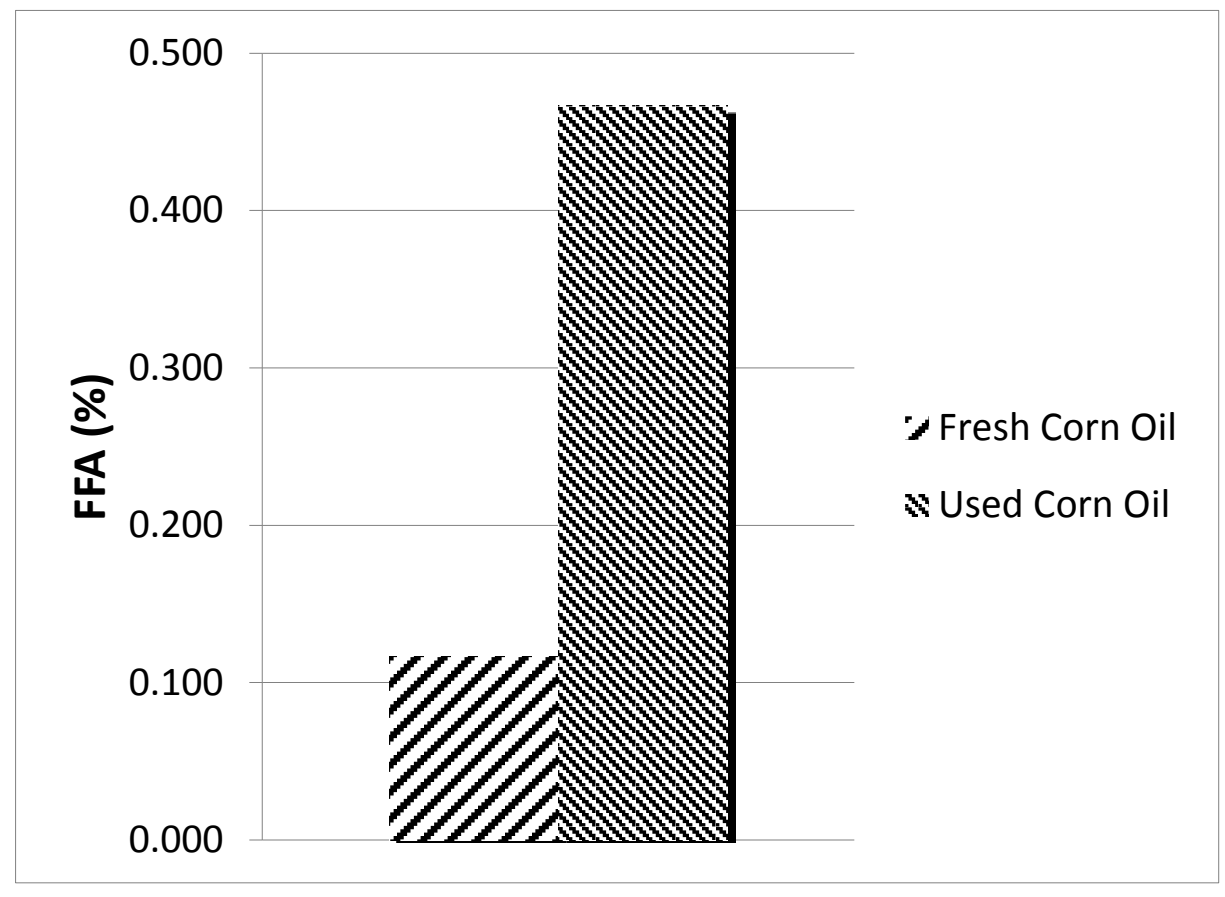

Figure 33: Free fatty acid test for fresh and used corn oils

FFA (\%) was seen to increase as corn oil was heated. This could be due to the cleavage and oxidation of double bonds to form carbonyl compounds. These could have further oxidized to low-molecular weight fatty acids [56]. Thus, FFA (\%) measures the 
amount of acids formed by oxidation of corn oil. Also, as explained in Section 2.9, free fatty acid content in the oil is a by-product of the "Free Radical Mechanism."

\subsubsection{Peroxide Value Test}

Peroxide value is indicative of the concentration of peroxides present in the oil. This is a useful test for determining the extent to which oxidation has occurred. The peroxide values shown in Figure 34 are $14.147 \mathrm{~m}_{\mathrm{eq}} / \mathrm{kg}$ oil and $19.63 \mathrm{~m}_{\mathrm{eq}} / \mathrm{kg}$ oil for fresh corn oil and used corn oil, respectively.

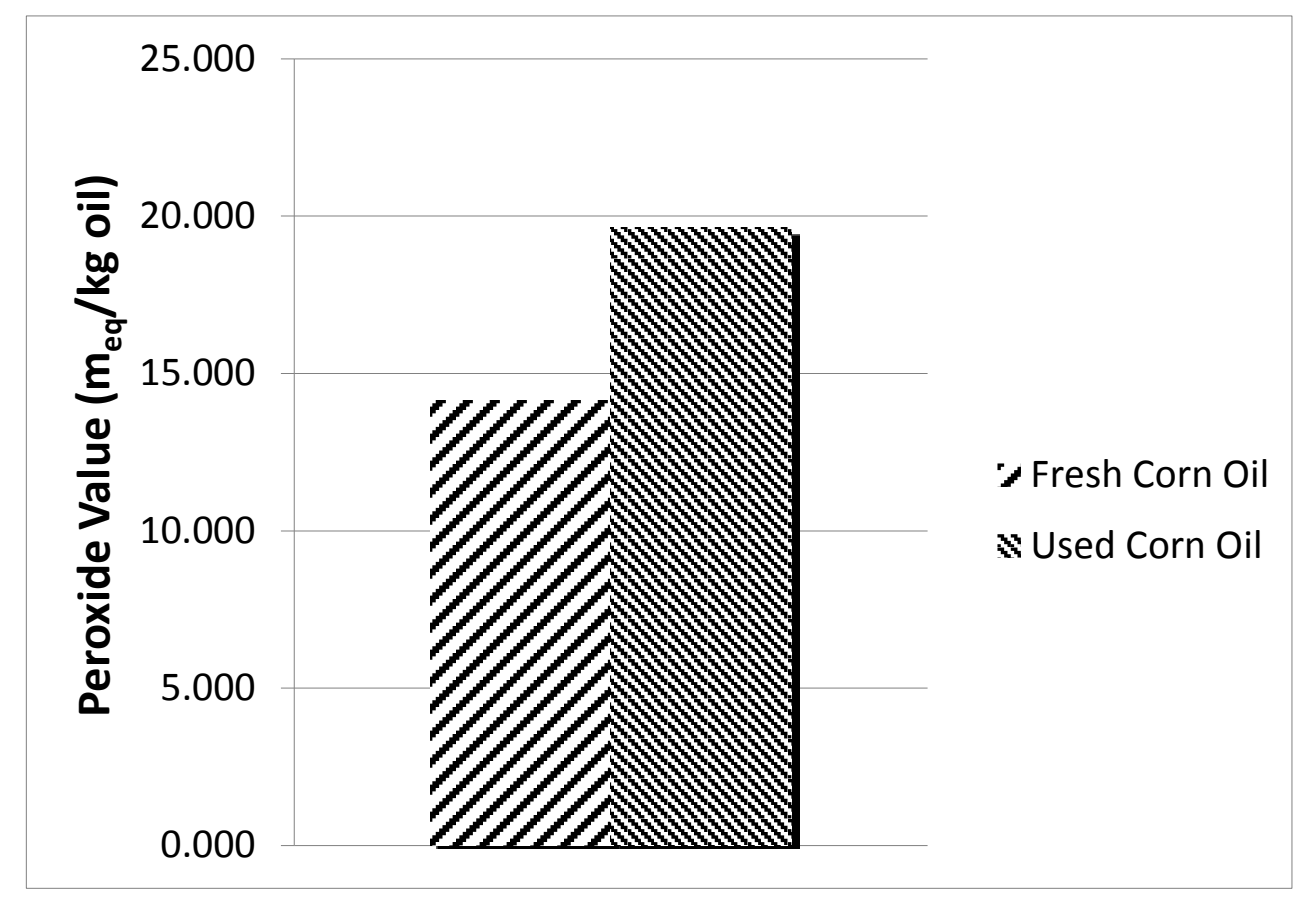

Figure 34: Peroxide value test for fresh and used corn oils 
Peroxide value is a useful indicator of oxidation in corn oil, especially during the nascent stages of oxidation. It depends on the rate of formation and breakdown of the oxidation products [56]. In other words, the higher level of peroxide oxygen in used corn oil suggests that at some point during oxidation, free radicals outnumbered the antioxidants present in the oil. As a result, the formation of peroxides (via the Free Radical Mechanism) was accelerated, thereby increasing the peroxide value from fresh corn oil to used corn oil (Figure 34). This formation mechanism is explained in detail in Section 2.9.

\subsection{Combustion Experimental Parameters}

The three main parameters used to study the emissions of the different blends were equivalence ratio, fuel composition (or fuel type) and swirl number. The formulae used for different fuel blends have been discussed in Section 6.1. The swirl number equation is given in Section 2.12. This section shows the different calculations for the fuel and air flow rates for all the fuels in order to get a constant heat output of $68,620 \mathrm{~kJ} / \mathrm{hr}$ at equivalence ratios $0.8,0.9,1.0,1.05$ and 1.1 .

\subsubsection{Fuel Flow Rate}

In order to achieve $68,620 \mathrm{~kJ} / \mathrm{hr}$ of heat of combustion, the volumetric flow rate was calculated based on the heating values of the different fuels using the following formula: 
$V\left(\frac{m l}{\text { minute }}\right)=\frac{\left[68620\left(\frac{k J}{h r}\right) * 1000\left(\frac{g}{k g}\right)\right]}{\left[H H V\left(\frac{k J}{k g}\right) * \rho f u e l\left(\frac{g}{m l}\right) * 60\left(\frac{\min }{h r}\right)\right]}$

Higher heating values of the blends were estimated using Equation (9), assuming that there were no chemical changes taking place while blending:

$\operatorname{HHV}_{\text {blend }}(\mathrm{kJ} / \mathrm{kg})=\left(\mathrm{m}_{\mathrm{f}, \text { corn oil }} * \mathrm{HHV}_{\text {corn oil }}\right)+\left(\mathrm{m}_{\mathrm{f} \text {,diesel }} * \mathrm{HHV}_{\text {diesel }}\right)+$ $\left(\mathrm{m}_{\mathrm{f}, \text { butanol }} * \mathrm{HHV}_{\text {butanol }}\right)+\left(\mathrm{m}_{\mathrm{f}, \text { ethanol }} * \mathrm{HHV}_{\text {ethanol }}\right)$

where,

$\mathrm{m}_{\mathrm{f}}=$ mass fraction of component in the blend.

The table below displays the higher heating values of each component used in the fuels.

Table 32: Higher heating values of each component in the fuels

\begin{tabular}{|c|c|}
\hline Liquid & Higher Heating Value (kJ/kg) \\
\hline Diesel & 45,775 \\
\hline Fresh Corn Oil & 39,364 \\
\hline Used Corn Oil & 39,250 \\
\hline Butanol & 35,506 \\
\hline Ethanol & 26,297 \\
\hline Jet Fuel & 45,989 \\
\hline
\end{tabular}


Based on the calculations above, the volumetric fuel flow rates for fresh corn oil, used corn oil, FCO:D50, FCO:D40, UCO:D50, and UCO:D40 were determined to be $31.6 \mathrm{ml} / \mathrm{min}(0.5 \mathrm{gal} / \mathrm{hr}), 31.6 \mathrm{ml} / \mathrm{min}(0.5 \mathrm{gal} / \mathrm{hr}), 33.6 \mathrm{ml} / \mathrm{min}(0.53 \mathrm{gal} / \mathrm{hr}), 33.7$ $\mathrm{ml} / \mathrm{min}(0.53 \mathrm{gal} / \mathrm{hr}), 32.8 \mathrm{ml} / \mathrm{min}(0.52 \mathrm{gal} / \mathrm{hr})$, and $33.8 \mathrm{ml} / \mathrm{min}(0.54 \mathrm{gal} / \mathrm{hr})$ respectively.

Similarly the volumetric flow rates for FCO:JF50, FCO:JF40, UCO:JF50, and UCO:JF40 were $33.2 \mathrm{ml} / \mathrm{min}(0.53 \mathrm{gal} / \mathrm{hr}), 33.4 \mathrm{ml} / \mathrm{min}(0.53 \mathrm{gal} / \mathrm{hr}), 33.5 \mathrm{ml} / \mathrm{min}(0.53$ $\mathrm{gal} / \mathrm{hr})$ and $33.7 \mathrm{ml} / \mathrm{min}(0.54 \mathrm{gal} / \mathrm{hr})$, respectively.

Table 33 summarizes the empirical formula, HHV and the density values of the fuels.

Table 33: Empirical formula, HHV and density of the fuels

\begin{tabular}{|c|c|c|c|c|}
\hline Fuel Type & Chemical Empirical Formula & $\begin{array}{c}\text { Mol. Wt } \\
\text { (g/mol-C) }\end{array}$ & $\begin{array}{c}\text { HHV } \\
\text { (kJ/kg) }\end{array}$ & $\begin{array}{c}\text { Density } \\
\text { (g/ml) }\end{array}$ \\
\hline Fresh Corn Oil & $\mathrm{CH}_{1.52} \mathrm{O}_{0.106} \mathrm{~N}_{0.0013} \mathrm{~S}_{0.000024}$ & 15.23 & 39,364 & 0.92 \\
\hline Used Corn Oil & $\mathrm{CH}_{1.55} \mathrm{O}_{0.073} \mathrm{~N}_{0.0013} \mathrm{~S}_{0.000005}$ & 14.74 & 39,250 & 0.92 \\
\hline FCO:D50 & $\mathrm{CH}_{1.696} \mathrm{O}_{0.066} \mathrm{~N}_{0.0011} \mathrm{~S}_{0.000035}$ & 14.77 & 40,828 & 0.83 \\
\hline FCO:D40 & $\mathrm{CH}_{1.704} \mathrm{O}_{0.079} \mathrm{~N}_{0.00108} \mathrm{~S}_{0.00002}$ & 14.98 & 40,211 & 0.84 \\
\hline UCO:D50 & $\mathrm{CH}_{1.702} \mathrm{O}_{0.0567} \mathrm{~N}_{0.00109} \mathrm{~S}_{0.000006}$ & 14.62 & 42,156 & 0.83 \\
\hline UCO:D40 & $\mathrm{CH}_{1.713} \mathrm{O}_{0.067} \mathrm{~N}_{0.00106} \mathrm{~S}_{0.0000056}$ & 14.8 & 40,346 & 0.84 \\
\hline FCO:JF50 & $\mathrm{CH}_{1.95} \mathrm{O}_{0.0676} \mathrm{~N}_{0.000603} \mathrm{~S}_{0.0000112}$ & 15.04 & 41,420 & 0.83 \\
\hline FCO:JF40 & $\mathrm{CH}_{1.914} \mathrm{O}_{0.0812} \mathrm{~N}_{0.00068} \mathrm{~S}_{0.0000135}$ & 15.22 & 40,681 & 0.84 \\
\hline UCO:JF50 & $\mathrm{CH}_{1.96} \mathrm{O}_{0.0582} \mathrm{~N}_{0.000608} \mathrm{~S}_{0.00000368}$ & 14.89 & 41,390 & 0.82 \\
\hline UCO:JF40 & $\mathrm{CH}_{1.92} \mathrm{O}_{0.069} \mathrm{~N}_{0.000673} \mathrm{~S}_{0.0000036}$ & 15.03 & 40,641 & 0.83 \\
\hline
\end{tabular}


It is observed that the heating values of the blends consisting of fresh and used corn oil and diesel or jet fuel are higher than the heating values of fresh corn oil and used corn oil alone. This increase in the heating values can be attributed to the fact that almost half of the blend accounts for ultra-low sulfur diesel or jet fuel, which has the highest heating value of any component of the fuel blends, at $45,775 \mathrm{~kJ} / \mathrm{kg}$ and $45,989 \mathrm{~kJ} / \mathrm{kg}$ respectively. The densities of the fuels were measured by taking $50 \mathrm{ml}$ of each fuel in a graduated flask and measuring the mass on a weight scale. It is seen that the density values for the blends were slightly lower than the 2 parent fuels, fresh corn oil and used corn oil. This was due to the addition of diesel, butanol and ethanol, all of which have lower density values than fresh and used corn oil.

\subsubsection{Air Flow Calculations}

After calculating the required fuel flow rate for each fuel, the required air flow rate was calculated in order to ensure that proper combustion took place, depending on the equivalence ratios used. Equation (10) below shows a stoichiometric combustion reaction equation for fresh corn oil.

$$
\mathrm{CH}_{1.52} \mathrm{O}_{0.106} \mathrm{~N}_{0.0013} \mathrm{~S}_{0.000024}+x^{*}\left(\mathrm{O}_{2}+3.76 \mathrm{~N}_{2}\right) \rightarrow \mathrm{a}^{*} \mathrm{CO}_{2}+\mathrm{b} * \mathrm{H}_{2} \mathrm{O}+\mathrm{c} * \mathrm{~N}_{2}+\mathrm{d}^{*} \mathrm{SO}_{2}
$$

Table 34 shows the stoichiometric coefficients for Equation (10) after balancing the atoms on both sides. 
Table 34: Stoichiometric coefficients for complete combustion of fresh corn oil

\begin{tabular}{|c|c|}
\hline $\begin{array}{c}\text { Stoichiometric } \\
\text { Coefficient }\end{array}$ & Value \\
\hline$x$ & 1.327 \\
\hline $\mathrm{a}$ & 1 \\
\hline $\mathrm{b}$ & 0.76 \\
\hline $\mathrm{c}$ & 4.99 \\
\hline $\mathrm{d}$ & 0.000024 \\
\hline
\end{tabular}

Equation (10) above actually represents the combustion of $15.23 \mathrm{~g}$ of fresh corn oil, which is the molecular weight of fresh corn oil. This molecular weight is based on the empirical formula of corn oil (i.e. $15.23 \mathrm{~g} /$ mol-Carbon). The following method was used to calculate the amount of air needed for complete combustion of $15.23 \mathrm{~g}$ of fresh corn oil:

$$
\begin{aligned}
\mathrm{m}_{\text {air,total }} & =x * 4.76 \text { moles of air } \\
& =1.327 * 4.76 \text { moles of air } \\
& =6.3165 \text { moles of air } \\
& =6.3165 \text { moles } * \mathrm{M}_{\text {air }} \text { (molecular weight of air) } \\
& =6.3165 \text { moles } * 28.97 \mathrm{~g} / \text { mole of air } \\
& =182.99 \text { grams of air }
\end{aligned}
$$

Thus the amount of air needed by each gram of corn oil was given by:

$$
\begin{aligned}
\operatorname{Air}_{\text {per gram oil }} & =182.99 \mathrm{~g} \text { of air } / 15.23 \mathrm{~g} \text { of corn oil } \\
& =12.02 \mathrm{~g} \text { of air } / \mathrm{g} \text { of corn oil }
\end{aligned}
$$

As a result, the air-fuel ratio for stoichiometric combustion (or $\phi=1$ ) for pure corn oil was: 
$(\text { Air/Fuel })_{\text {stoichiometric }}=12.02$

Now the volumetric flow rate (V) for fresh corn oil was calculated using equation (8) as shown below:

$\mathrm{V}=31.545 \mathrm{ml} / \mathrm{min} * 0.921 \mathrm{~g} / \mathrm{ml} \ldots$ (density of fresh corn oil)

$=29.05 \mathrm{~g} / \mathrm{min}$ (mass flow rate)

Mass flow rate of the air required:

$\mathrm{m}_{\mathrm{air}}=29.05 \mathrm{~g}$ of corn oil $/ \mathrm{min} * 12.02 \mathrm{~g}$ of air/g of corn oil $=349.181 \mathrm{~g}$ of $\mathrm{air} / \mathrm{min}$

At standard temperature and pressure conditions, density of air $=1.2 \mathrm{~g} / \mathrm{l}$

Therefore, the total volumetric air flow rate at stoichiometric conditions was:

$$
\begin{aligned}
\mathrm{V}_{\text {air, total }} & =349.181 \mathrm{~g} \text { of air per min } / 1.2 \mathrm{~g} / 1 \\
& =290.9 \mathrm{l} / \mathrm{min} \text { of air }
\end{aligned}
$$

Thus, a total air flow of $290.9 \mathrm{l} / \mathrm{min}$ was needed for stoichiometric combustion of $31.55 \mathrm{ml} / \mathrm{min}$ of pure corn oil. Since the primary air was kept constant at $10 \mathrm{l} / \mathrm{min}$, the secondary air flow was adjusted to $280.9 \mathrm{l} / \mathrm{min}$ as shown in Table 35 below.

Similar calculations were done for all the other fuel types at the given equivalence ratios. The table below shows the air and fuel flow rates for all the fuels at all the equivalence ratios. 
Table 35: Air and fuel flow rates for all the combustion experiments

\begin{tabular}{|c|c|c|c|c|c|c|}
\hline Fuel Type & $\begin{array}{c}\text { Equivalence } \\
\text { ratio } \Phi\end{array}$ & $\begin{array}{c}\text { Fuel } \\
\text { Flow } \\
\text { Rate } \\
\text { (mL/min) }\end{array}$ & $\begin{array}{c}\text { Total Air } \\
\text { Required } \\
\text { (L/min) }\end{array}$ & $\begin{array}{l}\text { Primary } \\
\text { Air } \\
\text { Required } \\
\text { (L/min) }\end{array}$ & $\begin{array}{l}\text { Secondary } \\
\text { Air } \\
\text { Required } \\
\text { (L/min) }\end{array}$ & $\begin{array}{l}\text { A:F } \\
\text { ratio }\end{array}$ \\
\hline \multirow{5}{*}{$\begin{array}{l}\text { Fresh } \\
\text { Corn } \\
\text { Oil }\end{array}$} & 0.8 & 31.6 & 363.7 & 10 & 353.7 & 15 \\
\hline & 0.9 & 31.6 & 323.1 & 10 & 313.1 & 13.3 \\
\hline & 1 & 31.6 & 290.9 & 10 & 280.9 & 12 \\
\hline & 1.05 & 31.6 & 277.1 & 10 & 267.1 & 11.4 \\
\hline & 1.1 & 31.6 & 264.4 & 10 & 254.4 & 10.9 \\
\hline \multirow{5}{*}{$\begin{array}{c}\text { Used } \\
\text { Corn Oil } \\
(25 \% \text { TPM })\end{array}$} & 0.8 & 31.6 & 383.7 & 10 & 373.7 & 15.8 \\
\hline & 0.9 & 31.6 & 340.9 & 10 & 330.9 & 14 \\
\hline & 1 & 31.6 & 306.9 & 10 & 296.9 & 12.6 \\
\hline & 1.05 & 31.6 & 292.3 & 10 & 282.3 & 12 \\
\hline & 1.1 & 31.6 & 278.9 & 10 & 268.9 & 11.5 \\
\hline \multirow{5}{*}{ FCO:D50 } & 0.8 & 33.6 & 379 & 10 & 369 & 16.2 \\
\hline & 0.9 & 33.6 & 336.9 & 10 & 326.9 & 14.4 \\
\hline & 1 & 33.6 & 303.1 & 10 & 293.1 & 13 \\
\hline & 1.05 & 33.6 & 288.8 & 10 & 278.8 & 12.4 \\
\hline & 1.1 & 33.6 & 275.4 & 10 & 265.4 & 11.8 \\
\hline \multirow{5}{*}{ FCO:D40 } & 0.8 & 33.7 & 378 & 10 & 368 & 16 \\
\hline & 0.9 & 33.7 & 336.1 & 10 & 326.1 & 14.2 \\
\hline & 1 & 33.7 & 302.5 & 10 & 292.5 & 12.8 \\
\hline & 1.05 & 33.7 & 288.1 & 10 & 278.1 & 12.2 \\
\hline & 1.1 & 33.7 & 274.8 & 10 & 264.8 & 11.6 \\
\hline \multirow{5}{*}{ UCO:D50 } & 0.8 & 32.8 & 372.3 & 10 & 362.3 & 16.5 \\
\hline & 0.9 & 32.8 & 330.9 & 10 & 320.9 & 14.6 \\
\hline & 1 & 32.8 & 297.9 & 10 & 287.9 & 13.2 \\
\hline & 1.05 & 32.8 & 283.8 & 10 & 273.8 & 12.6 \\
\hline & 1.1 & 32.8 & 270.8 & 10 & 260.8 & 12 \\
\hline \multirow{5}{*}{ UCO:D40 } & 0.8 & 33.8 & 383.6 & 10 & 373.6 & 16.2 \\
\hline & 0.9 & 33.8 & 341.1 & 10 & 331.1 & 14.4 \\
\hline & 1 & 33.8 & 307 & 10 & 297 & 13 \\
\hline & 1.05 & 33.8 & 292.3 & 10 & 282.3 & 12.4 \\
\hline & 1.1 & 33.8 & 279.1 & 10 & 269.1 & 11.8 \\
\hline
\end{tabular}


Table 35 (Continued)

\begin{tabular}{|c|c|c|c|c|c|c|}
\hline Fuel Type & $\begin{array}{c}\text { Equivalence } \\
\text { ratio } \Phi\end{array}$ & $\begin{array}{c}\text { Fuel } \\
\text { Flow } \\
\text { Rate } \\
\text { (mL/min) }\end{array}$ & $\begin{array}{c}\text { Total Air } \\
\text { Required } \\
\text { (L/min) }\end{array}$ & $\begin{array}{l}\text { Primary } \\
\text { Air } \\
\text { Required } \\
\text { (L/min) }\end{array}$ & $\begin{array}{c}\text { Secondary } \\
\text { Air } \\
\text { Required } \\
\text { (L/min) }\end{array}$ & $\begin{array}{l}\text { A:F } \\
\text { ratio }\end{array}$ \\
\hline \multirow{5}{*}{ FCO:JF50 } & 0.8 & 33.2 & 383.3 & 10 & 373.3 & 16.7 \\
\hline & 0.9 & 33.2 & 340.7 & 10 & 330.7 & 14.8 \\
\hline & 1 & 33.2 & 306.7 & 10 & 296.7 & 13.3 \\
\hline & 1.05 & 33.2 & 292.2 & 10 & 282.2 & 12.7 \\
\hline & 1.1 & 33.2 & 278.7 & 10 & 268.7 & 12.1 \\
\hline \multirow{5}{*}{ FCO:JF40 } & 0.8 & 33.4 & 381.4 & 10 & 371.4 & 16.3 \\
\hline & 0.9 & 33.4 & 339.2 & 10 & 329.2 & 14.5 \\
\hline & 1 & 33.4 & 305.2 & 10 & 295.2 & 13 \\
\hline & 1.05 & 33.4 & 290.6 & 10 & 280.6 & 12.4 \\
\hline & 1.1 & 33.4 & 277.4 & 10 & 267.4 & 11.8 \\
\hline \multirow{5}{*}{ UCO:JF50 } & 0.8 & 33.5 & 389.3 & 10 & 379.3 & 16.9 \\
\hline & 0.9 & 33.5 & 346.1 & 10 & 336.1 & 15 \\
\hline & 1 & 33.5 & 311.5 & 10 & 301.5 & 13.5 \\
\hline & 1.05 & 33.5 & 296.6 & 10 & 286.6 & 12.9 \\
\hline & 1.1 & 33.5 & 283.2 & 10 & 273.2 & 12.3 \\
\hline \multirow{5}{*}{ UCO:JF40 } & 0.8 & 33.7 & 388.7 & 10 & 378.7 & 16.6 \\
\hline & 0.9 & 33.7 & 345.5 & 10 & 335.5 & 14.7 \\
\hline & 1 & 33.7 & 311 & 10 & 301 & 13.3 \\
\hline & 1.05 & 33.7 & 296.2 & 10 & 286.2 & 12.6 \\
\hline & 1.1 & 33.7 & 282.6 & 10 & 272.6 & 12.1 \\
\hline
\end{tabular}

\subsection{Combustion Emissions}

The results for the emissions of the corn oils and blends in the combustion experiments were obtained using the ENERAC Model 3000E Emissions Analyzer. Data for $\mathrm{NO}_{\mathrm{x}}\left(\mathrm{NO}+\mathrm{NO}_{2}\right), \mathrm{CO}, \mathrm{CO}_{2}$, and exhaust $\mathrm{O}_{2}$ were collected at different equivalence ratios. 
It was observed that for fresh corn oil, an excessive amount of soot was produced at all equivalence ratios. This soot blocked the sintered filter on the analyzer probe, as seen in Figure 35 below. The same observation was made for UCO:D50 at swirl number (SN) of 1.0. Moreover, the $\mathrm{CO}$ emissions were very high for most of the fuel blends towards the richer side. Therefore, for safety purposes and for protecting the integrity of the analyzer, emissions data was not collected for the aforementioned two fuels. Also, data for $\mathrm{CO}$ and $\mathrm{NO}_{\mathrm{x}}$ emissions at equivalence ratios greater than 1 were not collected for all the fuels since soot formation was prevalent in those cases.

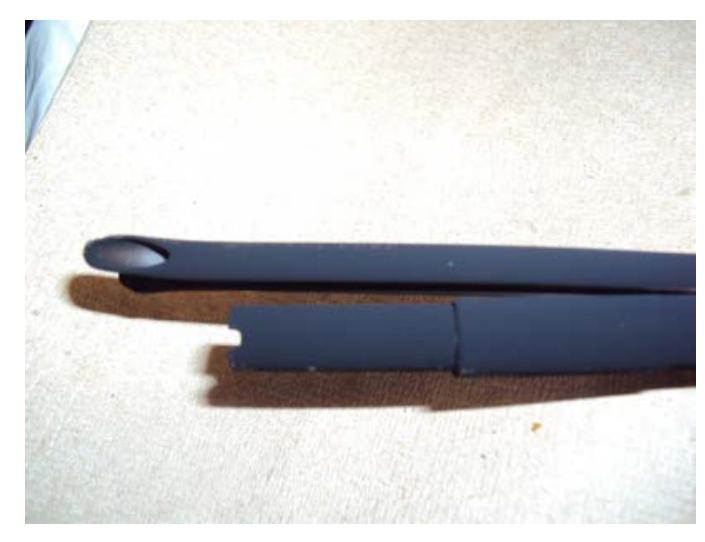

Figure 35: Soot formed on the sintered filter of analyzer probe

Thus used corn oil was selected as the parent fuel instead of fresh corn oil. The corresponding fuel blends were made and tested in the combustion chamber using used corn oil. Combustion emissions of UCO:D50 and UCO:D40 were first compared with each other. The composition showing lower emissions was chosen to make the other two 
blends, viz. the blend with fresh corn oil and diesel, and the blend with used corn oil and jet fuel.

Detailed explanations of emission results are described in the following paragraphs.

\subsection{1 $\mathrm{NO}_{\mathrm{x}}$ Emissions}

There are three main types of $\mathrm{NO}_{\mathrm{x}}$ formation mechanisms: Thermal $\mathrm{NO}_{\mathrm{x}}$, Prompt $\mathrm{NO}_{\mathrm{x}}$, and Fuel $\mathrm{NO}_{\mathrm{x}}$ mechanisms. Since all the fuels in this study were almost nitrogenfree, the assumption was made that $\mathrm{NO}_{\mathrm{x}}$ formation was mainly due to the first two mechanisms.

Thermal $\mathrm{NO}_{\mathrm{x}}$ is formed by the oxidation of molecular nitrogen in the atmosphere. $\mathrm{NO}_{\mathrm{x}}$ formed via this mechanism is very temperature-sensitive and is mainly formed between $1600{ }^{\circ} \mathrm{C}$ to $1900{ }^{\circ} \mathrm{C}$. This is because the strong triple bond between the atmospheric nitrogen atoms can be broken only at elevated temperatures and are eventually oxidized to thermal $\mathrm{NO}_{\mathrm{x}}[45]$. 
The Prompt $\mathrm{NO}_{\mathrm{x}}$ mechanism, which takes place at lower temperatures, involves hydrocarbons reacting with molecular nitrogen in air to rapidly form $\mathrm{NO}_{\mathrm{x}}$, via the formation of intermediate products like $\mathrm{HCN}$ and $\mathrm{NH}$. This type of $\mathrm{NO}_{\mathrm{x}}$ is observed in the flame front of the combustion flame. Prompt $\mathrm{NO}_{\mathrm{x}}$ formation is also independent of temperature, mixture ratio, and residence time [45].

Soot formation was observed in some of the experiments as the combustion mixture went from lean towards rich conditions. This soot caused some of the $\mathrm{NO}_{\mathrm{x}}$ to react with it to form $\mathrm{CO}$, which could partly explain the downward trend of $\mathrm{NO}_{\mathrm{x}}$ for a few of the fuel blends. This is due to the reduction reaction of $\mathrm{NO}$ and $\mathrm{C}$ to $\mathrm{CO}[44,45]$. This mechanism is explained in more detail in Section 2.15. During the combustion experiments, soot formation was validated when the sintered filter got blocked due to excessive soot. Table 36 depicts this soot formation in terms of whether or not the filter got blocked. The temperatures of the emission gases at the outlet port are also shown in this table.

Table 36 shows the values $\mathrm{NO}_{\mathrm{x}}$ emissions recorded during the combustion experiments of all the fuels. 
Table 36: $\mathrm{NO}_{\mathrm{x}}$ emissions for all fuels at both swirl numbers

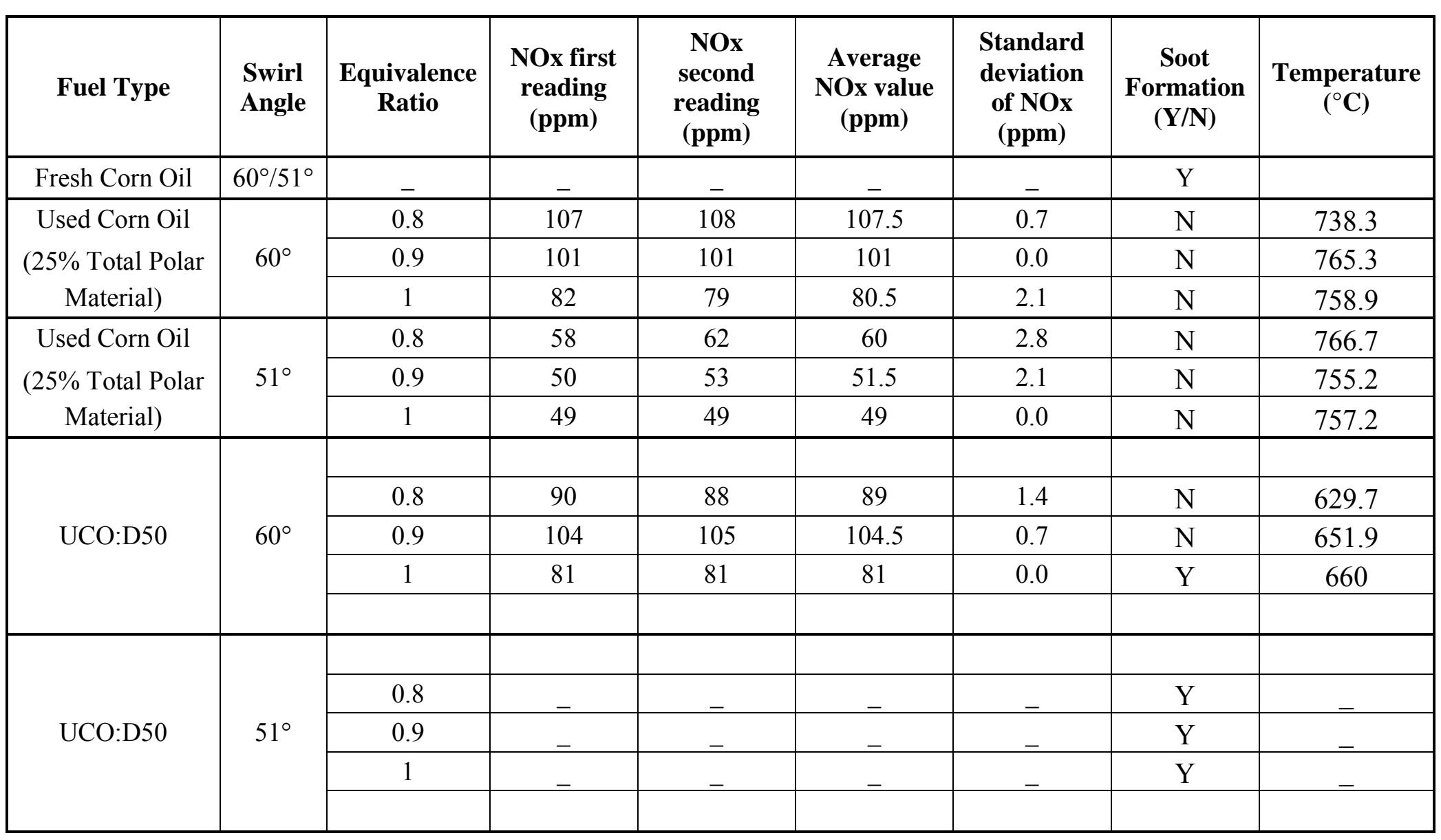


Table 36 (Continued)

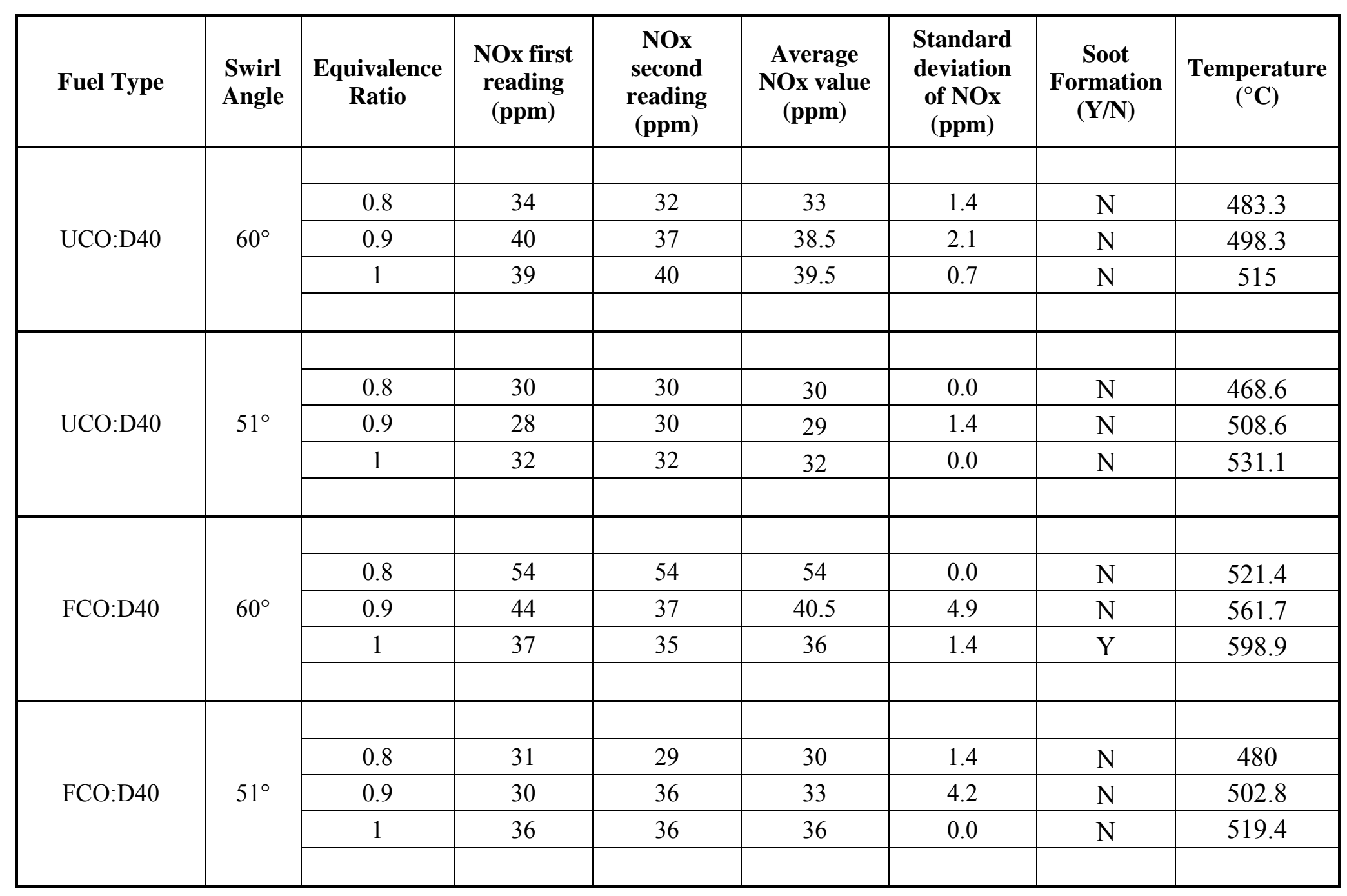


Table 36 (Continued)

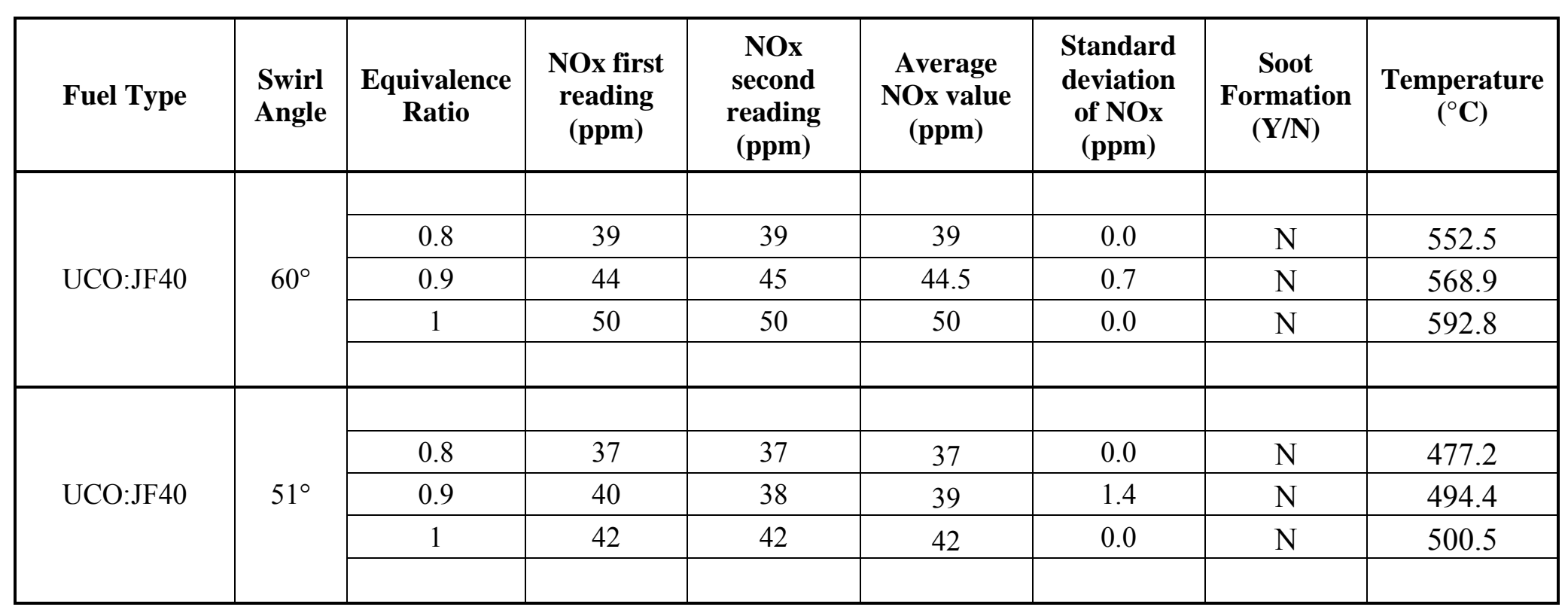




\subsubsection{Effect of Equivalence Ratio on $\mathrm{NO}_{x}$ Emissions}

As seen in Figure 36, $\mathrm{NO}_{\mathrm{x}}$ values for used corn oil show a decreasing trend for both swirl numbers, but the range of $\mathrm{NO}_{\mathrm{x}}$ values for swirl number (SN) of 1.4 is much higher than for swirl number (SN) of 1.0. Since temperatures were well below $1600{ }^{\circ} \mathrm{C}$, it can be hypothesized that the Prompt $\mathrm{NO}_{\mathrm{x}}$ mechanism was much more dominant than the Thermal $\mathrm{NO}_{\mathrm{x}}$ mechanism. Also, since the maximum temperatures reached at both swirl numbers were almost the same, one can eliminate the fact that temperature had a major role in the large difference in $\mathrm{NO}_{\mathrm{x}}$ levels for both cases.

Figure 36 show that more $\mathrm{NO}_{\mathrm{x}}$ was produced at very lean conditions compared to stoichiometric conditions. It can be suggested that the presence of excess air at very lean conditions enabled more nitrogen to react with hydrocarbon groups to form $\mathrm{NO}_{\mathrm{x}}$ via the Prompt $\mathrm{NO}_{\mathrm{x}}$ mechanism. More importantly, $\mathrm{NO}_{\mathrm{x}}$ formation is higher at lower equivalence ratios due to availability of oxygen and high combustion temperatures. Ishak et al. [35] also observed a decrease in $\mathrm{NO}_{\mathrm{x}}$ for their diesel experiments from equivalence ratio 0.83 to 1.2. Mafra et al. [34], however, found opposing $\mathrm{NO}_{\mathrm{x}}$ trends in their LPG combustion experiments, when they went from richer towards leaner combustion. They found that $\mathrm{NO}_{\mathrm{x}}$ was lesser at lower equivalence ratios. The difference between the results presented by Ishak et al. [35] and Mafra et al. [24] can be attributed to the much lower $\mathrm{H} / \mathrm{C}$ ratio of diesel compared to LPG. Fuels with low H/C ratios exhibit pronounced prompt $\mathrm{NO}_{\mathrm{x}}$ mechanisms especially at lower equivalence ratios [45]. Moreover, thermal $\mathrm{NO}_{\mathrm{x}}$ could have played a role at near stoichiometric conditions since 
less secondary air was available to reduce the combustion temperature by convection heat transfer.

Figure 36 show $\mathrm{NO}_{\mathrm{x}}$ emissions of used corn oil at swirl angles $60^{\circ}(\mathrm{SN}=1.4)$ and $51^{\circ}$ $(\mathrm{SN}=1.0)$, respectively.

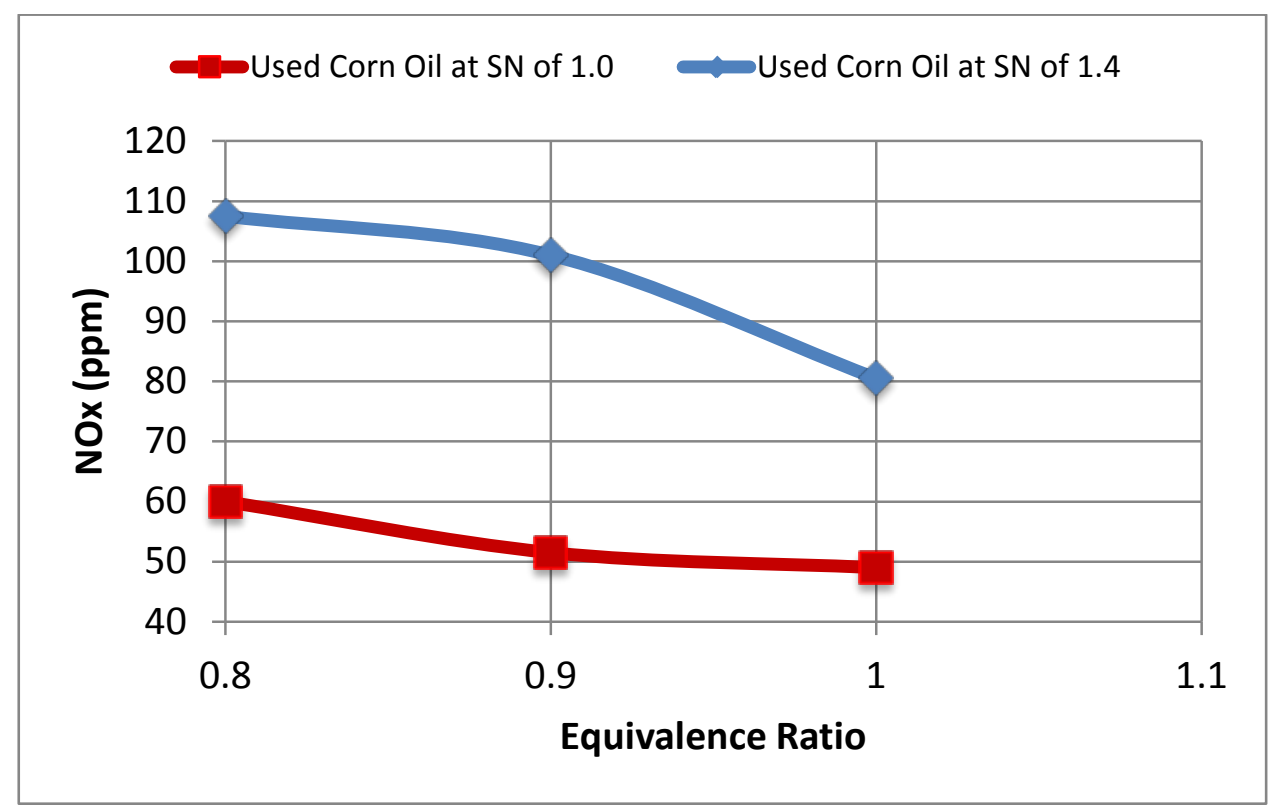

Figure 36: $\mathrm{NO}_{\mathrm{x}}$ emissions for used corn oil at $\mathrm{SN}$ of 1.4 and 1.0 for a constant heat output of $68,620 \mathrm{~kJ} / \mathrm{hr}$

Lower $\mathrm{NO}_{\mathrm{x}}$ production at higher equivalence ratios could also be explained by the Reverse Prompt $\mathrm{NO}_{\mathrm{x}}$ mechanism. This involved the reaction of hydrogen cyanide $(\mathrm{HCN})$ and ammonia $\left(\mathrm{NH}_{3}\right)$ with $\mathrm{NO}$, thereby converting $\mathrm{NO}_{\mathrm{x}}$ back to molecular nitrogen $\left(\mathrm{N}_{2}\right)$ [57]. The effect of swirl number on NOx emission is discussed in the following Section

\subsubsection{3.}


Figure 37 shows the $\mathrm{NO}_{\mathrm{x}}$ emission comparison between UCO:D50 and UCO:D40 at a SN of 1.4. For UCO:D50, a lot of soot was formed at equivalence ratio of 0.9 or higher compared to UCO:D40. UCO:D50 also exhibited a substantial drop in NOx levels which can be attributed to $\mathrm{NO}_{\mathrm{x}}$ reacting with soot as suggested by Cooper et al. [44]. Wagner et al. [58] also hypothesized that soot formed during the combustion process increases with increasing local equivalence ratio.

Based on the $\mathrm{NO}_{\mathrm{x}}$ emissions for the first two blends, $40 \%$ diesel was used in the remaining blends, since a higher content of diesel results in greater NOx levels.

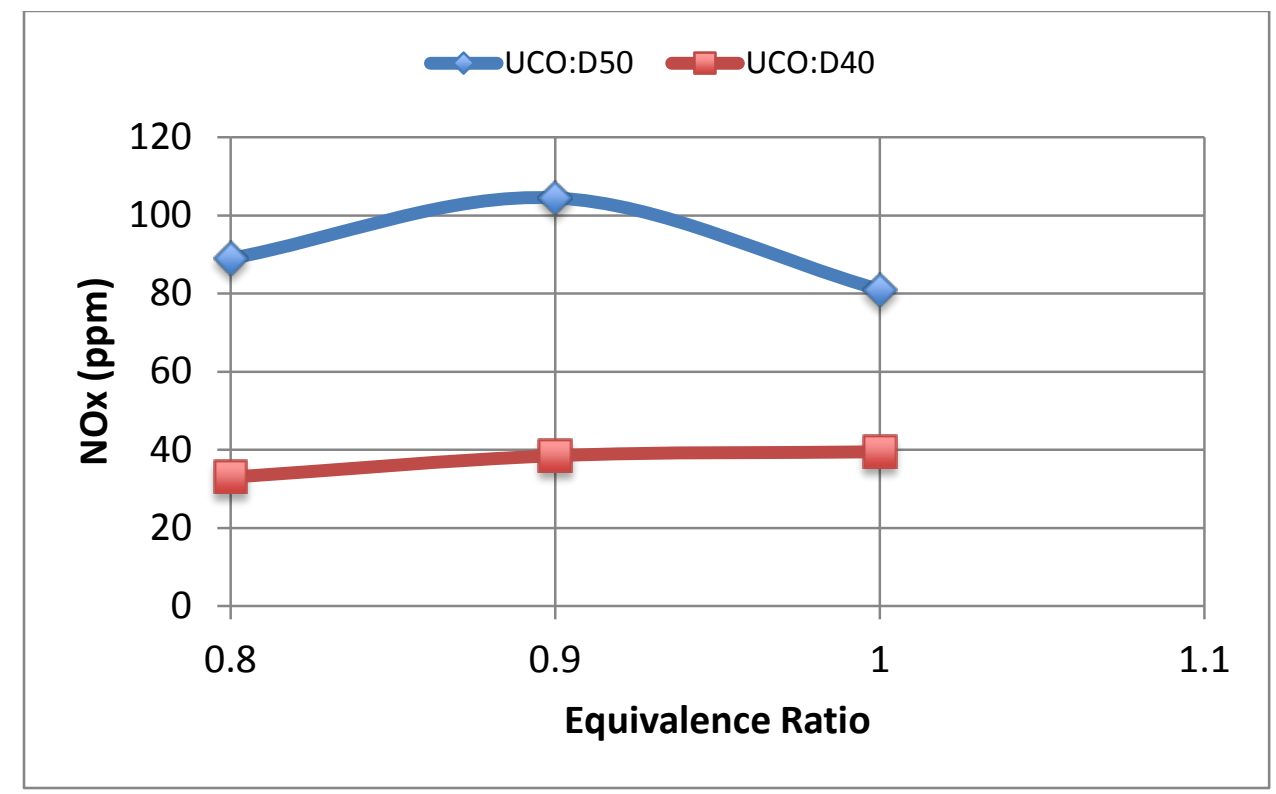

Figure 37: $\mathrm{NO}_{\mathrm{x}}$ emissions for UCO:D50 and UCO:D40 at SN of 1.4, at a constant heat output of $68,620 \mathrm{~kJ} / \mathrm{hr}$ 
Figure 38 and 39 show the $\mathrm{NO}_{\mathrm{x}}$ emission comparison of UCO:D40, FCO:D40, and UCO:JF40 at SN of 1.4 and SN of 1.0 respectively. At both swirl angles, UCO:JF40 showed a similar increasing trend as UCO:D40 with respect to equivalence ratio. Based on the findings of Mafra et al. [34], it can be suggested that there was significant heat loss to the excess of unreacted oxygen (and nitrogen) at low equivalence ratios (i.e. more air), which caused temperatures and $\mathrm{NO}_{\mathrm{x}}$ levels to be lower at leaner conditions for these blends due in part to convective heat transfer. Soot formation was observed in FCO:D40 when SN was 1.4 which can be attributed to the high level of unsaturation in fresh corn oil in the blend. This soot in turn reacted with $\mathrm{NO}_{\mathrm{x}}$ via the $\mathrm{NO}_{\mathrm{x}}$-soot mechanism, thereby validating the downward trend of $\mathrm{NO}_{\mathrm{x}}$ as in this case [44].

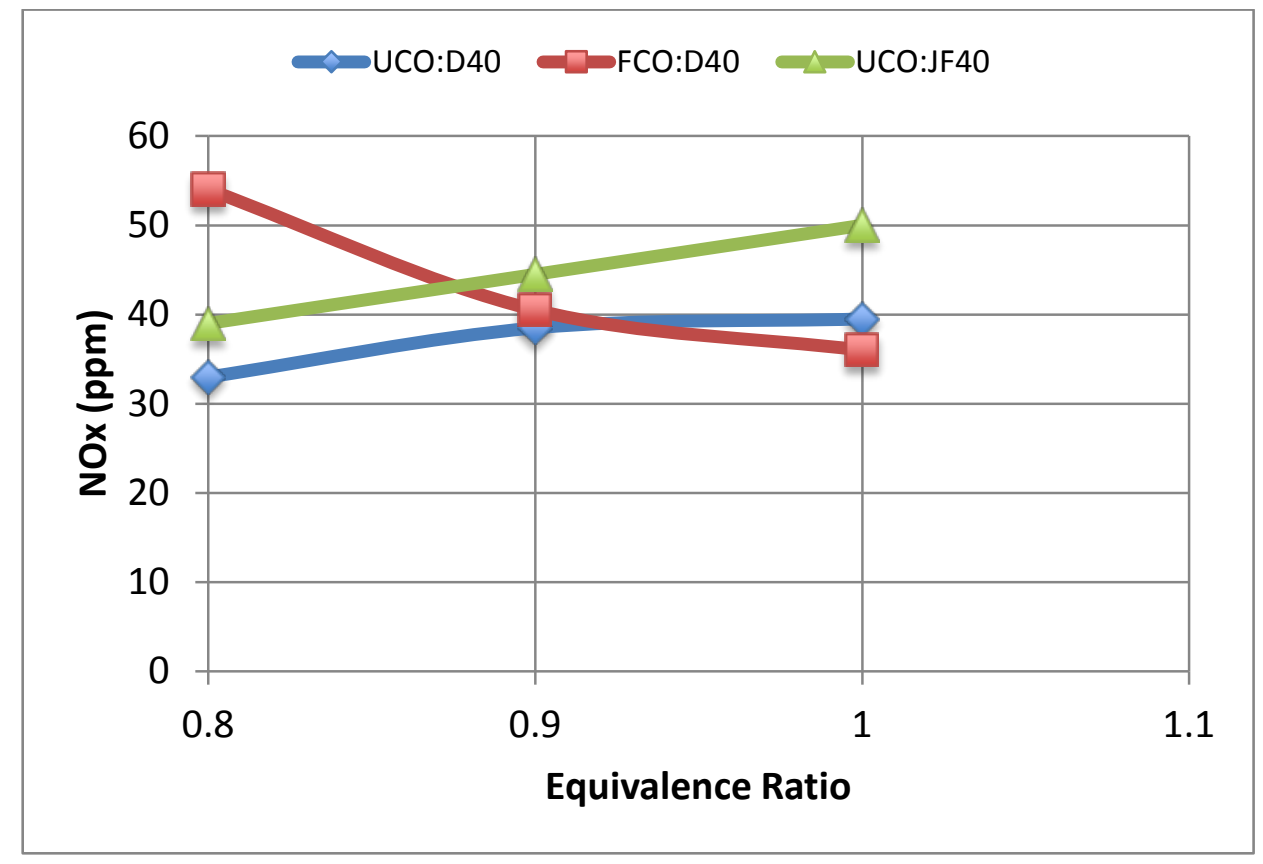

Figure 38: $\mathrm{NO}_{\mathrm{x}}$ emissions for UCO:D40, FCO:D40, and UCO:JF40 at SN of 1.4, at constant heat output of $68,620 \mathrm{~kJ} / \mathrm{hr}$ 


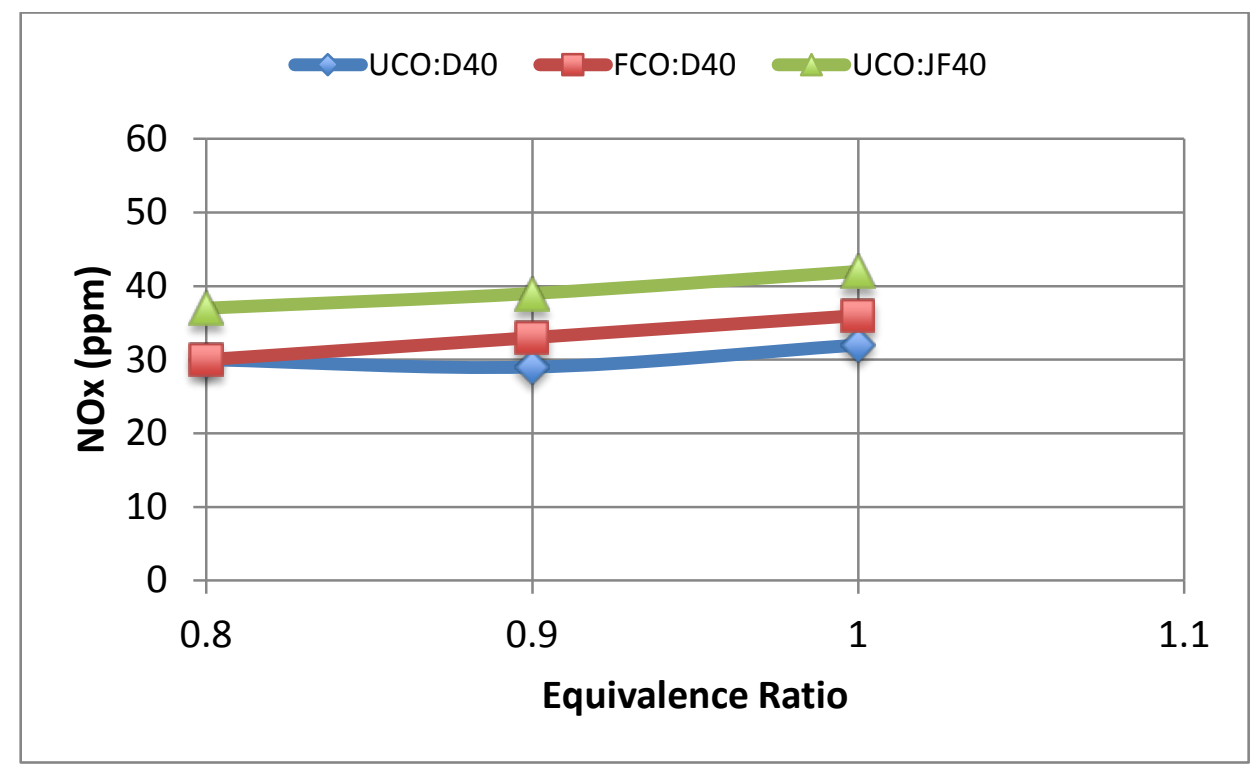

Figure 39: $\mathrm{NO}_{\mathrm{x}}$ emissions for UCO:D40, FCO:D40, and UCO:JF40 at SN of 1.0, at constant heat output of $68,620 \mathrm{~kJ} / \mathrm{hr}$

\subsubsection{Effect of Fuel Type on $\mathrm{NO}_{x}$ Emissions}

The effect of fuel composition on NOx emission was also undertaken as part of the study. Experimental data suggest that the $\mathrm{H} / \mathrm{C}$ ratio in the blends shown in Table 33 played a decisive role in NOx formation as seen in Table 36. The data support the notion that the Prompt $\mathrm{NO}_{\mathrm{x}}$ mechanism [45] was mainly responsible for NOx formation. Predictably, higher $\mathrm{NO}_{\mathrm{x}}$ levels were observed for used corn oil than the blends, as seen in Figures 36-39.

The addition of alcohols such as n-butanol and ethanol-95 to the blends contributed to their very low emissions as well, compared to used corn oil. Rakopoulos et al. [59] used a multi-zone combustion model to understand the behavior of ethanol-diesel fuel blends. Rakopoulos et al. [59] found that NO emissions for the blends were lower than 
those for pure diesel. Similarly, higher $\mathrm{H} / \mathrm{C}$ ratios of the blends compared to pure diesel could have been a contributing factor to lower prompt NO levels [45].

Figure 37 shows that UCO:D40 had lower $\mathrm{NO}_{\mathrm{x}}$ emissions compared to UCO:D50 at SN of 1.4. Table 35 shows that temperatures were higher for UCO:D50 (by about 150 $\left.{ }^{\circ} \mathrm{C}\right)$ than for UCO:D40. This was caused by the larger amount of diesel in UCO:D50, which has a much higher heating value compared to the other components. These higher temperatures could have evoked higher $\mathrm{NO}_{\mathrm{x}}$ emissions for UCO:D50 via the thermal NOx mechanism route, in addition to the Prompt NOx [45] mechanism. Ban-Weiss et al. [4] also observed higher $\mathrm{NO}_{\mathrm{x}}$ formation at higher temperatures while burning biodiesel.

The higher percentage of oxygen in fresh corn oil than used corn oil might explain the downward trend of $\mathrm{NO}_{\mathrm{x}}$ in FCO:D40 as seen in Figure 38. This effect disappears as the swirl angle is reduced due to poorer air-fuel mixing, causing $\mathrm{NO}_{\mathrm{x}}$ to increase with equivalence ratio as seen in Figure 39. However, higher soot formation for the same fuel at $\mathrm{SN}$ of 1.4 seems to be the dominating factor due to the high degree of unsaturation of fresh corn oil. The soot in turn most likely reacted with $\mathrm{NO}_{\mathrm{x}}$ via $\mathrm{NO}_{\mathrm{x}}$-soot mechanism [44]. Puhan et al. [43] found higher soot formation for highly unsaturated linseed oil methyl ester compared to the saturated coconut oil methyl ester. These arguments further support the downward trend of $\mathrm{NO}_{\mathrm{x}}$ levels for FCO:D40 at SN of 1.4.

For UCO:D40 and UCO:JF40, it is observed in Figures 38 and 39 that the jet fuel blend has slightly higher $\mathrm{NO}_{\mathrm{x}}$ values than those of the diesel blend. This could be attributed to the slightly higher temperatures reached by UCO:JF40, owing to its higher heating value compared to diesel (see temperature graphs in Section 6.3.6). Jayakumar et 
al. [60] reported that $\mathrm{NO}_{\mathrm{x}}$ emissions increase for JP-8 fuel due to elevated peak temperatures achieved. The tests were performed in a single-cylinder diesel engine, wherein $\mathrm{NO}_{\mathrm{x}}$ formation was strongly dependent on local combustion temperatures. Venkanna et al. [61] conducted tests of neat diesel fuel, kerosene (jet fuel), and honne oil blends in a DI diesel engine. It was observed that $\mathrm{NO}_{\mathrm{x}}$ levels were higher for the kerosene-honne oil blends compared to the diesel-honne oil blends. These findings further support the $\mathrm{NO}_{\mathrm{x}}$ results obtained for the blends in this study.

McCormick et al. [62] discovered a direct correlation between the number of double bonds (measured by iodine value) in biodiesels and $\mathrm{NO}_{\mathrm{x}}$ emissions. They found that as the number of double bonds increased, $\mathrm{NO}_{\mathrm{x}}$ levels increased. This could explain why, especially at leaner conditions, the fresh corn oil component of FCO:D40 caused the $\mathrm{NO}_{\mathrm{x}}$ emissions to be slightly higher than the $\mathrm{NO}_{\mathrm{x}}$ emissions of UCO:D40 (Figures 38 and 39). Fresh corn oil has more number of double bonds than used corn oil. One of the major chemical changes that corn oil undergoes when it is heated or oxidized is a decrease in the number of double bonds (or a decrease in the degree of unsaturation). This is evident from the Figure 32 in Section 6.1.4.2, which shows that the decrease in the degree of unsaturation from fresh to used corn oil is measured by a corresponding decrease in iodine value.

Saravanan et al. [63] reported a direct effect of free fatty acids (FFA) present in crude rice bran oil $(\mathrm{CRBO})$ on $\mathrm{NO}_{\mathrm{x}}$ emissions. Out of a series of tests on three samples of CRBO blends with diesel, each having progressively higher FFA content, it was observed that $\mathrm{NO}_{\mathrm{x}}$ emissions were the least for the CRBO blend having the highest FFA. 
A similar theory can be applied in this study as well. It is evident from Figures 38 and 39 that UCO:D40 has $\mathrm{NO}_{\mathrm{x}}$ levels slightly lower than those of FCO:D40. This is due to the fact that the FFA content in fresh corn oil is lesser than in used corn oil, as illustrated in Figure 33 in Section 6.1.4.3.

Knowledge about chain lengths and molecular structures of the fuel blend components, and how they factor in with regards to $\mathrm{NO}_{\mathrm{x}}$ emissions is also needed to understand more clearly the effect of fuel type on these emissions.

\subsubsection{Effect of Swirl Number on $\mathrm{NO}_{x}$ Emissions}

From Figures 40 to 42 , a common observation is made with regards to the $\mathrm{NO}_{\mathrm{x}}$ emission levels. It was observed that $\mathrm{NO}_{\mathrm{x}}$ was higher at $\mathrm{SN}$ of 1.4 compared to $\mathrm{SN}$ of 1.0. $\mathrm{NO}_{\mathrm{x}}$ emissions for used corn oil were much more sensitive to a change in swirl angle than in the blends. Habib et al. [64] observed a decrease in $\mathrm{NO}_{\mathrm{x}}$ emissions as the swirl angle increased $30^{\circ}$ to $45^{\circ}$, in their fuel gas industrial boiler experiments. However, results showed that a further increase in the swirl angle beyond $45^{\circ}$ increased the $\mathrm{NO}_{\mathrm{x}}$ emissions, due to more turbulent mixing of fuel and air which caused an increase in the maximum temperature of the furnace. This can validate the observations made above, but only with the assumption that thermal $\mathrm{NO}_{\mathrm{x}}$ played a major role. Jayakumar et al. [60] also reported an increase in $\mathrm{NO}_{\mathrm{x}}$ emissions with an increase in swirl when studying $\mathrm{JP}-8$ fuel combustion, performance, and emissions in a 1-cylinder diesel engine. This was due to an improved premixed combustion fraction at higher swirl angles, which produced 
higher peak temperatures in the flame. Further tests at a higher pair of swirl angles might be required in order to get data more consistent with the classical literature.

Among the blends, FCO:D40 was the only fuel showing a downward trend in $\mathrm{NO}_{\mathrm{x}}$ at SN of 1.4 , most probably due to the soot produced from the fresh corn oil component of the blend reacting with $\mathrm{NO}_{\mathrm{x}}[44]$.

Figures 40, 41 and 42 show the comparison of UCO:D40, FCO:D40, and UCO:JF40 at the two swirl angles.

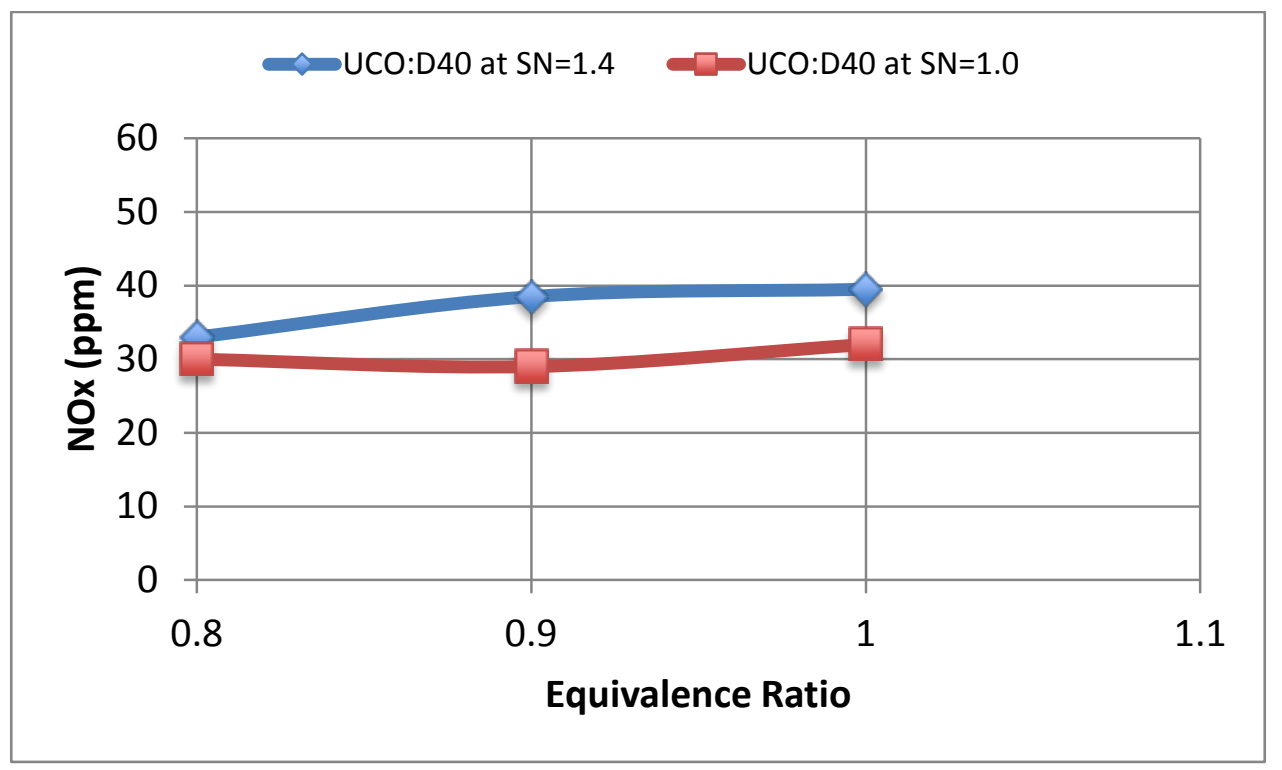

Figure 40: $\mathrm{NO}_{\mathrm{x}}$ emissions for UCO:D40 at $\mathrm{SN}$ of 1.0 and 1.4, at constant heat output of $68,620 \mathrm{~kJ} / \mathrm{hr}$ 


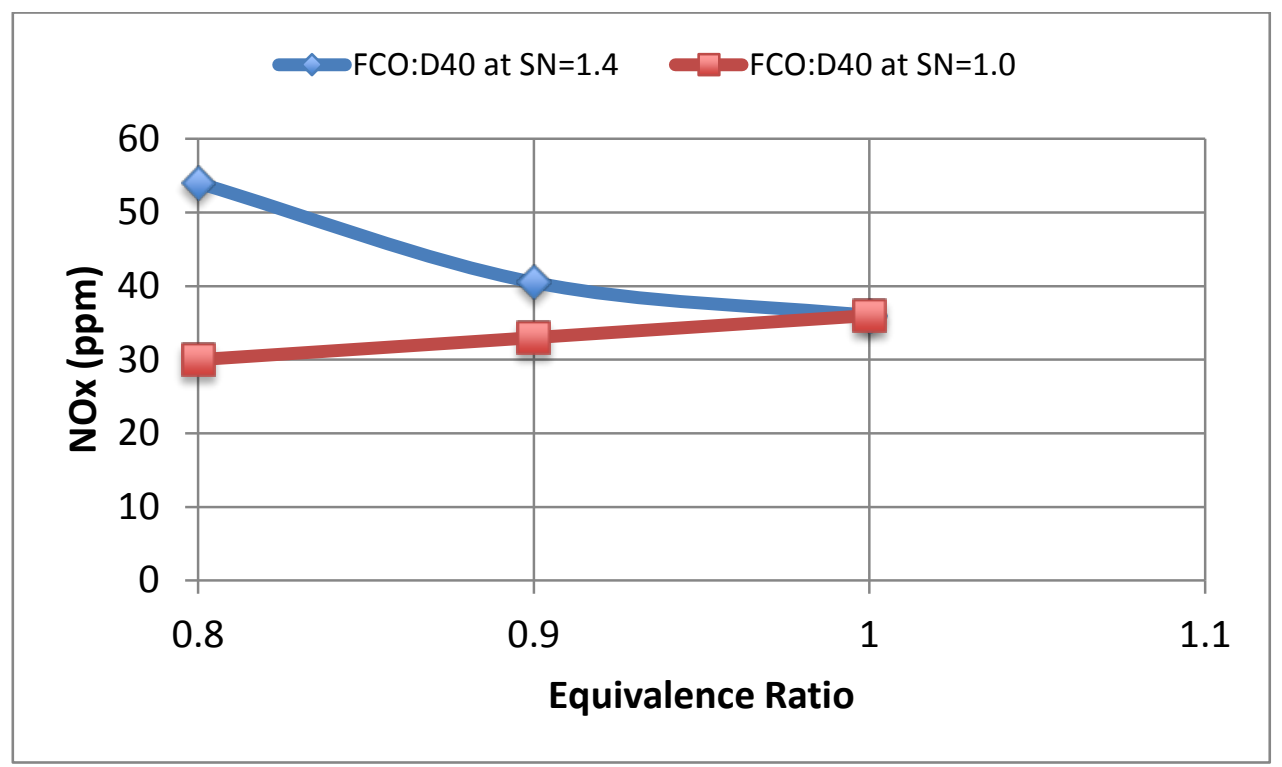

Figure 41: $\mathrm{NO}_{\mathrm{x}}$ emissions for FCO:D40 at $\mathrm{SN}$ of 1.0 and 1.4, at constant heat output of $68,620 \mathrm{~kJ} / \mathrm{hr}$

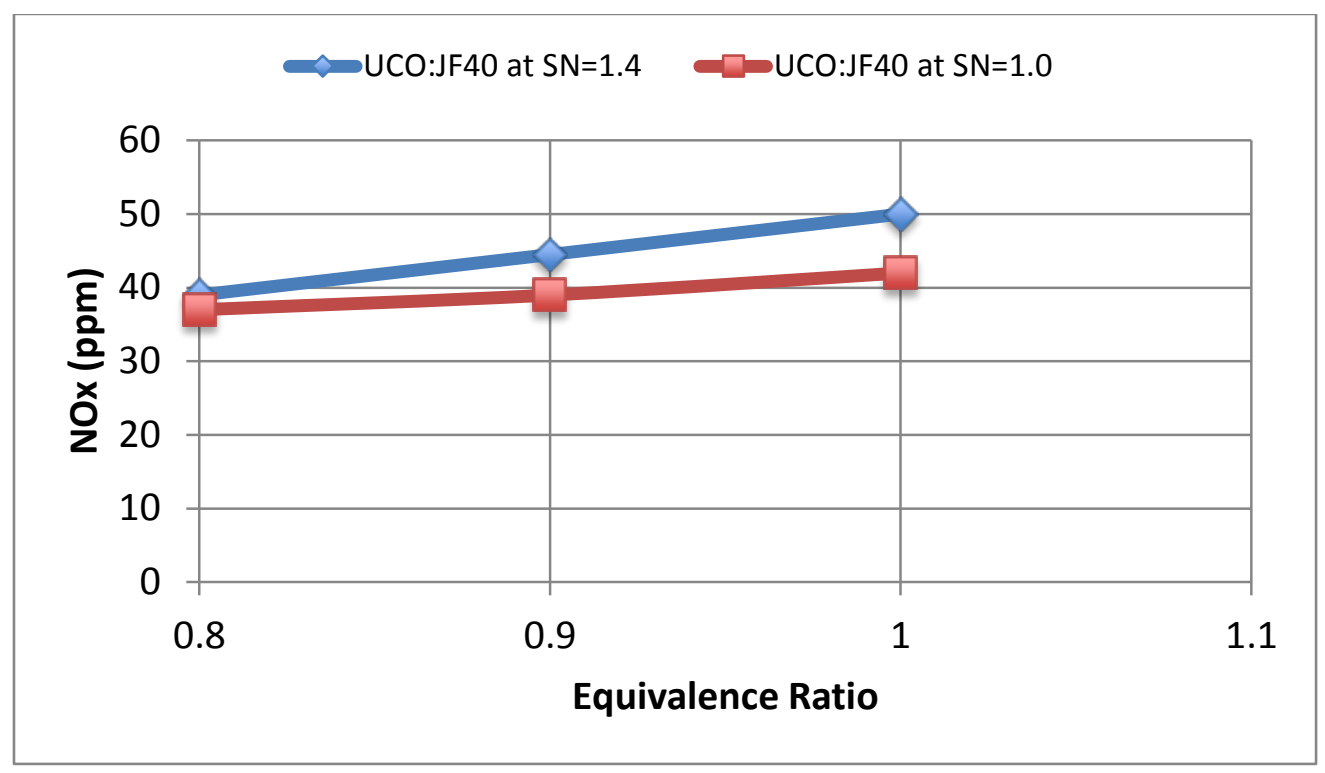

Figure 42: $\mathrm{NO}_{\mathrm{x}}$ emissions for UCO:JF40 at SN of 1.0 and 1.4, at constant heat output of $68,620 \mathrm{~kJ} / \mathrm{hr}$ 


\subsection{2 $\mathrm{NO}_{\mathrm{x}}$ Emissions Corrected for 3\% Oxygen in the Exhaust}

It is general practice that the amount of $\mathrm{NO}$ emitted from a combustion process be normalized by the quantity of $\mathrm{O}_{2}$ provided to the combustion chamber. In fact, if the amount of $\mathrm{NO}_{\mathrm{x}}$ formed during a combustion process is kept constant, then one can reduce the $\mathrm{NO}_{\mathrm{x}}(\mathrm{ppm})$ by supplying excess air to the chamber [45]. For low excess air applications, like in power utilities, the standard oxygen mole fraction is 0.03 , or $3 \%$. The corrected NO mole fraction is determined using this value and using the following equation [45]:

$\frac{\mathrm{X}_{\mathrm{NO}, \mathrm{std}}}{\mathrm{X}_{\mathrm{NO}}}=\frac{\mathrm{X}_{02, \mathrm{a}}-\mathrm{X}_{02, \mathrm{std}}}{\mathrm{X}_{02, \mathrm{a}}-\mathrm{X}_{02}}$

where,

$\mathrm{X}_{\mathrm{NO}, \text { std }}=$ corrected $\mathrm{NO}$ mole fraction at standard oxygen mole fraction (ppm)

$\mathrm{X}_{\mathrm{NO}}=$ uncorrected $\mathrm{NO}$ mole fraction at oxygen mole fraction $(\mathrm{ppm})$

$\mathrm{X}_{\mathrm{O} 2, \mathrm{a}}=$ ambient oxygen mole fraction $=0.21$

$\mathrm{X}_{\mathrm{O} 2 \text {,std }}=$ standard oxygen mole fraction $=3 \%$ or 0.03 mole fraction

$\mathrm{X}_{\mathrm{O} 2}=$ measured oxygen mole fraction in the exhaust gas stream

Table 37 shows the $\mathrm{NO}_{\mathrm{x}}$ emissions corrected to $3 \% \mathrm{O}_{2}$ in the exhaust. It is observed that at lean conditions, $\mathrm{NO}_{\mathrm{x}}$ emissions decreased slightly for the used corn oil but increased in case of the fuel blends. This is due to the fact that the actual emissions recorded at the time of the experiment (before applying the correction factor) were at less than $3 \% \mathrm{O}_{2}$ in the case of used corn oil, and more than $3 \% \mathrm{O}_{2}$ for the fuel blends. 
Table 37: $\mathrm{NO}_{\mathrm{x}}$ emissions corrected to $3 \% \mathrm{O}_{2}$ in the exhaust stream

\begin{tabular}{|c|c|c|c|c|}
\hline Fuel Type & $\begin{array}{l}\text { Swirl } \\
\text { Angle }\end{array}$ & $\begin{array}{c}\text { Equivalence } \\
\text { Ratio }\end{array}$ & $\begin{array}{l}\text { Average } \\
\text { NOx value } \\
\text { (ppm) }\end{array}$ & $\begin{array}{l}\text { NOx mole fraction } \\
\text { corrected to } 3 \% \text { oxygen } \\
\text { in exhaust }\end{array}$ \\
\hline Fresh Corn Oil & $60^{\circ} / 51^{\circ}$ & _ & _- & \\
\hline \multirow{3}{*}{$\begin{array}{c}\text { Used Corn Oil } \\
\text { (25\% Total Polar } \\
\text { Material) }\end{array}$} & \multirow{3}{*}{$60^{\circ}$} & 0.8 & 107.5 & 105.45 \\
\hline & & 0.9 & 101 & 89.34 \\
\hline & & 1 & 80.5 & 69.50 \\
\hline \multirow{3}{*}{$\begin{array}{c}\text { Used Corn Oil } \\
\text { (25\% Total Polar } \\
\text { Material) }\end{array}$} & \multirow{3}{*}{$51^{\circ}$} & 0.8 & 60 & 52.30 \\
\hline & & 0.9 & 51.5 & 44.14 \\
\hline & & 1 & 49 & 42 \\
\hline \multirow{3}{*}{ UCO:D50 } & \multirow{3}{*}{$60^{\circ}$} & 0.8 & 89 & 91.28 \\
\hline & & 0.9 & 104.5 & 100.59 \\
\hline & & 1 & 81 & 75.94 \\
\hline \multirow{4}{*}{ UCO:D50 } & \multirow{4}{*}{$51^{\circ}$} & & & \\
\hline & & 0.8 & - & - \\
\hline & & 0.9 & - & - \\
\hline & & 1 & _ & _ \\
\hline & \multirow{4}{*}{$60^{\circ}$} & & & \\
\hline \multirow{3}{*}{ UCO:D40 } & & 0.8 & 33 & 39.34 \\
\hline & & 0.9 & 38.5 & 41.50 \\
\hline & & 1 & 39.5 & 38.02 \\
\hline & \multirow{5}{*}{$51^{\circ}$} & & & \\
\hline \multirow{4}{*}{ UCO:D40 } & & 0.8 & 30 & 35.64 \\
\hline & & 0.9 & 29 & 30.44 \\
\hline & & 1 & 32 & 31.48 \\
\hline & & & & \\
\hline
\end{tabular}


Table 37 (Continued)

\begin{tabular}{|c|c|c|c|c|}
\hline Fuel Type & $\begin{array}{l}\text { Swirl } \\
\text { Angle }\end{array}$ & $\begin{array}{c}\text { Equivalence } \\
\text { Ratio }\end{array}$ & $\begin{array}{l}\text { Average } \\
\text { NOx value } \\
\text { (ppm) }\end{array}$ & $\begin{array}{c}\text { NOx mole fraction } \\
\text { corrected to } 3 \% \text { oxygen in } \\
\text { exhaust }\end{array}$ \\
\hline \multirow{3}{*}{ FCO:D40 } & \multirow{3}{*}{$60^{\circ}$} & 0.8 & 54 & 62.31 \\
\hline & & 0.9 & 40.5 & 42.63 \\
\hline & & 1 & 36 & 33.23 \\
\hline \multirow{3}{*}{ FCO:D40 } & \multirow{3}{*}{$51^{\circ}$} & 0.8 & 30 & 36.24 \\
\hline & & 0.9 & 33 & 34.14 \\
\hline & & 1 & 36 & 34.84 \\
\hline \multirow{3}{*}{ UCO:JF40 } & \multirow{3}{*}{$60^{\circ}$} & 0.8 & 39 & 42.29 \\
\hline & & 0.9 & 44.5 & 45.51 \\
\hline & & 1 & 50 & 47.87 \\
\hline \multirow{3}{*}{ UCO:JF40 } & \multirow{3}{*}{$51^{\circ}$} & 0.8 & 37 & 46.25 \\
\hline & & 0.9 & 39 & 42.55 \\
\hline & & 1 & 42 & 43.70 \\
\hline
\end{tabular}

Figure 43 shows the plots for $\mathrm{NO}_{\mathrm{x}}$ emissions corrected to $3 \%$ oxygen for used corn oil (at both swirl numbers). Figures 44 and 45 show the same at SN of 1.4 and 1.0, respectively, for the fuel blends. 


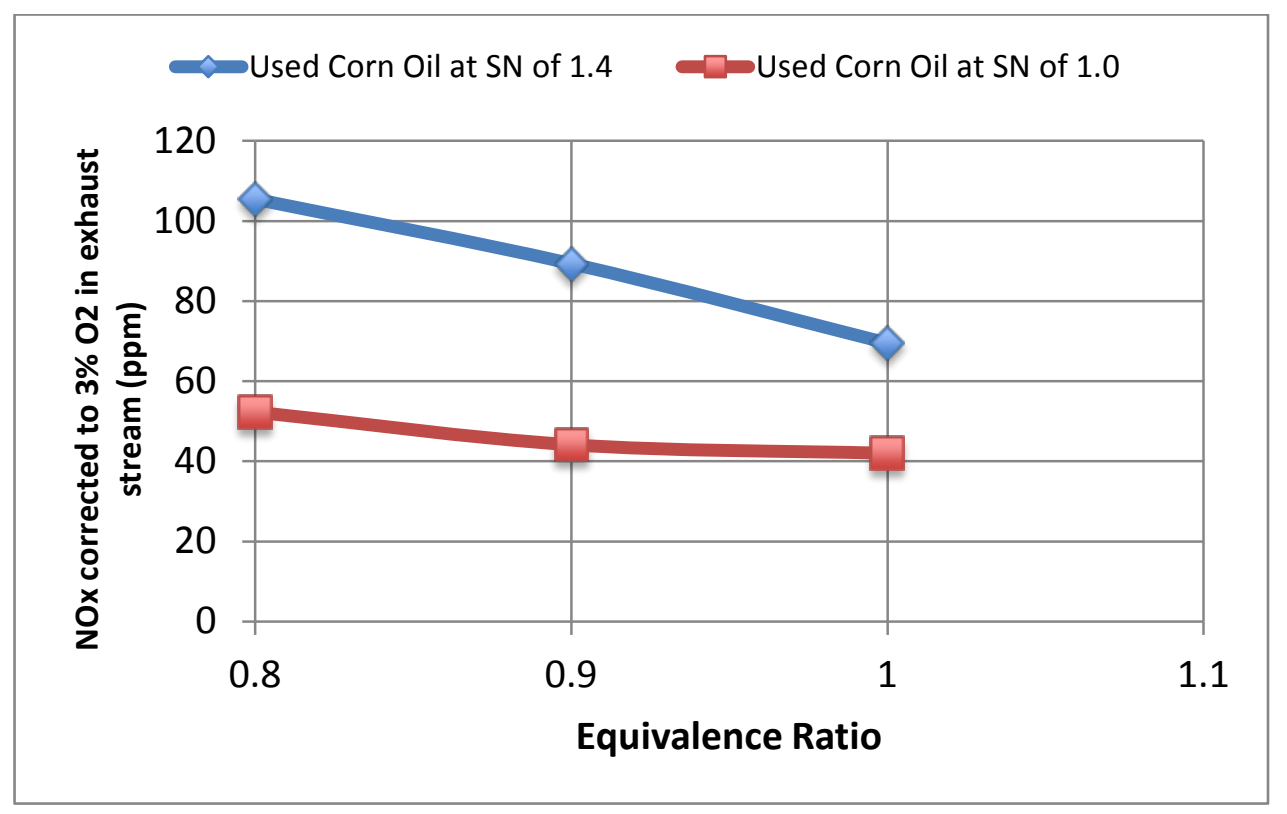

Figure 43: $\mathrm{NO}_{\mathrm{x}}$ emissions, corrected to $3 \% \mathrm{O}_{2}$, for used corn oil at $\mathrm{SN}$ of 1.4 and 1.0, for a constant heat output of $68,620 \mathrm{~kJ} / \mathrm{hr}$

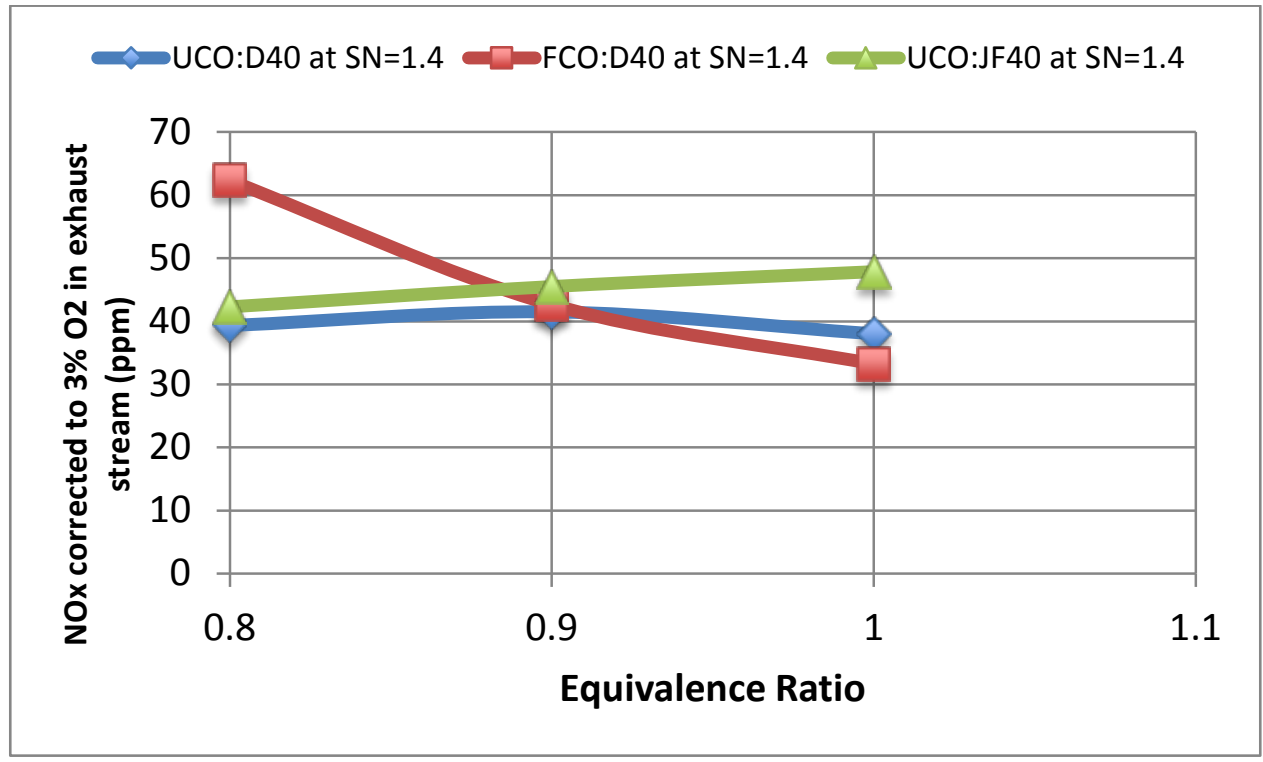

Figure 44: $\mathrm{NO}_{\mathrm{x}}$ emissions, corrected to $3 \% \mathrm{O}_{2}$ for UCO:D40, FCO:D40, and UCO:JF40 at $\mathrm{SN}$ of 1.4 , for a constant heat output of $68,620 \mathrm{~kJ} / \mathrm{hr}$ 


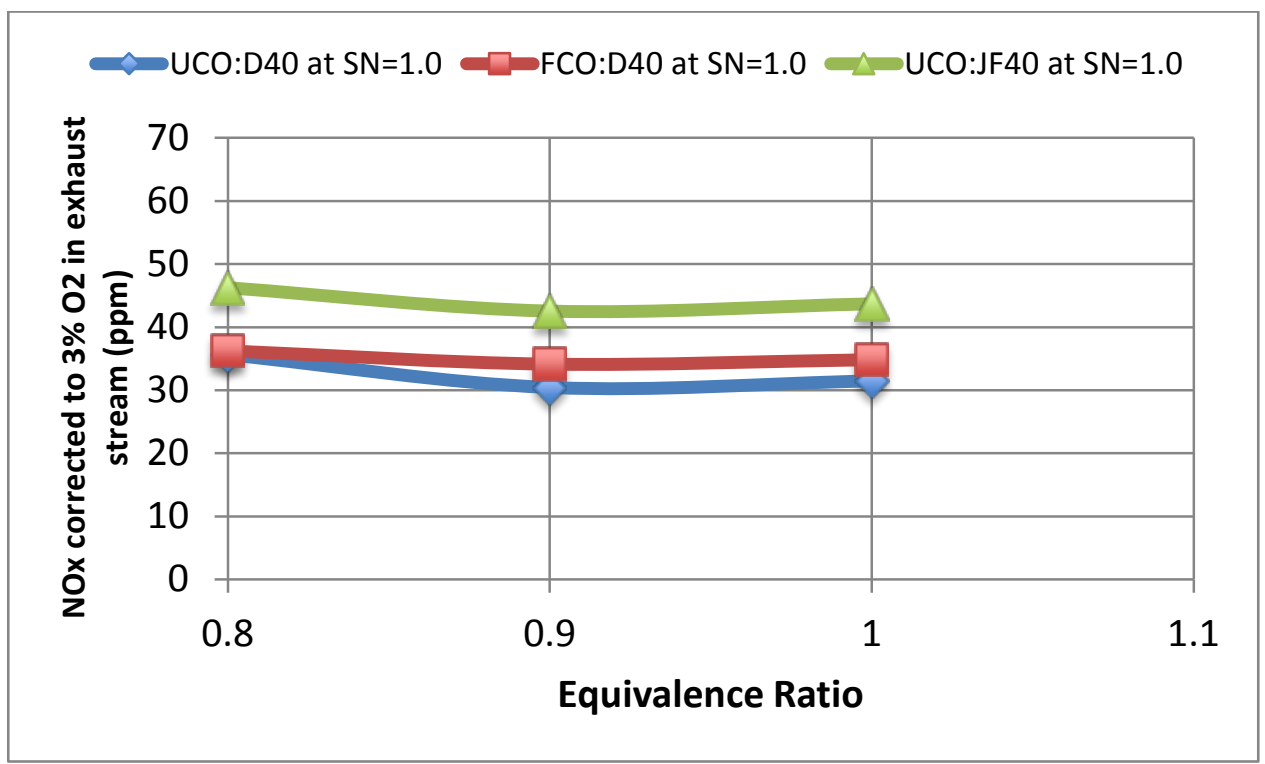

Figure 45: $\mathrm{NO}_{\mathrm{x}}$ emissions, corrected to $3 \% \mathrm{O}_{2}$ for UCO:D40, FCO:D40, and UCO:JF40 at $\mathrm{SN}$ of 1.0 , for a constant heat output of $68,620 \mathrm{~kJ} / \mathrm{hr}$

\subsection{3 $\mathrm{NO}_{x}$ Emissions in Terms of Heat Input ( $\left.\mathrm{g} / \mathrm{GJ}\right)$}

Annamalai et al. [45] suggested that there is another way to prevent $\mathrm{NO}_{\mathrm{x}}$ emission dilution. This involves reporting $\mathrm{NO}_{\mathrm{x}}$ emissions on a heat input basis via the following equation [45]:

NO $\left(\frac{\mathrm{g}}{\mathrm{GJ}}\right)=\frac{\mathrm{c} * \mathrm{X}_{\mathrm{NO}} * \mathrm{M}_{\mathrm{k}} * 1000\left(\frac{\mathrm{g}}{\mathrm{kg}}\right)}{\mathrm{M}_{\mathrm{F}} * \mathrm{HHV}_{\mathrm{F}} *\left(\mathrm{X}_{\mathrm{CO}}+\mathrm{X}_{\mathrm{CO} 2}\right)}$

where,

$c=$ number of carbon atoms in the fuels (empirical formula $\mathrm{C}_{c} \mathrm{H}_{h} \mathrm{O}_{0} \mathrm{~N}_{n} \mathrm{~S}_{\mathrm{s}}$ )

$\mathrm{X}_{\mathrm{NO}}=\mathrm{NO}_{\mathrm{X}}$ dry mole fraction

$\mathrm{M}_{\mathrm{k}}=\mathrm{M}_{\mathrm{NO} 2}=\mathrm{NO}_{2}$ molecular weight $(\mathrm{kg} / \mathrm{kmol})$ 
$\mathrm{M}_{\mathrm{F}}=$ molecular weight of fuel

$\mathrm{HHV}_{\mathrm{F}}=$ higher heating value of the fuel $(\mathrm{GJ} / \mathrm{kg})$ on a Dry-Ash-Free Basis

$\mathrm{X}_{\mathrm{CO}}=\mathrm{CO}$ mole fraction (dry)

$\mathrm{X}_{\mathrm{CO} 2}=\mathrm{CO}_{2}$ mole fraction (dry)

Table 38 below shows the $\mathrm{NO}_{\mathrm{x}}$ emissions for all the fuels in terms of heat input $(\mathrm{g} / \mathrm{GJ})$. Figures 46 and 47 show the $\mathrm{NO}_{\mathrm{x}}(\mathrm{g} / \mathrm{GJ})$ emissions of all the fuels at both swirl numbers.

Table 38: $\mathrm{NO}_{\mathrm{x}}$ emissions in terms of heat input $(\mathrm{g} / \mathrm{GJ})$

\begin{tabular}{|c|c|c|c|c|c|c|c|}
\hline Fuel Type & $\begin{array}{l}\text { Swirl } \\
\text { Angle }\end{array}$ & $\varnothing$ & $\begin{array}{c}\text { NOx } \\
\text { mole } \\
\text { fraction } \\
\left(* 10^{\wedge}-6\right) \\
\end{array}$ & $\begin{array}{l}\text { CO mole } \\
\text { fraction } \\
\left(* 10^{\wedge}-6\right)\end{array}$ & $\begin{array}{l}\text { Average } \\
\mathrm{CO}_{2} \text { mole } \\
\text { fraction }\end{array}$ & $\begin{array}{l}\text { NOx } \\
\text { (g/kg } \\
\text { fuel) }\end{array}$ & $\begin{array}{c}\text { NOx } \\
\text { (g/GJ) }\end{array}$ \\
\hline \multirow{3}{*}{$\begin{array}{c}\text { Used Corn Oil } \\
(25 \% \text { TPM })\end{array}$} & \multirow{3}{*}{$60^{\circ}$} & 0.8 & 107.5 & 1950 & 0.144 & 2.30 & 58.6 \\
\hline & & 0.9 & 101 & 5150 & 0.1585 & 1.93 & 49.1 \\
\hline & & 1 & 80.5 & 21600 & 0.1545 & 1.43 & 36.3 \\
\hline \multirow{3}{*}{$\begin{array}{c}\text { Used Corn Oil } \\
(25 \% \text { TPM })\end{array}$} & \multirow{3}{*}{$51^{\circ}$} & 0.8 & 60 & 3300 & 0.149 & 1.23 & 31.3 \\
\hline & & 0.9 & 51.5 & 14550 & 0.147 & 1.00 & 25.3 \\
\hline & & 1 & 49 & 14700 & 0.15 & 0.93 & 23.7 \\
\hline \multirow{3}{*}{ UCO:D50 } & \multirow{3}{*}{$60^{\circ}$} & 0.8 & 89 & 2650 & 0.135 & 2.03 & 49.2 \\
\hline & & 0.9 & 104.5 & 3300 & 0.1435 & 2.24 & 54.2 \\
\hline & & 1 & 81 & 10400 & 0.13 & 1.82 & 43.9 \\
\hline \multirow{5}{*}{ UCO:D50 } & & & & & & & \\
\hline & \multirow{4}{*}{$51^{\circ}$} & 0.8 & _- & - & - & & $\ldots$ \\
\hline & & 0.9 & - & _- & _- & & - \\
\hline & & 1 & _- & _ & _- & & 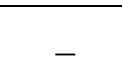 \\
\hline & & & & & & & \\
\hline
\end{tabular}


Table 38 (Continued)

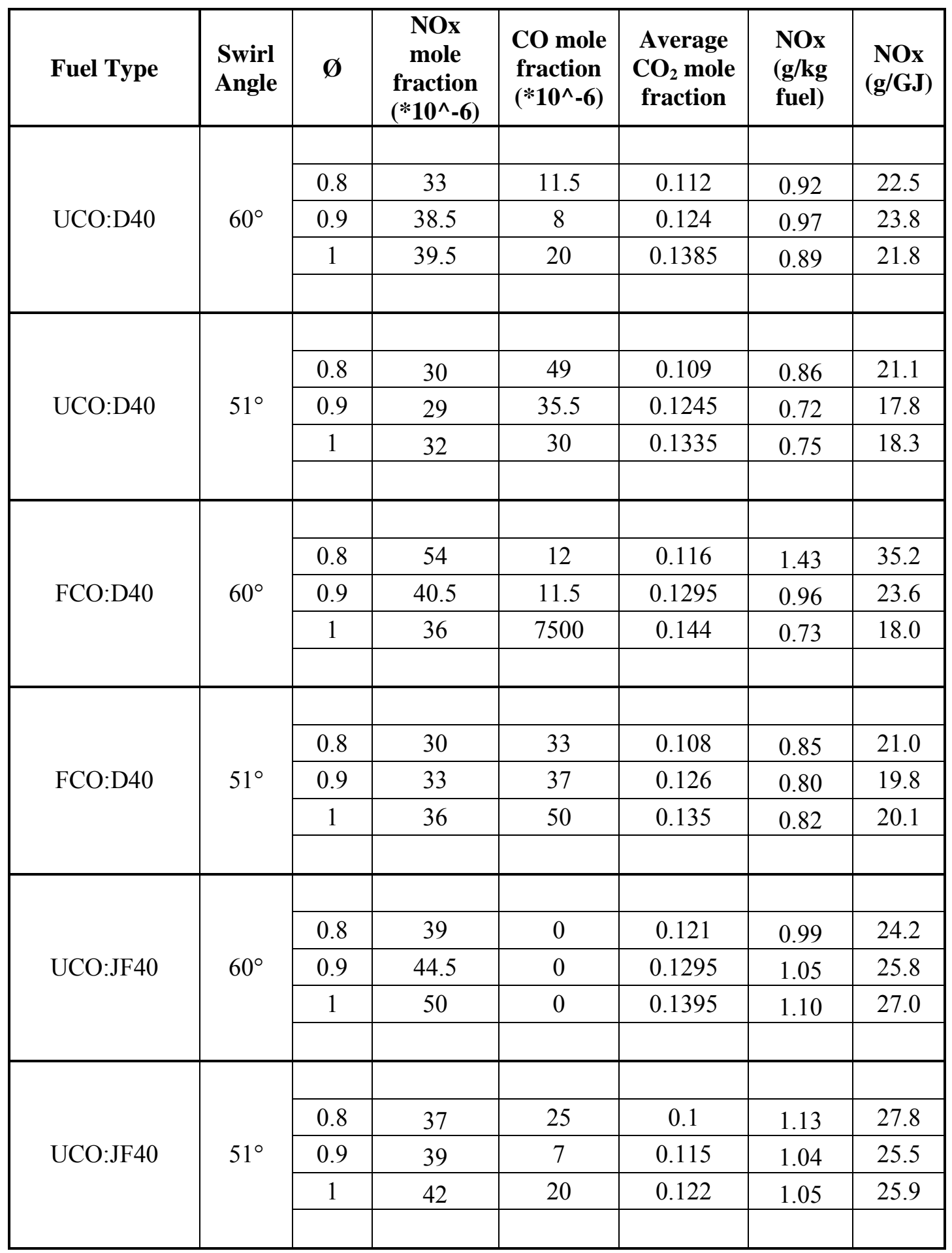




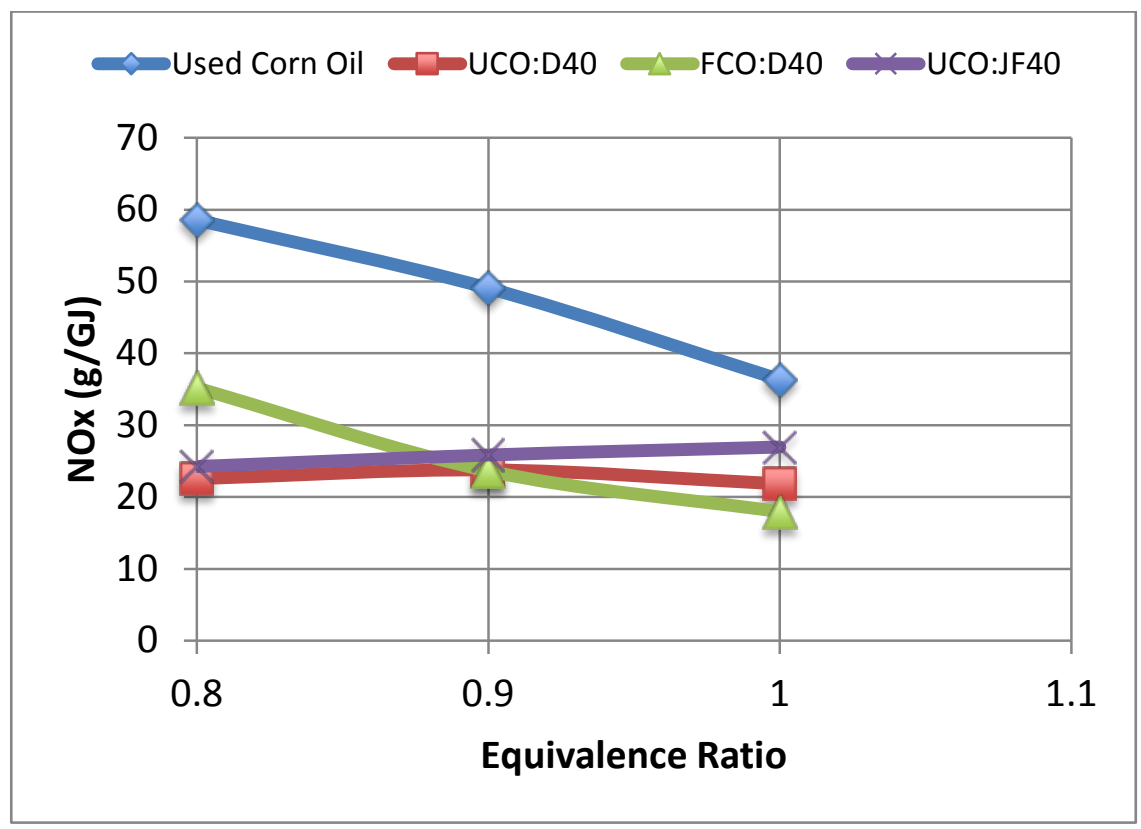

Figure 46: $\mathrm{NO}_{\mathrm{x}}(\mathrm{g} / \mathrm{GJ})$ emissions for all fuels at $\mathrm{SN}$ of 1.4 for a constant heat output of $68,620 \mathrm{~kJ} / \mathrm{hr}$

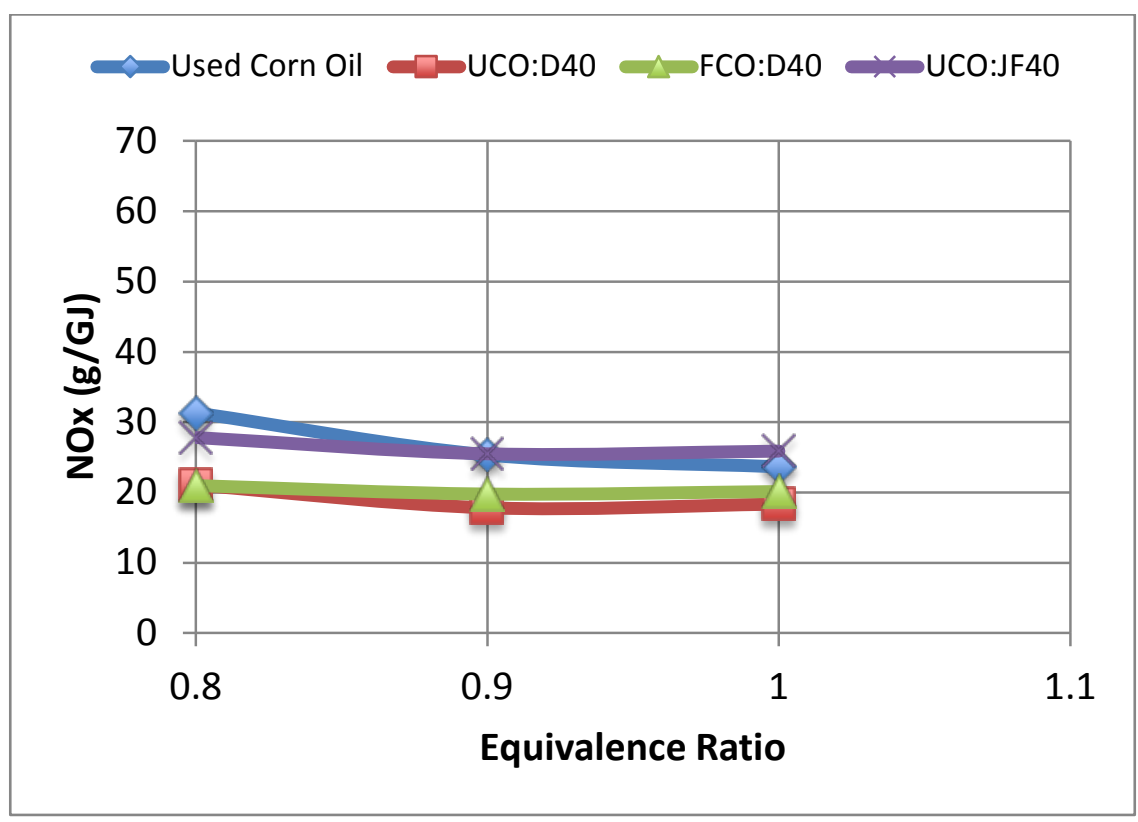

Figure 47: $\mathrm{NO}_{\mathrm{x}}(\mathrm{g} / \mathrm{GJ})$ emissions for all fuels at $\mathrm{SN}$ of 1.0 for a constant heat output of $68,620 \mathrm{~kJ} / \mathrm{hr}$ 
From the Figures 46 and 47, $\mathrm{NO}_{\mathrm{x}}(\mathrm{g} / \mathrm{GJ})$ emissions for the blends were generally lower than those for used corn oil. The equation above takes into account the mole fractions of $\mathrm{CO}$ and $\mathrm{CO}_{2}$. Since used corn oil had the highest $\mathrm{NO}_{\mathrm{x}}$ emissions, $\mathrm{NO}_{\mathrm{x}}(\mathrm{g} / \mathrm{GJ})$ emissions were also very high at both swirl numbers compared to the blends. Among the blends, $\mathrm{CO}_{2}$ produced was the minimum (Figure 49) at $\mathrm{SN}$ of 1.0 for UCO:JF40, resulting in the highest amount of $\mathrm{NO}_{\mathrm{x}}(\mathrm{g} / \mathrm{GJ})$ for that blend as seen in Figure 47.

\subsubsection{Carbon Dioxide and Carbon Monoxide Emissions}

Carbon dioxide levels of used corn oil and the fuel blends are listed on a percentage basis in Table 39. Carbon monoxide emission values are represented in Table 40.

Table 39: $\mathrm{CO}_{2}$ levels of all the fuels at both swirl numbers

\begin{tabular}{|c|c|c|c|c|c|c|}
\hline Fuel Type & $\begin{array}{l}\text { Swirl } \\
\text { Angle }\end{array}$ & $\begin{array}{c}\text { Equivalence } \\
\text { Ratio }\end{array}$ & $\begin{array}{c}\mathrm{CO}_{2} \\
\text { first } \\
\text { reading } \\
(\%)\end{array}$ & $\begin{array}{c}\mathrm{CO}_{2} \\
\text { second } \\
\text { reading } \\
(\%)\end{array}$ & $\begin{array}{c}\text { Average } \\
\mathrm{CO}_{2} \\
\text { value } \\
(\%)\end{array}$ & $\begin{array}{c}\text { Standard } \\
\text { deviation } \\
\text { of } \mathrm{CO}_{2} \\
(\%)\end{array}$ \\
\hline Fresh Corn Oil & $60^{\circ} / 51^{\circ}$ & - & - & - & - & - \\
\hline \multirow{3}{*}{$\begin{array}{c}\text { Used Corn Oil } \\
(25 \% \text { Total } \\
\text { Polar Material) }\end{array}$} & \multirow{3}{*}{$60^{\circ}$} & 0.8 & 14.4 & 14.4 & 14.4 & 0.0 \\
\hline & & 0.9 & 15.8 & 15.9 & 15.85 & 0.1 \\
\hline & & 1 & 15.5 & 15.4 & 15.45 & 0.1 \\
\hline \multirow{3}{*}{$\begin{array}{c}\text { Used Corn Oil } \\
(25 \% \text { Total } \\
\text { Polar Material) }\end{array}$} & \multirow{3}{*}{$51^{\circ}$} & 0.8 & 14.8 & 15 & 14.9 & 0.1 \\
\hline & & 0.9 & 14.6 & 14.8 & 14.7 & 0.1 \\
\hline & & 1 & 15 & 15 & 15 & 0.0 \\
\hline \multirow{3}{*}{ UCO:D50 } & \multirow{3}{*}{$60^{\circ}$} & 0.8 & 14.2 & 12.8 & 13.5 & 1.0 \\
\hline & & 0.9 & 14.6 & 14.1 & 14.35 & 0.4 \\
\hline & & 1 & 13.2 & 12.8 & 13 & 0.3 \\
\hline
\end{tabular}


Table 39 (Continued)

\begin{tabular}{|c|c|c|c|c|c|c|}
\hline Fuel Type & $\begin{array}{l}\text { Swirl } \\
\text { Angle }\end{array}$ & $\begin{array}{c}\text { Equivalence } \\
\text { Ratio }\end{array}$ & $\begin{array}{c}\mathrm{CO}_{2} \\
\text { first } \\
\text { reading } \\
(\%)\end{array}$ & $\begin{array}{c}\mathrm{CO}_{2} \\
\text { second } \\
\text { reading } \\
(\%)\end{array}$ & $\begin{array}{c}\text { Average } \\
\mathrm{CO}_{2} \\
\text { value } \\
(\%)\end{array}$ & $\begin{array}{c}\text { Standard } \\
\text { deviation } \\
\text { of } \mathrm{CO}_{2} \\
\text { (\%) }\end{array}$ \\
\hline & & & & & & \\
\hline \multirow{4}{*}{ UCO:D50 } & \multirow{4}{*}{$51^{\circ}$} & 0.8 & _. & _- & _- & _ \\
\hline & & 0.9 & _- & _ & _ & _- \\
\hline & & 1 & - & - & 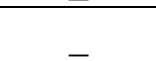 & 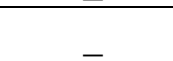 \\
\hline & & & & & & \\
\hline \multirow{4}{*}{ UCO:D40 } & \multirow{4}{*}{$60^{\circ}$} & & & & & \\
\hline & & 0.8 & 11.3 & 11.1 & 11.2 & 0.1 \\
\hline & & 0.9 & 12.3 & 12.5 & 12.4 & 0.1 \\
\hline & & 1 & 13.8 & 13.9 & 13.85 & 0.1 \\
\hline \multirow{5}{*}{ UCO:D40 } & \multirow{4}{*}{$51^{\circ}$} & & & & & \\
\hline & & 0.8 & 10.9 & 10.9 & 10.9 & 0.0 \\
\hline & & 0.9 & 12.5 & 12.4 & 12.45 & 0.1 \\
\hline & & 1 & 13.2 & 13.5 & 13.35 & 0.2 \\
\hline & & & & & & \\
\hline \multirow{3}{*}{ FCO:D40 } & \multirow{3}{*}{$60^{\circ}$} & 0.8 & 11.7 & 11.5 & 11.6 & 0.1 \\
\hline & & 0.9 & 12.8 & 13.1 & 12.95 & 0.2 \\
\hline & & 1 & 14.4 & 14.4 & 14.4 & 0.0 \\
\hline \multirow{4}{*}{ FCO:D40 } & \multirow{4}{*}{$51^{\circ}$} & & & & & \\
\hline & & 0.8 & 10.9 & 10.7 & 10.8 & 0.1 \\
\hline & & 0.9 & 12.6 & 12.6 & 12.6 & 0.0 \\
\hline & & 1 & 13.4 & 13.6 & 13.5 & 0.1 \\
\hline
\end{tabular}


Table 39 (Continued)

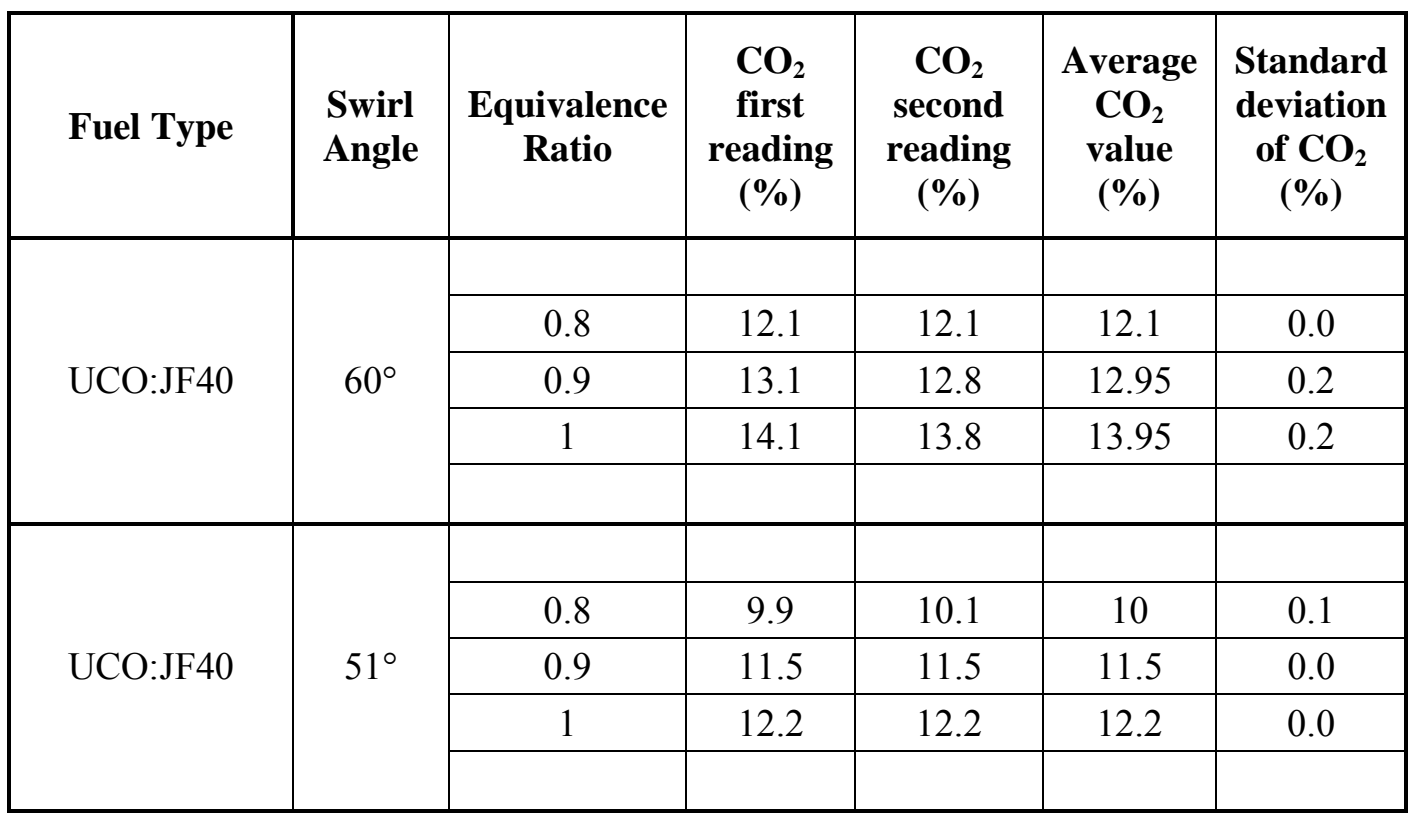

Table 40: $\mathrm{CO}$ emissions of all fuels at both swirl numbers

\begin{tabular}{|c|c|c|c|c|c|c|}
\hline Fuel Type & $\begin{array}{l}\text { Swirl } \\
\text { Angle }\end{array}$ & $\begin{array}{c}\text { Equivalence } \\
\text { Ratio }\end{array}$ & $\begin{array}{c}\mathrm{CO} \\
\text { first } \\
\text { reading } \\
(\mathrm{ppm}) \\
\end{array}$ & $\begin{array}{c}\text { CO } \\
\text { second } \\
\text { reading } \\
(\mathrm{ppm}) \\
\end{array}$ & $\begin{array}{c}\text { Average } \\
\text { CO } \\
\text { value } \\
\text { (ppm) } \\
\end{array}$ & 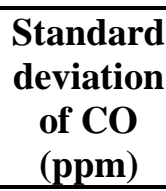 \\
\hline Fresh Corn Oil & $60^{\circ} / 51^{\circ}$ & _ & - & - & - & - \\
\hline \multirow{3}{*}{$\begin{array}{c}\text { Used Corn Oil } \\
\text { (25\% Total Polar } \\
\text { Material) }\end{array}$} & \multirow{3}{*}{$60^{\circ}$} & 0.8 & 1,900 & 2,000 & 1,950 & 70.7 \\
\hline & & 0.9 & 4,700 & 5,600 & 5,150 & 636.4 \\
\hline & & 1 & 22,000 & 21,200 & 21,600 & 565.7 \\
\hline \multirow{3}{*}{$\begin{array}{c}\text { Used Corn Oil } \\
\text { (25\% Total Polar } \\
\text { Material) }\end{array}$} & \multirow{3}{*}{$51^{\circ}$} & 0.8 & 3,300 & 3,300 & 3,300 & 0.0 \\
\hline & & 0.9 & 15,000 & 14,100 & 14,550 & 636.4 \\
\hline & & 1 & 14,700 & 14,700 & 14,700 & 0.0 \\
\hline \multirow{4}{*}{ UCO:D50 } & \multirow{4}{*}{$60^{\circ}$} & 0.8 & 2,600 & 2,700 & 2,650 & 70.7 \\
\hline & & 0.9 & 3,200 & 3,400 & 3,300 & 141.4 \\
\hline & & 1 & 10,400 & 10,400 & 10,400 & 0.0 \\
\hline & & & & & & \\
\hline
\end{tabular}


Table 40 (Continued)

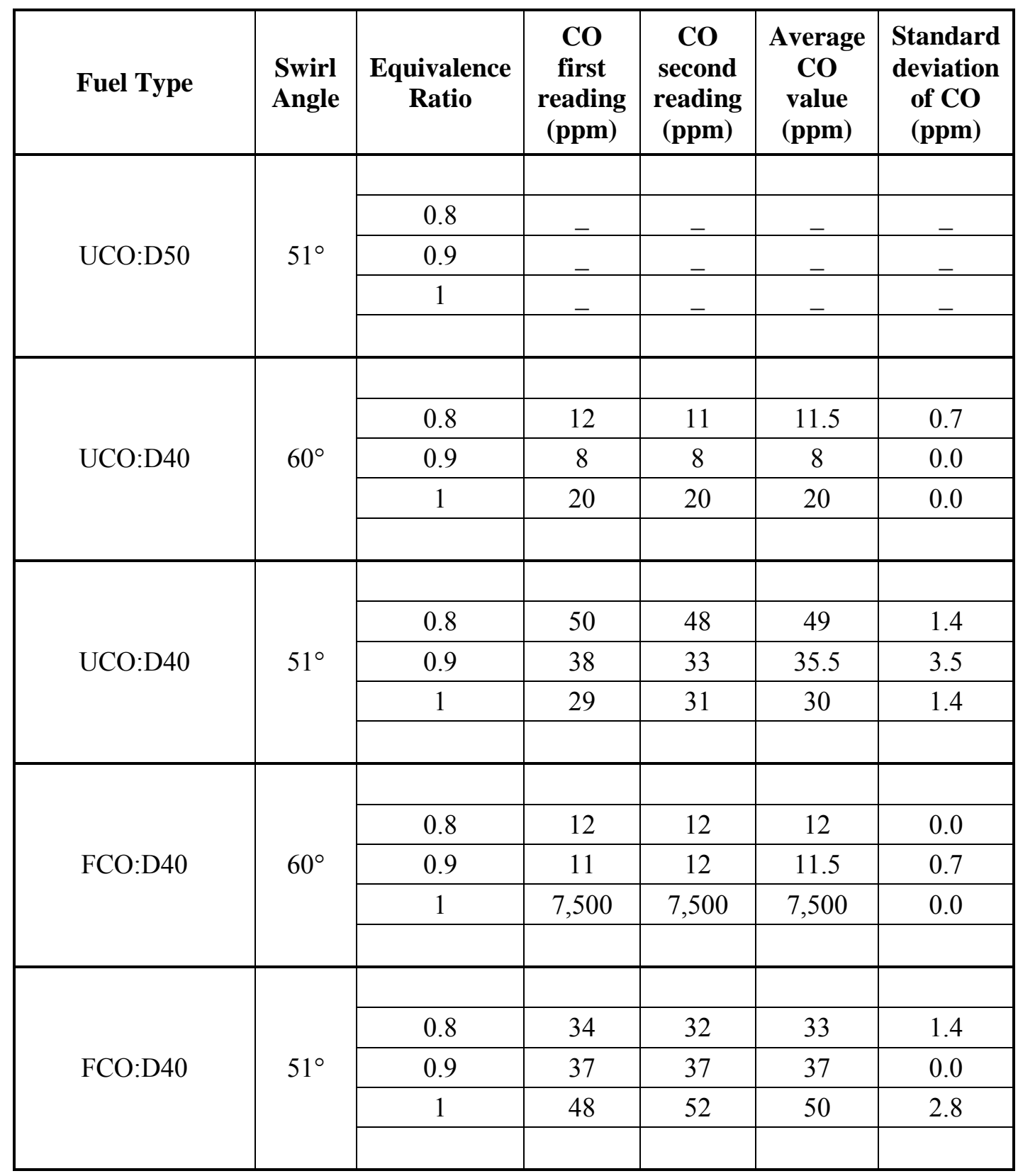


Table 40 (Continued)

\begin{tabular}{|c|c|c|c|c|c|c|}
\hline Fuel Type & $\begin{array}{l}\text { Swirl } \\
\text { Angle }\end{array}$ & $\begin{array}{c}\text { Equivalence } \\
\text { Ratio }\end{array}$ & $\begin{array}{c}\text { CO } \\
\text { first } \\
\text { reading } \\
(\mathbf{p p m})\end{array}$ & $\begin{array}{c}\text { CO } \\
\text { second } \\
\text { reading } \\
(\mathrm{ppm})\end{array}$ & $\begin{array}{c}\text { Average } \\
\text { CO } \\
\text { value } \\
\text { (ppm) }\end{array}$ & $\begin{array}{c}\begin{array}{c}\text { Standard } \\
\text { deviation }\end{array} \\
\text { of CO } \\
\text { (ppm) }\end{array}$ \\
\hline \multirow{3}{*}{ UCO:JF40 } & \multirow{3}{*}{$60^{\circ}$} & & & & & \\
\hline & & 0.9 & 0 & 0 & 0 & 0.0 \\
\hline & & 1 & 0 & 0 & 0 & 0.0 \\
\hline \multirow{5}{*}{ UCO:JF40 } & & & & & & \\
\hline & \multirow{4}{*}{$51^{\circ}$} & 0.8 & 24 & 26 & 25 & 1.4 \\
\hline & & 0.9 & 7 & 7 & 7 & 0.0 \\
\hline & & 1 & 20 & 20 & 20 & 0.0 \\
\hline & & & & & & \\
\hline
\end{tabular}

\subsubsection{Effect of Equivalence Ratio on $\mathrm{CO}_{2}$ and $\mathrm{CO}$ Emissions}

As seen in Figures 48 and 49, $\mathrm{CO}_{2}$ levels peaked for used corn oil at about $\phi=0.9$ at $\mathrm{SN}$ of 1.4. At $\mathrm{SN}$ of 1.0 , it remained almost constant from lean to stoichiometric conditions. As data was not collected beyond equivalence ratio of 1 due to excessive soot formation, one can only predict from classical literature that at richer conditions, $\mathrm{CO}_{2}$ levels would decrease due to lack of sufficient oxygen in the air to completely convert carbon to $\mathrm{CO}_{2}$, which results in incomplete combustion. The three blends at both swirl angles showed $\mathrm{CO}_{2}$ peaking at stoichiometric conditions (Figures 48 and 49).

It is known that theoretical $\mathrm{CO}_{2}$ or $\mathrm{CO}_{2(\max )}$ is proportional to the oxygen consumed during the combustion reaction (Air $\mathrm{O}_{2}-$ Exhaust $\mathrm{O}_{2}$ ). With an increase in equivalence ratio, the percentage of exhaust $\mathrm{O}_{2}$ reduces and tends towards an optimum value [65]. Also, $\mathrm{CO}_{2}(\%)$ and $\mathrm{O}_{2}(\%)$ are highly dependent on the type of fuel [45]. It was found in 
this study that used corn oil emitted much lesser exhaust $\mathrm{O}_{2}$ compared to the blends (Table 42). As a result, the $\mathrm{CO}_{2}$ values were observed to be higher for used corn oil than for the blends.

Figures 48 and 49 show the plots for $\mathrm{CO}_{2}$ levels for used corn oil, UCO:D40, FCO:D40, and UCO:JF40 at SN of 1.4 and 1.0, respectively.

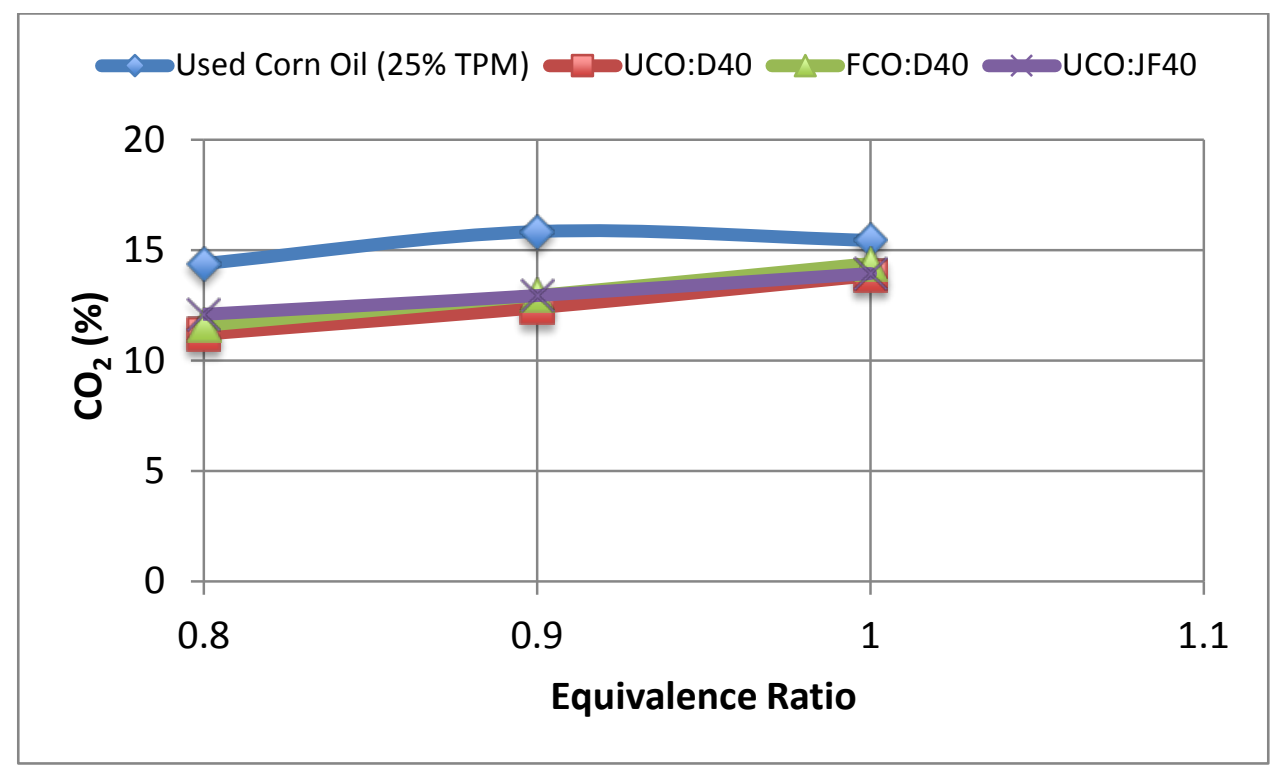

Figure 48: $\mathrm{CO}_{2}$ levels for used corn oil, UCO:D40, FCO:D40, and UCO:JF40 at SN of 1.4 , at a constant heat output of $68,620 \mathrm{~kJ} / \mathrm{hr}$ 


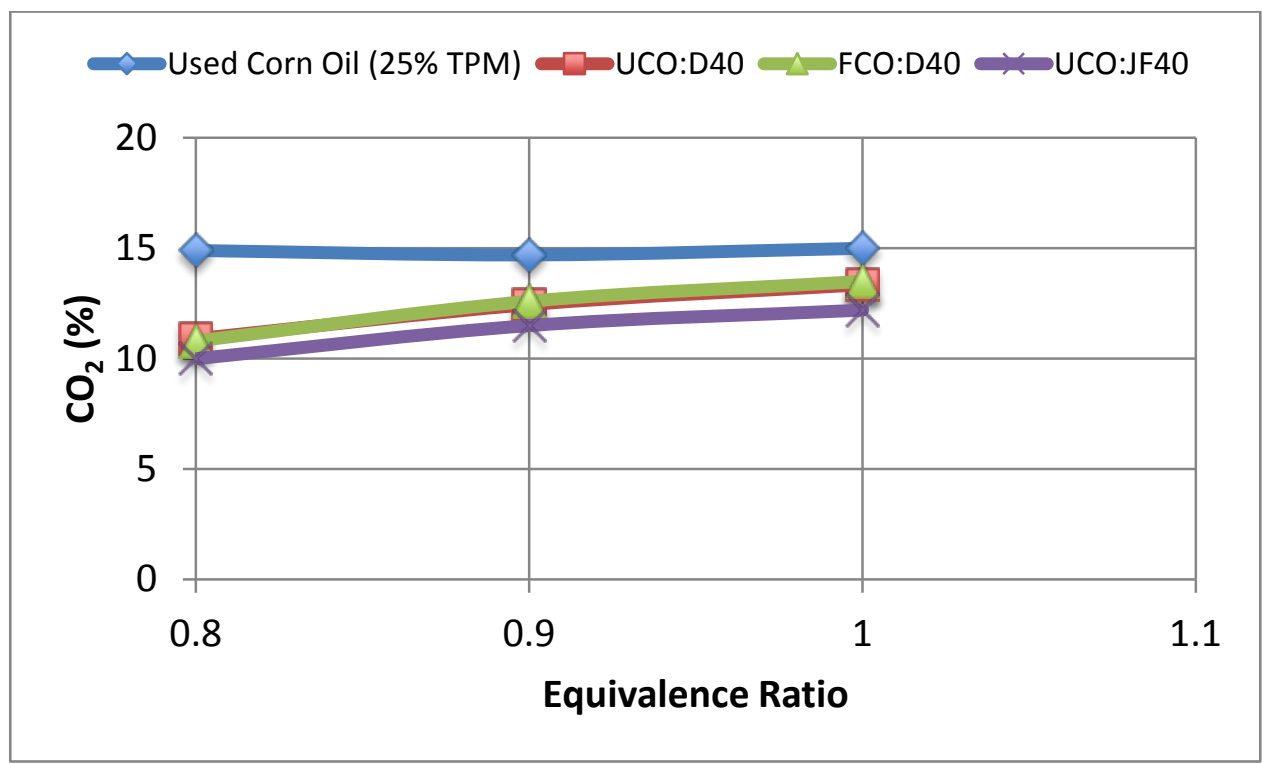

Figure 49: $\mathrm{CO}_{2}$ levels for used corn oil, UCO:D40, FCO:D40, and UCO:JF40 at SN of 1.0 , at a constant heat output of $68,620 \mathrm{~kJ} / \mathrm{hr}$

From Figure 50, $\mathrm{CO}$ is seen to generally increase with increasing equivalence ratio for used corn oil. This is expected, as more and more incomplete combustion is prevalent at higher equivalence ratios. It should be noted that the $\mathrm{CO}$ levels for used corn oil were exceedingly high. Extreme caution was taken to ensure that the exhaust fan was always on, in order to continuously remove the exhaust gases to the chimney. 


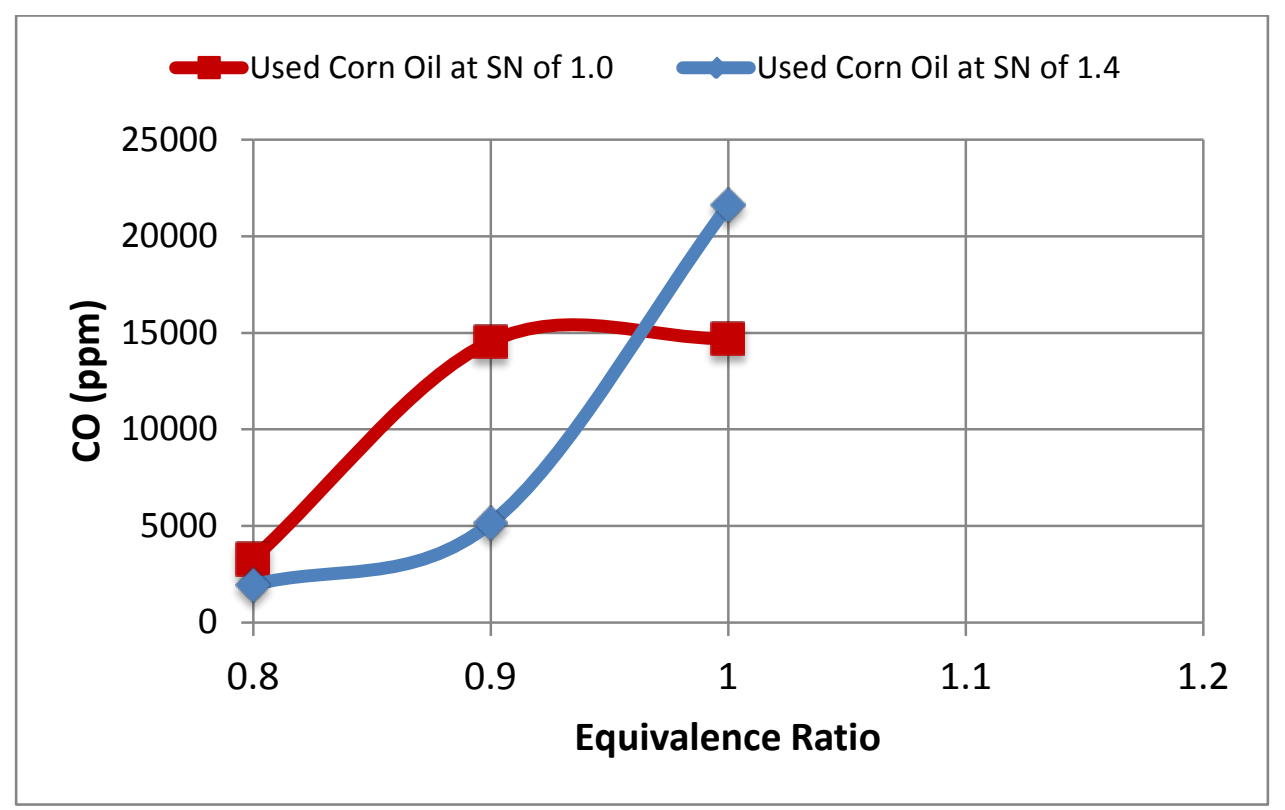

Figure 50: $\mathrm{CO}$ emissions for used corn oil at $\mathrm{SN}$ of 1.0 and 1.4, at a constant heat output of $68,620 \mathrm{~kJ} / \mathrm{hr}$

It was observed that the local (flue) equivalence ratio $\left(\phi_{\text {flue }}\right)$ calculated by the approximation given by Annamalai et al. [45], was higher than the calculated equivalence ratio $\left(\phi_{\text {flow }}\right)$ in case of used corn oil, whereas the opposite was observed for the blends. These equivalence ratios are compared in Table 41 at $\phi$ of 0.8 and 0.9 , respectively at $\mathrm{SN}$ of 1.4. 
Table 41: Comparison of $\phi_{\text {flow }}$ and $\phi_{\text {flue }}$ for all tested fuels at $\mathrm{SN}$ of 1.4

\begin{tabular}{|c|c|c|}
\hline Fuel Type & $\begin{array}{c}\text { Calculated (flow) } \\
\text { Equivalence Ratio }\end{array}$ & $\begin{array}{c}\text { Actual (flue) } \\
\text { Equivalence Ratio }\end{array}$ \\
\hline \multirow{2}{*}{ Used Corn Oil } & 0.8 & 0.87 \\
\cline { 2 - 3 } & 0.9 & 0.97 \\
\hline \multirow{2}{*}{ UCO:D40 } & 0.8 & 0.72 \\
\cline { 2 - 3 } & 0.9 & 0.8 \\
\hline \multirow{2}{*}{ FCO:D40 } & 0.8 & 0.74 \\
\cline { 2 - 3 } & 0.9 & 0.81 \\
\hline \multirow{2}{*}{ UCO:JF40 } & 0.8 & 0.79 \\
\cline { 2 - 3 } & 0.9 & 0.84 \\
\hline
\end{tabular}

It is observed that $\phi_{\text {flue }}$ was greater than $\phi_{\text {flow }}$ in case of used corn oil, but $\phi_{\text {flue }}$ was less than $\phi_{\text {flow }}$ in case of the blends at all the conditions specified above. This means that for used corn oil, combustion at lean conditions was richer than it was calculated, whereas for the blends, combustion was slightly leaner than usual. In other words, combustion closer to stoichiometric conditions for used corn oil might be able to explain the $\mathrm{CO}_{2}$ values being higher than those for the blends (Figures 48 and 49). However, this means that the high $\mathrm{CO}$ formation in used corn oil is likely to have occurred through other routes (i.e. other than due to incomplete combustion) as explained in Section 6.3.4.3.

Daho et al. [65] reported very high CO values during the combustion of domestic fuel-oil and cottonseed oil blends as the equivalence ratio came closer to stoichiometric conditions. This was attributed to the appearance of fuel-rich zones. Similar observations 
were made by Gianfranco et al. [66] in their methane gas burner experiments, wherein there was also a temperature drop that was noticed in addition to the formation of overrich zones. A similar hypothesis can be applied in this study for explaining the high $\mathrm{CO}$ emissions for used corn oil. Figures 55 and 56 also show that there is a slight temperature drop from $\phi$ of 0.9 to 1 at $\mathrm{SN}$ of 1.4 , and from $\phi$ of 0.8 to 1 at $\mathrm{SN}$ of 1.0 , for used corn oil which suggest the formation of over rich zone in the flame as proposed by Gianfranco et al. [66] as a CO generating mechanism. An explanation of other temperature related effects can be found below.

From Figures 51 and 52, it is seen that $\mathrm{CO}$ emissions for the blends show a generally decreasing trend with increasing equivalence ratio. At both swirl numbers, this decrease in $\mathrm{CO}$ was observed until $\phi$ of 0.9 for some of the blends, after which $\mathrm{CO}$ started increasing. This phenomenon could be due to the gas phase homogenous reaction of $\mathrm{CO}$ (produced from initial soot oxidation) to $\mathrm{CO}_{2}$ at very lean conditions [45]. Increasing temperatures observed up to $\phi$ of 0.9 accelerated this reaction, causing a further drop in $\mathrm{CO}$ levels. However, as the equivalence ratio increased towards stoichiometric combustion conditions, soot oxidation started dominating the CO-to- $\mathrm{CO}_{2}$ reaction, resulting in the sudden upward trend in CO. Ghazikhani et al. [67] also found decreasing $\mathrm{CO}$ trends with increasing equivalence ratio in their dual fuel HCCI-engine experiments with gasoline. The mechanism of soot oxidation to $\mathrm{CO}$ is explained in Section 6.3.4.3. 


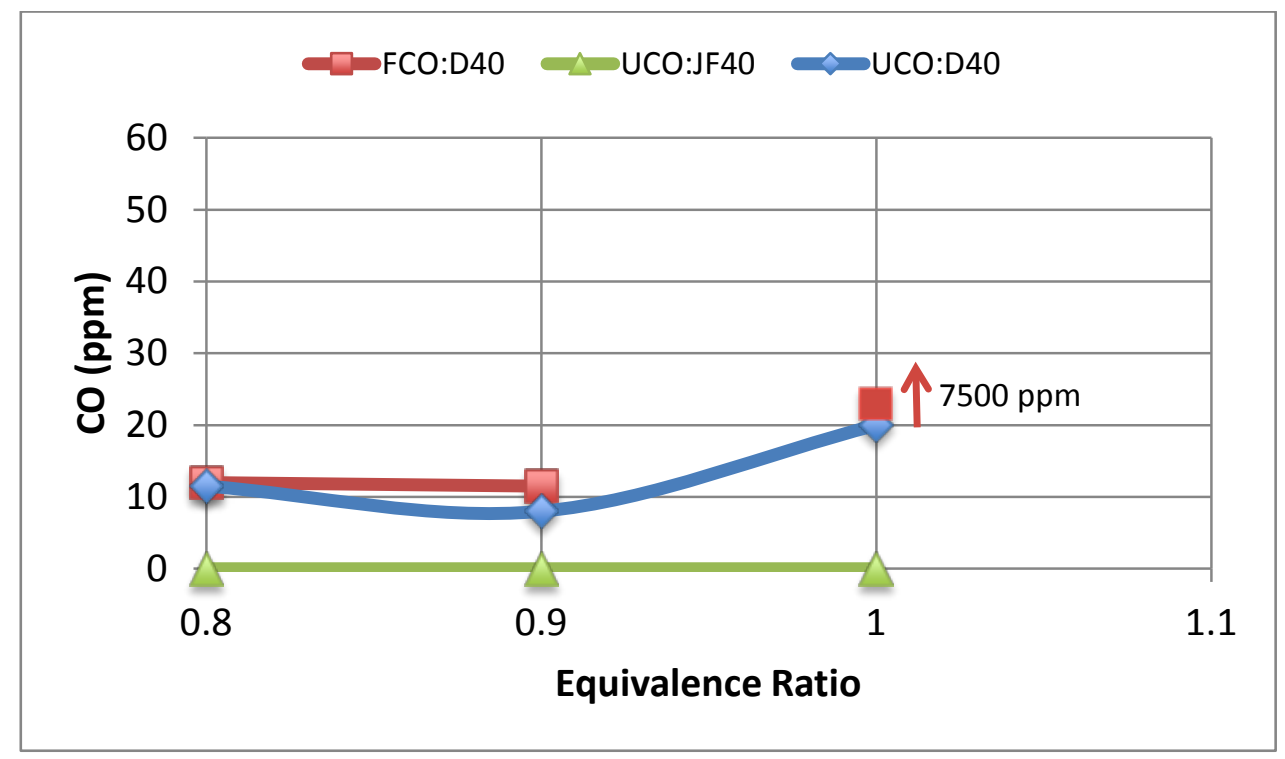

Figure 51: CO emissions for UCO:D40, FCO:D40, and UCO:JF40 at SN of 1.4, at constant heat output of $68,620 \mathrm{~kJ} / \mathrm{hr}$

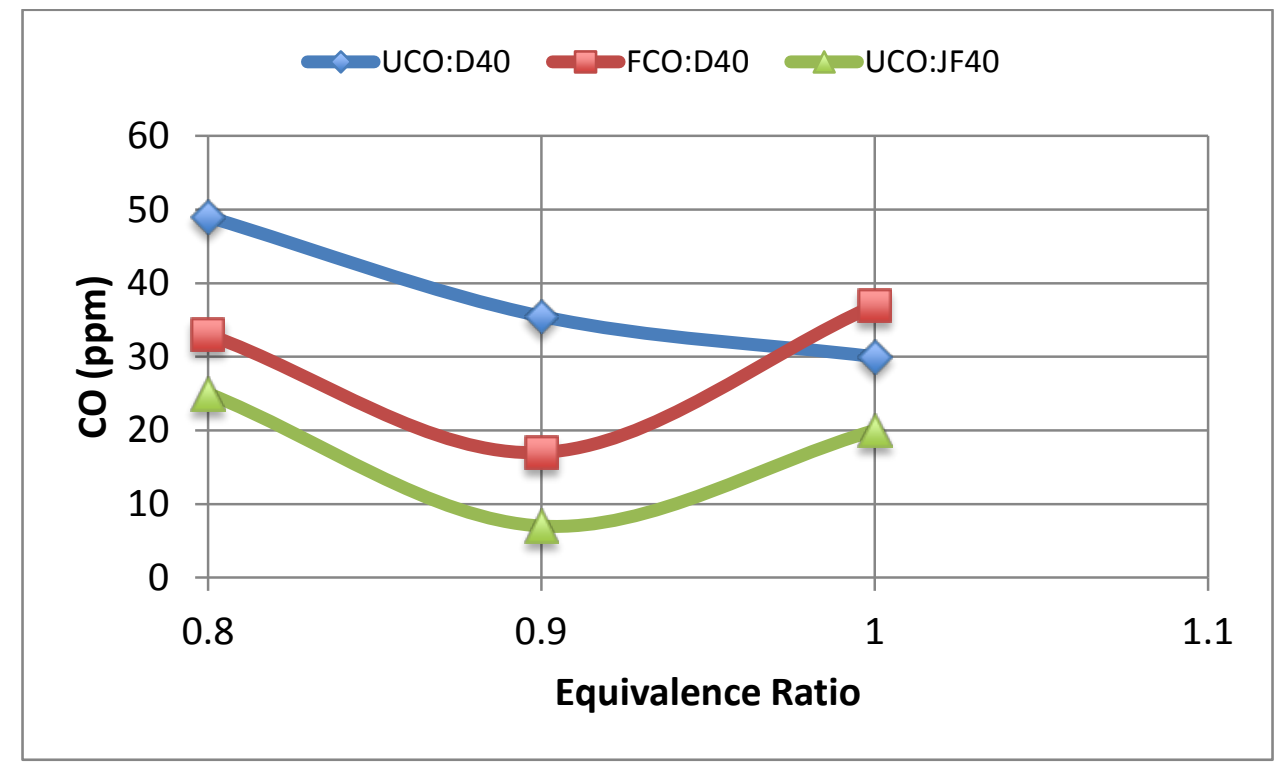

Figure 52: CO emissions for UCO:D40, FCO:D40, and UCO:JF40 at SN of 1.0, at constant heat output of $68,620 \mathrm{~kJ} / \mathrm{hr}$ 
Additionally, it can be hypothesized that at $\mathrm{SN}$ of 1.4, higher soot formation due to the fresh corn oil component in FCO:D40 enabled the reaction with $\mathrm{NO}_{\mathrm{x}}$ which causes CO to rise sharply after $\phi$ of 0.9 [44]. Soot formed to a much lesser extent when combusting UCO:D40, which could explain the much less drastic rise in CO in this case. This NOx-soot mechanism [44]; however, was of secondary importance compared to soot oxidation.

\subsubsection{Effect of Swirl Number on $\mathrm{CO}_{2}$ and $\mathrm{CO}$ Emissions}

Figures 48 and 49 show that $\mathrm{CO}_{2}$ levels are slightly higher for $\mathrm{SN}$ of 1.4 than for $\mathrm{SN}$ of 1.0, for all fuels. This is expected because of the higher vorticity imparted to the secondary air by the higher swirl angle, which improves fuel-air mixing and increases residence time. It is evident that higher SN results in better combustion especially at SN of 1.4 than at $\mathrm{SN}$ of 1.0 .

Change in swirl number had a more profound effect on $\mathrm{CO}$ emissions for used corn oil than for the blends. From Figures 51 and 52, CO ranges for the blends are observed to be slightly higher at $\mathrm{SN}$ of 1.0 than at $\mathrm{SN}$ of 1.4. This is because better mixing and hence more complete combustion is occurring at $\mathrm{SN}$ of 1.4.

\subsubsection{Effect of Fuel Type on $\mathrm{CO}_{2}$ and $\mathrm{CO}$ Emissions}

Fuel composition was observed to have a major role in $\mathrm{CO}_{2}$ and $\mathrm{CO}$ emissions. $\mathrm{CO}_{2}$ levels were lower for the blends compared to used corn oil, due in part to the blends' higher $\mathrm{H} / \mathrm{C}$ ratios [45]. Also, much more oxygen was consumed for the combustion of 
used corn oil than for the combustion of blends as shown in Table 42, which in turn could have also contributed to the higher $\mathrm{CO}_{2}$ levels for used corn oil.

While used corn oil and the blends had the same fuel flow rates, the fuel pressure for used corn oil was slightly higher than that for the blends. This condition was imposed in order to achieve a mist-like spray for the high-viscosity used corn oil. As a result, this could have enabled better atomization, causing droplet sizes for used corn oil to be smaller than those for the blends. This in turn could have caused faster evaporation and shorter ignition delay times, producing large amounts of $\mathrm{CO}$ via partial oxidation of used corn oil. This theory is based on findings by Anderson et al. [68] in their gas turbine combustion experiments. They hypothesized that $\mathrm{CO}$ levels increased as droplet size decreases.

Another theory explaining high CO levels in used corn oil involves soot (carbon) oxidation. Soot can react with $\mathrm{O}_{2}, \mathrm{CO}_{2}$, and $\mathrm{H}_{2} \mathrm{O}$ via the following heterogeneous reactions [45].

$$
\begin{aligned}
& \mathrm{C}_{(\mathrm{s})}+1 / 2 \mathrm{O}_{2} \rightarrow \mathrm{CO} \\
& \mathrm{C}_{(\mathrm{s})}+\mathrm{O}_{2} \rightarrow \mathrm{CO}_{2} \\
& \mathrm{C}_{(\mathrm{s})}+\mathrm{CO}_{2} \rightarrow 2 \mathrm{CO} \\
& \mathrm{C}_{(\mathrm{s})}+\mathrm{H}_{2} \mathrm{O}_{(\mathrm{g})} \rightarrow \mathrm{CO}+\mathrm{H}_{2}
\end{aligned}
$$

Owing to the high temperatures reached during the combustion of used corn oil, soot could be oxidizing to $\mathrm{CO}$ via Reaction (13), which dominates at high temperatures [52] and as shown in Figures 55 and 56. Reaction (14) might have been coming into play to a 
much lesser extent, since it only dominates at lower temperatures [52]. Eventually, low concentrations of $\mathrm{O}_{2}$ might have initiated Reactions (15) and (16), causing an even higher production of $\mathrm{CO}$ for used corn oil [45].

Moreover, the high degree of unsaturation present in used corn oil could be a contributing factor to some soot formation, which reacts with $\mathrm{NO}_{\mathrm{x}}$ to form some $\mathrm{CO}[43$, 44], although this might be occurring to a much lesser degree.

Saravanan et al. [63] in their CRBO experiments found that both $\mathrm{CO}_{2}$ and $\mathrm{CO}$ emissions decrease with increasing FFA content. From Figures 48 and 49, it is observed that $\mathrm{CO}_{2}$ levels for UCO:D40 are slightly lower than those of FCO:D40. Similar observations are made in Figures 51 and 52, where CO emissions for UCO:D40 are lower than those for FCO:D40 due to the higher FFA in used corn oil than fresh corn oil. The FFA analysis for fresh and used corn oils can be seen in Section 6.1.4.3.

Venkanna et al. [61] reported in their DI diesel engine tests of diesel/kerosene (jet fuel)/honne oil blends, that honne oil-kerosene blends gave significantly lower CO emissions compared to honne oil-diesel blends. Similar results were observed with the blends in this study as can be seen in Figures 51 and 52, wherein UCO:JF40 had CO levels much lower than the corresponding diesel blends. 


\subsubsection{Burned Fraction (BF)}

Thien [69] derived an approximation for the burned fraction of a fuel, which is basically a term used to find out the fraction of fuel that underwent complete combustion. The approximation is given by the following equation:

$\mathrm{BF}=\left(\frac{1}{\emptyset}\right) *\left[1-\frac{\mathrm{X}_{02}}{\mathrm{X}_{02, \mathrm{a}}}\right]$

where,

$\phi=$ measured equivalence ratio from air and fuel flow rates

$\mathrm{X}_{\mathrm{O} 2}=$ mole fraction of $\mathrm{O}_{2}$ in exhaust gas (dry basis)

$\mathrm{X}_{\mathrm{O} 2 \mathrm{a}}=$ mole fraction of $\mathrm{O}_{2}$ in ambient air (dry basis)

Table 42 shows the burned fraction (BF) values of all the fuels at both swirl numbers. 
Table 42: Burned fraction values for all fuels at both swirl numbers

\begin{tabular}{|c|c|c|c|c|c|c|c|}
\hline Fuel Type & $\begin{array}{l}\text { Swirl } \\
\text { Angle }\end{array}$ & $\begin{array}{c}\text { Equivalence } \\
\text { Ratio }\end{array}$ & $\begin{array}{c}\text { Excess } \mathrm{O}_{2} \\
\text { in exhaust } \\
(\%)\end{array}$ & $\begin{array}{c}\text { Excess } \mathrm{O}_{2} \text { in } \\
\text { exhaust } \\
\text { (mole } \\
\text { fraction) }\end{array}$ & $\begin{array}{c}\mathrm{O}_{2} \text { mole } \\
\text { fraction in } \\
\text { ambient }\end{array}$ & $\begin{array}{c}\text { Measured } \\
\text { Equivalence } \\
\text { Ratio }\end{array}$ & $\begin{array}{l}\text { Burned } \\
\text { Fraction }\end{array}$ \\
\hline \multirow{3}{*}{$\begin{array}{c}\text { Used Corn Oil } \\
\text { (25\% Total Polar } \\
\text { Material) }\end{array}$} & \multirow{3}{*}{$60^{\circ}$} & 0.8 & 2.65 & 0.0265 & 0.21 & 0.8 & 1.09 \\
\hline & & 0.9 & 0.65 & 0.0065 & 0.21 & 0.9 & 1.08 \\
\hline & & 1 & 0.15 & 0.0015 & 0.21 & 1 & 0.99 \\
\hline \multirow{3}{*}{$\begin{array}{c}\text { Used Corn Oil } \\
\text { (25\% Total Polar } \\
\text { Material) } \\
\end{array}$} & \multirow{3}{*}{$51^{\circ}$} & 0.8 & 0.35 & 0.0035 & 0.21 & 0.8 & 1.23 \\
\hline & & 0.9 & 0 & 0 & 0.21 & 0.9 & 1.11 \\
\hline & & 1 & 0 & 0 & 0.21 & 1 & 1.00 \\
\hline \multirow{3}{*}{ UCO:D50 } & \multirow{3}{*}{$60^{\circ}$} & 0.8 & 3.45 & 0.0345 & 0.21 & 0.81 & 1.03 \\
\hline & & 0.9 & 2.3 & 0.023 & 0.21 & 0.9 & 0.99 \\
\hline & & 1 & 1.8 & 0.018 & 0.21 & 1 & 0.91 \\
\hline \multirow{4}{*}{ UCO:D50 } & \multirow{4}{*}{$51^{\circ}$} & 0.8 & 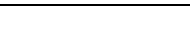 & 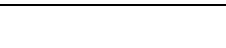 & 0.21 & 0.8 & 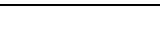 \\
\hline & & 0.9 & 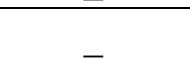 & 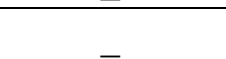 & 0.21 & 0.9 & 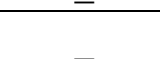 \\
\hline & & 1 & 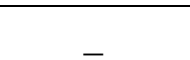 & - & 0.21 & 1 & 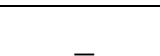 \\
\hline & & & & & & & \\
\hline
\end{tabular}


Table 42 (Continued)

\begin{tabular}{|c|c|c|c|c|c|c|c|}
\hline Fuel Type & $\begin{array}{l}\text { Swirl } \\
\text { Angle }\end{array}$ & $\begin{array}{c}\text { Equivalence } \\
\text { Ratio }\end{array}$ & $\begin{array}{c}\text { Excess } \mathrm{O}_{2} \\
\text { in exhaust } \\
(\%)\end{array}$ & $\begin{array}{c}\text { Excess } \mathrm{O}_{2} \text { in } \\
\text { exhaust } \\
\text { (mole } \\
\text { fraction) }\end{array}$ & $\begin{array}{c}\mathrm{O}_{2} \text { mole } \\
\text { fraction in } \\
\text { ambient }\end{array}$ & $\begin{array}{c}\text { Measured } \\
\text { Equivalence } \\
\text { Ratio }\end{array}$ & $\begin{array}{l}\text { Burned } \\
\text { Fraction }\end{array}$ \\
\hline \multirow{4}{*}{ UCO:D40 } & \multirow{4}{*}{$60^{\circ}$} & & & & & & \\
\hline & & 0.8 & 5.9 & 0.059 & 0.21 & 0.8 & 0.90 \\
\hline & & 0.9 & 4.3 & 0.043 & 0.21 & 0.9 & 0.88 \\
\hline & & 1 & 2.3 & 0.023 & 0.21 & 1.01 & 0.88 \\
\hline \multirow{3}{*}{ UCO:D40 } & \multirow{3}{*}{$51^{\circ}$} & 0.8 & 5.85 & 0.0585 & 0.21 & 0.79 & 0.91 \\
\hline & & 0.9 & 3.85 & 0.0385 & 0.21 & 0.91 & 0.90 \\
\hline & & 1 & 2.7 & 0.027 & 0.21 & 1 & 0.87 \\
\hline \multirow{3}{*}{ FCO:D40 } & \multirow{3}{*}{$60^{\circ}$} & 0.8 & 5.4 & 0.054 & 0.21 & 0.81 & 0.92 \\
\hline & & 0.9 & 3.9 & 0.039 & 0.21 & 0.91 & 0.89 \\
\hline & & 1 & 1.5 & 0.015 & 0.21 & 1 & 0.93 \\
\hline \multirow{3}{*}{ FCO:D40 } & \multirow{3}{*}{$51^{\circ}$} & 0.8 & 6.1 & 0.061 & 0.21 & 0.8 & 0.89 \\
\hline & & 0.9 & 3.6 & 0.036 & 0.21 & 0.9 & 0.92 \\
\hline & & 1 & 2.4 & 0.024 & 0.21 & 1 & 0.89 \\
\hline
\end{tabular}


Table 42 (Continued)

\begin{tabular}{|c|c|c|c|c|c|c|c|}
\hline Fuel Type & $\begin{array}{l}\text { Swirl } \\
\text { Angle }\end{array}$ & $\begin{array}{c}\text { Equivalence } \\
\text { Ratio }\end{array}$ & $\begin{array}{c}\text { Excess } \mathrm{O}_{2} \\
\text { in exhaust } \\
(\%)\end{array}$ & $\begin{array}{c}\text { Excess } \mathrm{O}_{2} \text { in } \\
\text { exhaust } \\
\text { (mole } \\
\text { fraction) }\end{array}$ & $\begin{array}{c}\mathrm{O}_{2} \text { mole } \\
\text { fraction in } \\
\text { ambient }\end{array}$ & $\begin{array}{c}\text { Measured } \\
\text { Equivalence } \\
\text { Ratio }\end{array}$ & $\begin{array}{c}\text { Burned } \\
\text { Fraction }\end{array}$ \\
\hline \multirow{3}{*}{ UCO:JF40 } & \multirow{3}{*}{$60^{\circ}$} & 0.8 & 4.4 & 0.044 & 0.21 & 0.8 & 0.99 \\
\hline & & 0.9 & 3.4 & 0.034 & 0.21 & 0.9 & 0.93 \\
\hline & & 1 & 2.2 & 0.022 & 0.21 & 1 & 0.90 \\
\hline \multirow{3}{*}{ UCO:JF40 } & \multirow{3}{*}{$51^{\circ}$} & 0.8 & 6.6 & 0.066 & 0.21 & 0.8 & 0.86 \\
\hline & & 0.9 & 4.5 & 0.045 & 0.21 & 0.91 & 0.86 \\
\hline & & 1 & 3.7 & 0.037 & 0.21 & 1.01 & 0.82 \\
\hline
\end{tabular}


Figures 53 and 54 show the effect of equivalence ratio on the burned fraction for all the fuels at $\mathrm{SN}$ of 1.4 and $\mathrm{SN}$ of 1.0, respectively.

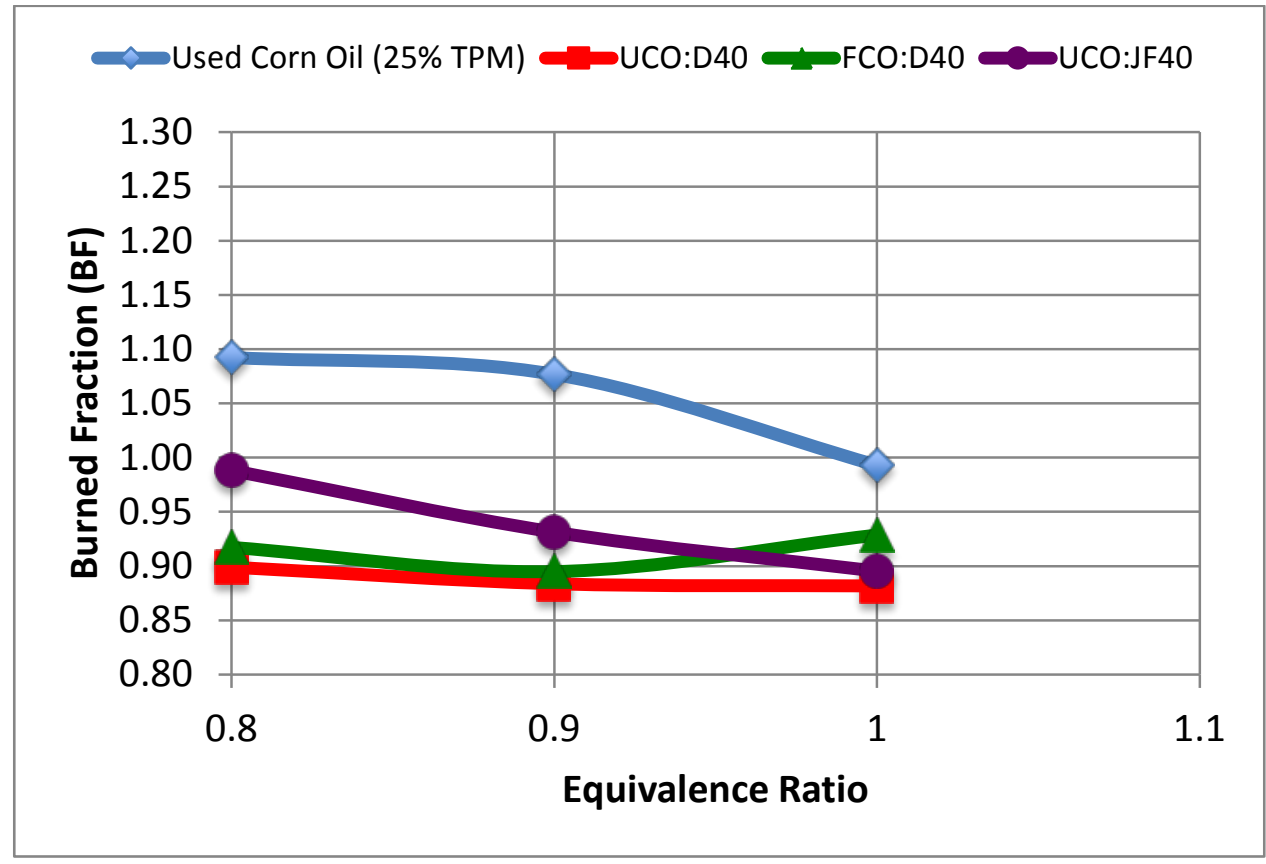

Figure 53: Burned fraction (BF) of all the fuels at $\mathrm{SN}$ of 1.4, at a constant heat output of $68,620 \mathrm{~kJ} / \mathrm{hr}$ 


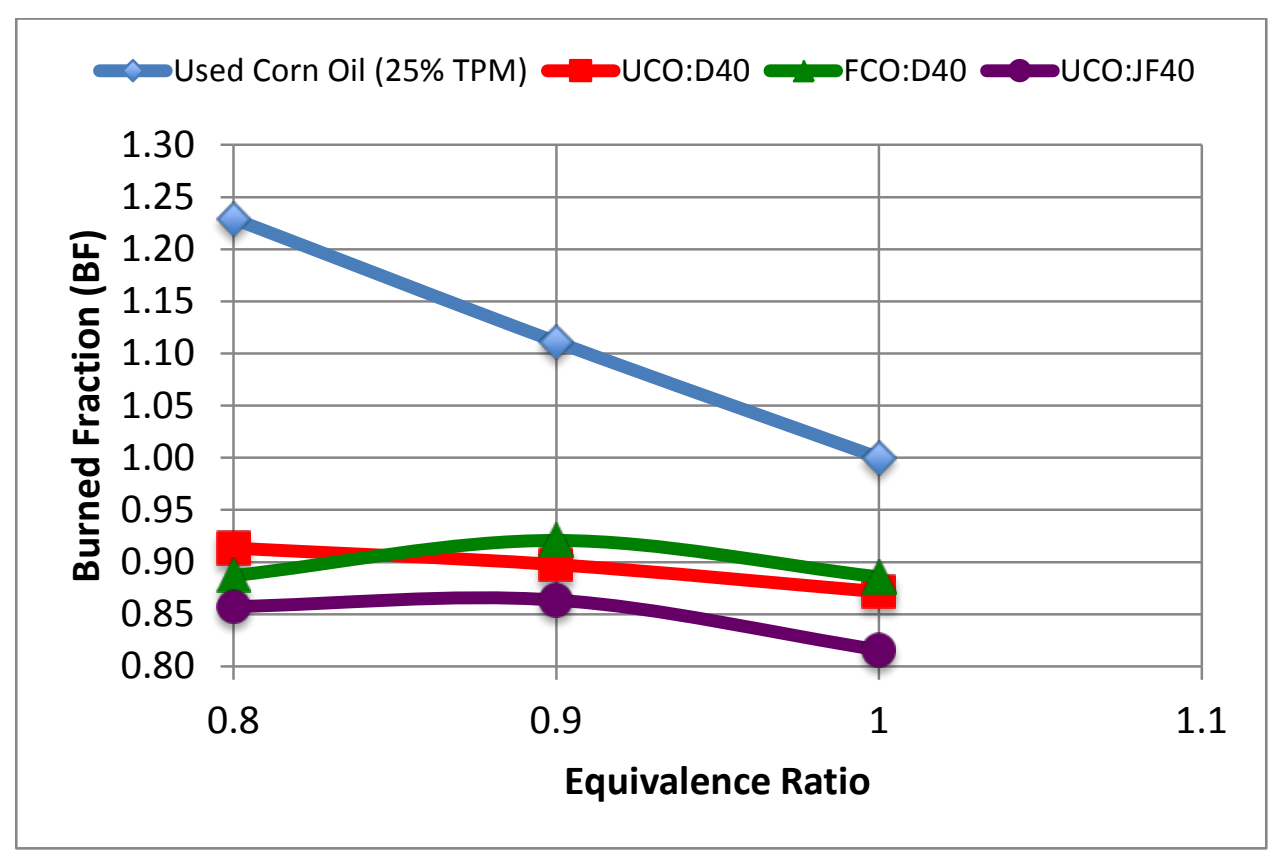

Figure 54: Burned fraction (BF) of all the fuels at $\mathrm{SN}$ of 1.0, at a constant heat output of $68,620 \mathrm{~kJ} / \mathrm{hr}$

It should be noted that the burned fraction for some of the fuels exceeded 1 at lean conditions.

\subsubsection{Effect of Equivalence Ratio on BF}

A general downward trend is observed for all fuels in the burned fraction graphs, Figures 53 and 54, with the maximum burned fraction occurring at equivalence ratio of 0.8. There was sufficient oxygen in the air at this lean condition for the fuel to undergo a more efficient combustion. As the equivalence ratio was increased, less and less oxygen became available for the fuel to be able to burn completely and efficiently. 


\subsubsection{Effect of Swirl Number on BF}

The range of burned fraction values is observed to be higher at SN of 1.4 than at SN of 1.0. This is expected, since the higher vorticity and therefore better mixing achieved at the higher swirl number enabled higher combustion efficiency.

From the findings of Gupta et al. [70], it can also be suggested that the higher swirl number created a large torroidal recirculation zone, enhancing turbulence and enabling better fuel-air mixing. This produced a stable flame, which acted as storage for heat and chemically active combustion species. This in turn resulted in better combustion of the freshly sprayed fuel.

\subsubsection{Effect of Fuel Type on BF}

At both swirl numbers, used corn oil depicted higher burned fraction values than the blends at all equivalence ratios. One possible explanation could be the higher pressure at which used corn oil was injected compared to the blends, which enabled small droplets to form. These small droplets improved the mixing between the used corn oil and air, and thus a higher burned fraction was observed especially at lean conditions. Larger droplet sizes for the blends could have reduced the blends' ability to mix well with air, thereby validating the lower values of burned fraction. A more comprehensive study on the fuels' molecular structures and their effect on combustion are needed to further corroborate these arguments. 


\subsubsection{Temperature Profiles of all Fuels}

Figures 55 and 56 show the variation of temperature for each fuel with respect to equivalence ratio, at $\mathrm{SN}$ of 1.4 and $\mathrm{SN}$ of 1.0 , respectively.

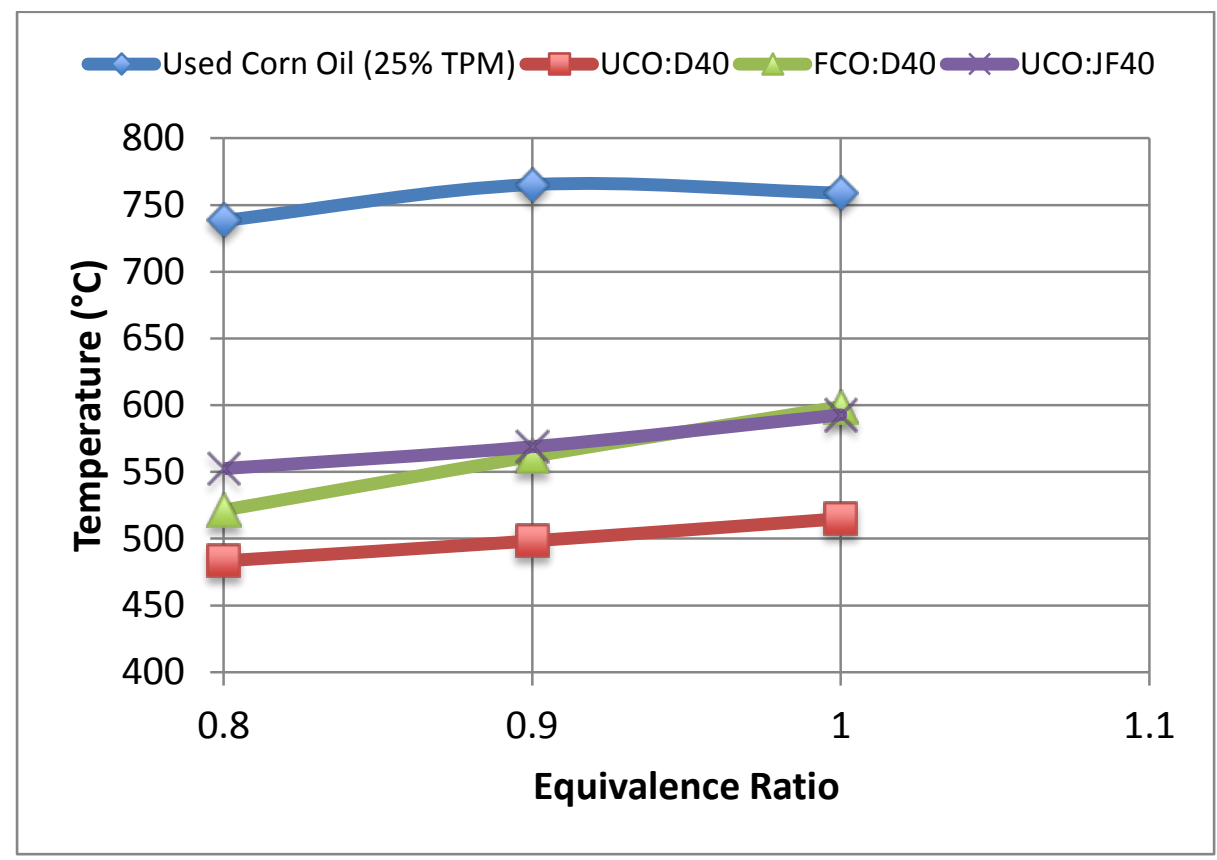

Figure 55: Variation of temperature with respect to equivalence ratio for used corn oil, UCO:D40, FCO:D40, and UCO:JF40 at SN of 1.4, for a constant heat output of 68,620 $\mathrm{kJ} / \mathrm{hr}$ 


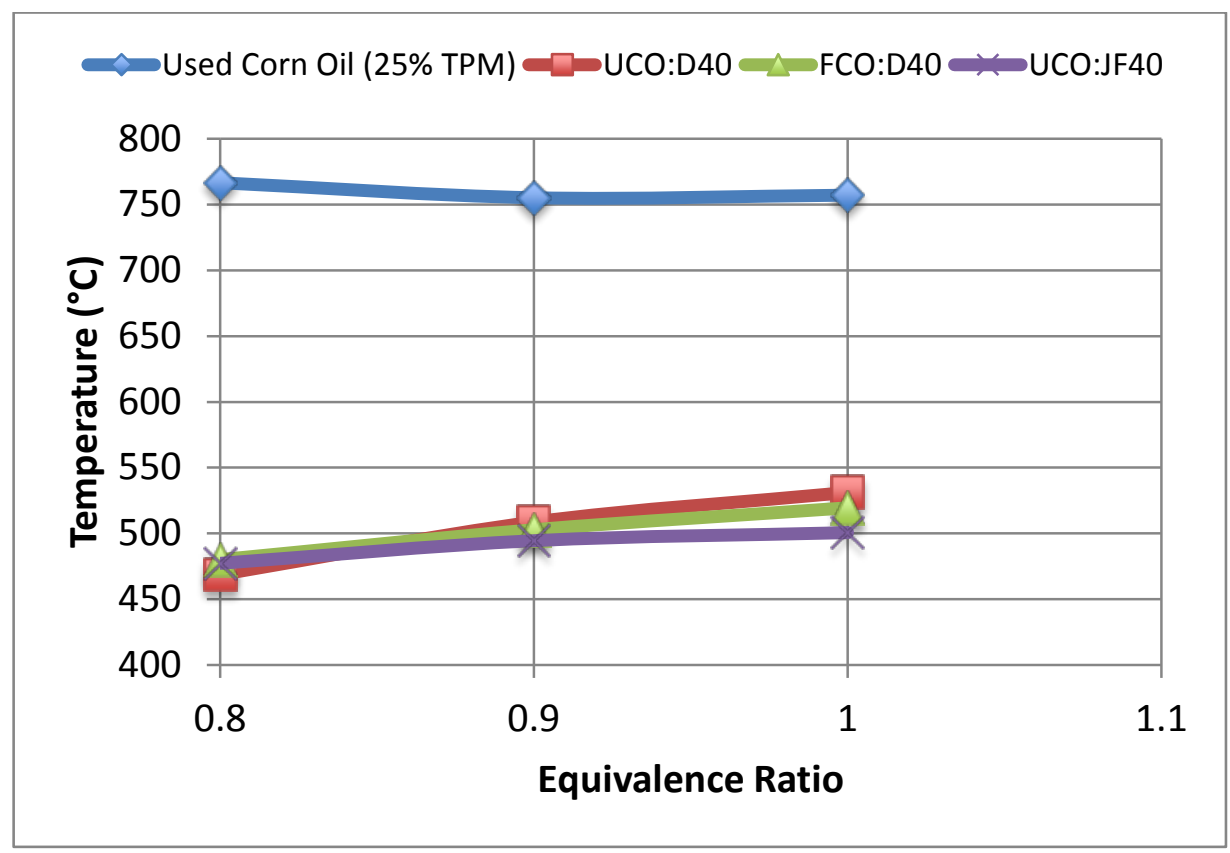

Figure 56: Variation of temperature with respect to equivalence ratio for used corn oil, UCO:D40, FCO:D40, and UCO:JF40 at SN of 1.0, for a constant heat output of 68,620 $\mathrm{kJ} / \mathrm{hr}$

There are a few factors that contribute to the differences in the temperatures reached for each fuel. It is important to note; however, that the temperatures shown in the plots above represent the temperatures at the analyzer outlet port. In effect, they can be approximated as the temperatures of the emission gases entering the analyzer. Another factor to take into consideration is the different temperatures that the combustion chamber was preheated to for the used corn oil and for the blends. For used corn, the chamber had to be preheated to about $800{ }^{\circ} \mathrm{C}$ (according to the chamber's uppermost thermocouple) in order for the combustion flame to sustain itself; but for the blends, it was preheated to just $550^{\circ} \mathrm{C}$, for safety purposes. This also may have played a small role in the values of the emissions obtained, especially $\mathrm{NO}_{\mathrm{x}}$. 
It is seen from Figures 55 and 56 above that the temperatures reached by the fuels were slightly higher at $\mathrm{SN}$ of 1.4 than at $\mathrm{SN}$ of 1.0 , especially at equivalence ratios 0.9 and 1. This is in agreement with literature in that higher swirls impart stronger fuel-air mixing due to higher turbulent intensity, which results in more efficient combustion and eventually higher flame temperatures due to the formation of hot combustion products [71].

Lower temperatures are observed at lower equivalence ratios, mainly due to the fact that the unreacted extra oxygen provides a cooling effect to the combustion products inside the chamber. Mafra et al. [34] also found that as the equivalence ratio was decreased, the temperature inside the furnace reduced. It was concluded that even though the released heat of reaction was the same at all equivalence ratios, the unreacted oxygen suppressed the maximum temperature at lean conditions.

As explained in Section 6.3.4.1, the formation of fuel-rich zones closer to stoichiometric conditions may have contributed to a slight drop in temperature [66], from $\phi$ of 0.9 to $\phi$ of 1 , at $\mathrm{SN}$ of 1.4 , and from $\phi$ of 0.8 to $\phi$ of 1 , at $\mathrm{SN}$ of 1.0. However, this was only observed in the used corn oil tests. The blends' temperatures steadily increased as equivalence ratio was increased.

It can be hypothesized that soot played a role in controlling the temperatures of the emission gases as well. Soot exhibits very good radiative heat transfer which was formed more in the blends than in used corn oil (around and above stoichiometric conditions). This could mean that for blends, the higher amount of soot enabled more heat transfer by radiation to take place, causing the flame temperature to drop. Conversely, lesser soot 
formed in the case of used corn oil resulted in lesser heat transfer, and thereby causing the flame temperature to increase. This could partly explain why temperatures of the emission gases for the used corn oil tests at both swirls were higher than those for the blends tests [72]. Moreover, soot formation entails that less energy was released during combustion due to hydrocarbons pyrolyzing to stable aggregates of carbon particles.

\subsubsection{Respiratory Quotient (RQ)}

Respiratory quotient is defined as the ratio of $\mathrm{CO}_{2}$ eliminated from a system to the $\mathrm{O}_{2}$ consumed by the system [73]. It is a common term used in medical literature.

$R Q=\frac{\mathrm{CO}_{2}}{\mathrm{O}_{2}}$

In this study, RQ was calculated based on the number of moles of carbon, hydrogen, and oxygen in each fuel. From Equation (18) above, $\mathrm{CO}_{2}$ was then calculated by multiplying RQ with the amount of oxygen consumed (the difference between ambient oxygen and exhaust oxygen). This calculated $\mathrm{CO}_{2}$ was then compared to the measured $\mathrm{CO}_{2}$ in the exhaust. Table 43 shows the comparison of calculated and measured $\mathrm{CO}_{2}$. 
Table 43: Comparison of calculated and measured $\mathrm{CO}_{2}$ using RQ

\begin{tabular}{|c|c|c|c|c|c|c|c|c|c|}
\hline Fuel Type & $\begin{array}{c}\text { Equivalence } \\
\text { Ratio }\end{array}$ & $\begin{array}{l}\text { Swirl } \\
\text { Angle }\end{array}$ & $\begin{array}{c}\text { Excess } \\
\mathrm{O}_{2} \text { in } \\
\text { exhaust } \\
(\%)\end{array}$ & $\begin{array}{c}\text { Excess } \mathrm{O}_{2} \\
\text { in exhaust } \\
\text { (mole } \\
\text { fraction) }\end{array}$ & $\begin{array}{c}\mathrm{O}_{2} \\
\text { consumed } \\
\text { (mole } \\
\text { fraction) }\end{array}$ & RQ & $\begin{array}{c}\mathrm{CO}_{2}(\%) \\
\text { [calculated] }\end{array}$ & $\begin{array}{c}\mathrm{CO}_{2}(\%) \\
\text { [measured] }\end{array}$ & $\begin{array}{c}\text { Difference } \\
\text { (\%) in } \\
\mathrm{CO}_{2}\end{array}$ \\
\hline $\begin{array}{c}\text { Fresh Corn } \\
\text { Oil }\end{array}$ & - & $60^{\circ} / 51^{\circ}$ & - & - & - & - & - & - & - \\
\hline \multirow{3}{*}{$\begin{array}{c}\text { Used Corn } \\
\text { Oil } \\
(25 \% \text { TPM })\end{array}$} & 0.8 & \multirow{3}{*}{$60^{\circ}$} & 2.65 & 0.0265 & 0.1835 & 0.74 & 13.58 & 14.4 & 6.0 \\
\hline & 0.9 & & 0.65 & 0.0065 & 0.2035 & 0.74 & 15.06 & 15.85 & 5.2 \\
\hline & 1 & & 0.15 & 0.0015 & 0.2085 & 0.74 & 15.43 & 15.45 & 0.1 \\
\hline \multirow{3}{*}{$\begin{array}{c}\text { Used Corn } \\
\text { Oil } \\
(25 \% \text { TPM })\end{array}$} & 0.8 & \multirow{3}{*}{$51^{\circ}$} & 0.35 & 0.0035 & 0.2065 & 0.74 & 15.28 & 14.9 & -2.5 \\
\hline & 0.9 & & 0 & 0 & 0.21 & 0.74 & 15.54 & 14.7 & -5.4 \\
\hline & 1 & & 0 & 0 & 0.21 & 0.74 & 15.54 & 15 & -3.5 \\
\hline \multirow{3}{*}{ UCO:D50 } & 0.8 & \multirow{3}{*}{$60^{\circ}$} & 3.45 & 0.0345 & 0.1755 & 0.71 & 12.44 & 13.5 & 8.6 \\
\hline & 0.9 & & 2.3 & 0.023 & 0.187 & 0.71 & 13.25 & 14.35 & 8.3 \\
\hline & 1 & & 1.8 & 0.018 & 0.192 & 0.71 & 13.60 & 13 & -4.4 \\
\hline \multirow{5}{*}{ UCO:D50 } & & \multirow{5}{*}{$51^{\circ}$} & & & & & & & \\
\hline & 0.8 & & _ & _ & _ & _ & _ & _ & _ \\
\hline & 0.9 & & _- & - & - & - & - & - & - \\
\hline & 1 & & _- & _- & $\ldots$ & _- & $\ldots$ & _- & - \\
\hline & & & & & & & & & \\
\hline
\end{tabular}


Table 43 (Continued)

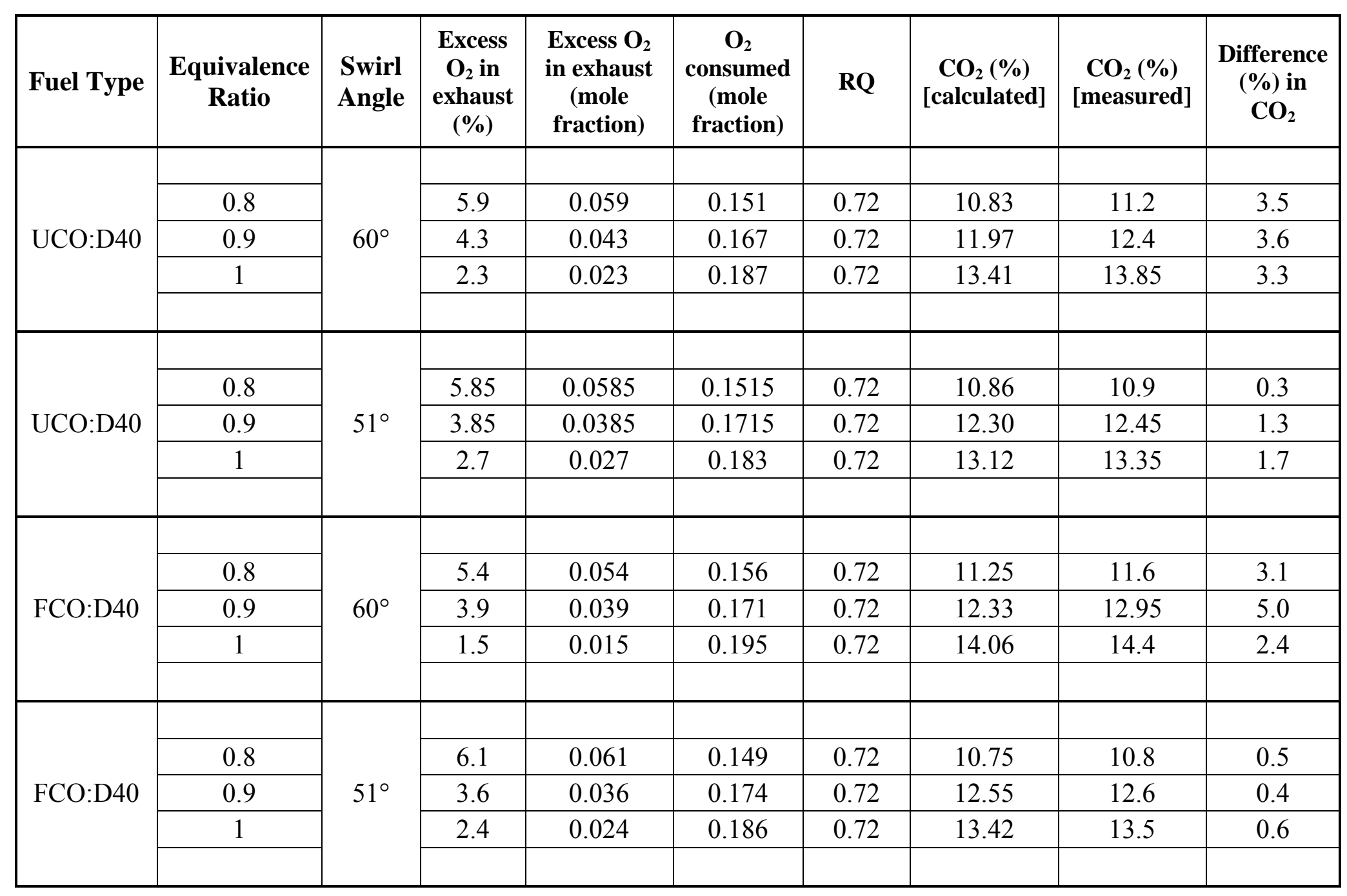


Table 43 (Continued)

\begin{tabular}{|c|c|c|c|c|c|c|c|c|c|}
\hline Fuel Type & $\begin{array}{c}\text { Equivalence } \\
\text { Ratio }\end{array}$ & $\begin{array}{l}\text { Swirl } \\
\text { Angle }\end{array}$ & $\begin{array}{c}\text { Excess } \\
\mathrm{O}_{2} \text { in } \\
\text { exhaust } \\
(\%)\end{array}$ & $\begin{array}{c}\text { Excess } \mathrm{O}_{2} \\
\text { in exhaust } \\
\text { (mole } \\
\text { fraction) }\end{array}$ & $\begin{array}{c}\mathrm{O}_{2} \\
\text { consumed } \\
\text { (mole } \\
\text { fraction) }\end{array}$ & RQ & $\begin{array}{c}\mathrm{CO}_{2}(\%) \\
\text { [calculated] }\end{array}$ & $\begin{array}{c}\mathrm{CO}_{2}(\%) \\
\text { [measured] }\end{array}$ & $\begin{array}{c}\text { Difference } \\
(\%) \text { in } \\
\mathrm{CO}_{2}\end{array}$ \\
\hline \multirow{4}{*}{ UCO:JF40 } & & \multirow{4}{*}{$60^{\circ}$} & & & & & & & \\
\hline & 0.8 & & 4.4 & 0.044 & 0.166 & 0.69 & 11.48 & 12.1 & 5.4 \\
\hline & 0.9 & & 3.4 & 0.034 & 0.176 & 0.69 & 12.18 & 12.95 & 6.4 \\
\hline & 1 & & 2.2 & 0.022 & 0.188 & 0.69 & 13.01 & 13.95 & 7.3 \\
\hline \multirow{3}{*}{ UCO:JF40 } & 0.8 & \multirow{3}{*}{$51^{\circ}$} & 6.6 & 0.066 & 0.144 & 0.69 & 9.96 & 10 & 0.4 \\
\hline & 0.9 & & 4.5 & 0.045 & 0.165 & 0.69 & 11.41 & 11.5 & 0.7 \\
\hline & 1 & & 3.7 & 0.037 & 0.173 & 0.69 & 11.97 & 12.2 & 1.9 \\
\hline
\end{tabular}


RQ considers that the fuels have undergone complete oxidation. For the fuels in this study, complete oxidation did not occur since all carbon was not able to fully convert to $\mathrm{CO}_{2}$

Used corn oil at both swirl angles and UCO:D50 blend show the highest difference between the calculated and measured $\mathrm{CO}_{2}$ levels of all the fuels. Among the rest of the blends, the ones at $\mathrm{SN}$ of 1.4 show a more significant difference between calculated and measured $\mathrm{CO}_{2}$, compared to those at $\mathrm{SN}$ of 1.0 .

\subsubsection{Heating Value Based on Stoichiometric Oxygen}

Based on the HHV of the fuels and knowing the amount of stoichiometric air needed for complete combustion of each fuel (or the stoichiometric A:F ratio), the heating value per mass of stoichiometric oxygen can be determined. This value should be approximately the same for most hydrocarbon fuels [45]. Table 44 shows the heating values per unit mass of $\mathrm{O}_{2}$ for all the proposed fuels in this study. The same values for diesel and jet fuel are also shown for comparison.

From Table 44, fresh corn oil had the highest value of HHV based on stoichiometric $\mathrm{O}_{2}$, whereas UCO:JF40 had the lowest value. This difference is due to the low stoichiometric A:F ratio required for the combustion of fresh corn oil. 
Table 44: HHV of the Fuels Based on Stoichiometric Oxygen

\begin{tabular}{|c|c|c|c|c|c|c|}
\hline Fuel Type & $\begin{array}{c}\text { Molecular } \\
\text { wt (kg/kmol) }\end{array}$ & $\begin{array}{c}\text { HHV } \\
\mathbf{( k J / k g )}\end{array}$ & $\begin{array}{c}\text { HHV } \\
\mathbf{( M J / k g )}\end{array}$ & $\begin{array}{c}\text { Stoichiometric } \\
\text { (A:F) ratio }\end{array}$ & $\begin{array}{c}\text { HHV based on } \\
\text { stoichiometric } \\
\text { air (MJ/kg } \\
\text { air) }\end{array}$ & $\begin{array}{c}\text { HHV based on } \\
\text { stoichiometric } \mathbf{O}_{2} \\
\text { (MJ/kg of } \mathbf{O}_{\mathbf{2}} \text { ) }\end{array}$ \\
\hline Diesel & 13.6 & $45,775.30$ & 45.8 & 14.2 & 3.23 & 14.02 \\
\hline Jet Fuel & 14.04 & $45,989.10$ & 46 & 14.8 & 3.11 & 13.51 \\
\hline FCO & 15.23 & $39,364.50$ & 39.36 & 12 & 3.28 & 14.26 \\
\hline UCO & 14.74 & $39,250.60$ & 39.25 & 12.6 & 3.12 & 13.54 \\
\hline FCO:D50 & 14.77 & $40,828.60$ & 40.83 & 13 & 3.14 & 13.66 \\
\hline FCO:D40 & 14.98 & $40,210.80$ & 40.21 & 12.8 & 3.14 & 13.66 \\
\hline UCO:D50 & 14.62 & $42,156.50$ & 42.16 & 13.2 & 3.19 & 13.89 \\
\hline UCO:D40 & 14.8 & $40,346.20$ & 40.35 & 13 & 3.10 & 13.49 \\
\hline FCO:JF50 & 15.04 & $41,420.60$ & 41.42 & 13.3 & 3.11 & 13.54 \\
\hline FCO:JF40 & 15.22 & $40,680.90$ & 40.68 & 13 & 3.13 & 13.61 \\
\hline UCO:JF50 & 14.89 & $41,389.80$ & 41.39 & 13.5 & 3.07 & 13.33 \\
\hline UCO:JF40 & 15.03 & 40,641 & 40.64 & 13.3 & 3.06 & 13.29 \\
\hline
\end{tabular}




\section{CONCLUSIONS}

This research study, performed at the Coal and Biomass Energy Laboratory at Texas A\&M University, was undertaken in a $30 \mathrm{~kW}$ modified combustion chamber to study the effects of equivalence ratio, swirl number, and fuel type on the emissions of two different types of diesel-corn oil blends. These blends were stabilized by mixing with ethanol-95 and n-butanol. The following conclusions have been drawn based on all the experimental data obtained during the execution of the project.

\subsection{Stability and Viscosity}

- All the fuel blends remained stable at all times since they never reached the very low phase separation temperatures.

- The viscosity of corn oil increased significantly upon heating and oxidation. On the other hand, the blends exhibited low viscosity values since most of the constituents were diesel or jet fuel, ethanol and butanol.

\subsection{Equivalence Ratio}

The equivalence ratio was controlled by varying the amount of secondary air entering into the combustion chamber. For fuel blends, data were recorded for equivalence ratio between 0.8 and 1 . It was concluded for the corn oil that:

- The very high degree of unsaturation for fresh corn oil compared to used corn oil likely caused the excessive formation of soot at all equivalence ratios.

- At both swirl numbers, $\mathrm{NO}_{\mathrm{x}}$ levels decreased with increasing equivalence ratio. 
- $\mathrm{CO}$ and $\mathrm{CO}_{2}$ increased with increasing equivalence ratio for used corn oil.

Similarly, the following conclusions were made for the fuel blends:

- All fuel blends showed $\mathrm{NO}_{\mathrm{x}}$ levels significantly lower than those of used corn oil at both swirl numbers.

- $\mathrm{NO}_{\mathrm{x}}$ levels for UCO:D50 were higher than those for UCO:D40, due to the higher temperatures achieved for the former.

- Among the rest of the blends, except for FCO:D40 at SN of 1.4, the $\mathrm{NO}_{\mathrm{x}}$ levels increased with increasing equivalence ratio.

- Since exhaust $\mathrm{O}_{2}$ for fuel blends were higher than that for used corn oil, the $\mathrm{CO}_{2}$ levels observed for the blends were lower. These levels peaked at equivalence ratio of 1 .

- CO levels decreased first before increasing again for the blends when equivalence ratio was increased.

\subsection{Swirl Number}

The swirl number in the combustion experiments was varied by changing the swirler vanes to give either $\mathrm{SN}$ of $1.4\left(60^{\circ}\right.$ swirl angle $)$ or $1.0\left(51^{\circ}\right.$ swirl angle). The following conclusions were drawn for the used corn oil:

- $\mathrm{NO}_{\mathrm{x}}$ emissions were seen to be higher at $\mathrm{SN}$ of 1.4 than at $\mathrm{SN}$ of 1.0.

- $\mathrm{CO}$ emissions were lower for SN of 1.4, due to turbulent mixing of fuel and air and hence more complete combustion. 
- $\mathrm{CO}$ emissions were more significantly affected by a change in swirl number for used corn oil than for blends.

Similarly, for the fuel blends, it was concluded that:

- $\mathrm{NO}_{\mathrm{x}}$ levels at $\mathrm{SN}$ of 1.4 were slightly higher than those at $\mathrm{SN}$ of 1.0.

- $\mathrm{CO}$ emissions for the blends at SN of 1.4 were lower than those at $\mathrm{SN}$ of 1.0.

\subsection{Fuel Type}

The fuel type also played a crucial role in the emissions levels. The following observations were made:

- Soot formation for fresh corn oil can be attributed to the lower number of double bonds in used corn oil than fresh corn oil.

- UCO:JF40 showed higher $\mathrm{NO}_{\mathrm{x}}$ emission levels than the other two blends at both swirl numbers.

- Comparing used corn oil with the blends, the introduction of alcohols in the blends played a major role in keeping all the emissions low.

\subsection{Burned Fraction}

Burned fraction was indicative of the fraction of the fuel that underwent complete combustion. It basically gave a measure of combustion efficiency. The following conclusions were made based on the observations:

- The burned fraction for most of the fuels was maximum at equivalence ratio 0.8 . 
- The range of the burned fraction values was slightly higher at SN of 1.4 than at SN of 1.0.

\subsection{Temperature Profiles}

The temperatures were measured at the point of suction of the exhaust gases at the analyzer probe. They were recorded for each fuel, at each equivalence ratio and their respective profiles were generated. The following conclusions were drawn:

- Temperatures were lower at leaner conditions due to the heat lost to the unreacted air.

- The temperature profile for used corn oil at both swirl numbers is much higher than the profiles for the fuel blends.

- Temperatures reached by the fuels at SN of 1.4 were slightly higher than those at SN of 1.0.

- More soot also contributed to lower flame temperatures for the fuel blends. 


\section{FUTURE WORK}

This research study proved to be a useful approach for understanding the combustion characteristics of potential biofuel blends, viz. corn oil and its corresponding blends with the existing fossil fuels diesel and jet fuel, along with alcohols. Its application in mobile systems like engines could be the next possible step for a more comprehensive study from the point of view of fuel applications in the commercial world. The following suggestions for future work should be undertaken:

1. The amount of soot formed should be measured at each equivalence ratio by measuring smoke density.

2. Combustion experiments at each equivalence ratio should be initiated under the same preheating conditions.

3. Combustion of other biofuels derived from algae and gasification by-products of solid fuels like biomass can be pursued to observe the type of emissions obtained. This kind of research will only increase the potential in alternative fuels production. 


\section{REFERENCES}

[1] U.S. Energy Information Administration [EIA]. <http://www.eia.gov/steo/> (accessed 10.05.11.).

[2] H. Panchasara, B. Simmons, A. Agrawal, Combustion performance of biodiesel and diesel-vegetable oil blends in a simulated gas turbine burner, Journal of Engineering for Gas Turbines and Power 131 (2009) 1-11.

[3] L. Guarieiro, P. Pereira, E. Torres, G. da Rocha, J. de Andrade, Carbonyl compounds emitted by a diesel engine fuelled diesel and biodiesel-diesel blends: Sampling optimization and emissions profile, Atmospheric Environment 42 (2008) 8211-8218.

[4] G. Ban-Weiss, J. Chen, B. Buchholz, R. Dibble, A numerical investigation into the anomalous slight $\mathrm{NO}_{\mathrm{X}}$ increase when burning biodiesel; A new (old) theory, Fuel Processing Technology 88 (2007) 659-667.

[5] A. Demirbas, Biodiesel fuels from vegetable oils via catalytic and non-catalytic supercritical alcohol transesterifications and other methods: A survey, Energy Conversion and Management 44 (2003) 2093-2109.

[6] O. Nwafor, G. Rice, Performance of rapeseed oil blends in a diesel engine, Applied Energy 54 (1996) 345-354.

[7] R. Dunn, M. Bagby, Low temperature phase behavior of vegetable oil/co-solvent blends as alternative diesel fuel, Journal of the American Oil Chemists' Society 77 (2000) 1315-1323.

[8] A.W. Schwab, H.C. Nielsen, D.D. Brooks, and E.H. Pryde, Triglyceride/aqueous 
ethanol/1-butanol microemulsions, Journal of Dispersion Science and Technology $4(1983) 1-17$.

[9] C.E. Goering, A.W. Schwab, R.M. Campion, and E.H. Pryde, Soyoil-ethanol microemulsions as diesel fuel, Transactions of the ASABE 26 (1983) 1602-1604.

[10] T. Houlihan, The triple crown, Power Engineering 4 (2009) 44-45.

[11] Corn Refiners Association, $5^{\text {th }}$ Edition (2006). Accessed online (2012). $<$ http://www.corn.org/wp-content/uploads/2009/12/CornOil.pdf $>$.

[12] Fats, Oils, Fatty Acids, Triglycerides, Scientific Psychic. Accessed online (2012). $<$ http://www.scientificpsychic.com/fitness/fattyacids1.html $>$.

[13] Clean Diesel Fuel Alliance Information Center. $<$ http://www.cleandiesel.org/highway.html> (accessed 10.05.11.).

[14] Alternative and Advanced Vehicles, U.S. Department of Energy (December 2011). Accessed online (2011). $<$ http://www.afdc.energy.gov/afdc/vehicles/diesels_emissions.html $>$.

[15] Jet Fuels JP-4 and JP-7 (CRC 1984, Dukek 1978, IARC 1989). Accessed online (2012). <http://www.atsdr.cdc.gov/toxprofiles/tp76-c3.pdf> .

[16] S. Romanow-Garcia, H.L. Hoffman, Petroleum and its Products, Kent and Riegel's Handbook of Industrial Chemistry and Biotechnology Part 1 (2007) 801-842

[17] Jet Fuels JP-4 and JP-7 (Air Force 1989b). Accessed online (2012). $<$ http://www.atsdr.cdc.gov/toxprofiles/tp76-c4.pdf $>$. 
[18] Emulsion, Britannica Academic Edition (2012).

$<$ http://www.britannica.com/EBchecked/topic/186307/emulsion> (accessed 03.08.12.).

[19] S.M. Jafari, Y. He, B. Bhandari, Optimization of nano-emulsions production by microfluidization, European Food Research and Technology 225 (2007) 733-741.

[20] D.C. Rakopoulos, C.D. Rakopoulos, D.T. Hountalas, E.C. Kakaras, E.G. Giakoumis, R.G. Papagiannakis, Investigation of the performance and emissions of bus engine operating on butanol/diesel fuel blends, Fuel 89 (2010) 2781-2790.

[21] O. Dogăn, The influence of n-butanol/diesel fuel blends utilization on a small diesel engine performance and emissions, Fuel 90 (2011) 2467-2472.

[22] P.A. Boruff, A.W. Schwab, C.E. Goering, E.H. Pryde, Evaluation of diesel fuelethanol microemulsions, Transactions of the ASAE 25 (1982) 47-53.

[23] J. San Jose Alonso, J.A. Lopez Sastre, C. Romero-Avila, E. Lopez, Combustion of blends of diesel and soya, sunflower and rapeseed vegetable oils in a light boiler, Biomass and Bioenergy 32 (2007) 880-886.

[24] W.W. Nawar, Chemical changes in lipids produced by thermal processing, Journal of Chemical Education, 61, (1984) 299-302.

[25] J.F. Toro-Vazquez, A.A. Castillo-M, R. Hernandez-C, A multiple-variable approach to study corn oil oxidation, Journal of the American Oil Chemists' Society 70 (1993) 261-267. 
[26] Are you eating Rancid Oils?, Dr. Bruce Fife (2004) $<$ http://www.jctonic.com/include/healingcrisis/20rancid_oils.htm $>$ (accessed 03.08.12.).

[27] S. Erhan, B. Sharma, J. Perez, Oxidation and low temperature stability of vegetable oil-based lubricants, Industrial Crops and Products 24 (2006) 292-299.

[28] S. Naz, H. Sheikh, R. Siddiqi, S.A. Sayed, Oxidative stability of olive, corn and soybean oil under different conditions, Food Chemistry 88 (2004) 253-259.

[29] S. Wang, H. Hwang, S. Yoon, E. Choe, Temperature dependence of autoxidation of perilla oil and tocopherol degradation, Journal of Food Science 75 (2010) C498C505.

[30] Analysis of Lipids. <http://people.umass.edu/ mcclemen/581Lipids.html $>$ (accessed 03.08.12.).

[31] Field guide: Cooking oil measurement, TESTO (2006) 1-63.

[32] G.R. Takeoka, G.H. Full, L.T. Dao, Effect of heating on the characteristics and chemical composition of selected frying oils and fats, Journal of Agricultural and Food Chemistry 45 (1997) 3244-3249.

[33] J.M. Beer, N.A. Chigier, Combustion aerodynamics, John Wiley and Sons Inc., New York, 1972.

[34] M.R. Mafra, F.L. Fassani, E.F. Zanoelo, W.A. Bizzo, Influence of swirl number and fuel equivalence ratio on NO emission in an experimental LPG-fired chamber, Applied Thermal Engineering 30 (2010) 928-934. 
[35] M.S.A. Ishak, M.N.M. Jaafar, The effect of swirl number on reducing emissions from liquid fuel burner system, Journal Mechanical 19 (2005) 48-56.

[36] T. Kadota, H. Yamasaki, Recent advances in the combustion of water fuel emulsion, Progress in Energy and Combustion Science 28 (2002) 385-404.

[37] H. Bockhorn, Soot formation in combustion, Springer-Verlag, Heidelberg, 1994.

[38] D.C. Siegla, G.W. Smith, Particulate carbon formation during combustion, Plenum Press, New York, 1981.

[39] B.S. Haynes, H.Gg. Wagner, Soot formation, Progress in Energy and Combustion Science 7 (1981) 229-273.

[40] O.I. Smith, Fundamentals of soot formation in flames with application to diesel engine particulate emissions, Progress in Energy and Combustion Science 7 (1981) 275-291.

[41] B. van Setten, M. Makkee, J. Moulijn, Science and technology of catalytic diesel particulate filters, Catalysis Reviews 43 (2001) 489-564.

[42] R.C. Flagan, J.H. Seinfeld, Fundamentals of pollution engineering, Prentice Hall Inc., New Jersey, 1988.

[43] S. Puhan, N. Saravanan, G. Nagarajan, N. Vedaraman, Effect of biodiesel unsaturated fatty acid on combustion characteristics of a DI compression ignition engine, Biomass and Bioenergy 34 (2010) 1079-1088.

[44] B.J. Cooper, J.E. Thoss, Role of NO in diesel particulate emission control, SAE Technical Paper 890404, (1989) 171-183. 
[45] K. Annamalai, I.K. Puri, Combustion science and engineering, CRC Press, Florida, 2007.

[46] P. Kruglyakov, Hydrophile-Lipophile Balance of surfactants and solid particles, Elsevier Science B.V., $1^{\text {st }}$ edition, The Netherlands, 2000.

[47] P. Becher, Encyclopedia of emulsion technology Vol. 1 basic theory, Marcel Dekker Inc, New York, 1983.

[48] H. Mollet, A. Grubenmann, Formulation technology: emulsions, suspensions, solid forms, Wiley-VCH, Germany, 2001.

[49] The HLB System: A time-saving guide to emulsifier selection, ICI Americas Inc., Wilmington, Delaware, 1976.

[50] S. Bhimani, Experimental characterization of canola oil emulsion combustion in a modified furnace, Mechanical Engineering Department, Texas A\&M University, College Station, 2011.

[51] Corn Oil MSDS. <http://www.sciencelab.com/msds.php?msdsId=9927139> (accessed 03.08.12.).

[52] Determination of iodine value by pre-calibrated FT-NIR with disposable vials, AOCS Standard Procedure Cd 1e-01, Sampling and Analysis of Commercial Fats and Oils (2012) 1-5

[53] F. Orthoefer, Corn oil: Composition, processing, and utilization, Corn: Chemistry and Technology (2003) 671-693.

[54] F. Shahidi, Canola and rapeseed, Van Nostrand Reinhold, New York, 1990.

[55] Brevard BioDiesel. <http://www.brevardbiodiesel.org/iv.html $>$ (accessed 
03.08.12.).

[56] A.M. Sulieman, A. El-Makhzangy, M.F. Ramadan, Antiradical performance and physicochemical characteristics of vegetable oils upon frying of french fries: A preliminary comparative study, Journal of Food Lipids 13 (2006) 259-276.

[57] K.K. Kuo, Principles of combustion, John Wiley and Sons, Inc., New York, 2005.

[58] H.Gg. Wagner, Seventeenth Symposium (International) on Combustion, The Combustion Institute, Pittsburgh (1979) 3-19.

[59] C.D. Rakopoulos, K.A. Antonopoulos, D.C. Rakopoulos, D.T. Hountalas, Multizone modeling of combustion and emissions formation in DI diesel engine operating on ethanol-diesel fuel blends, Energy Conversion and Management 49 (2008) 625-643.

[60] C. Jayakumar, J. Nargunde, A. Sinha, N.A. Henein, W. Bryzik, Effect of swirl and injection pressure on performance and emissions of JP-8 fueled high speed single cylinder diesel engine, Journal of Engineering for Gas Turbines and Power 134 (2012) 1-9.

[61] B.K. Venkanna, C.V. Reddy, Performance emission and combustion characteristics of DI diesel engine running on blends of Linn oil (honne oil)/diesel/kerosene, International Journal of Renewable Energy Technology 3 (2011) 294-305.

[62] R.L. McCormick, M.S. Graboski, T.L. Alleman, A.M. Herring, Impact of biodiesel source material and chemical structure on emissions of criteria pollutants from a heavy-duty engine, Environmental Science and Technology, 35 (2001) 1742-1747.

[63] S. Saravanan, G. Nagarajan, G. Lakshmi Narayana Rao, Investigation on nonedible 
vegetable oil as a compression ignition engine fuel in sustaining the energy and environment, Journal of Renewable and Sustainable Energy 2 (2010) 1-8.

[64] M.A. Habib, M. Elshafei, M. Dajani, Influence of combustion parameters on $\mathrm{NO}_{\mathrm{x}}$ production in an industrial boiler, Computers \& Fluids 37 (2008) 12-23.

[65] T. Daho, G. Vaitilingom, O. Sanogo, Optimization of the combustion of blends of domestic fuel oil and cottonseed oil in a non-modified domestic boiler, Fuel 88 (2009) 1261-1268.

[66] S. Gianfranco, S Giulio, C. Aldo, Pollutant emissions reduction performance optimization of an industrial radiant tube burner, Experimental Thermal and Fluid Science 30 (2006) 605-612.

[67] M. Ghazikhani, M.R. Kalateh, Y.K. Toroghi, M. Dehnavi, An experimental study on the effect of premixed and equivalence ratios on $\mathrm{CO}$ and $\mathrm{HC}$ emissions of dual fuel HCCI engine, Engineering and Technology 52 (2009) 129-135.

[68] R.W. Anderson, P.B. Patil, J. Chin, J.A. Nicholls, W. Mirsky, V. Lyons, The effect of drop size on emissions from the primary zone of a gas turbine type combustor, Symposium (International) on Combustion 16 (1977) 265-275.

[69] B. Thien, Co-firing with coal-feedlot biomass blends, Ph.D. dissertation, Mechanical Engineering Department, Texas A\&M University, College Station, TX, 2002.

[70] A.K. Gupta, D.G. Lilley, N. Syred, Swirl flow, Abacus Press, Great Britain, 1984.

[71] T.S. Cheng, Y.C. Yao, D.C. Wu, C.C. Lu, C.K. Cheng, J.M. Chang, Effects of fuel-air mixing on flame structures and $\mathrm{NO}_{\mathrm{x}}$ emissions in swirling methane jet 
flames, Twenty-seventh Symposium (International) on Combustion/The Combustion Institute 27 (1998) 1229-1237.

[72] M. Lapuerta, O. Armas, J. Rodriguez-Fernandez, Effect of biodiesel fuels on diesel engine emissions, Progress in Energy and Combustion Science 34 (2008) 198-223.

[73] K. Annamalai, I.K. Puri, Advanced thermodynamics engineering, CRC Press, Florida, 2002.

[74] T.M. Kegel, Basic measurement uncertainty, $71^{\text {st }}$ International School of Hydrocarbon Measurement, Oklahoma City, OK April 9-11 (1996) 1-7.

[75] B. Lawrence, Co-firing of coal and dairy biomass in a 100,000 Btu/hr furnace, Master's Thesis, Mechanical Engineering Department, Texas A\&M University, College Station, 2007. 


\section{APPENDIX A}

\section{UNCERTAINTY ANALYSIS}

The uncertainty analysis in this research study follows the example of Kegel [74]. All the measured values in the combustion experiments have some uncertainty associated with them. They include the emission concentrations as measured by the analyzer, the equivalence ratios, and the stack temperatures. Table A.1 shows all the instruments used in the experiments, along with their respective uncertainty parameters, which were available in the instruments' manuals. The uncertainty analysis done by Lawrence et al. [75] has been used as a reference while doing the analysis for this study.

Total uncertainty of the instrument is defined as the root sum squared of the resolution and accuracy uncertainties:

$(\text { Uaccuracy })^{2}+(\text { Uresolution })^{2}=(\text { Utotal })^{2}$

$\mathrm{U}_{\text {total }}=$ Total uncertainty of the instrument

$\mathrm{U}_{\text {accuracy }}=$ Uncertainty due to accuracy of the instrument

$\mathrm{U}_{\text {resolution }}=$ Uncertainty due to resolution of the instrument 
Table A.1: Instrument Uncertainty

\begin{tabular}{|l|c|c|c|c|c|}
\hline \multicolumn{1}{|c|}{ Instrument } & Accuracy & Unit & Resolution & Units & $\begin{array}{c}\text { Total Instrument } \\
\text { Uncertainty }\end{array}$ \\
\hline Primary Air Flow Meter & \pm 3 & $\%$ & 0.1 & $1 / \mathrm{min}$ & 3.00 \\
\hline Secondary Air Flow Meter & \pm 15 & $1 / \mathrm{min}$ & 1 & $1 / \mathrm{min}$ & 15.03 \\
\hline Fuel Flow Meter & \pm 1 & $\%$ & 0.1 & $\mathrm{gal} / \mathrm{hr}$ & 1.00 \\
\hline Viscometer & \pm 1 & $\%$ & 0.1 & $\mathrm{cP}$ & 1.00 \\
\hline $\mathrm{O}_{2}$ sensor-analyzer & 0.2 & $\%$ & 0.1 & $\%$ & 0.22 \\
\hline $\mathrm{CO}_{2}$ sensor-analyzer & \pm 5 & $\%$ & 0.1 & $\%$ & varies \\
\hline $\mathrm{CO}^{\prime}$ sensor (low)-analyzer & \pm 2 & $\%$ & 1 & $\mathrm{ppm}$ & varies \\
\hline CO sensor (high)-analyzer & \pm 5 & $\%$ & 0.1 & $\%$ & varies \\
\hline NOx sensor-analyzer & \pm 2 & $\%$ & 1 & $\mathrm{ppm}$ & varies \\
\hline Stack Temperature Thermocouple & \pm 5 & ${ }^{\circ} \mathrm{F}$ & 1 & ${ }^{\circ} \mathrm{F}$ & 3.10 \\
\hline Ambient Temperature Thermocouple & \pm 3 & ${ }^{\circ} \mathrm{F}$ & 1 & ${ }^{\circ} \mathrm{F}$ & 3.16 \\
\hline Testo 270 Cooking Oil Tester & \pm 2 & $\%$ & 0.5 & $\%$ & 2.06 \\
\hline
\end{tabular}




\section{Equivalence Ratio $(\phi)$ Uncertainty}

The equivalence ratio uncertainty is directly affected by the measured values of the air flow meters and fuel flow meter, due to the uncertainties associated with those instruments.

From the definition of equivalence ratio:

$\phi=\left[\frac{(\mathrm{A}: \mathrm{F})_{\text {stoichiometric }}}{(\mathrm{A}: \mathrm{F}) \text { provided }}\right]$

Cancelling the fuel flow terms since they are constants, we get,

$\phi=\left(\frac{\text { Astoichiometric }}{\text { Aprovided }}\right)$

$\phi=\left(\frac{A p, s t+A s, s t}{A p, p r+A s, p r}\right)$

where,

$\mathrm{A}_{\mathrm{p}, \mathrm{st}}=$ Primary stoichiometric air

$\mathrm{A}_{\mathrm{s}, \mathrm{st}}=$ Secondary stoichiometric air

$A_{p, p r}=$ Primary provided air

$\mathrm{A}_{\mathrm{s}, \mathrm{pr}}=$ Secondary provided air

To determine the uncertainty, the partial derivative of $\phi$ to each independent variable is calculate as follows:

$$
\begin{aligned}
\frac{\partial \phi}{\partial \mathrm{Ap}, \mathrm{st}} & =\frac{1}{(\mathrm{Ap} \cdot \mathrm{pr}+\mathrm{As}, \mathrm{pr})} \\
\frac{\partial \phi}{\partial \mathrm{As}, \mathrm{st}} & =\frac{1}{(\mathrm{Ap}, \mathrm{pr}+\mathrm{As}, \mathrm{pr})} \\
\frac{\partial \phi}{\partial \mathrm{Ap}, \mathrm{pr}} & =-\frac{(\mathrm{Ap}, \mathrm{st}+\mathrm{As}, \mathrm{st})}{(\mathrm{Ap}, \mathrm{pr}+\mathrm{As}, \mathrm{pr})^{2}}
\end{aligned}
$$


$\frac{\partial \phi}{\partial \mathrm{As}, \mathrm{pr}}=-\frac{(\mathrm{Ap}, \mathrm{st}+\mathrm{As}, \mathrm{st})}{(\mathrm{Ap}, \mathrm{pr}+\mathrm{As}, \mathrm{pr})^{2}}$

Thus, by using the equations given above, the equivalence ratio uncertainty values were calculated. Table A.2 below shows a sample calculation for equivalence ratio uncertainty for UCO:D40 at stoichiometric conditions, for SN of 1.4. 
Table A.2: Complete uncertainty analysis in equivalence ratio for UCO:D40 at stoichiometric conditions and at SN of 1.4

\begin{tabular}{|c|c|c|c|c|c|c|c|c|c|c|}
\hline $\begin{array}{c}\text { Input } \\
\text { Variable }\end{array}$ & $\begin{array}{c}\text { Equivalence } \\
\text { Ratio }\end{array}$ & Air Type & Value & $\delta \varphi / \delta \mathrm{x}_{\mathrm{i}}$ & $\mathrm{x}_{\mathrm{i}} / \varphi$ & $\mathrm{s}_{\mathrm{xi}}=\left(\delta \varphi / \delta \mathrm{x}_{\mathrm{i}}\right)^{*}\left(\mathrm{x}_{\mathrm{i}} / \varphi\right)$ & $\mathrm{u}_{\mathrm{xi}}$ & $\mathrm{u}_{\mathrm{xi}} * \mathrm{~s}_{\mathrm{xi}}$ & $\left.\mathbf{u}_{\mathrm{xi}}{ }^{*} \mathrm{~s}_{\mathrm{xi}}\right)^{2}$ & $\begin{array}{c}\text { Contrib- } \\
\mathrm{ution}\end{array}$ \\
\hline $\mathrm{X} 1$ & 1 & $\begin{array}{c}\text { Primary } \\
\text { Air, st }\end{array}$ & 9.9 & 0.00328 & 9.9 & 0.03247 & 0.17576 & 0.00571 & 0.0000326 & 1.92 \\
\hline $\mathrm{X} 2$ & 1 & $\begin{array}{c}\text { Secondary } \\
\text { Air, st }\end{array}$ & 295 & 0.00328 & 295 & 0.96753 & 0.02955 & 0.02859 & 0.000817 & 48.06 \\
\hline $\mathrm{X} 3$ & 1 & $\begin{array}{c}\text { Primary } \\
\text { Air, pr }\end{array}$ & 9.9 & 0.00328 & 9.9 & 0.03247 & 0.17576 & 0.00571 & 0.0000326 & 1.92 \\
\hline $\mathrm{X} 4$ & 1 & $\begin{array}{c}\text { Secondary } \\
\text { Air, pr }\end{array}$ & 295 & 0.00328 & 295 & 0.96753 & 0.02955 & 0.02859 & 0.000817 & 48.06 \\
\hline
\end{tabular}


where,

Sxi $=$ Sensitivity coefficient

$\mathrm{Uxi}=$ Standard uncertainty

$\left(\mathrm{Sxi}^{*} \mathrm{Uxi}\right)=$ Combined Standard Uncertainty

Table A. 3 shows the uncertainty in equivalence ratio for the combustion experiments undertaken in this project. It was observed that the uncertainty in equivalence ratio generally increased with increasing equivalence ratio for most fuels. The instrument uncertainty values of the flow meters are also taken into account, and at higher flow rates (i.e. more secondary air at leaner conditions), the instrument showed higher accuracy. 
Table A.3: Percentage equivalence ratio uncertainty for all fuels at both swirl numbers

\begin{tabular}{|c|c|c|c|}
\hline $\begin{array}{c}\text { Fuel } \\
\text { Type/Swirl } \\
\text { Number }\end{array}$ & $\begin{array}{c}\text { Equivalence } \\
\text { Ratio }\end{array}$ & $\begin{array}{c}\text { Uncertainty } \\
(\%)\end{array}$ & $\begin{array}{c}\text { Average } \\
\text { Uncertainty } \\
(\%)\end{array}$ \\
\hline \multirow{3}{*}{$\begin{array}{c}\text { Used Corn Oil } \\
\begin{array}{c}(25 \% \mathrm{TPM}) \\
\mathrm{SN}=1.4\end{array}\end{array}$} & 0.8 & 4.11 & 4.107 \\
\hline & 0.9 & 4.12 & \\
\hline & 1 & 4.09 & \\
\hline \multirow{3}{*}{$\begin{array}{c}\mathrm{UCO}: \mathrm{D} 50 \\
\mathrm{SN}=1.4\end{array}$} & 0.8 & 4.24 & 4.25 \\
\hline & 0.9 & 4.26 & \\
\hline & 1 & 4.25 & \\
\hline \multirow{3}{*}{$\begin{array}{c}\mathrm{UCO}: \mathrm{D} 40 \\
\mathrm{SN}=1.4\end{array}$} & 0.8 & 4.09 & 4.11 \\
\hline & 0.9 & 4.12 & \\
\hline & 1 & 4.12 & \\
\hline \multirow{3}{*}{$\begin{array}{c}\text { FCO:D40 } \\
\mathrm{SN}=1.4\end{array}$} & 0.8 & 4.13 & 4.15 \\
\hline & 0.9 & 4.13 & \\
\hline & 1 & 4.19 & \\
\hline \multirow{3}{*}{$\begin{array}{c}\mathrm{UCO}: \mathrm{JF} 40 \\
\mathrm{SN}=1.4\end{array}$} & 0.8 & 4.06 & 4.07 \\
\hline & 0.9 & 4.07 & \\
\hline & 1 & 4.08 & \\
\hline \multirow{3}{*}{$\begin{array}{l}\text { Used Corn Oil } \\
\begin{array}{c}(25 \% \text { TPM }) \\
\text { SN }=1.0\end{array}\end{array}$} & 0.8 & 4.1 & 4.12 \\
\hline & 0.9 & 4.12 & \\
\hline & 1 & 4.14 & \\
\hline \multirow{3}{*}{$\begin{array}{c}\mathrm{UCO}: \mathrm{D} 40 \\
\mathrm{SN}=1.0\end{array}$} & 0.8 & 4.1 & 4.103 \\
\hline & 0.9 & 4.11 & \\
\hline & 1 & 4.1 & \\
\hline \multirow{3}{*}{$\begin{array}{c}\text { FCO:D40 } \\
\mathrm{SN}=1.0\end{array}$} & 0.8 & 4.18 & 4.183 \\
\hline & 0.9 & 4.18 & \\
\hline & 1 & 4.19 & \\
\hline \multirow{3}{*}{$\begin{array}{c}\text { UCO:JF40 } \\
\mathrm{SN}=1.0\end{array}$} & 0.8 & 4.05 & 4.063 \\
\hline & 0.9 & 4.06 & \\
\hline & 1 & 4.08 & \\
\hline
\end{tabular}




\section{VITA}

Gautam Sandesh Savant graduated with a Bachelor of Mechanical Engineering degree from Maharashtra Institute of Technology, Pune (University of Pune), India in June 2009. He entered the Mechanical Engineering Program at Texas A\&M University, College Station in Fall 2009 and received his Master of Science in mechanical engineering in May 2012.

Mr Savant can be contacted by email at gautamsavant@gmail.com. He can be contacted in person at,

Texas A\&M University

Department of Mechanical Engineering

3123 TAMU

College Station

TX 77843-3123

c/o Dr. Jorge Alvarado 